LUCIENE CRISTINA ALVES RINALDI

PROPOSIÇÃO E AVALIAÇÃO DE UM MODELO

DE TRANSMISSÃO DE CONHECIMENTO

COERENTE COM COMPORTAMENTOS OBSERVADOS 
LUCIENE CRISTINA ALVES RINALDI

\section{PROPOSIÇÃO E AVALIAÇÃO DE UM MODELO DE TRANSMISSÃO DE CONHECIMENTO COERENTE COM COMPORTAMENTOS OBSERVADOS}

Tese apresentada à Escola Politécnica da Universidade de São Paulo para obtenção do título de Doutor em Ciências 
LUCIENE CRISTINA ALVES RINALDI

\section{PROPOSIÇÃO E AVALIAÇÃO DE UM MODELO DE TRANSMISSÃO DE CONHECIMENTO COERENTE COM COMPORTAMENTOS OBSERVADOS}

Tese apresentada à Escola Politécnica da Universidade de São Paulo para obtenção do título de Doutor em Ciências

Área de Concentração:

Sistemas Eletrônicos

Orientador:

Prof. Dr. Marcio Lobo Netto 
Este exemplar foi revisado e corrigido em relação à versão original, sob responsabilidade única do autor e com a anuência de seu orientador.

São Paulo, 01 de dezembro de 2014.

Assinatura do autor

Assinatura do orientador

Catalogação-na-publicação

Rinaldi, Luciene Cristina Alves

Proposição e avaliação de um modelo de transmissão de conhecimento coerente com comportamentos observados /

L.C.A. Rinaldi. -- versão corr. -- São Paulo, 2014.

$157 \mathrm{p}$.

Tese (Doutorado) - Escola Politécnica da Universidade de São Paulo. Departamento de Engenharia de Sistemas Eletrônicos.

1.Comportamento social 2.Aprendizado computacional 3.Simulação computacional 4.Conhecimento (Transferência) 5.Redes sociais (Análise) I.Universidade de São Paulo. Escola Politécnica. Departamento de Engenharia de Sistemas Eletrônicos II.t. 


\section{DEDICATÓRIA}

Dedico este trabalho a meu filho Lucas Rinaldi Rodrigues. 


\section{AGRADECIMENTOS}

A meu filho Lucas Rinaldi Rodrigues, companheiro de jornada, pela compreensão, paciência, incentivo incondicional e prova diária de amor recebido durante todo esse período de ausência. Razão de existir deste trabalho.

A meus pais, Leonice Alves Rinaldi e Sérgio Rinaldi, que, com dedicação e carinho, ensinaram-me a mestra arte de lapidar as dificuldades da vida com as ferramentas de verdade aprendidas no lar. Grata pela vida!

Ao Professor Dr. Marcio Lobo Netto pela sua orientação, incentivo, apoio e paciência para comigo, durante todo o desenvolvimento deste trabalho.

A meus amigos que contribuíram de forma direta com o projeto: Mauro Enrique de Souza Muñoz (no simulador, com os conceitos do modelo, algoritmos em geral, algoritmo genético e conceitos matemáticos), Rodrigo Bossini Tavares Moreira (na teoria dos grafos resultando no desenvolvimento da ferramenta para o Laboratório de Etologia Cognitiva do Instituto de Psicologia da USP), Alexandre Gomes Rabelo de Almeida (que através da Iniciação Científica me auxiliou no segundo protótipo), Dinamérico Alonso Gaspar (que me auxiliou no primeiro protótipo da qualificação), Profa. Dra. Briseida Dogô de Resende (que forneceu os dados reais observados em campo do Parque Ecológico do Tiete, sem nenhuma restrição, desde a primeira vez que eu a conheci), Prof. Dr. André Hinkenjann da Alemanha com a tentativa de possível co-orientador, Prof. Dr. Romero Tori e Prof. Dr. Marco Túlio Carvalho de Andrade (que contribuíram com a qualificação), Andreia Zotovici (com publicação juntas em disciplina) e Lécio Carvalho (no inglês). Meus sinceros agradecimentos a todos vocês que fizeram este trabalho valer a pena.

Aos meus irmãos Andrea Cristina Alves Rinaldi e Sérgio Luiz Alves Rinaldi, aos meus amigos e colegas, Geraldo Antônio Pazini, Augusto Einsfeldt, Carmelinda da Silva Perez, Roze Araujo, Regiane Relva Romano, Daniel Costa de Paiva, João Ranhel, Julio Monteiro, Cícero da Conceição (in memory), Osvaldo Guimarães, Gilda Assis, Ana Grasielle, Conceição Torres, Sandra Cristina Silva, Sandra Bianca Henriques Geroldo, Eneida Almeida dos Reis, Flávio Crispim, e a todos que de forma direta ou indireta, contribuíram para a realização deste trabalho. 
O CÉREBRO ELETRÔNICO faz tudo

Faz quase tudo

Faz quase tudo

Mas ele é mudo

O CÉREBRO ELETRÔNICO comanda

Manda e desmanda

Ele é quem manda

Mas ele não anda

Só eu posso pensar

Se Deus existe

Só eu

Só eu posso chorar

Quando estou triste

Só eu

Eu cá com meus botões

De carne e osso

Eu falo e ouço.

Hum...

Eu penso e posso

Eu posso decidir

Se vivo ou morro por que

Porque sou vivo

Vivo pra cachorro e sei

Que CÉREBRO ELETRÔNICO nenhum me dá socorro

No meu caminho inevitável para a morte

Porque sou vivo

Sou muito vivo e sei

Que a morte é nosso impulso primitivo e sei

Que CÉREBRO ELETRÔNICO nenhum me dá socorro

Com seus botões de ferro e seus

Olhos de vidro

Moisés Santana e Tatá Aeroplano 


\section{RESUMO}

O avanço tecnológico faz com que simulações e experimentos computacionais sejam alternativas atraentes para estudar cientificamente princípios fundamentais de sistemas reais. Este trabalho foi desenvolvido buscando uma metodologia para encontrar um modelo de transmissão de conhecimento (competência) coerente com os comportamentos observados em campo na área de psicologia comparada que estuda primatas não humanos. O experimento visa apoiar os pesquisadores do Laboratório de Etologia Cognitiva do Instituto de Psicologia da USP que analisam os processos de aprendizagem de quebra de cocos, através da transferência de informações em um grupo de macacos prego que habitam uma ilha no Parque Ecológico do Tiete em São Paulo. O objetivo deste trabalho foi o desenvolvimento de um modelo computacional, implantado junto a uma plataforma de simulação, para avaliar experimentos virtuais de transmissão de conhecimento em macacos prego, analisando a influência de atividades periféricas sobre uma atividade específica (quebra de cocos). Além disso, a tese se propõe a discutir a coerência entre dados observados em campo e aqueles produzidos pela plataforma computacional. Embora as atividades periféricas não estejam diretamente relacionadas com a atividade específica do conhecimento a ser transmitido, contribuem indiretamente para isso, sendo este um tema de interesse da tese. O modelo desenvolvido trata tanto da proposição dos mecanismos de busca por uma matriz de transferência de conhecimento, como de um ambiente para simulação do sitio habitado pelos macacos, dando subsídios para ajuste e avaliação desta matriz (coeficientes que traduzem a importância de cada relação entre macacos nas suas diversas atividades). A plataforma computacional é alimentada com dados reais, que servem ainda como referencia para comparação com os resultados computacionais obtidos. A difusão do comportamento ocorre através da rede social considerando a proximidade entre os primatas (seus encontros). Cabe ressaltar que a simulação do comportamento dos indivíduos numa sociedade ocorre sobre um sistema matemático que não é capaz de representar suas propriedades mentais, nem de forma fiel o seu comportamento. Assim, o comportamento dos agentes são naturalmente limitados às características retratadas em modelos computacionais, de modo que os modelos mentais desses agentes e seus correspondentes comportamentos sociais são naturalmente simplificações da realidade.

Palavras-chave: comportamento social, aprendizado de máquina, simulação computacional, transferência de conhecimento, análise de rede social. 


\begin{abstract}
Technological advances allow simulations and computational experiment to be attractive alternatives to proceed with scientific studies of some fundamental principles of real systems. This work was developed searching for a methodology to find a coherent model of knowledge (competence) transfer, in the study area of behavioral psychology of non-human primates. The experiment intends to assist researchers from the Laboratory of Cognitive Ethology of the Psychology Institute from USP, involved with the analysis of coconut break learning processes, based on knowledge transfer of a monkey group living on an island at Tiete Ecology Park, in Sao Paulo. The goal is the development of a computational model, implemented on a simulation platform, to assess virtual experiments on knowledge transfer in monkeys, evaluating the influence of peripheral activities on another specific one (coconut break). Furthermore, this thesis discusses the coherence between real and simulated data. Although secondary activities are not directly related to the specific one, there are evidences that they play a contribution role, a subject of this thesis too. The developed model considers both, the mechanism used to evolve and evaluate the knowledge transfer matrix (whose coefficients reflect the importance of each monkey relationship in their various activities). The computational platform is feed with real data, used also as a reference for comparison with simulation results. The behavior diffusion is performed inside a social network considering primates proximities (meetings). It is worth mentioning that the simulation runs on top of mathematical substrate not able to take into account all mental properties neither with fidelity all nuances of the social behavior. Therefore, the behavior of the agents in the simulation stage is constrained by those characteristics embedded in the used computational models, in such a way that their mental models and consequent behavior are naturally simplifications of the reality.
\end{abstract}

Keywords: social behavior, computacional learning, computacional simulation, knowledge transfer, social network analysis. 


\section{LISTA DE ILUSTRAÇÕES}

FIGURA 1.1 - MODELO GERAL: AMBIENTE REAL X AMBIENTE VIRTUAL..........20

FIGURA 1.2- AMBIENTE REAL: ILHA DO PET .............................................21

FIGURA 1.3 - EXEMPLO DO GRAFO DA ESTRUTURA HIERÁRQUICA DOS

MACACOS GERADA PELA FERRAMENTA ANTIGA (RESENDE, 2004) ........25

FIGURA 1.4 - EXEMPLO DO GRAFO DA ESTRUTURA HIERÁRQUICA DOS

MACACOS FEITA NO WORD (RESENDE, 2004) ......................................25

FIGURA 2.1 - IMAGEM DO GOOGLE MAPS DO PARQUE ECOLÓGICO DO TIETE

FIGURA 2.2 - IMAGEM DA ILHA DOS MACACOS:

FIGURA 2.3 - FOTO DA ILHA VISTA POR FORA (CRÉDITOS: RINALDI, 2013) ...31

FIGURA 2.4 - FOTO DO MACACO PREGO CHAMADO HORÁCIO (CRÉDITOS:

RINALDI, 2013).

FIGURA 2.5 - A PRIMEIRA MATRIZ É A DE OBSERVAÇÃO EM CAMPO; A

SEGUNDA É A TRANSFORMAÇÃO DA PRIMEIRA PARA A DE

PROXIMIDADE (UTILIZADA NO HORÁCIO); A TERCEIRA É A

TRANSFORMAÇÃO DA PRIMEIRA UTILIZANDO A FÓRMULA DO

COEFICIENTE DE JACCARD E A QUARTA É A TRANSFORMAÇÃO DA

TERCEIRA UTILIZANDO A FÓRMULA DE DISTÂNCIA DE JACCARD

(UTILIZADA NO CUZCO).

FIGURA 2.6 - UM GRAFO SIMPLES DERIVADO A PARTIR DA MATRIZ DE PROXIMIDADE.

FIGURA 2.7 - UM GRAFO DERIVADO A PARTIR DA MATRIZ DE DISTÂNCIA DE

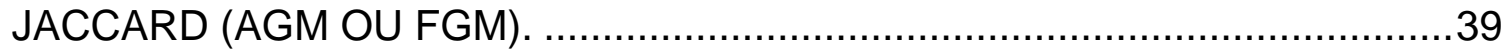

FIGURA 2.8- MARTELO: PEDRA UTILIZADA PARA GOLPEAR COCOS

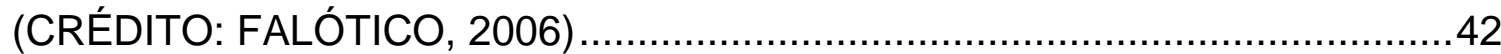

FIGURA 2.9 - BIGORNA (CRÉDITO: RINALDI, 2013) …................................42

FIGURA 2.10 -EPISÓDIO DE QUEBRA DE COCO (CRÉDITO: RINALDI, 2014) ...43

FIGURA 2.11 - FRUTO ENCAPSULADO - SYAGRUS ROMANZOFFINA (JERIVÁ)

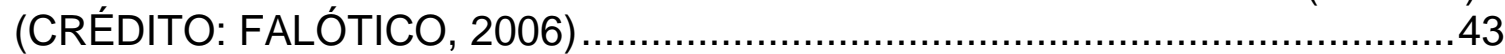

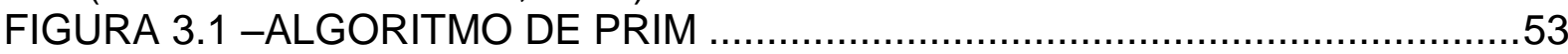

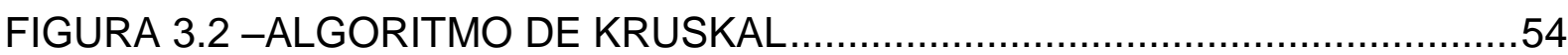

FIGURA 3.3 - TELA DE CADASTRO DE MACACOS ….................................55

FIGURA 3.4 - EXEMPLO DE PLANILHA ELETRÔNICA COM DADOS COLETADOS EM CAMPO FORNECIDOS PELOS PESQUISADORES DO LEC DO IPUSP...56

FIGURA 3.5 -TELA DE INSERÇÃO DE DADOS MANUAIS DOS MOMENTOS DE OBSERVAÇÃO EM CAMPO (SUBSTITUI A PLANILHA ELETRÔNICA) E OS DADOS JÁ SÃO GRAVADOS NA BASE DE DADOS.

FIGURA 3.6. - O MODELO RELACIONAL QUE A FERRAMENTA PROPOSTA USA

PARA ARMAZENAR OS DADOS OBSERVADOS.

FIGURA 4.1- EXEMPLO DO MODELO DE TRANSMISSÃO DE CONHECIMENTO

FIGURA 4.2 - EXEMPLO DA MATRIZ DE TRANSMISSÃO DE CONHECIMENTO 65

FIGURA 4.3 - AMBIENTE SIMULADO (PLATAFORMA PROPOSTA) …................69

FIGURA 4.4 - MODELO SOCIAL ...................................................................

FIGURA 4.5 - AGENTE SIMULADO QUE REPRESENTA O MACACO …..............71

FIGURA 4.6 - ALGORITMO DA SIMULAÇÃO …................................................ 72

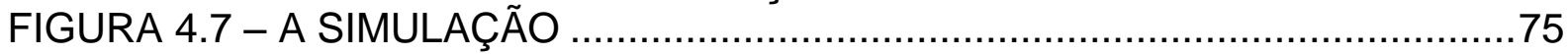


FIGURA 4.8 - O OBSERVADOR VIRTUAL

FIGURA 4.9 - CRITÉRIOS PARA AVALIAÇÃO DOS MELHORES RESULTADOS ENCONTRADOS DAS SIMULACÕES DA MATRIZ

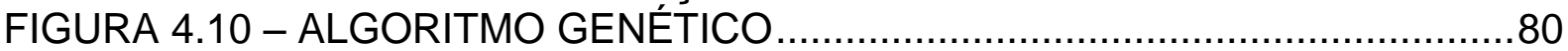

FIGURA 4.11 - TRANSPOSIÇÃO DO VETOR G[ ] (GENÓTIPO) CONTENDO AS NA ATIVIDADES (POR EXEMPLO, 26) PARA A MATRIZ M[ ] [ ] DE TRANSMISSÃO DE CONHECIMENTO.

FIGURA 4.12 - PONDERAÇÃO DOS CRITÉRIOS DE AVALIAÇÃO PARA ENCONTRAR O MENOR ERRO

FIGURA 4.13 - EXEMPLO DO PROCEDIMENTO DE SELEÇÃO ….......................83

FIGURA 4.14 - EXEMPLO DO PROCEDIMENTO DE CROSSOVER …................84

FIGURA 4.15 - EXEMPLO DO PROCEDIMENTO DE MUTAÇÃO …....................85

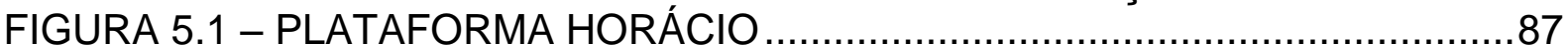

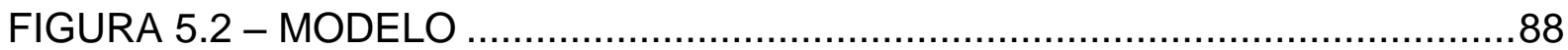

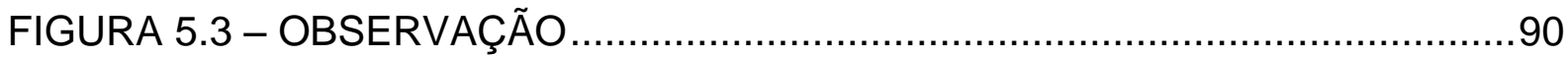

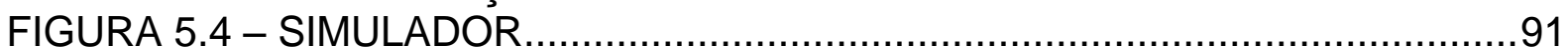

FIGURA 5.5 - ALGORITMO GENÉTICO …........................................................

FIGURA 6.1 - AGENTES EXECUTANDO AS ATIVIDADES SIMULADAS ..............96 


\section{LISTA DE GRÁFICOS}

GRÁFICO 3.1- UMA FLORESTA GERADORA MÍNIMA NA QUAL OS PESOS DAS ARESTAS SÃO REPRESENTADOS POR SUA LARGURA .57

GRÁFICO 3.2 - UMA FGM NA QUAL OS PESOS DAS ARESTAS SÃO REPRESENTADOS POR UM NÚMERO ASSOCIADO A ELAS COMO UM RÓTULO.

GRÁFICO 3.3 - FLORESTA GERADORA MÍNIMA CALCULADA PARA O SUBGRUPO DE FÊMEAS EM 16 DE JUNHO 2012.

GRÁFICO 3.4 - FLORESTA GERADORA MÍNIMA CALCULADA PARA O SUBGRUPO DE MACHOS EM 16 DE JUNHO 2012.

GRÁFICO 3.5 - GRAFO SEPARADO PELA FERRAMENTA PROPOSTA 61 


\section{LISTA DE TABELAS}

TABELA 6.1 - MATRIZ DE TRANSMISSÃO DE CONHECIMENTO 96

TABELA 6.2 - MATRIZ DOS COEFICIENTES DE TRANSMISSÃO 


\section{LISTA DE ABREVIATURAS E SIGLAS}

$\mathrm{AE} \quad$ Algoritmos Evolucionários

AG Algoritmos Genéticos

AGM Árvore Geradora Mínima

AR Ambiente Real

ARS Análise de Redes Sociais

AV Ambiente Virtual

CCE Centro de Computação Eletrônica

CNPQ Conselho Nacional de Desenvolvimento Científico e Tecnológico

CSV Comma Separated Valeus (formato de arquivo)

CUZCO Nome da Ferramenta para Análise de Rede Social para o IPUSP

EE Estratégias Evolucionárias

FGM Floresta Geradora Mínima

FUSP Fundação de Apoio á Universidade de São Paulo

GUI Graphic User Interface

HORÁCIO Nome do simulador desenvolvido para a tese e para o IPUSP

IA Inteligência Artificial

IC Iniciação Científica

IPUSP Instituto de Psicologia Comportamental da USP

LEC Laboratório de Etologia Cognitiva

PE Programação Evolutiva

PET Parque Ecológico do Tiete

RS Redes Sociais

SNA Social Network Analisys

USP Universidade de São Paulo 


\section{LISTA DE SIMBOLOS}

$\mathrm{B}_{\mathrm{i}}^{\mathrm{O}}$

$\mathrm{B}_{\mathrm{i}}^{\mathrm{S}}$

$c_{i}$

$c_{j}$

$\Delta c_{i}$

$\mathrm{c}_{\mathrm{i}}(\mathrm{t})$

$C_{r}^{M}(t)$

$C F^{O}$

$C F^{S}$

$C F_{i}^{O}$

$C F_{i}^{S}$

$\mathrm{CI}^{\mathrm{O}}$

$C I^{S}$

$C I_{j}^{O}$

$C I_{j}^{S}$

Cap

$d$

Erro

$\mathrm{e}_{\mathrm{i}}$

$f$

$g$

$H^{M}$

$h$

J

$L$

$l$

$\mathrm{l}_{\mathrm{i}}(\mathrm{t})$

$M$

$m f$

é o conjunto das $N_{A}$ atividades que podem ser realizadas pelos sujeitos representa a atividade realizada pelo sujeito $S_{i}$ representa a atividade realizada pelo sujeito $S_{j}$

é a atividade $i$ realizada pelo agente no instante $t$ simulado

é o conjunto de todos os perfis obtidos a partir das observação

é o conjunto de todos os perfis obtidos a partir da simulação

é o perfil observado do sujeito $S_{i}$

é o perfil simulado do sujeito $S_{i}$

é o aumento do conhecimento do sujeito $S_{i}$

é o aumento do conhecimento do sujeito $S_{j}$

é a variação do aumento do conhecimento do sujeito $S_{i}$

é o conhecimento do agente $S_{i}$ no instante $t$ simulado

são as proficiências dos agentes no instante de tempo $t$ da execução $r$ do simulador quando o modelo de transmissão $M$ é utilizado

é o vetor com as proficiências finais observadas

é o vetor com as proficiências finais da simulação

é o número de observações, no final do período de observação, nas quais o sujeito $S_{i}$ obteve sucesso na realização da atividade específica é o número de observações da simulação, no final do período de observação da simulação, nas quais o sujeito $S_{i}$ obteve sucesso na realização da atividade específica

é o vetor com as proficiências iniciais observadas

é o vetor com as proficiências iniciais da simulação

é o número de observações, no inicio do período de observação, nas quais o sujeito $S_{j}$ obteve sucesso na realização da atividade específica é o número de observações da simulação, no inicio do período de observação da simulação, nas quais o sujeito $S_{j}$ obteve sucesso na realização da atividade específica

é a função de capacitação que utiliza a eq.(19) para obter o erro de conformidade de $M(g)$ com os dados observados na eq.(22)

é a data (composta por dia, mês e ano) em que aquela observação foi feita

utiliza os critérios de distância e desvio padrão de forma ponderada

é o agente do ambiente virtual que representa o sujeito observado $S_{i}$ do ambiente real (macaco)

é a função que indica a capacitação dos genótipos

é o genótipo

representa os melhores resultados encontrados pelo simulador

é o horário da observação feita em campo pelos psicólogos

é o índice de Jaccard

é o conjunto dos $N_{L}$ locais onde os sujeitos podem realizar as atividades

são os locais onde estão sendo executadas as atividades

é o local onde o agente $S_{i}$ se encontra no instante $t$ simulado

é a matriz dos coeficientes de transmissão de conhecimento

animal focal 


\begin{tabular}{|c|c|}
\hline$N_{A}$ & é o número de atividades que podem ser realizadas pelos sujeitos \\
\hline$N_{L}$ & é o número de locais utilizados pelos sujeitos \\
\hline$N_{P}$ & é o número da população do conjunto de genótipos $P$ \\
\hline$N_{S}$ & é número de sujeitos utilizados \\
\hline$N_{r}$ & $\begin{array}{l}\text { é o número de vezes que o simulador é executado com os mesmos } \\
\text { parâmetros } M \text { e } W\end{array}$ \\
\hline$N_{G}$ & é o número de genótipos \\
\hline$N_{t}$ & é o número de iterações para cada execução do simulador \\
\hline$p$ & é a influência do desvio padrão \\
\hline$p_{g}$ & probabilidade de mutação de um gene específico \\
\hline$P$ & conjunto de genótipos $g$ \\
\hline$P^{O}$ & $\begin{array}{l}\text { é a matriz que armazena as informações referentes às freqüências dos } \\
\text { encontros observados entre as } N_{A} \text { atividades }\end{array}$ \\
\hline$P^{S}$ & $\begin{array}{l}\text { é a matriz que armazena as informações referentes às frequências dos } \\
\text { encontros simulados entre as } N_{A} \text { atividades }\end{array}$ \\
\hline$P_{i j}^{O}$ & indica a probabilidade do sujeito $S_{i}$ se aproximar do sujeito $S_{j}$ \\
\hline$q$ & é um vetor que contém o número de genótipos $g$ \\
\hline$Q I_{j}^{O}$ & $\begin{array}{l}\text { é o número de observações, no inicio do período de observação, nos } \\
\text { quais o sujeito } S_{j} \text { obteve sucesso na realização da atividade } \\
\text { específica }\end{array}$ \\
\hline$Q F_{j}^{O}$ & $\begin{array}{l}\text { é o número de observações, no final do período de observação, nos } \\
\text { quais o sujeito } S_{j} \text { obteve sucesso na realização da atividade específica }\end{array}$ \\
\hline$r$ & $\begin{array}{l}\text { é a função utilizada para representar a geração de números aleatórios } \\
\text { com distribuição uniforme }\end{array}$ \\
\hline$R_{r}$ & é a execução do simulador \\
\hline$s$ & é utilizado como um selecionador de genótipos \\
\hline$S$ & é o conjunto dos $N_{S}$ sujeitos utilizados no modelo \\
\hline$S_{i}$ & é o sujeito $i$ que representa o macaco prego do ambiente real \\
\hline$S_{j}$ & é o sujeito $j$ que representa o macaco prego do ambiente real \\
\hline$t^{O}$ & $\begin{array}{l}\text { horário (composto por hora, minuto e segundo) em que a observação } \\
\text { foi realizada no ambiente real }\end{array}$ \\
\hline$t$ & tempo em que a observação da simulação foi realizada \\
\hline$T F_{j}^{O}$ & $\begin{array}{l}\text { é o número total de observações, no final do período de observação, } \\
\text { nos quais o sujeito } S_{j} \text { se propôs a realizar a atividade específica }\end{array}$ \\
\hline$T I_{j}^{O}$ & $\begin{array}{l}\text { é o número total de observações, no inicio do período de observação, } \\
\text { nas quais o sujeito } S_{j} \text { se propôs a realizar a atividade específica }\end{array}$ \\
\hline$T I_{j}^{S}$ & $\begin{array}{l}\text { é o número total de simulações, no inicio do período de observação da } \\
\text { simulação, nas quais o sujeito } S_{j} \text { se propôs a realizar a atividade } \\
\text { específica }\end{array}$ \\
\hline$u$ & $\begin{array}{l}\text { genótipos resultantes da mutação de um ou mais genes do genótipo } \\
\text { original }\end{array}$ \\
\hline$U_{i}^{O}$ & $\begin{array}{l}\text { é o perfil de atividades observadas, sendo que } B a_{i j}^{O} \text { indica a proporção } \\
\text { de tempo que o sujeito } S_{i} \text { gastou realizando a atividade } A_{j}\end{array}$ \\
\hline$U_{i}^{S}$ & $\begin{array}{l}\text { é o perfil de atividades simuladas, sendo que } B a_{i j}^{S} \text { indica a proporção } \\
\text { de tempo que o sujeito } S_{i} \text { gastou realizando a atividade } A_{j}\end{array}$ \\
\hline$V_{i}^{O}$ & $\begin{array}{l}\text { é o perfil de locais observados, sendo que } B l_{i k}^{O} \text { indica a proporção de } \\
\text { tempo que o sujeito } S_{i} \text { gastou no } L_{k}\end{array}$ \\
\hline
\end{tabular}


$V_{i}^{S} \quad$ é o perfil de locais simulados, sendo que $B l_{i k}^{S}$ indica a proporção de tempo que o sujeito $S_{i}$ gastou no $L_{k}$

$x\left(S_{i}\right) \quad$ é o valor da proximidade atribuída para o sujeito $S_{i}$

$x\left(S_{j}\right) \quad$ é o valor da proximidade atribuída para o sujeito $S_{j}$

$\mathrm{W}$

é o modelo social que armazena os dados necessários à criação e execução do ambiente virtual

$y \quad \quad \quad$ é uma tupla (ou linha da matriz)

$z \quad$ é a distância a ser considerada

$\mu^{M} \quad$ é o ponto médio de $H^{M}$

$\sigma^{M} \quad$ é o desvio padrão dos pontos de $H^{M}$

$\delta^{M} \quad$ é a distância a ser considerada entre $C F^{O}$ o ponto médio de $H^{M}$ 


\section{SUMÁRIO}

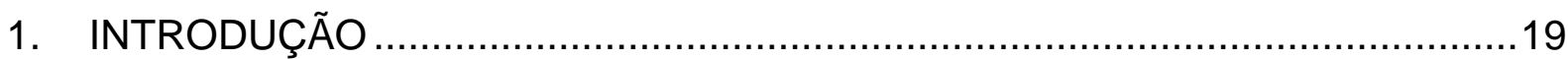

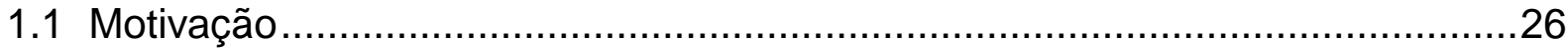

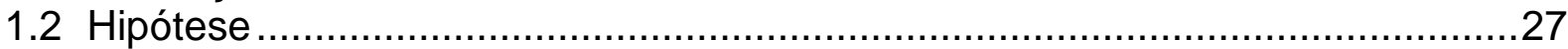

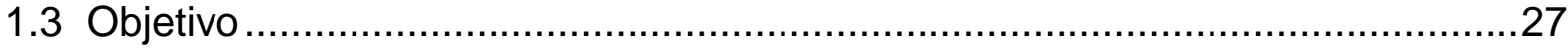

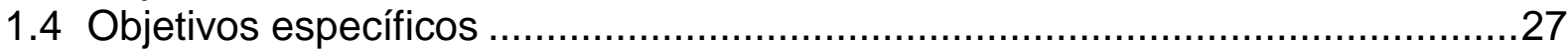

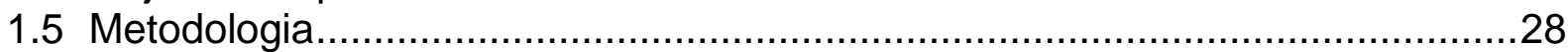

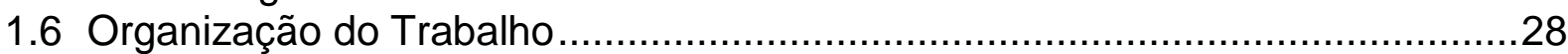

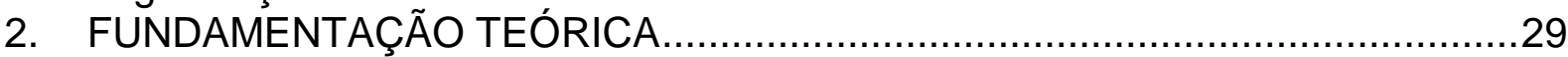

2.1. Ambiente Real: Ilha do Parque Ecológico do Tiete (PET) ...........................29

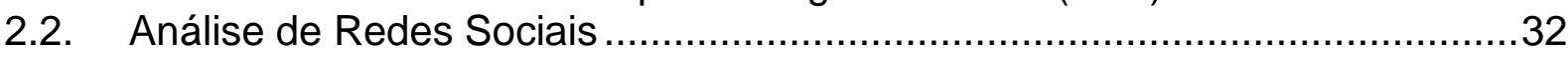

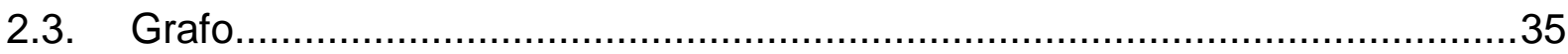

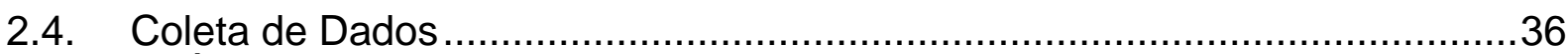

2.4.1. Árvore Geradora Mínima (AGM) ou Floresta Geradora Mínima (FGM) ......40

2.4.2. Objetivo do grupo de pesquisadores do LEC do IPUSP ...........................41

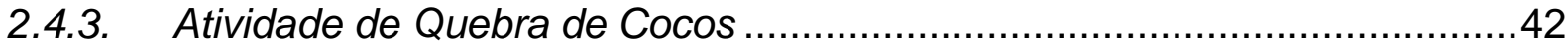

2.4.4. A representação do conhecimento....................................................43

2.5. Ambiente Virtual, Agentes e Multiagentes ............................................... 45

2.6. Algoritmos Genéticos.................................................................. 47

3. CONCEPÇÃO E DESENVOLVIMENTO DA FERRAMENTA DE ANÁLISE DE

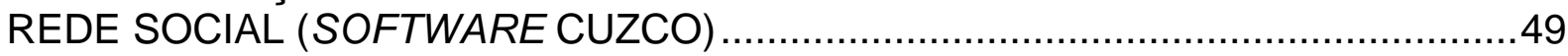

3.1. Momentos e intervalos de observação .................................................... 49

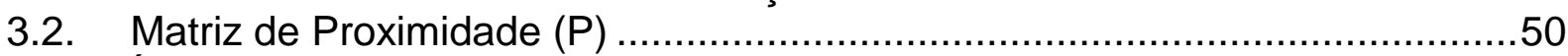

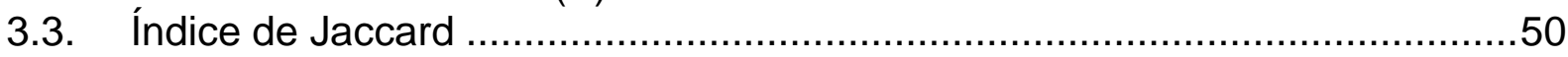

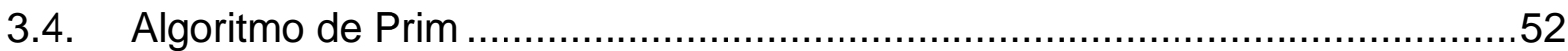

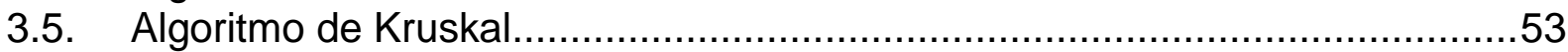

3.6. Implementação do Software Cuzco .....................................................54

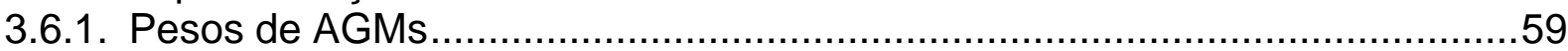

4. CONCEPÇÃO E DESENVOLVIMENTO DO MODELO E DO AMBIENTE DE

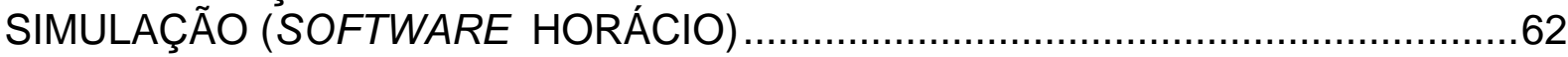

4.1. O Modelo de Transmissão de Conhecimento.............................................62

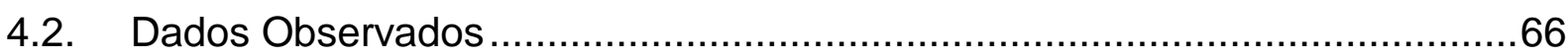

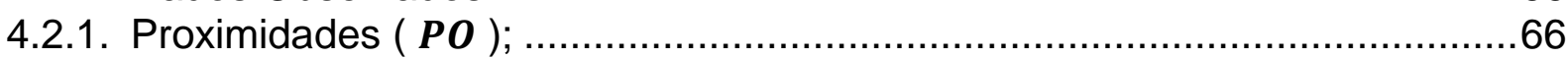

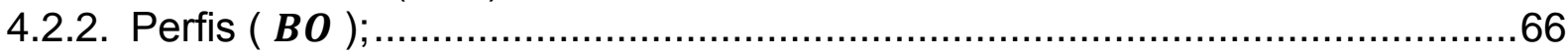

4.2.3. Proficiências Iniciais $(\boldsymbol{C I})$ e Proficiências Finais $(\boldsymbol{C F})$................................67

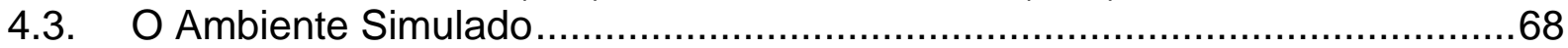

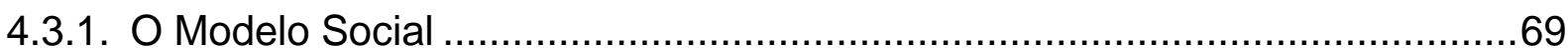

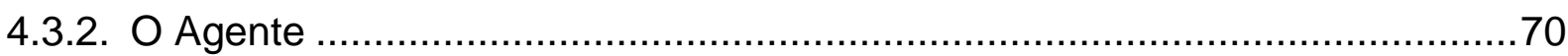

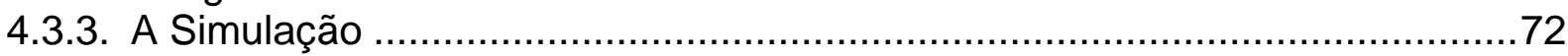

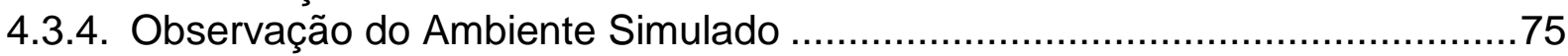

4.4. Exposição do Problema.....................................................................

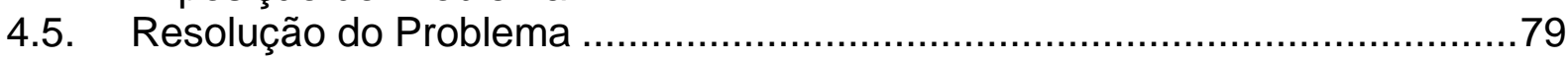

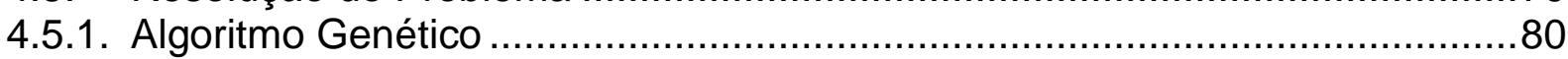

4.5.2. Adaptação do Problema ao Algoritmo Genético ............................................ 81

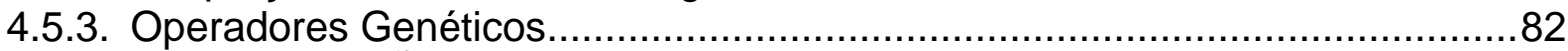

5. IMPLEMENTAÇÃO DA PLATAFORMA COMPUTACIONAL (SOFTWARE

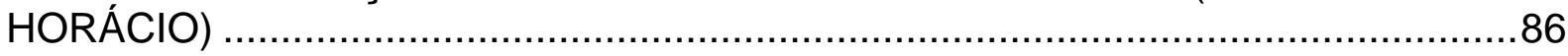

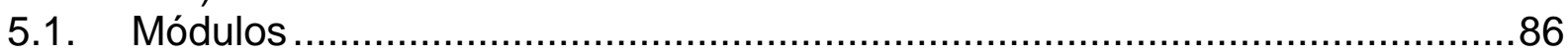




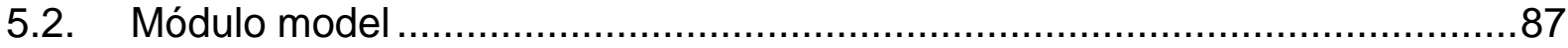

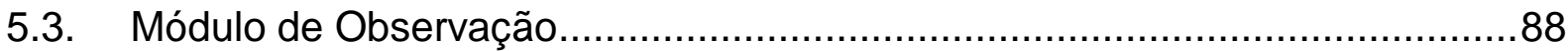

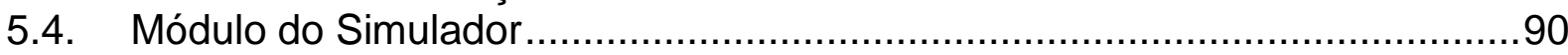

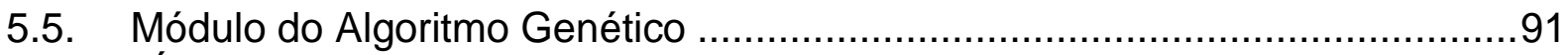

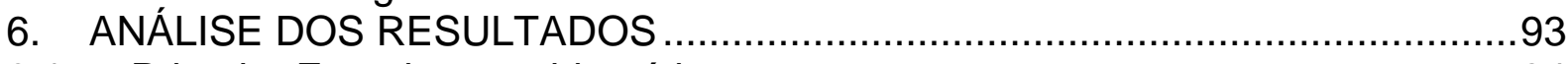

6.1. Primeiro Experimento: hipotético .........................................................94

6.2. Segundo Experimento (hipotético intermediário): utiliza os dados observados

( 6 agentes e 4 atividades)

6.3. Terceiro Experimento (Dados reais observados): utiliza os dados observados

(38 agentes e 26 atividades) na sua completude .................................................98

7. CONCLUSÕES E TRABALHOS FUTUROS ….......................................100

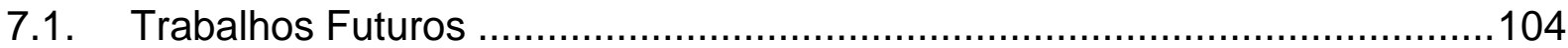

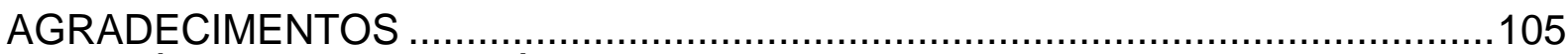

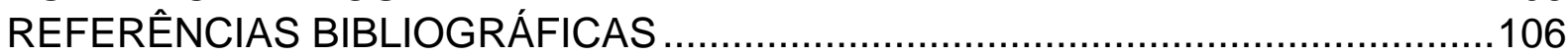

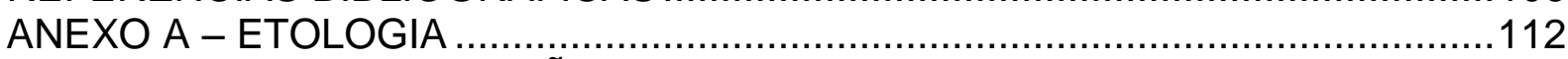

APENDICE A - COMPARAÇÃO DE SOFTWARE DE REDES SOCIAIS ...............117

APENDICE B - LISTAGEM DAS ANÁLISES DOS RESULTADOS ......................121 


\section{INTRODUÇÃO}

Dentre as inúmeras áreas que atraem a curiosidade cientifica está àquela tratada nesta tese, e que procura estudar e entender a forma como ocorre o processo de transferência de conhecimento (competência) em alguns grupos de primatas não humanos. Neste contexto, surgem algumas perguntas como: Um primata pode de alguma forma transferir seu conhecimento para outro? Pode um primata aprender alguma coisa com outro baseado apenas em observações? Quanto tempo leva para um primata aprender efetivamente algo que outro já sabe? Como é que ocorre o processo de transferência de conhecimento? Porque apenas alguns destes primatas são bem sucedidos em algumas tarefas? (LALAND; RICHERSON; BOYD, 1996).

Estas são algumas das questões abordadas pelos pesquisadores do Laboratório de Etologia Cognitiva do Instituto de Psicologia Comparada da Universidade de São Paulo (LEC IPUSP). Enquanto isso, com o suporte oferecido pela Inteligência Artificial (IA), modelos computacionais são propostos a fim de extrair e evidenciar algumas das características dos grupos de primatas analisados por estes psicólogos a fim de inferir regras coerentes relacionadas às propriedades que forem de interesse para a pesquisa relacionada, mesmo que de forma limitada, com a finalidade de ajudar a fornecer respostas para as perguntas mencionadas anteriormente.

O modelo computacional desenvolvido nesta tese simula o comportamento dos primatas observados, o que pode ser útil para se estudar situações de experimentos para testar hipóteses difíceis de serem observadas por diferir daquelas existentes. É amplamente aceito, no entanto, que os modelos computacionais de forma geral, podem refletir apenas algumas características do ambiente, utilizando-se de regras coerentes com os comportamentos observados. Mas, não importa o quão detalhado seja o modelo computacional proposto, ele não será capaz de representar todas as propriedades específicas do ambiente real. No entanto, é notável a forma como modelos computacionais refinados e propostos de forma adequada podem ser de grande ajuda na investigação deste campo ou de outras áreas, apesar de suas inevitáveis limitações.

Este trabalho foi inspirado no "estudo" sobre aprendizagem social em macacos prego do Parque Ecológico do Tiete (PET) que vem sendo realizado por 
pesquisadores do LEC do IPUSP que será explicado com mais detalhes no capítulo 2. A observação de comportamento em campo é um método de trabalho da Etologia que estuda o comportamento animal com base nas observações naturalísticas ou experimentos de campo com viés evolucionista que pode dar origem a dados valiosos, a partir dos quais é possível fazer deduções.

Para entender melhor o trabalho desenvolvido, que tenta responder algumas das questões citadas inicialmente, é preciso visualizá-lo sob dois cenários como mostra a Figura 1.1 a seguir: o cenário real e o cenário virtual.

Ambiente Real (Ilha do PET)

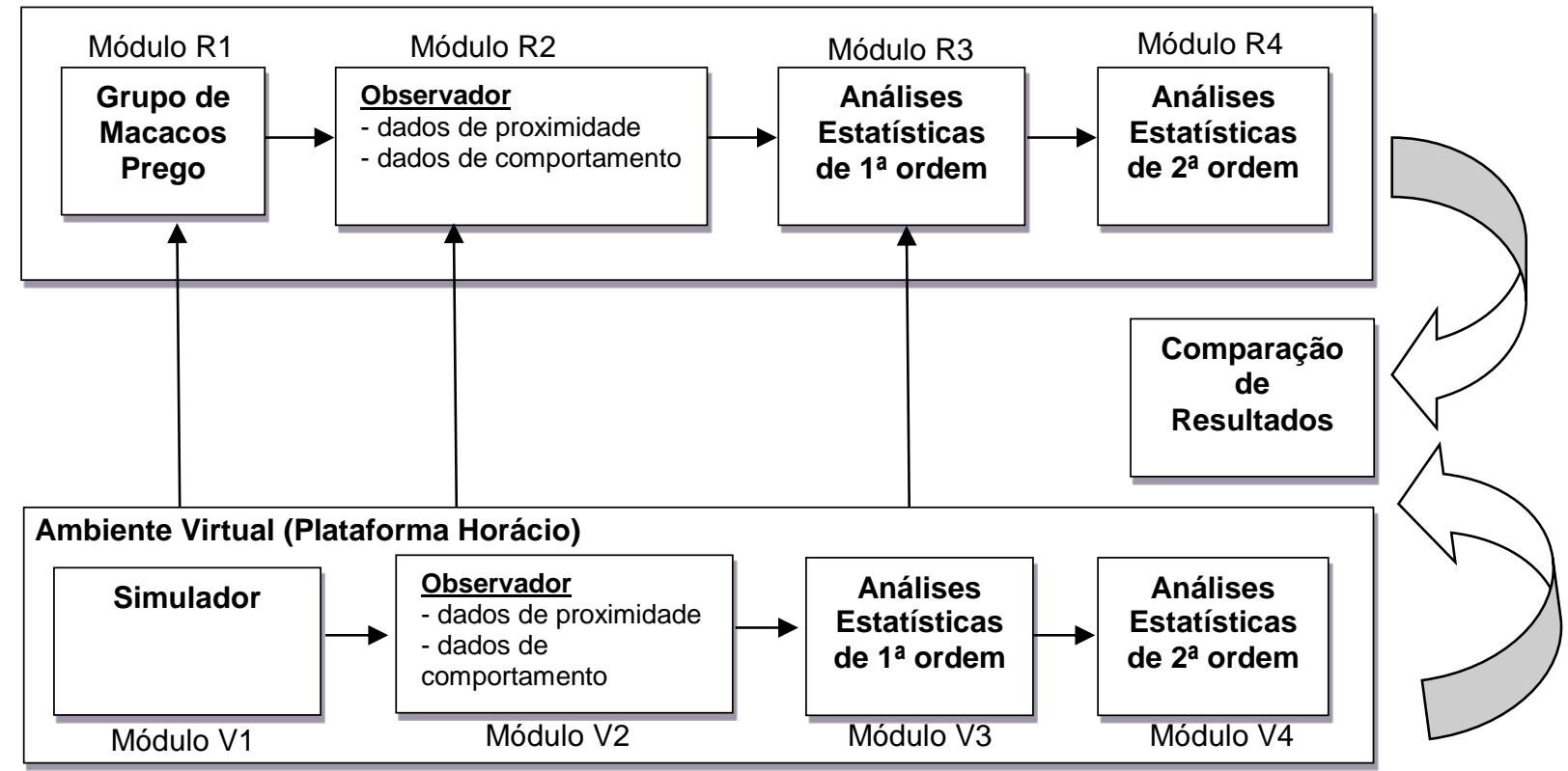

Figura 1.1 - Modelo geral: Ambiente Real x Ambiente Virtual

O primeiro cenário tratado como Ambiente Real (AR) (Figura 1.2) é a ilha do PET onde viviam 38 macacos prego. A maioria destes macacos nasceu lá embora alguns tenham sido apreendidos pela polícia federal ou tenham vindo de doações (IZAR, 1994).

Os pesquisadores do LEC do IPUSP vão em média três vezes por semana por um período de aproximadamente duas horas e gravam através de uma câmera digital o que está acontecendo neste ambiente, para depois anotarem suas observações em uma planilha eletrônica, registrando assim os dados coletados em campo, além de fazer uma análise primária (módulo R3) utilizando o método de varredura focal (ALTMAN, 1974) dos macacos no período observado, ou seja, quais 
primatas se encontravam próximos (em um raio de $1 \mathrm{~m}$ ou $10 \mathrm{~m}$ ) de um particular macaco escolhido, considerado como o "animal focal" (seção 2.4).

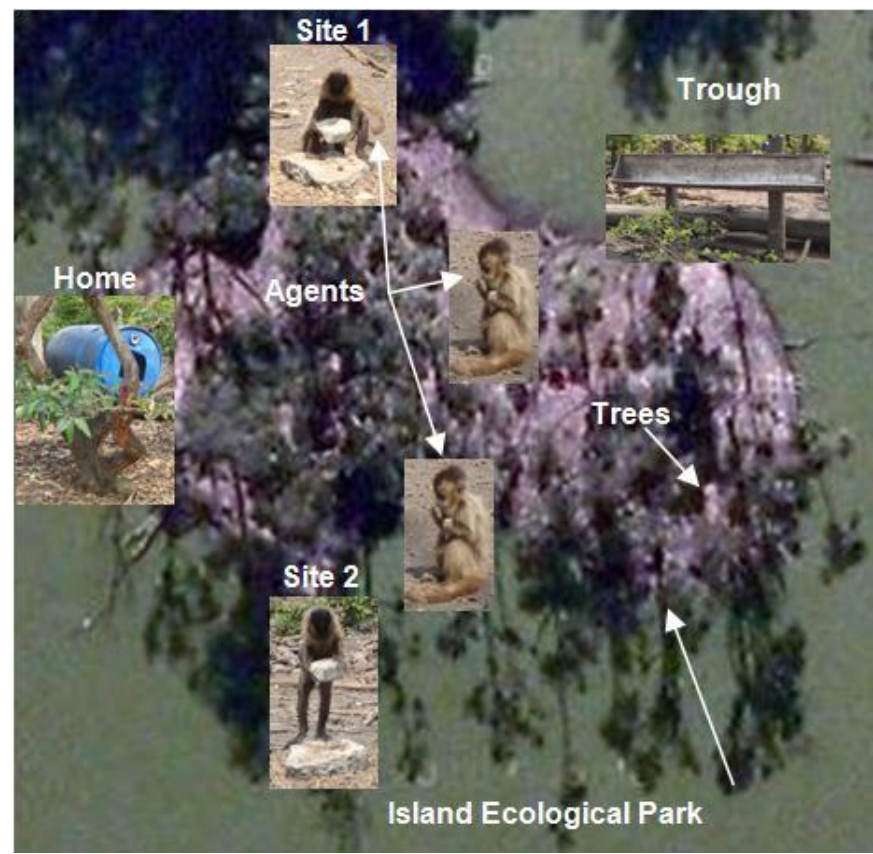

Figura 1.2 - Ambiente Real: Ilha do PET

A abordagem chamada de "animal focal" foi empregada para que a dificuldade de se observar todos os macacos simultaneamente pudesse ser contornada. Nesta abordagem, um macaco é escolhido arbitrariamente e a partir daquele instante ele é considerado como "animal focal". O animal focal é observado durante um intervalo de tempo e o observador faz anotações sobre quais macacos estão próximos o bastante dele (em um raio de $1 \mathrm{~m}$ ou $10 \mathrm{~m}$ ) a cada momento de observação em uma primeira planilha eletrônica. O registro destas observações permite verificar a frequência com que os macacos ficam próximos uns dos outros e com isto pode-se determinar um nível de proximidade média do encontro entre eles (módulo R2) (Figura 2.5).

A partir dos dados de proximidade observados entre os primatas, foram construídos grafos simples (seção 2.3) para representar a rede social (seção 2.2) desta comunidade (a primeira ferramenta chamada de Cuzco apresentada no capitulo 3). O grafo construído para a rede social através da matriz de proximidade (Figura 2.5) possui um conjunto de vértices (ou nós) que representam os 38 macacos e suas arestas representam por consequência o nível de proximidade 
médio dos encontros em que se deram entre os macacos (análises de primeira ordem) (módulo R3) (a plataforma chamada de Horácio, segunda ferramenta desenvolvida, utiliza somente a proximidade, enquanto o software Cuzco, utiliza a Floresta Geradora Mínima (FGM), apresentada na seção 2.4.1).

A outra planilha eletrônica com os dados de observação contém o acompanhamento do comportamento dos macacos que apresenta as atividades que os mesmos estavam executando e em qual local elas se deram (o local também é chamado de substrato) (módulo R2). Estes são os dados que serão trocados entre os macacos pela rede social de acordo com alguns critérios (regras) do ambiente. Estes comportamentos são as atividades diárias que os macacos executam como comer, forragear, dormir, entre outros. Alguns destes comportamentos são inatos (por exemplo, dormir e mamar) e outros comportamentos decorrem de um aprendizado a partir da observação de outros macacos, ou seja, que apresentam alguma relação através de um nível de proximidade que pode ser observado através do modelo de rede social (análise de segunda ordem) (módulo R4).

Através destes dados de observação e de seus parâmetros representativos, os pesquisadores do LEC fazem suas análises interpretando os dados e apresentando seus resultados. A interpretação desses dados é uma tarefa realizada pelos psicólogos do LEC.

Essas pesquisas nos motivaram no desenvolvimento da plataforma Horácio que representa o segundo cenário tratado como Ambiente Virtual (AV). A ideia da plataforma Horácio foi propor um modelo que encontre a influência de outras atividades (por exemplo, brincadeira social, observação da quebra de cocos, tolerância social, entre outras), chamadas de atividades periféricas, que auxilie na transmissão de um conhecimento específico (por exemplo, quebra de cocos). Nesta tese, as atividades periféricas são as que não estão diretamente relacionadas com a transmissão do conhecimento da atividade específica. É importante frisar que atualmente o agente utilizado possui um único conhecimento (chamado de conhecimento específico) que é utilizado para expressar a proficiência ${ }^{1}$ do agente na realização da atividade específica. Esse conhecimento é utilizado para comparar o resultado real com o resultado simulado (proficiência).

\footnotetext{
${ }^{1}$ Proficiência: macacos que aprenderam a quebrar cocos
} 
Em Resende (2004), verificou-se o levantamento da hipótese de que a atividade de brincadeira social poderia influenciar a aprendizagem de quebra de cocos devido à constatação de que os macacos intercalavam os episódios de quebra de cocos (seção 2.4.3) com a brincadeira social. Com isso, surgiu a motivação de criar um sistema computacional que pudesse apontar a influência das outras atividades periféricas que possam auxiliar na transmissão do conhecimento sobre a atividade específica de quebra de cocos, utilizando como referência os dados reais observados.

O simulador desenvolvido utilizado pela plataforma Horácio é alimentado com os dados brutos observados em campo gerados automaticamente de forma pseudoaleatória com distribuição gaussiana, modulado, porém pelos dados observados do $A R$, e que servem para definir as regras coerentes com o $A R$, incluindo informações estatísticas sobre proximidade e perfil de comportamento (módulo V2) dos agentes que estão representando no AV (simulado), os macacos prego.

A plataforma Horácio é composta pela simulação que funciona, portanto para gerar as informações do cenário virtual compatível com aquelas que foram observadas no cenário real. Estas informações geradas pelo simulador são novamente tratadas em primeira (módulo V3) e segunda ordem (módulo V4) respectivamente, permitindo a identificação de características essenciais deste grupo de primatas e assim podendo ser comparadas e testadas para encontrar 0 melhor resultado esperado.

Este trabalho esta relacionado inicialmente com a análise de um modelo de rede social usado para a transferência do conhecimento de comportamentos que seja coerente com os dados observados em campo deste grupo de primatas.

Para isso, com os dados observados em campo, obteve-se a relação de proximidade simulada como realizado anteriormente com os dados do ambiente real (módulo V2), que é utilizado pelo modelo da rede social para a transferência de conhecimento de um agente para o outro apenas quando eles estão próximos (por exemplo, no mesmo local: sítio de quebra de cocos).

Depois de estabelecido o relacionamento através da proximidade (Figura 2.5), é verificado o conhecimento entre os dois agentes envolvido (proficiência), pois o 
conhecimento é transmitido de forma direcionada, ou seja, do agente com maior conhecimento (transmissor) para o agente com menor conhecimento (receptor).

Em seguida, o modelo (Figura 4.1) considera as atividades que os dois agentes estão realizando naquele momento. A transmissão de conhecimento é dada exclusivamente pelas atividades que estão sendo realizadas e a proximidade entre os dois agentes, onde é verificado um coeficiente de transmissão de conhecimento específico. Esse coeficiente é encontrado a partir do algoritmo genético (que será explicado com mais detalhes na seção 4.5.1). O conhecimento do agente receptor é aumentado, de acordo com o modelo de transmissão de conhecimento (seção 4.1), que usa uma equação com os parâmetros referente ao coeficiente de conhecimento encontrado pelo algoritmo genético, e que está relacionado com as duas atividades que os agentes estavam executando naquele momento.

Esta tese propõe uma extensão do experimento criado em Rinaldi et al. (2013), através da incorporação do $\mathrm{AV}$, simulando o cenário real do PET de forma que possa servir de base para a realização de novos experimentos, cuja realização em um cenário real se depararia com dificuldades de diferentes naturezas. Além disso, do ponto de vista computacional, esta tese se debruça sobre questões que tratam da validade e abrangência do AV para poder de fato servir como um laboratório de experimentos virtuais.

Sendo assim, no desenvolvimento da tese, foram construídos dois softwares:

(1) Na primeira etapa foi construído um software para auxiliar os pesquisadores do LEC do IPUSP no armazenamento dos dados brutos coletados em campo, atualmente armazenados em um servidor virtual da USP fornecido pelo serviço de computação na nuvem mantido pelo CCE (Centro de Computação Eletrônica). Verificou-se a dificuldade que os pesquisadores do LEC tinham em armazenar e recuperar as informações coletadas em campo com as planilhas eletrônicas e depois gerar um grafo da estrutura hierárquica do grupo de macacos de forma gráfica para as análises posteriores. A Figura 1.3 apresenta um grafo gerado pela ferramenta que era utilizada. Com esta Figura 1.3, os pesquisadores do LEC geravam a Figura 1.4 desenhada no processador de texto Word da Microsoft. 


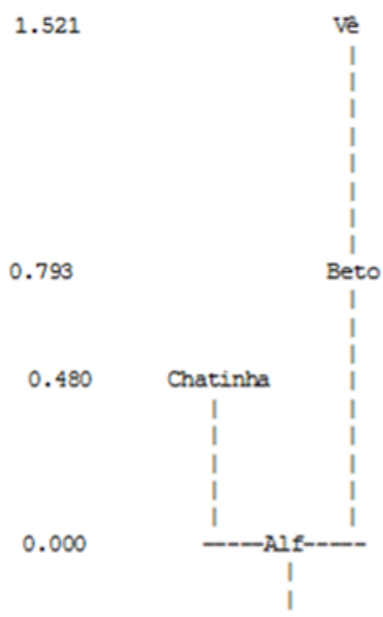

Figura 1.3 - Exemplo do grafo da estrutura hierárquica dos macacos gerada pela ferramenta antiga (RESENDE, 2004)

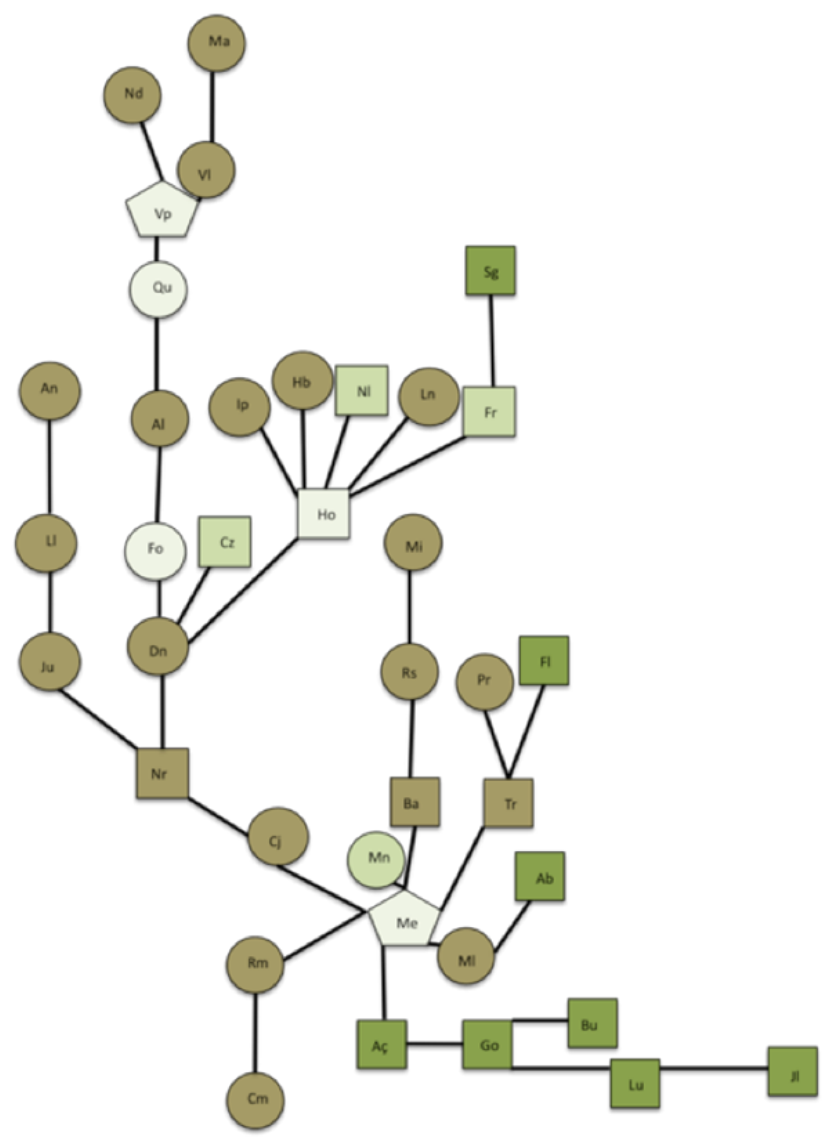

Figura 1.4 - Exemplo do grafo da estrutura hierárquica dos macacos feita no Word (RESENDE, 2004)

Essa ferramenta permite armazenar os dados coletados em campo, com apoio de uma interface gráfica simplificada próxima à planilha eletrônica utilizada anteriormente, para que os alunos de Iniciação Científica (IC) que digitam os dados coletados em campo não se sintam intimidados com a nova ferramenta. A ferramenta gera a estrutura hierárquica do grupo, também chamada como Árvore 
Geradora Mínima (AGM) de forma gráfica. O desenvolvimento dessa ferramenta foi fundamental para o aprofundamento na área de primatologia e para entender como funcionavam as análises desse grupo de pesquisadores do LEC, pois as áreas são multidisciplinares, e assim, também se pode auxiliar esses pesquisadores oferecendo uma ferramenta de trabalho. Esta ferramenta é apresentada no capítulo 3 ;

(2) Na segunda etapa também foi concebido e implementado um software, ou seja, uma plataforma que utiliza um simulador para buscar as proficiências simuladas próximas às proficiências reais observadas. Essa plataforma funciona como um laboratório de experimentos virtuais. A simulação utilizada pela plataforma desenvolvida é um elemento fundamental de apoio ao tema desta tese, a saber: a questão de transferência de conhecimento entre primatas para gerar ideias de experimentos para testar hipóteses.

Concluindo, inicialmente a ideia de colaboração com os pesquisadores do LEC do IPUSP era utilizar os dados etológicos coletados em campo por serem consolidados em longos estudos teóricos sobre os fenômenos naturais utilizando metodologias e fornecendo requisitos seguros para experimentos sintéticos. A maioria das simulações que não utilizam dados reais pode abusar das suposições que normalmente se caracteriza pelo enorme grau de liberdade no seu desenvolvimento (LOULA, 2004). Sendo assim, partindo de bases sólidas, pretendemos mostrar que as simulações auxiliam como um laboratório de experimentos virtuais onde situações do mundo real às vezes não possibilitam testes como estes laboratórios virtuais podem oferecer.

\subsection{Motivação}

Verificou-se na revisão bibliográfica que existe a hipótese de que a atividade de brincadeira social (atividade periférica) pode influenciar na transmissão do conhecimento sobre a atividade de quebra de cocos (conhecimento específico). 


\subsection{Hipótese}

Será que existem outras atividades (periféricas) que podem influenciar na transmissão do conhecimento sobre a atividade de quebra de cocos (conhecimento específico) como aponta a hipótese da revisão bibliográfica relativa à atividade de brincadeira social?

\subsection{Objetivo}

Estudar a transferência de conhecimento (competência) com o apoio de uma ferramenta computacional que permita ressaltar a influência das atividades periféricas que possam estar envolvidas na transmissão de um conhecimento específico.

\subsection{Objetivos específicos}

- Utilizar o cálculo de proximidade entre o encontro dos primatas com o mesmo método utilizado pelo LEC para criar um mapa de relações sociais;

- Apresentar a transferência de conhecimento dos comportamentos entre os agentes que estão ligados pela rede social;

- Verificar se a transferência de conhecimento da rede social apresenta resultados simulados próximos aos resultados reais;

- Ajustar o simulador com as regras de coerência de acordo com o ambiente real para que os resultados de proficiências simulados se aproximem dos resultados de proficiências reais;

- Encontrar os valores correspondentes aos coeficientes de transmissão de conhecimento utilizado pelo modelo de transmissão de conhecimento social com o algoritmo genético para a troca de conhecimento;

- Validar a proposta do modelo de transmissão de conhecimento através de testes realizados pelo simulador. 


\subsection{Metodologia}

- Coleta de dados (foi utilizada a coleta de dados em campo feita pelos pesquisadores do LEC do IPUSP no PET);

- Revisão bibliográfica (análise de rede social, grafos, AGM, FGM, representação do conhecimento, ambientes virtuais, agentes, multiagentes, algoritmos genéticos, conceitos de primatologia, entre outros);

- Visita técnica para conhecer a ilha do PET e entender como funciona o ambiente real;

- Análise de documentos (teses, dissertações, monografias de IC, entre outros) referente ao funcionamento do ambiente real que foram fornecidos pelos pesquisadores do LEC do IPUSP;

- Análise de dados gerados pelo simulador da plataforma Horácio construído na tese;

- Análise das observações em campo dos pesquisadores do IPUSP.

\subsection{Organização do Trabalho}

Esta tese esta organizada em 7 capítulos. O capítulo 1 apresentou uma breve introdução do trabalho para situar o leitor a respeito dos assuntos abordados pela tese, o objetivo geral, os objetivos específicos e a motivação do trabalho. O capítulo 2 mostra temas e conceitos relacionados à área da primatologia que estuda o comportamento de primatas, redes sociais, transmissão de conhecimento, algoritmo genético, entre outros. O capítulo 3 apresenta a implementação da primeira ferramenta desenvolvida para o LEC do IPUSP que serviu como base para consolidação dos conceitos necessários para o desenvolvimento da tese, bem como para a organização das informações tratadas através da implementação de ferramentas apropriadas a este propósito. O capítulo 4 apresenta os conceitos do modelo proposto da tese. O capítulo 5 apresenta a implementação de uma plataforma chamada Horácio onde utilizamos um simulador para testar e validar o modelo proposto. O capítulo 6 mostra os resultados alcançados e suas análises. Finalmente o capítulo 7 apresenta as conclusões e os trabalhos futuros. 


\section{FUNDAMENTAÇÃO TEÓRICA}

Este capítulo apresenta alguns conceitos relacionados com o trabalho como o ambiente real estudado pelos pesquisadores do Laboratório de Etologia Cognitiva do IPUSP para que o leitor entenda as regras que regem o ambiente real, pois elas serviram de referência para implantação das regras do ambiente simulado e também para entender como funciona a área de primatologia. Além disso, apresenta a fundamentação teórica de alguns dos componentes considerados mais importantes para implementação dos dois softwares desenvolvidos neste contexto.

\subsection{Ambiente Real: Ilha do Parque Ecológico do Tiete (PET)}

A ilha estudada como ambiente real possui $4.000 \mathrm{~m}^{2}$ (Figura 2.2) estando localizada em uma das três lagoas do PET (Figura 2.3). O PET está localizado no Km 18 da rodovia Ayrton Senna, Zona Leste da cidade de São Paulo e possui uma área de $200.000 \mathrm{~m}^{2}$ (Figura 2.1). Os macacos que nela residem têm como principal fonte de alimentos frutas, verduras, legumes, polenta e ração que são colocados diariamente na ilha, mas também podem forragear por insetos, ovos de pássaros, flores e folhas. Na ilha estudada (Figura 2.3), a vegetação é escassa e arbustiva em sua maior parte, com poucas árvores frutíferas, predominando árvores de eucalipto (IZAR, 1994).

O ambiente real, ou seja, a ilha do PET é habitada por primatas (macacos prego do gênero "Sapajus"). Os primatas do gênero "Sapajus" (Figura 2.4) são divididos em dois grupos: com tufo e sem tufo (C. a. apela, C. a. fatuellus, C. a. macrocephalus, C. a. margaritae, C. a. peruanus e C. a. tocantinus). Eles ocupam praticamente todos os tipos de florestas neotropicais, tropicais úmidas e secas, manguezais, deciduais, alagadas e matas ciliares distribuídas geograficamente desde Honduras até a Argentina (RESENDE, 2004).

Eles vivem nas Américas (cerca de $60 \%$ deles vivem no Brasil) sendo macacos considerados do novo mundo ${ }^{2}$. Eles se comunicam através de assobios, gritos e chiados, entre outros tipos de sons e se reconhecem pelo cheiro. São

\footnotetext{
${ }^{2}$ São os considerados macacos do novo mundo aqueles que habitam o continente americano da família Cebidae, espécie Simia apella e subgênero Sapajus classificados anteriormente como Cebus apella
} 
pequenos, atingem no máximo $60 \mathrm{~cm}$ de comprimento e em média $3,5 \mathrm{~kg}$ de peso. Eles podem viver de 30 a 40 anos. O período de gestação é de aproximadamente 180 dias com o nascimento de um único filhote. Seus principais predadores são gaviões, cobras, águias e alguns felinos de porte maior que o deles. Suas principais características são a flexibilidade, o oportunismo e a adaptabilidade (FRAGASZY; VISALBERGHI; FEDIGAN, 2004).

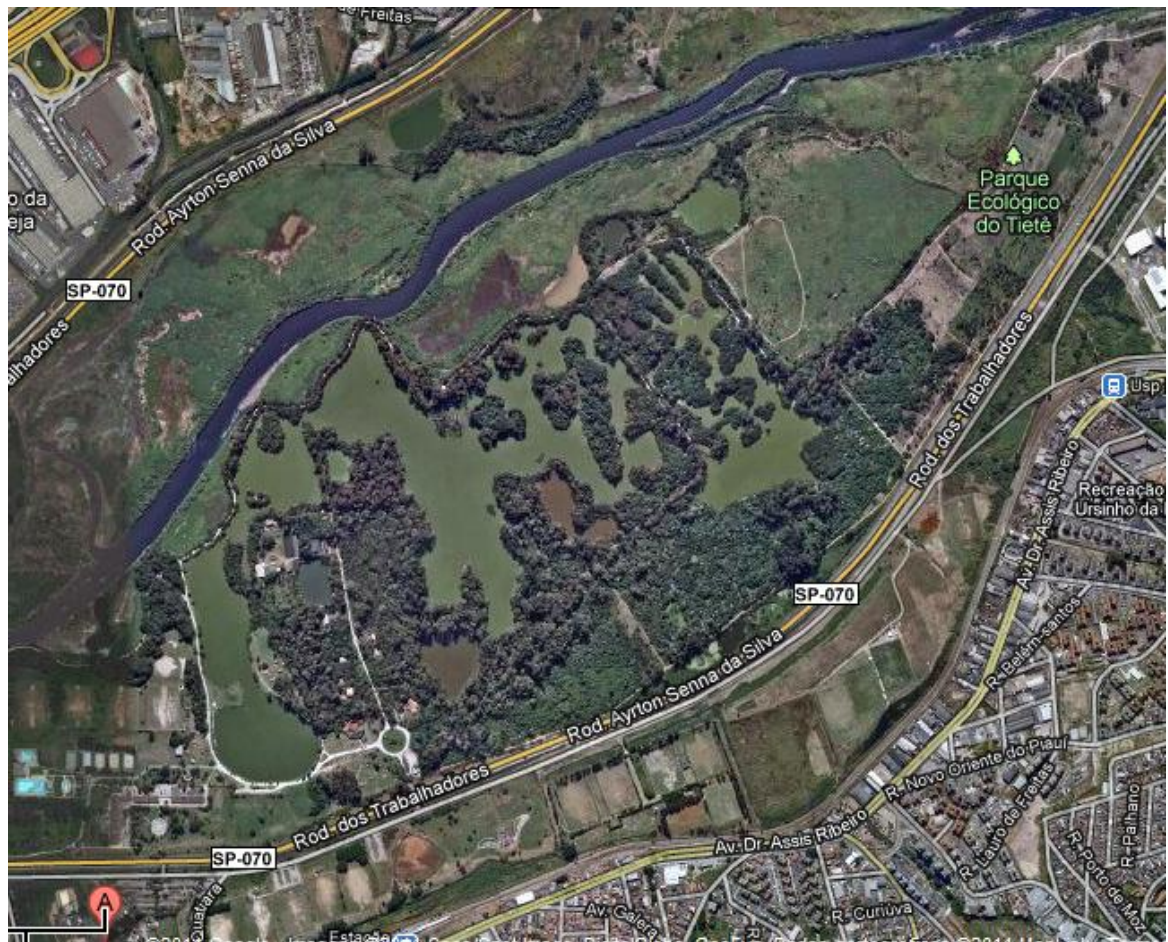

Figura 2.1 - Imagem do Google Maps do Parque Ecológico do Tiete

O grupo de macacos prego estudado em semicativeiro foi formado em 1981 com animais apreendidos pela polícia federal ou provenientes de doações (IZAR, 1994). Grupos desta espécie podem conter de 3 a 40 indivíduos na proporção de um macho adulto dominante (conhecido como alfa) para quatro fêmeas adultas. Os machos conforme atingem a maturidade tendem a sair do grupo natal e migrar para outros, enquanto as fêmeas tendem a permanecer no mesmo grupo (RESENDE, 2004). 


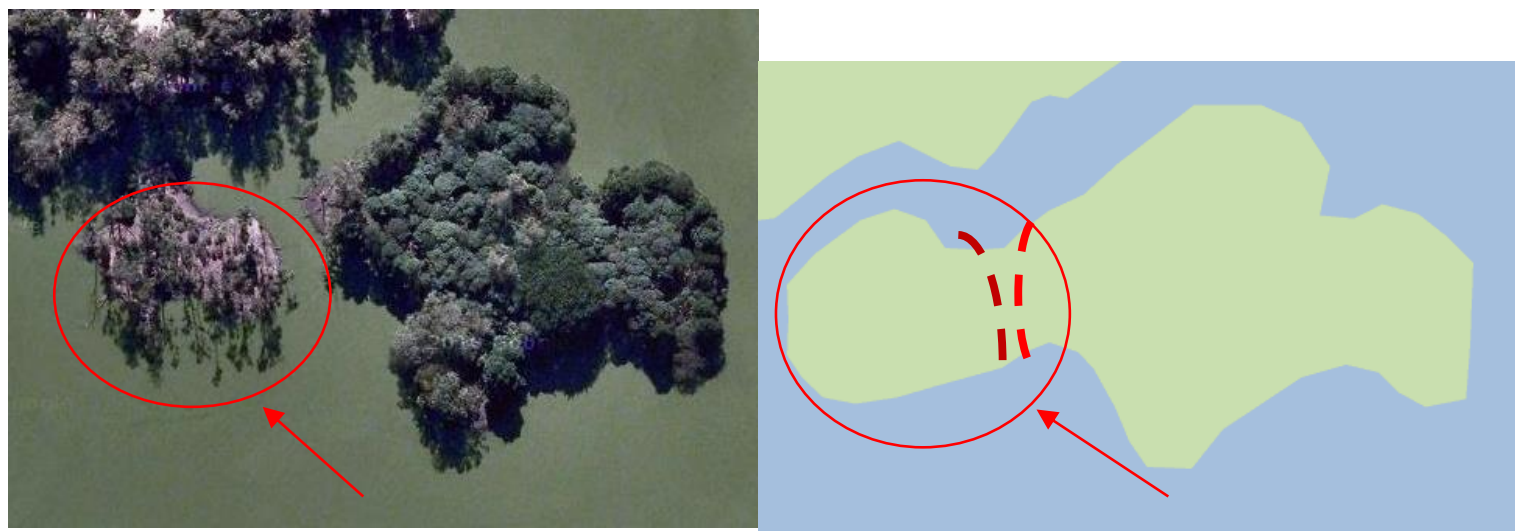

Figura 2.2 - Imagem da ilha dos macacos:

a) (esquerda) via satélite e b) (direita) mapas.

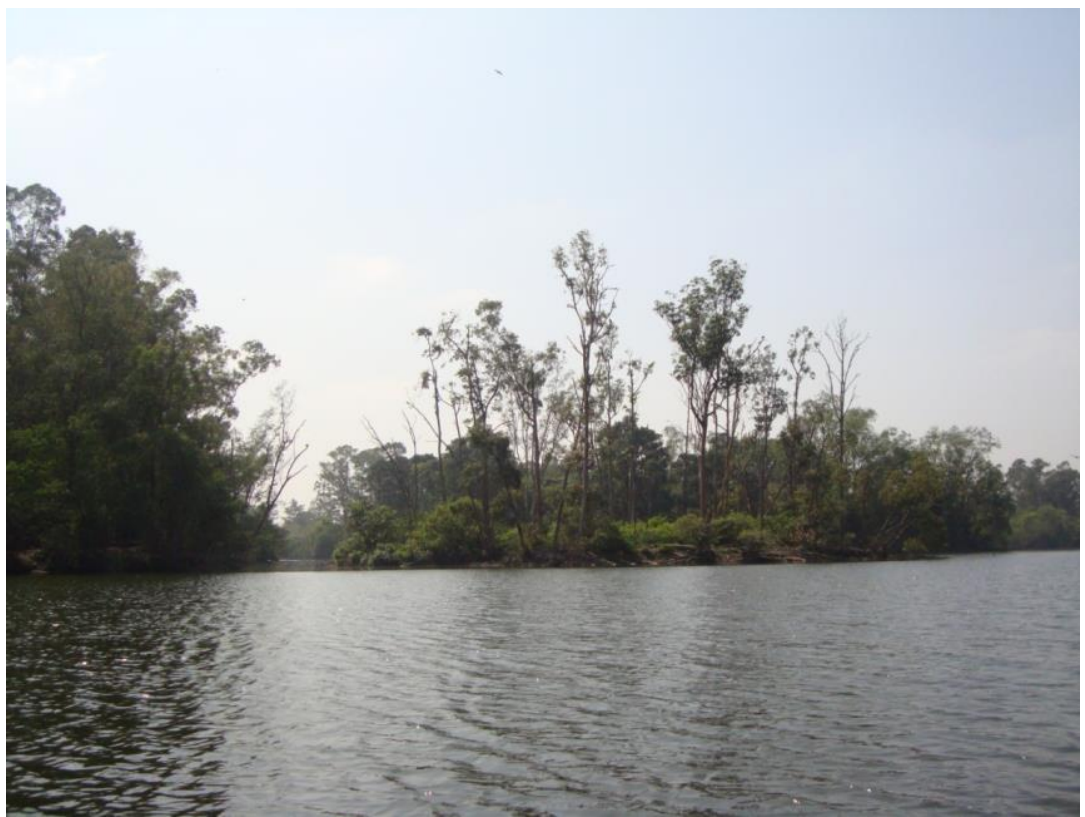

Figura 2.3 - Foto da llha vista por fora (Créditos: RINALDI, 2013)

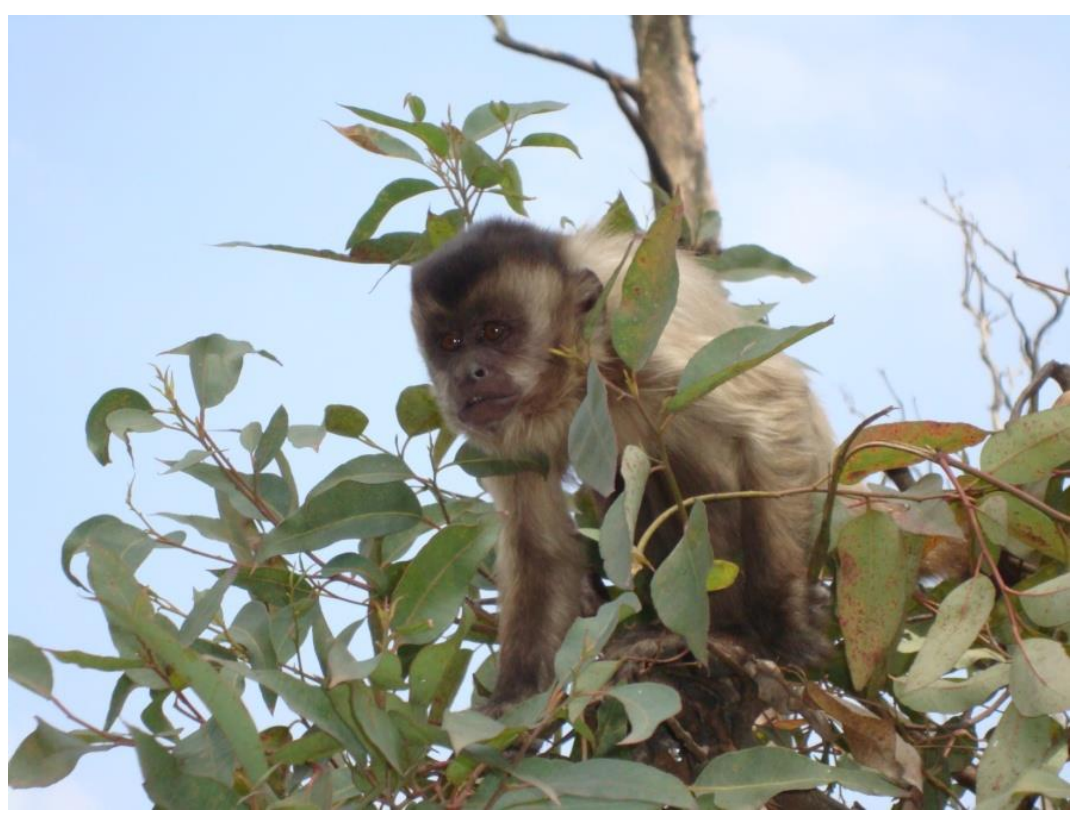

Figura 2.4 - Foto do macaco prego chamado Horácio (Créditos: RINALDI, 2013) 
Em ambiente natural, durante o período de escassez de alimentos, pode haver a formação de subgrupos (IZAR, 2004). No grupo estudado, apesar de ser uma situação de semicativeiro, o número de indivíduos encontra-se dentro do padrão de macacos prego em liberdade. Este grupo já chegou a ter cerca de 50 membros, mas hoje o grupo é composto por 38 macacos. A Tabela A.1 do Anexo A deste trabalho apresenta a relação de macacos do grupo estudado na tese contendo o nome, sua abreviação, faixa etária (infante, juvenil, etc.), o sexo e a proficiência com relação à quebra de cocos.

No grupo estudado a proporção é de um macho adulto para seis fêmeas adultas, sendo uma proporção um pouco acima da média normal de condições em liberdade. Houve a formação de subgrupos periféricos de machos adultos. Como o deslocamento na ilha é limitado, os machos, na impossibilidade de mudar de grupo, como acontece em condições de liberdade, formaram subgrupos (RESENDE, 2004). Aqui se justifica a implementação da ferramenta Cuzco desenvolvida no capitulo 3 utilizando-se o algoritmo de Kruskal e não o algoritmo de Prim (como utilizado anteriormente pelo LEC) para encontrar subgrupos de um grupo (será explicado com mais detalhes na seção 3.4 e 3.5).

Essa formação da estrutura social do grupo é fundamental para as análises referentes aos fatores relacionados à transmissão social de conhecimento. Na próxima seção, será apresentado um histórico sobre análise de redes sociais de primatas para um melhor entendimento sobre a formação da estrutura social de grupos.

\subsection{Análise de Redes Sociais (ARS)}

Segundo Hinde (1993) a estrutura social de primatas pode ser definida como "um sistema emergente das relações interindividuais estabelecidas pelos membros do grupo", ou seja, é o relacionamento resultante das interações em longo prazo entre os primatas do mesmo grupo formando uma rede de relacionamento.

A Análise de Redes Sociais (ARS) (ou Social Network Analysis - SNA) ou apenas Redes Sociais (RS) é uma ferramenta utilizada para estudar a estrutura das sociedades. Muitas situações de nossa sociedade podem ser modeladas usando diagramas compostos por um conjunto de pontos interligados por linhas. Os pontos podem representar, por exemplo, pessoas, peixes, carros, entre outros, ou seja, 
objetos da realidade em geral. Neste trabalho, especificamente, eles representam macacos. As linhas que ligam esses pontos podem representar associações em geral entre os objetos modelados pelos pontos, como a transmissão de conhecimento entre dois macacos, a amizade entre duas pessoas, etc. Este modelo, ou abstração matemática de uma situação, ainda que informalmente falando, pode ser chamado de grafo (seção 2.3). A RS, de uma forma simplificada, pode ser representada por um grafo (WASSERMAN; FAUST, 1994).

O termo genérico ARS engloba uma série de ferramentas gráficas para visualizar as redes (por exemplo, sociogramas), bem como ferramentas de modelagem matemática (por exemplo, álgebra matricial e análises baseada em permutação) que permitem a detecção e quantificação de padrões de redes sociais (FREEMAN, 2004; BRENT; LEHMANN; RAMOS-FERNÁNDEZ, 2011).

É difícil nomear qualquer fundador para as RS. Em geral, sua origem pode ser rastreada no século $18 \mathrm{com}$ o desenvolvimento da teoria dos grafos (para uma revisão ver BIGGS et al. (1986)). Com a introdução da abordagem denominada sociometria (MORENO, 1934; SCOTT, 2000; WASSERMAN; FAUST, 1994) os estudos foram formalizados e chamados de ARS (BRENT; LEHMANN; RAMOSFERNÁNDEZ, 2011).

A sociometria é definida como "aplicação de métodos quantitativos que investiga a evolução e a organização dos grupos e posição dos indivíduos dentro delas" (tradução nossa) (MORENO, 1934). De acordo com a sociometria, as interações entre pares de indivíduos forma a estrutura conceitual da ARS (SCOTT, 2000) e atualmente as ferramentas modernas apresentam evidências de padrões entre os indivíduos que pode impactar em uma série de propriedades emergentes de grupos, incluindo o fluxo de informações (VOELKL; NOE, 2008; WATTS; STROGATZ, 1998), o bem estar individual (FOWLER; CHRISTAKIS, 2008; HILL et al. 2010; SEEMAN, 1996) e a cooperação (VOELKL; KASPER, 2009) (BRENT; LEHMANN; RAMOS-FERNÁNDEZ, 2011).

A solução de problemas em grupo foi uma das primeiras preocupações dos estudos sociométricos (BAVELAS, 1950) e através deles foram desenvolvidos muitas métricas de rede que ainda são utilizadas, tais como densidade, número de laços presentes em relação a todos os laços possíveis, centralidade, grau, coeficiente de agrupamento (ou clusterizção), medida em que os vizinhos de um indivíduo são diretamente ligados ao outro, entre outras (para visões gerais de 
métricas de redes consulte Wasserman e Faust (1994) e Wey et al. (2008)) (BRENT; LEHMANN; RAMOS-FERNÁNDEZ, 2011).

Além da influência que as ARS tiveram na área de ciências sociais expressando dados sociométricos como matrizes em 1940 (FORSYTH; KATZ, 1946), elas também beneficiaram a área de matemática e física através da geração de modelos computacionais para analisar o padrão de ligação entre os nós de uma rede na teoria dos grafos (FREEMAN, 2004), resultando em modelos de redes aleatórias no final de 1950 (ERDÓs; RÉNYI, 1959; GILBERT, 1959) que influenciaram as ARS permitindo os pesquisadores identificar processos que mostram as causas em que as redes observadas se diferem das redes geradas aleatoriamente (NEWMAN et al. 2002) (BRENT; LEHMANN; RAMOS-FERNÁNDEZ, 2011).

As ARS surgiram em 1980 com a criação do Journal Social Network e o estabelecimento de uma sociedade profissional chamada International Network for Social Network Analysis (BORGATTI, 2009). Desde então, várias disciplinas tem utilizado as ARS (OTTE; ROUSSEAU, 2002), expandindo-se para as áreas de antropologia, matemática, economia, ciências da computação, física, ciências políticas, psicologia, estatística, etologia, zoologia e epidemiologia (FREEMAN, 2004) (BRENT; LEHMANN; RAMOS-FERNÁNDEZ, 2011).

Os estudos voltados à primatologia ocorreram em grande parte na última década (KRAUSE et al., 2009), mas algumas das técnicas e ferramentas voltadas a essa área já vinham sendo usadas desde 1960. Nos últimos quinze anos, os avanços resultaram em novas perspectivas para estrutura de redes complexas (BARABASI, 2002; WATTS; STROGATZ, 1998) com o desenvolvimento de novas métricas de rede (BARRAT et al., 2004; NEWMAN, 2005; NEWMAN, 2006; OPSAHL, 2009) e a criação de inúmeros pacotes de softwares disponíveis no mercado (BORGATTI et al., 2002; OPSAHL, 2009) como os mais populares: UCINET (BORGATTI et al., 2002), TNET (OPSAHL, 2009), PAJEK (BATAGELJ; MRVAR, 2003) e SOCPROG (WHITEHED, 2007) (BRENT; LEHMANN; RAMOSFERNÁNDEZ, 2011). A Tabela A.1.1 no Apêndice A apresenta as características de alguns desses softwares que estão disponíveis no mercado (HANNEMAN; RIDDELE, 2011) fazendo uma comparação com o software desenvolvido que é apresentado no capítulo 3. 


\subsection{Grafo}

São comuns estudos que modelam o comportamento de grupos de animais utilizando diferentes definições para a estrutura matemática usualmente chamada de grafo. Em geral, os estudos limitam-se à modelagem considerando que as possíveis relações entre os sujeitos somente podem ser binárias.

Baseado nos autores Bondy e Murty (2008) e Kasper e Voelkl (2009), um grafo pode ser definido por dois conjuntos e uma função. Um conjunto é composto por pontos chamado de nós ou vértices $V$ e o outro conjunto é composto por linhas chamadas de arestas $E$. A função de incidência $\Psi$ associa cada aresta de um grafo a um par de vértices (LUCCHESI, 1979). Os conjuntos de vértices do grafo geralmente modelam os sujeitos de um dado grupo e o conjunto de arestas modela possíveis relações binárias entre os sujeitos modelados pelos vértices. Em geral, se uma aresta está associada aos vértices $u$ e $v$ de $a$, diz-se que $a$ une $u$ a $v$. É comum dar o nome $u v$ à aresta e assim a função de incidência pode ser omitida da definição, o que acontece com frequência. A definição dada acima permite que exista a aresta, tal que $\Psi(e)=u v$ para algum vértice $u$ pertencente à $V$, a qual geralmente é chamada de laço. Também, nada impede que existam arestas e e $g$, tais que, $\Psi(e)=\Psi(\mathrm{g})$, as quais são geralmente chamadas múltiplas.

Em muitos estudos utiliza-se uma simplificação nesta definição excluindo estas duas possibilidades. De acordo com a definição dada, os grafos que não possuem laços e nem arestas múltiplas são chamados de grafos simples.

Estudos utilizando esta definição ignoram a possibilidade de existir um relacionamento entre mais de dois sujeitos, o que pode estar razoavelmente dentro do contexto que se deseja estudar. Para casos em que se deseja modelar relacionamento não apenas binário, pode-se utilizar um hipergrafo, uma generalização da definição dada que permite que uma aresta una um número arbitrário de vértices, permitindo a modelagem de relacionamentos não necessariamente binários.

Para alguns tipos de relacionamentos, pode ser necessária a modelagem utilizando-se grafos chamados orientados ou dirigidos. Nestes casos, as arestas uv e vu são essencialmente diferentes. Por exemplo, para um grupo de $S$ sujeitos, deseja-se modelar a relação em que $v$ gosta de $u$; faz-se necessário o uso de grafo 
dirigido, já que, neste caso, a existência da aresta uv não implica na existência da aresta $v u$.

Pode-se também associar números às arestas de um grafo, em geral, chamados de pesos, que permitem modelar aspecto como a importância de um relacionamento ou o número de vezes em que dois sujeitos se relacionam.

Grafos com $N$ vértices podem ser descritos utilizando-se uma matriz $M$ quadrada de ordem $N$ em que cada entrada $i j$ representa uma informação a respeito dos relacionamentos existentes entre os sujeitos $i$ e $j$. Em um grafo sem pesos, a entrada $i j$ da matriz tem valor 1 caso a aresta $i j$ exista e 0 caso contrário. Em grafos com peso, cada entrada $i j$ da matriz $M$ corresponde ao peso da entrada $i j$. Na primeira ferramenta desenvolvida no capítulo 3, foi feita a implementação do grafo utilizando o algoritmo de Kruskal para a geração da FGM (seção 3.5) para representar a estrutura hierárquica do grupo de macacos prego, ou seja, a rede social daquela comunidade.

\subsection{Coleta de Dados}

A coleta de dados em campo para estabelecer a RS dos macacos prego do PET iniciou-se com a fase de reconhecimento dos macacos, determinação do sexo e faixa etária de cada indivíduo. Segundo Resende (2004), as faixas etárias foram determinadas seguindo os seguintes critérios conforme apresentado na Tabela $2.1 \mathrm{a}$ seguir:

Os pesquisadores do LEC do IPUSP observaram o grupo de macacos durante nove meses (de Dezembro 2011 a Agosto de 2012), aproximadamente três vezes por semana e durante aproximadamente duas horas. Normalmente os observadores eram alunos de IC que filmavam e faziam suas anotações sobre o comportamento dos macacos, incluindo informações sobre quais macacos estavam próximos uns aos outros em um dado momento (em um raio de $1 \mathrm{~m}$ ou $10 \mathrm{~m}$ ) e quais tipos de atividades eles estavam realizando em um determinado local. 
Tabela 2.1 - Faixa etária dos macacos prego do PET seguindo os critérios estabelecidos por Resende (2004).

\begin{tabular}{ll}
\hline Faixa Etária & Descrição da faixa etária \\
\hline Infantes & $\begin{array}{l}\text { Desde o nascimento até a independência (quando passam mais de } 4 \text { semanas } \\
\text { sem serem transportados pelas mães ou ajudantes). Isso ocorreu entre } 9 \text { e 15 } \\
\text { meses. }\end{array}$ \\
Juvenil & $\begin{array}{l}\text { Para fêmeas desde a independência até a maturidade sexual (foi considerado 180 } \\
\text { dias da data de nascimento do primeiro filhote). Optou-se por esse método ao } \\
\text { invés de considerar a data do primeiro cio por não se ter informações a respeito } \\
\text { da fertilidade das fêmeas. Para os machos foi considerado desde a independência } \\
\text { até os } 5 \text { anos quando o indivíduo adquire tamanho corporal de adulto. Optou-se } \\
\text { por esse método por não se ter informações a respeito da maturidade sexual. } \\
\text { machos com idades entre } 5 \text { e } 7 \text { anos. Eles possuem tamanho de adulto, mas não } \\
\text { tem topete desenvolvido. Para as fêmeas não se tem a informação. }\end{array}$ \\
Subadulto & $\begin{array}{l}\text { fêmeas reprodutivas (idade reprodutiva atingida por volta de 5 anos) e machos } \\
\text { com idade superior a 7 anos. }\end{array}$ \\
\hline
\end{tabular}

Os dados brutos coletados em campo são os relacionados ao comportamento diário dos primatas. Esses dados de comportamento manipulativos (RESENDE, 2004) estão relacionados a:

- Objeto: aquilo que não é comestível e que os macacos podem transportar;

- Alimento: itens que são ingeridos pelos macacos;

- Substrato ou Local: aquilo que não é manipulável, sendo imóvel e extenso e não podendo ser carregado (por exemplo, chão, árvores, cocho, entre outros).

Um momento ou intervalo de observação dos pesquisadores do LEC do IPUSP é composto pelo grupo de macacos, a data (composta por dia, mês e ano) em que aquela observação foi feita, o horário (composto por hora, minuto e segundo) em que a observação foi realizada, à distância a ser considerada (um raio de $1 \mathrm{~m}$ ou $10 \mathrm{~m})$ e o animal focal. Foi empregado o método de varredura focal (ALTMAN, 1974) onde um animal é escolhido por sorteio para ser observado durante um instante de tempo para contornar a dificuldade de se observar todos os animais simultaneamente.

Nesta seção é fornecido um exemplo para ilustrar a transformação que os dois softwares desenvolvidos utilizam sobre um dado intervalo de observação. Os softwares recebem um intervalo de observação como entrada, calculou a matriz de proximidade (Horácio e Cuzco) e executou o algoritmo de Kruskal (Cuzco) a fim de encontrar uma FGM. O exemplo desta seção é ilustrativo; ainda não se usa os dados reais que o sistema armazena atualmente. 
Considere a primeira matriz de observação exibida na Figura 2.5. Ela apresenta um intervalo de observação que é composto por cinco momentos de tempo $(t)$ nos quais cinco sujeitos $(S)$ foram observados em campo, tendo o sujeito $S_{3}$ como animal focal e, assim, sua coluna contém o valor 1 para todos os momentos de observação. Os outros macacos que também recebem o valor 1 são aqueles que estão próximos do animal focal $S_{3}$ (em um raio de $1 \mathrm{~m}$ ou $10 \mathrm{~m}$ ), e os outros sujeitos que não estão próximos do animal focal recebem o valor 0 .

A segunda matriz, chamada de proximidade, é a transformação da primeira matriz, composta por cinco sujeitos que foram observados e estão representados na linha e pelos mesmos cinco sujeitos observados apresentados na coluna. Nesta matriz são somados todos os sujeitos que estavam próximos do animal focal em um determinado período de observação. Essa matriz já pode ser usada como um grafo simples (Figura 2.6). O software Horácio do capítulo 4 utiliza esse tipo de matriz.

Para a construção da AGM ou FGM (seção 2.4.1), foi necessário transformar a primeira matriz na terceira utilizando a fórmula da eq. (2.1) do coeficiente de Jaccard (seção 3.3). Essa matriz foi chamada de proximidade utilizando 0 coeficiente de Jaccard. A quarta matriz de proximidade utilizando a distância de Jaccard foi uma transformação da terceira matriz utilizando a fórmula da eq. (2.2) da distância de Jaccard. Esta quarta matriz pode ser exibida como um grafo mostrado na Figura 2.7. Este grafo foi o utilizado no software Cuzco para a construção da estrutura hierárquica do grupo de macacos na forma visual gráfica.

$$
\begin{gathered}
\mathrm{J}\left(S_{i}, S_{j}\right)=\frac{m_{11}\left(S_{i}, S_{j}\right)}{m_{01}\left(S_{i}, S_{j}\right)+m_{10}\left(S_{i}, S_{j}\right)+m_{11}\left(S_{i}, S_{j}\right)} \\
d_{J}=1-\mathrm{J}\left(S_{i}, S_{j}\right)=\frac{m_{01}\left(S_{i}, S_{j}\right)+m_{10}\left(S_{i}, S_{j}\right)}{m_{01}\left(S_{i}, S_{j}\right)+m_{10}\left(S_{i}, S_{j}\right)+m_{11}\left(S_{i}, S_{j}\right)}
\end{gathered}
$$

$m_{11}$ representa o total de números onde o atributo de $S_{i}$ e $S_{j}$ tem o valor $=1$;

$m_{01}$ representa o total de números com o atributo de $S_{i}=0$ e $S_{j}=1$;

$m_{10}$ representa o total de números onde o atributo de $S_{i}=1$ e $S_{j}=0$;

$m_{00}$ representa o total de números onde o atributo de $S_{i}$ e $S_{j}$ tem o valor $=0$. 


\begin{tabular}{cccccc} 
& $\boldsymbol{S}_{\mathbf{1}}$ & $\boldsymbol{S}_{\mathbf{2}}$ & $\boldsymbol{S}_{\mathbf{3}}$ & $\boldsymbol{S}_{\mathbf{4}}$ & $\boldsymbol{S}_{\mathbf{5}}$ \\
\cline { 2 - 6 } $\boldsymbol{t}_{\mathbf{1}}$ & 1 & 1 & $\mathbf{1}$ & 0 & 1 \\
$\boldsymbol{t}_{\mathbf{2}}$ & 1 & 0 & $\mathbf{1}$ & 0 & 0 \\
$\boldsymbol{t}_{\mathbf{3}}$ & 0 & 0 & $\mathbf{1}$ & 0 & 1 \\
$\boldsymbol{t}_{\mathbf{4}}$ & 1 & 1 & $\mathbf{1}$ & 0 & 0 \\
$\boldsymbol{t}_{\mathbf{5}}$ & 1 & 0 & $\mathbf{1}$ & 0 & 1 \\
\hline \multicolumn{4}{l}{ Matriz de observação }
\end{tabular}

\begin{tabular}{cccccc}
\cline { 2 - 6 } & $\boldsymbol{S}_{\mathbf{1}}$ & $\boldsymbol{S}_{\mathbf{2}}$ & $\boldsymbol{S}_{\mathbf{3}}$ & $\boldsymbol{S}_{\mathbf{4}}$ & $\boldsymbol{S}_{\mathbf{5}}$ \\
\cline { 2 - 6 } $\boldsymbol{S}_{\mathbf{1}}$ & $\infty$ & 0,50 & 0,80 & 0 & 0,40 \\
$\boldsymbol{S}_{\mathbf{2}}$ & 0,50 & $\infty$ & 0,40 & 0 & 0,25 \\
$\boldsymbol{S}_{\mathbf{3}}$ & 0,80 & 0,40 & $\infty$ & 0 & 0,60 \\
$\boldsymbol{S}_{\mathbf{4}}$ & 0 & 0 & 0 & $\infty$ & 0 \\
$\boldsymbol{S}_{\mathbf{5}}$ & 0,40 & 0,25 & 0,60 & 0 & $\infty$ \\
\hline
\end{tabular}

\begin{tabular}{cccccc}
\cline { 2 - 6 } & $\boldsymbol{S}_{\mathbf{1}}$ & $\boldsymbol{S}_{\mathbf{2}}$ & $\boldsymbol{S}_{\mathbf{3}}$ & $\boldsymbol{S}_{\mathbf{4}}$ & $\boldsymbol{S}_{\mathbf{5}}$ \\
\cline { 2 - 6 } $\boldsymbol{S}_{\mathbf{1}}$ & 0 & 2 & 4 & 0 & 2 \\
$\boldsymbol{S}_{\mathbf{2}}$ & 2 & 0 & 2 & 0 & 1 \\
$\boldsymbol{S}_{\mathbf{3}}$ & 4 & 2 & 0 & 0 & 3 \\
$\boldsymbol{S}_{\mathbf{4}}$ & 0 & 0 & 0 & 0 & 0 \\
$\boldsymbol{S}_{\mathbf{5}}$ & 2 & 1 & 3 & 0 & 0 \\
\hline \multicolumn{5}{l}{ Matriz de proximidade $\left(P^{O}\right)$}
\end{tabular}

\begin{tabular}{lccccc}
\cline { 2 - 6 } & $\boldsymbol{S}_{\mathbf{1}}$ & $\boldsymbol{S}_{\mathbf{2}}$ & $\boldsymbol{S}_{\mathbf{3}}$ & $\boldsymbol{S}_{\mathbf{4}}$ & $\boldsymbol{S}_{\mathbf{5}}$ \\
\cline { 2 - 6 } $\boldsymbol{S}_{\mathbf{1}}$ & $\infty$ & 0,50 & 0,20 & 1 & 0,60 \\
$\boldsymbol{S}_{\mathbf{2}}$ & 0,50 & $\infty$ & 0,60 & 1 & 0,75 \\
$\boldsymbol{S}_{\mathbf{3}}$ & 0,20 & 0,60 & $\infty$ & 1 & 0,40 \\
$\boldsymbol{S}_{\mathbf{4}}$ & 1 & 1 & 1 & $\infty$ & 1 \\
$\boldsymbol{S}_{\mathbf{5}}$ & 0,60 & 0,75 & 0,40 & 1 & $\infty$ \\
\hline \\
\multicolumn{5}{l}{ Matriz de proximidade utilizando a } \\
distância de Jaccard $\left(d_{J}\right)$
\end{tabular}

Figura 2.5 - A primeira matriz é a de observação em campo; a segunda é a transformação da primeira para a de proximidade (utilizada no Horácio); a terceira é a transformação da primeira utilizando a fórmula do coeficiente de Jaccard e a quarta é a transformação da terceira utilizando a fórmula de distância de Jaccard (utilizada no Cuzco).

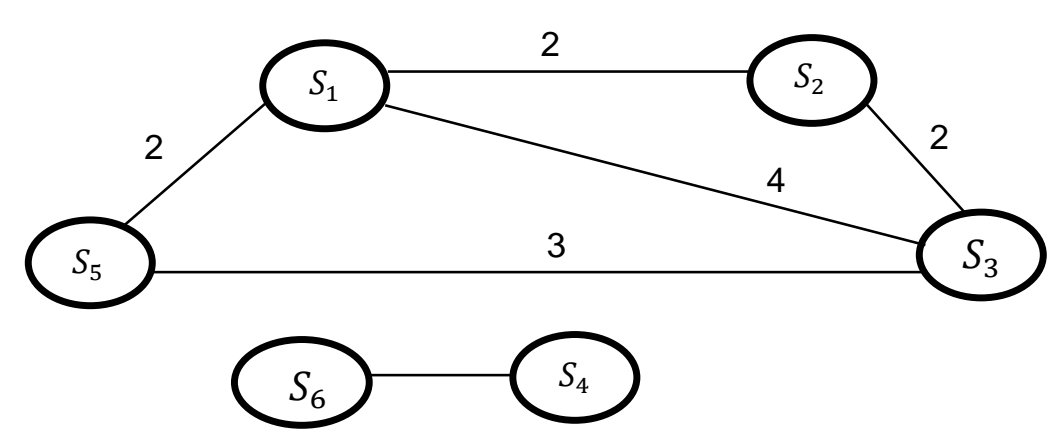

Figura 2.6 - Um grafo simples derivado a partir da matriz de proximidade.

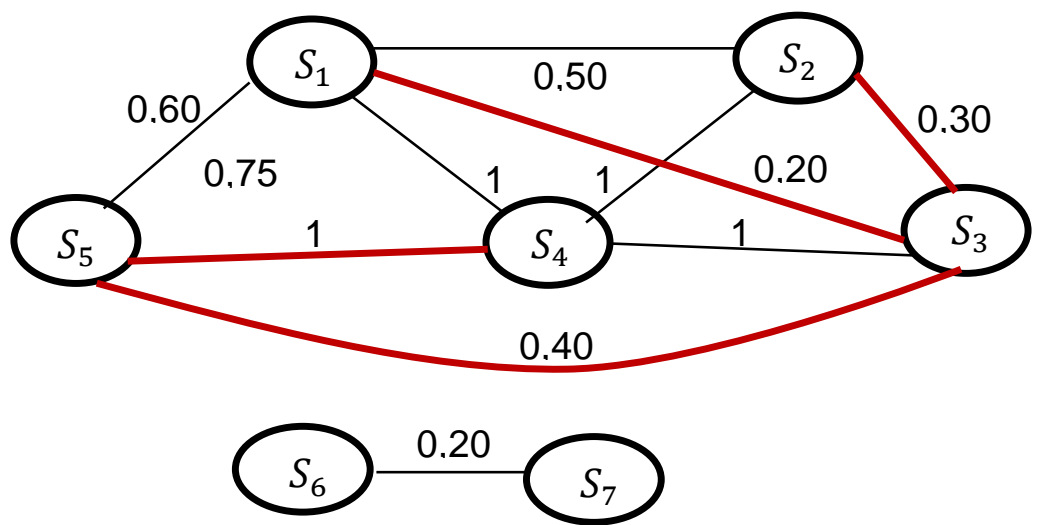

Observação

Gráfico conexo (considerando somente o primeiro - AGM)

$-\mathrm{N}=5$ vértices

$-\mathrm{N}-1=5-1=4$ arestas

- Não pode ter circuito

- $1^{o}$ pegar as arestas mínimas

Gráfico desconexo

(considerando o segundo) juntamente com o primeiro (FGM)

Figura 2.7 - Um grafo derivado a partir da matriz de distância de Jaccard (AGM ou FGM). 
Os dados observados de comportamento foram armazenados da mesma forma que os dados coletados para a matriz de proximidade (grupo de macacos, a data, horário, à distância e o animal focal), e além disso, a atividade que os macacos estavam executando; podendo ser ou não realizada em conjunto com outro sujeito em um determinado local. Esses dados observados foram utilizados para as ferramentas construídas nos capítulos 3 e 4.

\subsection{1. Árvore Geradora Mínima (AGM) ou Floresta Geradora Mínima (FGM)}

Encontrar uma Árvore Geradora Mínima (AGM) ou a Floresta Geradora Mínima (FGM) de um grafo é uma tarefa fácil e algoritmos eficientes já são conhecidos há décadas. Neste trabalho foi utilizado dois algoritmos para a sua construção: o algoritmo de Kruskal e o algoritmo de Prim. Estas duas estratégias são descritas matematicamente na seção 3.4 e 3.5 .

Em Resende (2004), os dados coletados foram utilizados para construir a estrutura social do grupo. Com explicado na seção anterior, os dados coletados são transformados em uma matriz de proximidade para se verificar a proximidade dos encontros entre os macacos utilizando-se o índice de Jaccard para medir o peso das arestas. Esses dados podem ser representados por um grafo não orientado como apresentado na Figura 2.7. Isso significa que uma árvore de extensão deste grafo é um subconjunto (caminho mínimo = linha em vermelho na Figura 2.7) de uma mesma árvore que conecta todos os vértices. Um único grafo pode ter diferentes árvores de extensão mínima. Sendo assim, uma AGM é uma árvore de extensão com peso menor ou igual a cada uma das outras árvores de extensões mínimas possíveis (outros caminhos mínimos possíveis). Generalizando, qualquer grafo não direcionado tem uma AGM que é a união de árvores de extensão mínima de cada um de seus componentes conexos.

Já uma FGM encontra várias árvores (AGMs) de uma floresta (FGM). A FGM encontra subgrafos de um grafo. Para se implementar uma AGM ou FGM são utilizados dois algoritmos: o algoritmo de Prim e o algoritmo de Kruskal.

A ferramenta utilizada anteriormente pelo grupo de pesquisa do LEC do IPUSP utilizava o algoritmo de Prim (CORMEN et al., 2009), que pode ser inapropriado quando se deseja detectar subgrupos de um grupo. Sendo assim, neste trabalho foi utilizado o algoritmo de Kruskal (CORMEN et al., 2009), que assim 
como o algoritmo de Prim, também encontra a estrutura social de um grupo e que, além disso, encontra subgrupos de um grupo, abrangendo assim grafos desconexos. A AGM é utilizada pelos pesquisadores do LEC do IPUSP para o estudo da difusão de conhecimento no grupo, ou seja, o conhecimento que cada macaco possui pode ser transmitido pela RS relacionada à estrutura social do grupo.

Como dito anteriormente, devido o deslocamento da ilha ser limitado, acabou formando-se subgrupos dentro deste grupo de macacos prego estudado. Assim, justifica-se a utilização do algoritmo de Kruskal apresentado com mais detalhes no capítulo 3 que foi implementado na primeira ferramenta (Cuzco) para a estrutura hierárquica social do grupo de primatas estudado.

A AGM pode ajudar os pesquisadores a entender o contexto social (ambiente) no qual os macacos se encontram de acordo com a proximidade. A AGM é uma forma simplificada de ver os dados, pois se os pesquisadores do LEC fossem analisar todas as possibilidades de ligação (arestas) com os 38 macacos (vértices) em um grafo de acordo com a proximidade, teriam pelo menos 1444 ligações.

Entender como funciona o contexto social pode explicar a influência das outras atividades na tarefa de aprendizagem de quebra de cocos, por exemplo, quanto maior a proximidade e quanto mais tempo os macacos permanecerem juntos, maior a probabilidade de trocarem conhecimento. Outro fator que pode influenciar no aprendizado é a tolerância social, pois quanto mais tolerantes os macacos forem uns com os outros, maior a probabilidade de interação entre eles, favorecendo também a oportunidade de envolvimento entre eles (RESENDE; IZAR; OTTONNI, 2004).

\subsubsection{Objetivo do grupo de pesquisadores do LEC do IPUSP}

Um dos objetivos do grupo de pesquisadores do LEC do IPUSP coordenado pela Profa. Briseida Dôgo de Resende foi verificar o surgimento e a difusão do comportamento de quebra de cocos com o uso de ferramentas. Esse grupo é composto por macacos prego em semicativeiro, considerado ingênuo para a tarefa de quebra de cocos porque a maioria dos macacos nasceu na ilha e por isso são interessantes para o estudo, ou seja, segundo Coussi-Korbel e Fragaszy (1995) esses macacos ingênuos podem aprender algo sobre a tarefa de quebra de cocos através da observação de outro macaco experiente (RESENDE, 2004). 


\subsubsection{Atividade de Quebra de Cocos}

A atividade de quebra de cocos envolve o uso de ferramentas (considerada como uma extensão funcional do corpo para agir sobre outro objeto com a intenção de um objetivo final) (GOODALL, 1970). São elas a bigorna e o martelo. A bigorna (Figura 2.9) é a pedra base que fica no chão. O martelo (Figura 2.8) é a pedra utilizada pelo macaco para golpear os cocos e os cocos são os frutos encapsulados (Figura 2.11). A Tabela A.5 que se encontra no Anexo A apresenta alguns tipos de ferramentas. O local onde essa tarefa acontece é chamado de sítio de quebra de cocos (Figura 2.10). O episódio de quebra de cocos se refere à situação que ocorre quando o macaco efetua o posicionamento dos cocos na bigorna e bate o martelo na bigorna. O episódio termina quando o macaco cessa os golpes contra a bigorna e passa a efetuar outra atividade não relacionada à quebra de cocos (RESENDE, 2004).

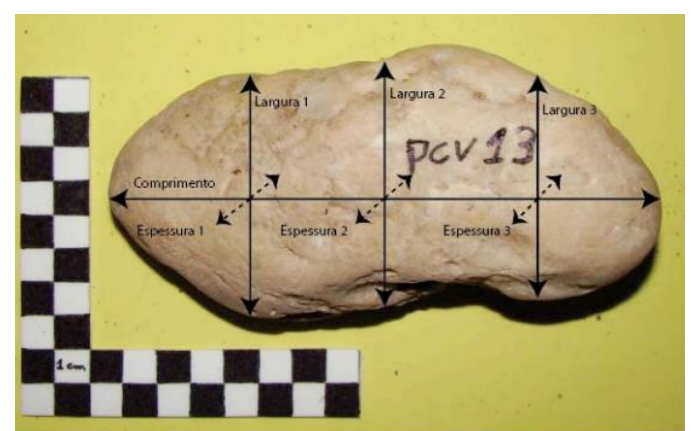

Figura 2.8- Martelo: pedra utilizada para golpear cocos (crédito: FALÓTICO, 2006)

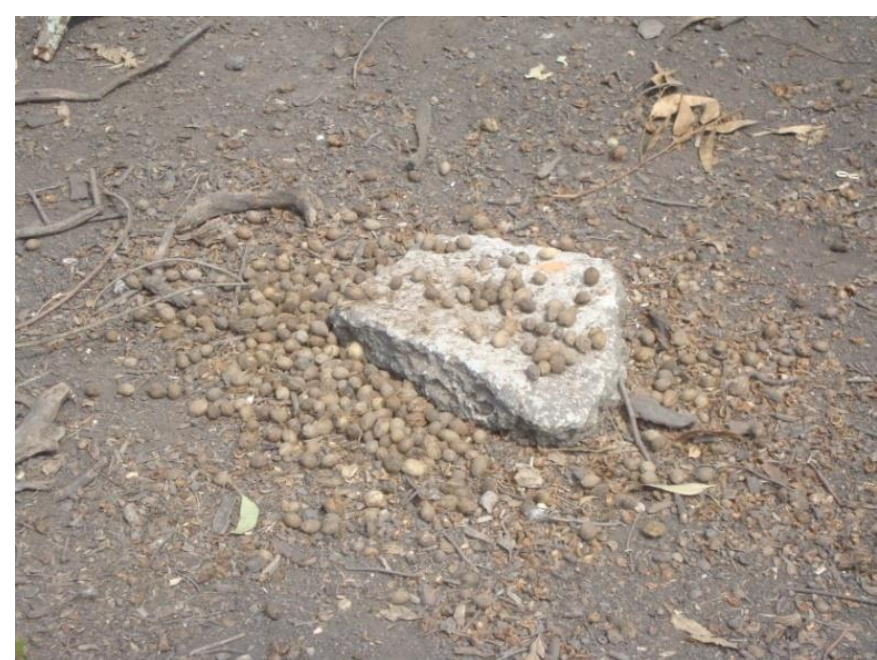

Figura 2.9 - Bigorna (crédito: RINALDI, 2013) 


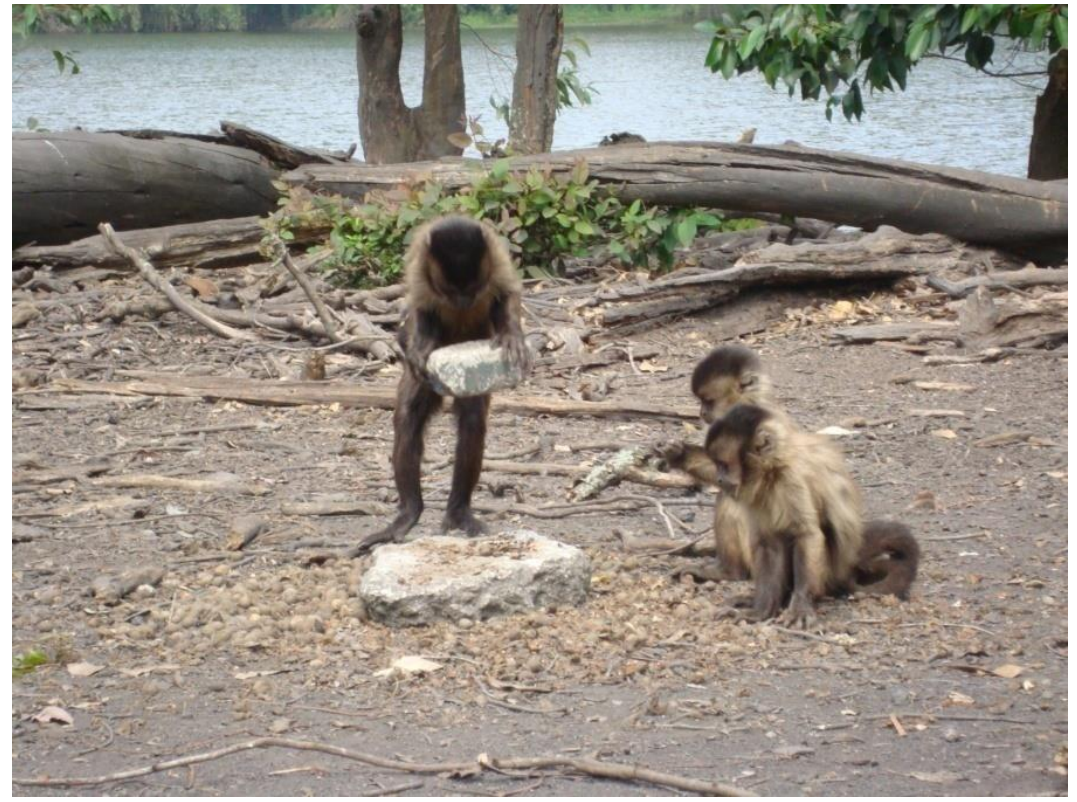

Figura 2.10 - Episódio de quebra de cocos (crédito: RINALDI, 2014)

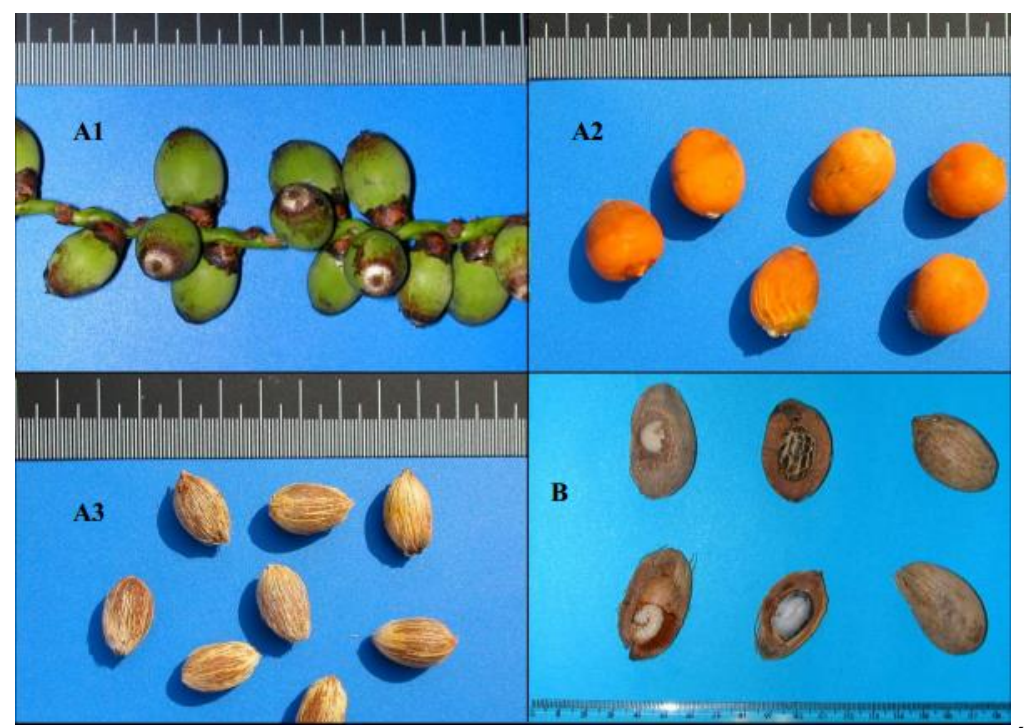

Figura 2.11 - Fruto encapsulado - Syagrus romanzoffina (jerivá) (crédito: FALÓTICO, 2006)

\subsubsection{A representação do conhecimento}

Com as anotações em campo de proximidade entre os macacos, os pesquisadores do LEC pretendem avaliar a possibilidade de transmissão de conhecimento entre eles, mas isso ainda não é feito e não se sabe se é possível. Estes pesquisadores também anotaram o comportamento dos primatas, ou seja, as atividades diárias de cada um e onde e quando essas atividades estavam acontecendo.

Esses dados de comportamento coletados são utilizados para a análise de como ocorre a aprendizagem de uma tarefa específica entre os primatas. Os 
pesquisadores do LEC, baseados em suas análises, levantam hipóteses de que a aprendizagem pode ocorrer através da transferência de conhecimento entre primatas, em uma proporção direta com o nível de relacionamento entre eles, e da estrutura social subjacente.

A representação do conhecimento em primatas e seres humanos é um tópico de grandes discussões. Nestes casos, está ainda intimamente relacionado aos conceitos de inteligência, bem como de cognição. Ao se tratar dessa representação, uma das principais questões abordadas é como um indivíduo adquire conhecimento através da aprendizagem e como isso ocorre através da interação com o ambiente.

O LEC do IPUSP utiliza o termo transmissão de informação, que nesta tese é tratado como transmissão de conhecimento, já que para alguns autores, a transmissão de informação é a transmissão de uma mensagem de um emissor para um receptor através de alguma forma ou algum tipo de símbolo. Este é um processo pelo qual as pessoas ou animais interagem em sociedade se fazendo compreender e influenciando umas às outras por um tipo de linguagem (BORDENAVE, 2002 apud DEUS, 2006). Devido essa abordagem, decidiu-se utilizar o termo transmissão de conhecimento, que em nosso ponto de vista esta mais relacionada a aprendizagem.

Segundo Piaget (1982), a aprendizagem ocorre através da interação entre o indivíduo e o objeto de estudo, sendo que essa aprendizagem não deve ser transmitida, e sim, descoberta, transferindo a preocupação do processo de ensino para o processo de aprendizagem, caracterizando o construtivismo. O conhecimento não é transmitido de um indivíduo para outro, mas construído através da atuação do próprio indivíduo sobre o que deve ser conhecido. O indivíduo deverá aprender a aprender, ou seja, construir seu conhecimento e atribuir novos significados aos acontecimentos desde muito cedo.

Para Vygotsky (1989), o sujeito não é somente ativo, mas também interativo, construindo o conhecimento através de relações intra e interpessoais. Através dessas interações, o indivíduo cria uma série de ideias e estratégias para a solução de problemas. Estas interações sociais poderão ser utilizadas como suporte intelectual e afetivo. Não existe construção do conhecimento somente por registro de informações e observações, o conhecimento é adquirido através de atividades do próprio aprendiz sem a necessidade de memorização, ou seja, através de descobertas e soluções de problemas. 
Segundo a abordagem de aprendizagem social etológica e a existência de tradições de primatas não humanos (HEYES, 1993), a aprendizagem em um contexto social (FRAGASZY; PERRY, 2003) pode ser transmitida de acordo com as próprias experiências do primata com o ambiente, bem como pela observação de atividades realizadas por outros primatas no mesmo ambiente ao longo do tempo acumulando as modificações de comportamento. Acredita-se ainda que a aprendizagem possa acontecer mesmo na ausência do primata que estava realizando a atividade, mas que deixou vestígios da mesma no ambiente (FRAGASZY; VISALBERGHI, 2004).

Devido ao fato dos termos transferência, difusão ou transmissão de conhecimento aparece várias vezes no decorrer do trabalho e terem vários sentidos dependendo do ponto de vista, é importante ser fixado o sentido atribuído aqui, a fim de evitar enganos. Quando se diz que os primatas estão transferindo ou transmitindo conhecimento, queremos dizer que eles estão próximos uns dos outros (em um raio de $1 \mathrm{~m}$ ou $10 \mathrm{~m}$ ), se tocando ou apenas se observando, de modo que é reconhecida a existência de um nível de relacionamento que favorece a transferência de conhecimento de um para o outro.

\subsection{Ambiente Virtual, Agentes e Multiagentes}

O ambiente simulado é composto por um ambiente virtual que é habitado por agentes que representam os macacos prego na simulação, o modelo social e um observador virtual. O modelo social e o observador virtual serão descritos com mais detalhes no capítulo 4. O ambiente virtual pode ser visto como um laboratório virtual onde podem ser feitos experimentos envolvendo interação com os agentes que na vida real envolveriam riscos, por exemplo. Com as simulações, pode-se fazer a representação computacional de primatas através de agentes evitando esse problema de presença, segurança e limitações físicas (TORI et al., 2006).

Uma das definições de agente, segundo Wooldrige (2002) diz que "um agente é um sistema de computação que é capaz de agir independentemente de um usuário...". Aprimorando essa definição seria interessante frisar que o agente segue um objetivo para que suas ações modifiquem o ambiente de acordo com as suas necessidades. 
Os agentes trazem a proposta não somente da representação de um primata por meio da replicação de comportamentos exteriores como, por exemplo, a movimentação [...] (CHAl et al., 2003; KING et al., 2000), mas também podem ser usados como substitutos de "primatas reais" em testes de laboratórios virtuais (TORI et al., 2006).

Quando se tem mais de um agente em um ambiente, os mesmos são chamados de multiagentes. Os sistemas multiagentes podem ser caracterizados como cooperativos, quando possuem relacionamentos estabelecidos com os agentes da mesma comunidade e se comunicam de alguma forma para em conjunto, mesmo com objetivos distintos, resolverem os mesmos problemas ou atingir o mesmo objetivo do grupo (WEISS, 2001; BRENNER, 1998).

Os agentes, ou personagens virtuais, com comportamento convincente em computadores, ao invés de seguirem um roteiro, apresentam um comportamento não totalmente previsível, dando a impressão de estarem vivos e terem suas próprias vontades, ou seja, tomarem suas próprias decisões em tempo real e de forma coerente e eficaz. Eles devem passar a impressão de que se comportam de tal forma que possam ser chamados de inteligentes. Esses agentes devem ser capazes de perceber seu ambiente e decidir o que fazer para alcançar um objetivo pretendido. As decisões são então transformadas em ações de forma que o comportamento pareça com o de um personagem real (GUTIÉRREZ; FRÉDÉRIC; THALMANN, 2008).

Os agentes deste trabalho, representando os macacos prego, não tomam suas próprias decisões de qual tarefa executar em seu dia a dia. Eles são controlados pelo simulador. É o simulador que rege as regras de todos os agentes.

O agente foi construído dessa forma porque ele precisa agir de acordo com as regras que regem o ambiente real. Sendo assim, quando se troca um conjunto de regras de acordo com o ambiente real, com novas variações para testar um novo conjunto de valores para a simulação de outro ambiente, o agente precisa agir conforme essas novas regras do ambiente simulado escolhido. 


\subsection{Algoritmos Genéticos}

A plataforma desenvolvida no trabalho utiliza os dados observados para construir o modelo social. Os dados observados são utilizados para regrar o sistema de forma coerente com o ambiente real. O modelo social utiliza uma equação para a transmissão do conhecimento que constitui a base para o comportamento da simulação do ambiente virtual. Para implementar a função que ajusta o mapa de transmissão de conhecimento entre os agentes, foi utilizada a técnica computacional dos algoritmos genéticos. A seguir será apresentado um breve conceito sobre como são utilizados os algoritmos genéticos (de forma geral) na área computacional.

Os Algoritmos Genéticos (AG), desenvolvidos por John Holland, seus colegas e estudantes na Universidade de Michigan (GOLDBERG, 1989), juntamente com as Estratégias Evolucionárias (EE) desenvolvidas por Rechenberg (1960) e a Programação Evolutiva (PE) desenvolvida por Koza (1992), formam uma classe de algoritmos de pesquisa baseados em evolução natural, chamados de Algoritmos Evolucionários (AE) (RIBEIRO et al., 1994).

Os AGs, mais especificamente, são métodos que simulam através de algoritmos, os processos de evolução natural (de base biológica) visando resolver problemas do qual as representações matemáticas sejam adequadas para serem tratadas por tais algoritmos (algoritmos inspirados nas teorias de Darwin e da genética) (FUTUYAMA, 1992) resultando em uma solução adequada. Podem ser resumidos pela descrição de seus principais componentes:

- Evolução: é o processo que opera sobre os genes do organismo e não sobre o organismo que os carrega. Assim sendo, o que acontecer com um organismo durante sua existência não irá se refletir sobre os genes. Mas os genes definem o projeto e terão reflexos diretos sobre todas as características desse organismo (decodificação dos genes -> DNA).

- Seleção Natural: este processo faz com que os agentes mais bem adaptados ao ambiente sobrevivam e reproduzam mais do que aqueles menos adaptados, preservando assim seus genes (VIANA, 1998).

- Reprodução: é a forma através da qual a evolução opera. Inicialmente ocorre a recombinação (ou cruzamento) onde os genes dos pais são combinados para formar um novo genótipo (dos filhos). Processos de recombinação (crossover) também podem fazer com que os genes dos 
filhos sejam bastante diferentes dos seus pais (BARCELLOS, 2000). Além disso, podem sofrer mutações que são causadas por erros na cópia dos genes dos pais.

O objetivo de Holland não era projetar algoritmos para resolver problemas específicos, mas desenvolver métodos para representar mecanismos de adaptação natural nos sistemas de computador (MITCHELL, 1996). A ideia consiste em uma forma similar à teoria biológica dos sistemas naturais, ou seja, na sobrevivência dos melhores indivíduos (membros da população) (VIANA, 1998) adaptados ao ambiente que poderiam sobreviver e se reproduzir em taxas maiores do que os indivíduos menos adaptados. Depois de muitas gerações, estes indivíduos adquirem características que lhes conferem uma maior adaptabilidade ao ambiente desfavorecendo os indivíduos de gerações anteriores, podendo-se dizer que a população evoluiu (KOZA, 1992). 


\section{CONCEPÇÃO E DESENVOLVIMENTO DA FERRAMENTA DE ANÁLISE DE REDE SOCIAL (SOFTWARE CUZCO)}

Neste capítulo serão apresentados os principais conceitos relacionados à primeira ferramenta desenvolvida para o Laboratório de Etologia Cognitiva do IPUSP, a qual foi chamada de $\mathrm{CUZCO}^{3}$. Também será mostrado como foi feita a implementação da ferramenta.

\subsection{Momentos e intervalos de observação}

Um momento de observação (seção 2.5) é uma tupla $y$ de $d, h, z, m f, x\left(S_{1}\right)$, $x\left(S_{2}\right), \ldots, x\left(S_{N_{S}}\right)$ em que $N_{S}$ é o número de elementos que compõem o grupo de sujeitos, $d$ é a data em que aquela observação foi efetuada, $h$ é o horário em que a observação foi realizada, $x\left(\mathrm{~S}_{\mathrm{j}}\right) \in\{0,1\}$ para $j \in 1,2, . . N_{S}$, é um valor de proximidade atribuído a cada sujeito, $z$ é a distância a ser considerada (por exemplo, $1 \mathrm{~m}$ e $10 \mathrm{~m}$ ) e $m f$ é o animal focal. Para uma tupla $y$, foi considerado $d, h, z, m f$ e para cada macaco $S_{\mathrm{j}}$ de $y, x\left(S_{j}\right)=1$ se $S_{j}$ foi visto perto o bastante $(1 \mathrm{~m}$ ou $10 \mathrm{~m})$ do animal focal $(m f)$ no dia $d$, horário $h$ e para uma distância $z$; e $y, x\left(S_{j}\right)=0$, caso contrário. Por convenção, se $S_{j}$ é o animal foca, a tupla $y, x\left(S_{j}\right)=1$, considerando que o animal focal está sempre próximo o suficiente dele mesmo, por isso, ele possui o valor = 1 em sua coluna na matriz de observação da Figura 2.5. Durante os cálculos, esta convenção permite que a medida de proximidade seja aumentada entre o animal focal e cada sujeito visto próximo o bastante dele (o conceito de proximidade foi explicado na seção 2.5).

Um intervalo de observação é um conjunto de momentos de observação. Este pode ser representado por uma matriz composta pelo número de momentos de observação, número de elementos que compõe o grupo de macacos e por $d, h, z$ e $m f$, como citado anteriormente (Figura 2.5, primeira matriz).

\footnotetext{
${ }^{3} \mathrm{O}$ nome da ferramenta vem de um dos macacos da ilha do PET
} 


\subsection{Matriz de Proximidade (P)}

Dada uma matriz $m$ na qual as linhas representam os momentos de observação e as colunas representam os objetos sob a observação (o conceito foi explicado na seção 2.5), foi construída uma matriz quadrada $\mathrm{P}$ de ordem $N_{S}$, a qual foi chamada de matriz de proximidade. P é uma matriz simétrica com $P_{i j}=J\left(S_{i}, S_{j}\right)$ se $J(i, j)$ é definido para o par de objetos observados $S_{i}$ e $S_{j}$, e -1 caso contrário. Neste contexto, a matriz de proximidade é a representação de um grafo simples com peso nas arestas (o peso é definido pelo índice de Jaccard).

\section{3. Índice de Jaccard}

O índice de Jaccard (JACCARD, 1901) fornece uma maneira simples para fazer comparação de elementos de um dado conjunto. Ele é utilizado para medir a intensidade das relações sociais com base nos encontros físicos (proximidade) entre os macacos. O grafo que representa a RS utiliza o índice de Jaccard para representar a intensidade das relações sociais. Esta é uma definição genérica do índice de Jaccard. Nesta tese, foi definida de uma maneira apropriada para lidar com os dados em estudo seguindo os pesquisadores do LEC do IPUSP (RESENDE, 2004). Para simplificar a análise da RS, o grafo é transformado em uma AGM utilizando-se o algoritmo de Prim ou o algoritmo de Kruskal. A AGM é uma das formas utilizadas para se estudar a estrutura hierárquica do grupo de macacos pelo LEC. A seguir é apresentado como foi implementado na ferramenta Cuzco.

Considere um conjunto de objetos $S$ que contém $N_{S}$ elementos. Suponha que estes elementos foram observados durante um intervalo de tempo discreto $h$ com $m$ momentos de observações. Quando uma dada propriedade de interesse é verdadeira para um elemento observado $\left(h_{i} \leq i \leq m\right)$, esse elemento recebe o valor 1 em observação $h_{i}$, caso contrário, o elemento recebe o valor 0 .

Isto pode ser visto como uma matriz $\mathrm{P}$ onde $m_{i j}=1$ se a propriedade de interesse é verdadeira para o elemento $j$ na observação $h_{i}$ e 0 caso contrário. Nesta pesquisa, os elementos do conjunto são os macacos representados por $S$ e as propriedades de interesse são "estar próximo o suficiente do animal focal" (dentro do raio de $1 \mathrm{~m}$ ou $10 \mathrm{~m}$ do animal focal). Para dois elementos observados $S_{i}$ e $S_{j}$, foi 
definida uma matriz $\mathrm{P}$ e a partir de $\mathrm{P}$ tem-se definidos os índices de $\mathrm{m}$ $\left(m_{11}, m_{10}, m_{01}, m_{00}\right)$. Todas elas têm $S \times S$ como o domínio e $\mathbb{Z}$ como conjunto imagem. Somam-se todos os momentos de observação nos quais a propriedade de interesse é verdadeira para ambos os elementos $S_{i}$ e $S_{j}$. Em outras palavras, sempre que os macacos $S_{i}$ e $S_{j}$ são vistos perto o bastante do animal focal, o valor de $m_{11}\left(S_{i}, S_{j}\right)$ é aumentado em 1.

$$
m_{11}\left(S_{i}, S_{j}\right)=\sum_{i=1}^{n} P_{i S_{i}} . P_{i S_{j}}
$$

Em seguida, somam-se os momentos de observação nos quais a propriedade de interesse é verdadeira para o elemento $S_{j}$, mas não para o elemento $S_{i}$ eq.(2). Isto é, somam-se os momentos de observação nos quais o macaco $S_{j}$ está perto do animal focal e o macaco $S_{i}$ não está.

$$
m_{01}\left(S_{i}, S_{j}\right)=\sum_{i=1}^{n}\left(1-P_{i S_{i}}\right) \cdot P_{i S_{j}}
$$

Outro caso é, somam-se somente os momentos de observação nos quais a propriedade de interesse é verdadeira para o elemento $S_{i}$ e não é verdadeira para o elemento $S_{j}$, eq.(3). Para os dados utilizados, estes são os momentos de observação nos quais o macaco $S_{i}$ está próximo o bastante do animal focal e $S_{j}$ não está.

$$
m_{10}\left(S_{i}, S_{j}\right)=\sum_{i=1}^{n} P_{i S_{i}} \cdot\left(1-P_{i S_{j}}\right)
$$

Agora foi definido o índice de Jaccard para cada par de sujeitos $S_{i}$ e $S_{j}$ como é apresentado na eq.(4) dada:

$$
J\left(S_{i}, S_{j}\right)=\frac{m_{11}\left(S_{i}, S_{j}\right)}{m_{11}\left(S_{i}, S_{j}\right)+m_{01}\left(S_{i}, S_{j}\right)+m_{10}\left(S_{i}, S_{j}\right)}
$$

Observa-se que, $0 \leq J\left(S_{i}, S_{j}\right) \leq 1 \forall S_{i}, S_{j} \in S$. Quando $J\left(S_{i}, S_{j}\right)=1$, a propriedade de interesse era verdadeira para ambos $S_{i}$ e $S_{j}$ em todos os momentos 
de observação pertencentes ao intervalo de observação sob consideração. Neste caso, os elementos têm o maior nível de proximidade possível.

Para os dados utilizados, isto significa que os macacos $S_{i}$ e $S_{j}$ foram vistos próximos o bastante do animal focal em todos os momentos de observação e neste caso, foi considerado que são maiores as chances de haver a transmissão social de conhecimento ou processo de aprendizagem entre eles. Note que $J\left(S_{i}, S_{j}\right)$ continua válido mesmo no caso em que o animal focal é $S_{i}$ ou $S_{j}$, dado que foi considerado que o animal focal está sempre próximo de si mesmo.

Sem perda de generalidade, se o animal focal é $S_{i}$, então se $S_{j}$ é visto próximo o bastante dele, sendo assim, o valor de $m_{11}\left(S_{i}, S_{j}\right)$ é aumentado em 1 . Em um momento de observação no qual $S_{j}$ não está próximo o bastante de $S_{i}, m_{10}\left(S_{i}, S_{j}\right)$ recebe o valor 1 . O índice é indefinido os sujeitos $S_{i}$ e $S_{j}$ se, para todos os momentos de observação eles nunca são vistos próximos o bastante do animal focal.

\subsection{Algoritmo de Prim}

O algoritmo de Prim é um algoritmo da teoria dos grafos que busca a AGM em um grafo conexo, com peso e não direcionado. Isso significa que ele encontra um subgrafo (caminho mínimo) do grafo original (com todas as ligações de arestas possíveis) no qual a soma total das arestas é minimizada onde todos os vértices estão interligados.

Nesta seção é descrito o algoritmo de Prim que calcula a AGM apenas com o intuito de apresentar seu funcionamento por ter sido utilizado pelo LEC até o momento atual. Mas, este algoritmo não calcula a FGM enquanto o algoritmo de Kruskal calcula. Para o sistema proposto (Cuzco), é utilizado o algoritmo de Kruskal para construir a FGM que representa a estrutura social de um intervalo de observação escolhido pelo usuário. Foram implementados os dois algoritmos para comparação. A justificativa para a implementação do algoritmo de Kruskal e não o algoritmo de Prim foi explicado na seção 2.4.1 com mais detalhes, inclusive seus conceitos. Nesta seção e na seção posterior, apresentamos somente a forma como os algoritmos foram implementados.

O algoritmo de Prim pode ser usado para encontrar uma AGM de um dado grafo $G$. Seus detalhes internos de funcionamento supõem que $G$ é um grafo conexo, 
ou seja, $c(G)=1$. A Figura 3.1 apresenta uma descrição de alto nível deste algoritmo.

O Algoritmo de Prim pode encontrar uma AGM, mas não pode encontrar subgrupos de um grupo porque assume que $G$ é um grafo conexo. Se o vértice $r$ (vértice inicial) pertence, por exemplo, a um componente qualquer de $G$ e $c(G)>1$, o algoritmo de Prim irá encontrar uma AGM somente para aquele componente. Neste caso, o laço "enquanto" será interrompido pela segunda condição, ou seja, o corte dos vértices do grafo $T$ torna-se vazio antes que aconteça $|V(T)|=|V(G)|$.

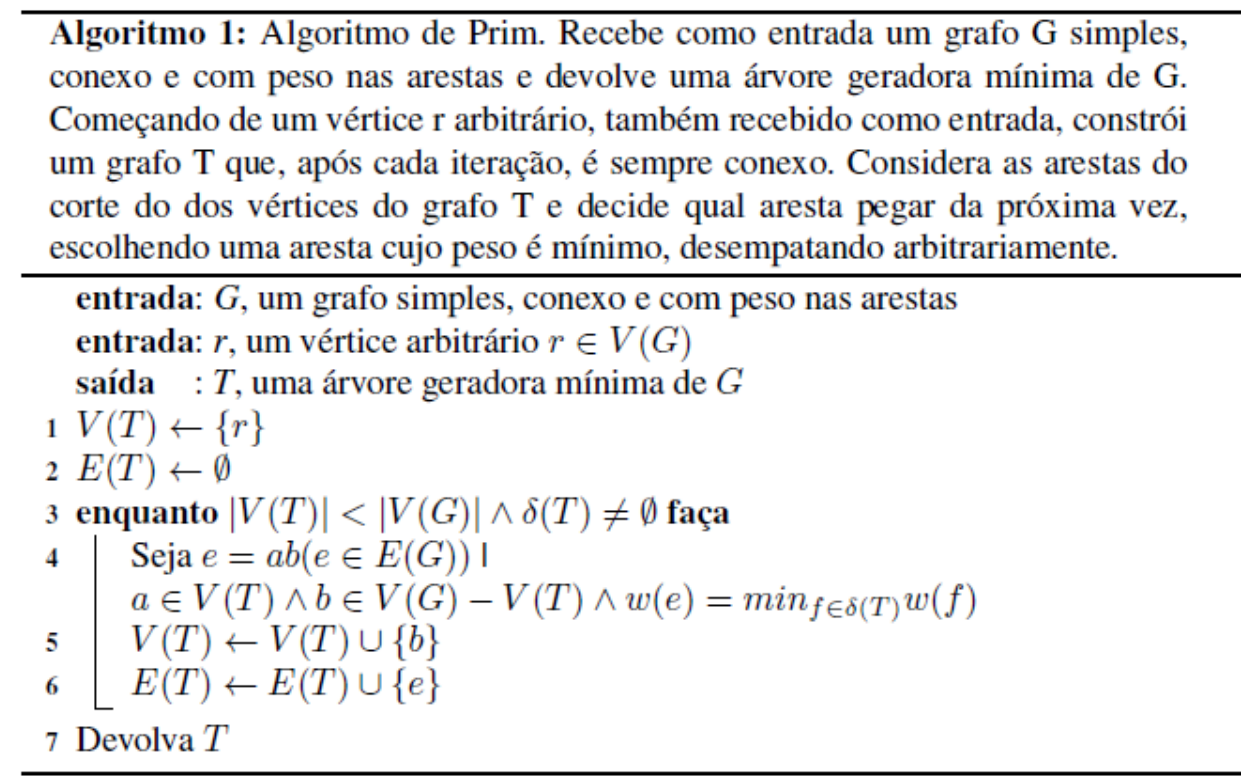

Figura 3.1 - Algoritmo de Prim

\subsection{Algoritmo de Kruskal}

O algoritmo de Kruskal também é um algoritmo da teoria dos grafos que busca uma AGM para grafos conexos ou desconexos e com pesos. Isso significa que ele encontra um subconjunto das arestas que formam uma árvore e inclui todos os vértices onde o peso total é dado pela soma dos pesos das arestas da árvore que é minimizado (AGM). Se o grafo não for conexo, então ele encontra a FGM (uma AGM para cada componente conexo do grafo), ou seja, subgrupos de um grupo.

A ferramenta implementada utilizou o algoritmo de Kruskal (Figura 3.2) a fim de encontrar uma FGM representada pelo grafo $G$, ou seja, divide um grupo maior em subgrupos, pois como dito anteriormente, devido o problema de deslocamento da ilha, acabou formando-se subgrupos na ilha. Para isso, o algoritmo de Kruskal 
fornece subgrafos o que é mais interessante para o estudo e comparação dos subgrupos pelos pesquisadores do LEC. Em seus detalhes de funcionamento, 0 algoritmo de Kruskal funciona de modo similar ao algoritmo de Prim. É um algoritmo interativo que, em cada iteração, faz uma escolha localmente ótima e constrói um subgrafo de $G$ que, no final, é uma FGM de $G$. Apesar disso, diferente do algoritmo de Prim, o algoritmo de Kruskal não requer que o subgrafo seja conexo após cada iteração.

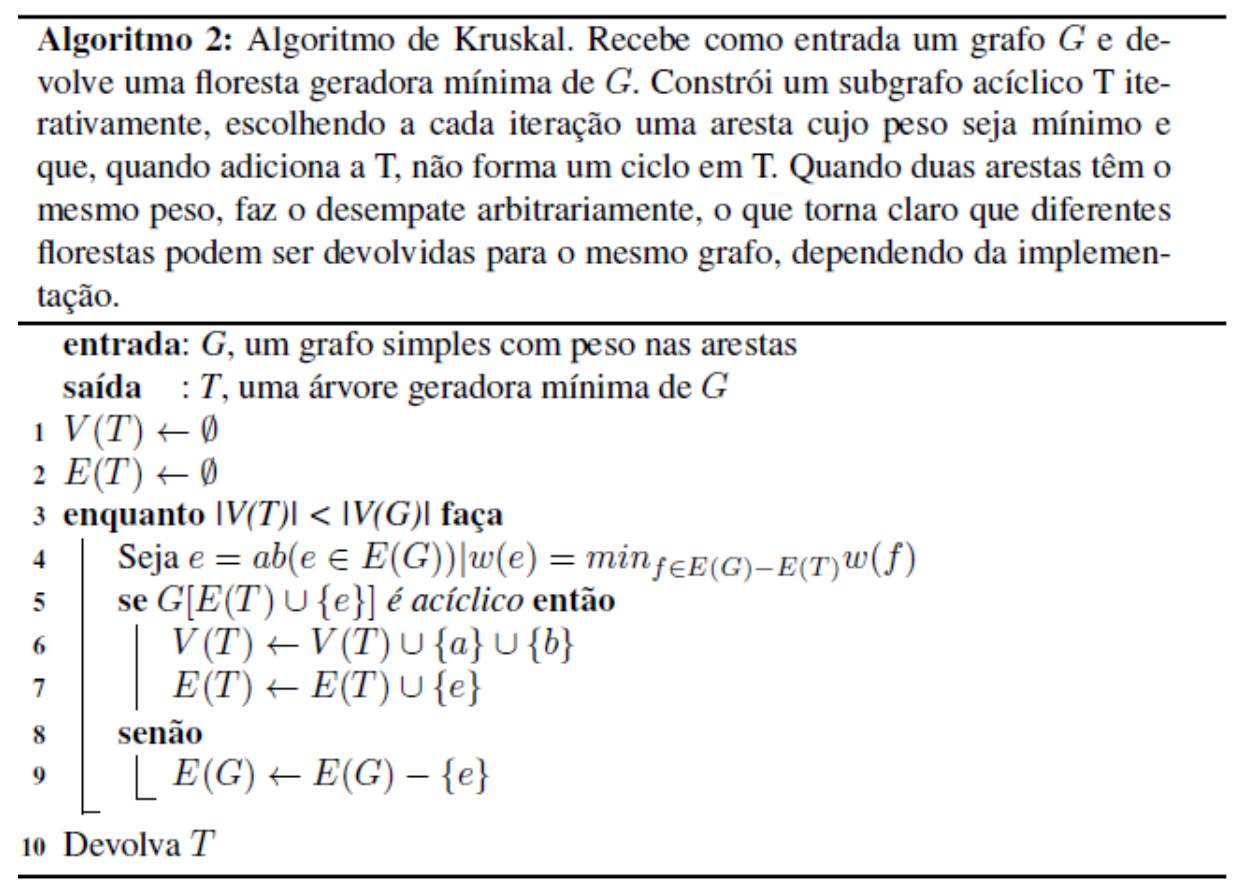

Figura 3.2 - Algoritmo de Kruskal

\subsection{Implementação do Software Cuzco}

O software desenvolvido nesta primeira etapa apresenta uma interface simples e de fácil utilização, além de utilizar dispositivos de interação (mouse, teclado e monitor) acessíveis à maioria dos usuários. As tecnologias utilizadas são computacionalmente baratas (linguagem de programação Java e banco de dados MySQL que são gratuitos e de código aberto) e altamente eficientes para a representação de fenômenos dinâmicos. A ferramenta permitirá que os pesquisadores substituam os processos atualmente manuais e em papéis por fluxos eletrônicos de informações que serão armazenados como um histórico e podem ser requisitados a qualquer momento. 
A ferramenta desenvolvida utiliza dados observados em campo, além do cadastro dos macacos que vão representar os vértices do grafo. Também possui o cadastro de substratos, ferramentas, alunos de IC, entre outras coisas. Um exemplo da tela de cadastro de macacos é apresentado a seguir na Figura 3.3.

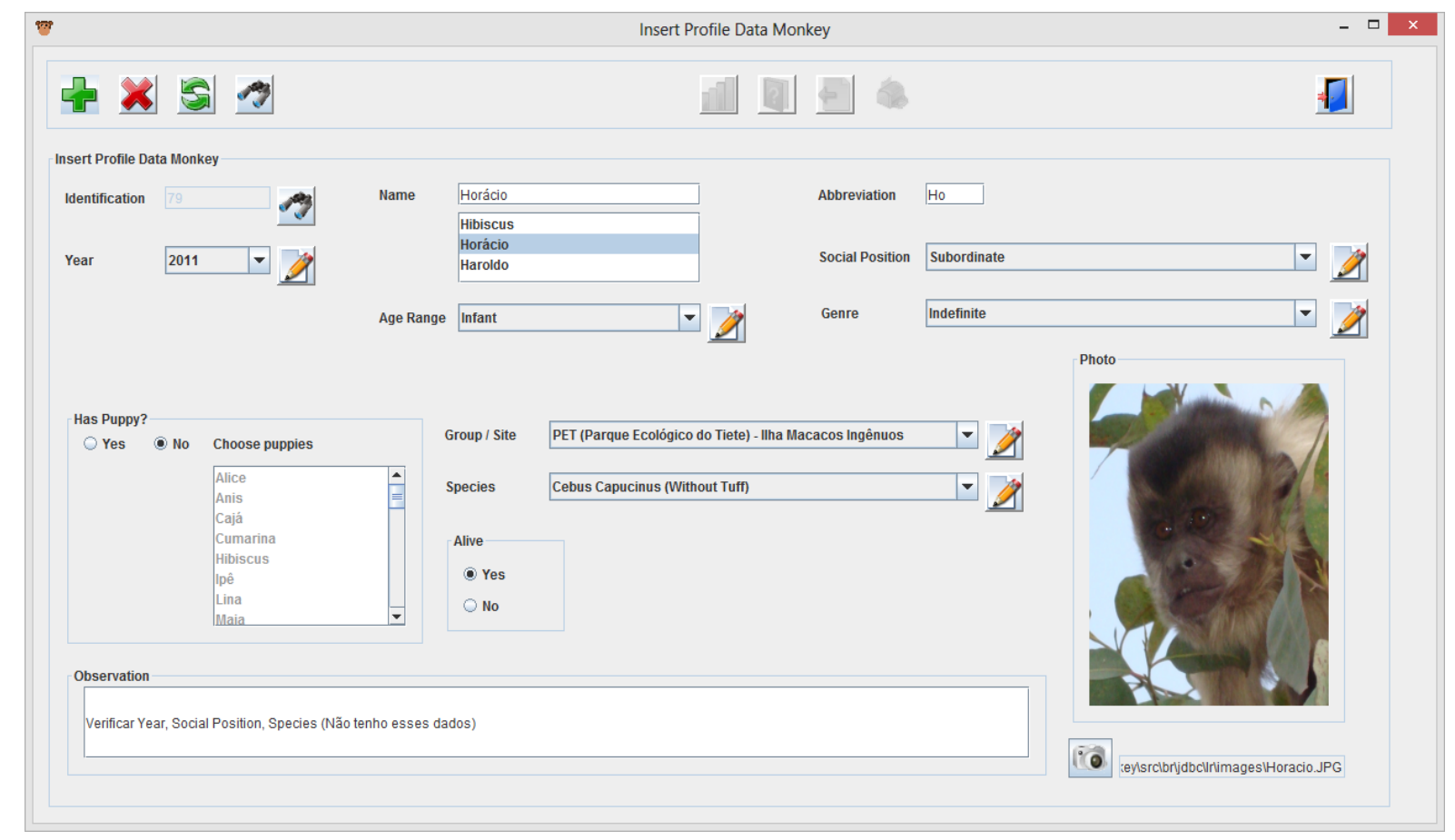

Figura 3.3 - Tela de Cadastro de Macacos

A inserção dos dados coletados em campo para a criação da rede social pode ser feita de forma automática, utilizando as planilhas eletrônicas fornecidas pelos pesquisadores do LEC do IPUSP que já foram coletados (veja o exemplo da planilha eletrônica na Figura 3.4). Essas planilhas alimentam 0 banco de dados automaticamente sem a necessidade da digitação dos dados pelos alunos de IC. Mas é necessário salvar a planilha com a extensão .CSV ${ }^{4}$ para a leitura no sistema.

Os dados também podem ser inseridos diretamente na ferramenta (não utilizando mais a planilha eletrônica) de forma manual pelos alunos de IC onde os mesmos escolhem os momentos de observações específicos como a data (dia, mês e ano), horário (hora, minuto e segundo) daquele momento, além de selecionar cada um dos macacos que estavam próximos o bastante do animal focal para uma determinada distância $(1 \mathrm{~m}$ ou $10 \mathrm{~m})$, conforme mostra a tela de cadastro na Figura 3.5.

\footnotetext{
${ }^{4}$ Formato de extensão de arquivo Comma Separated Values.
} 


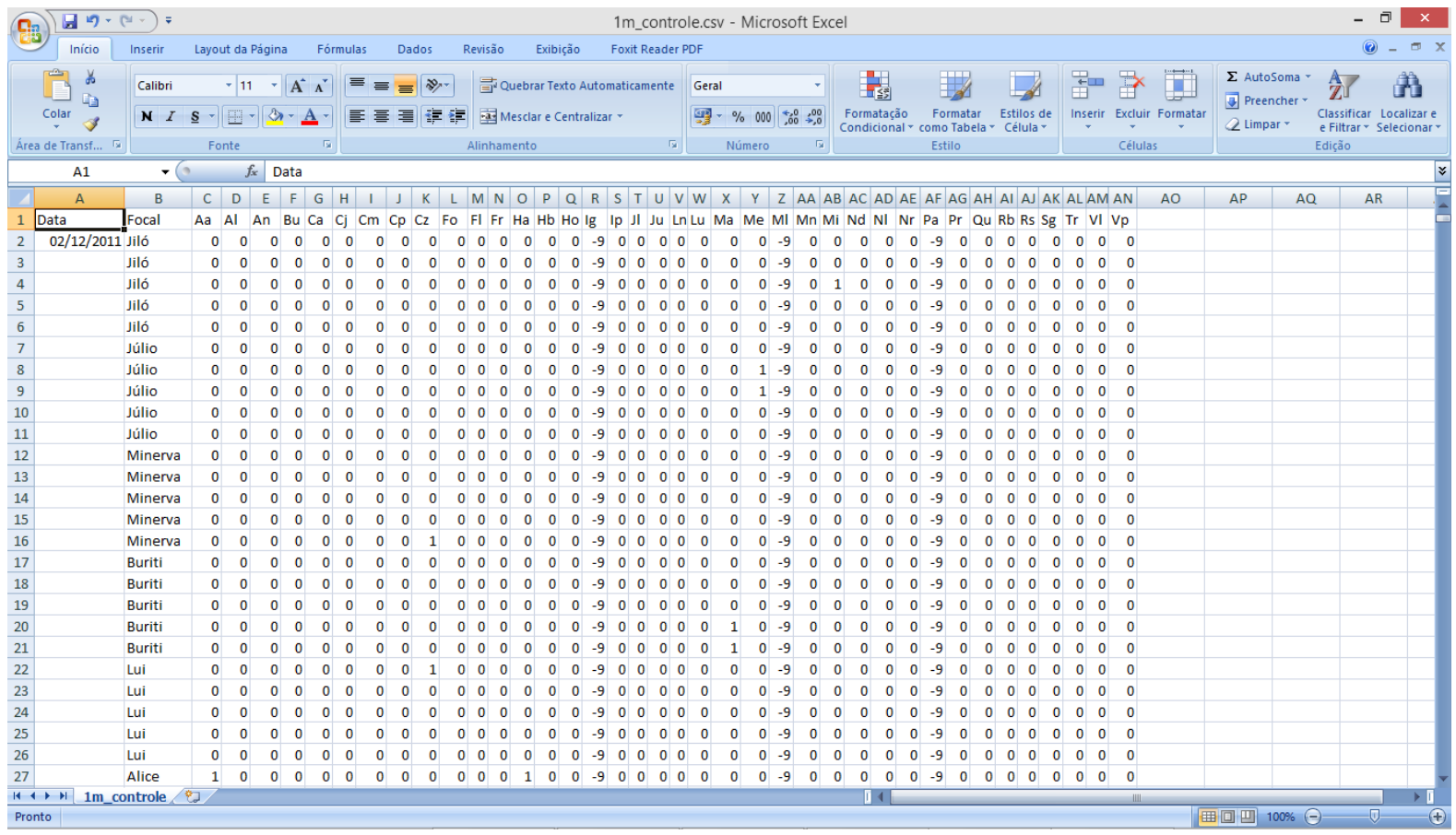

Figura 3.4 - Exemplo de planilha eletrônica com dados coletados em campo fornecidos pelos pesquisadores do LEC do IPUSP.

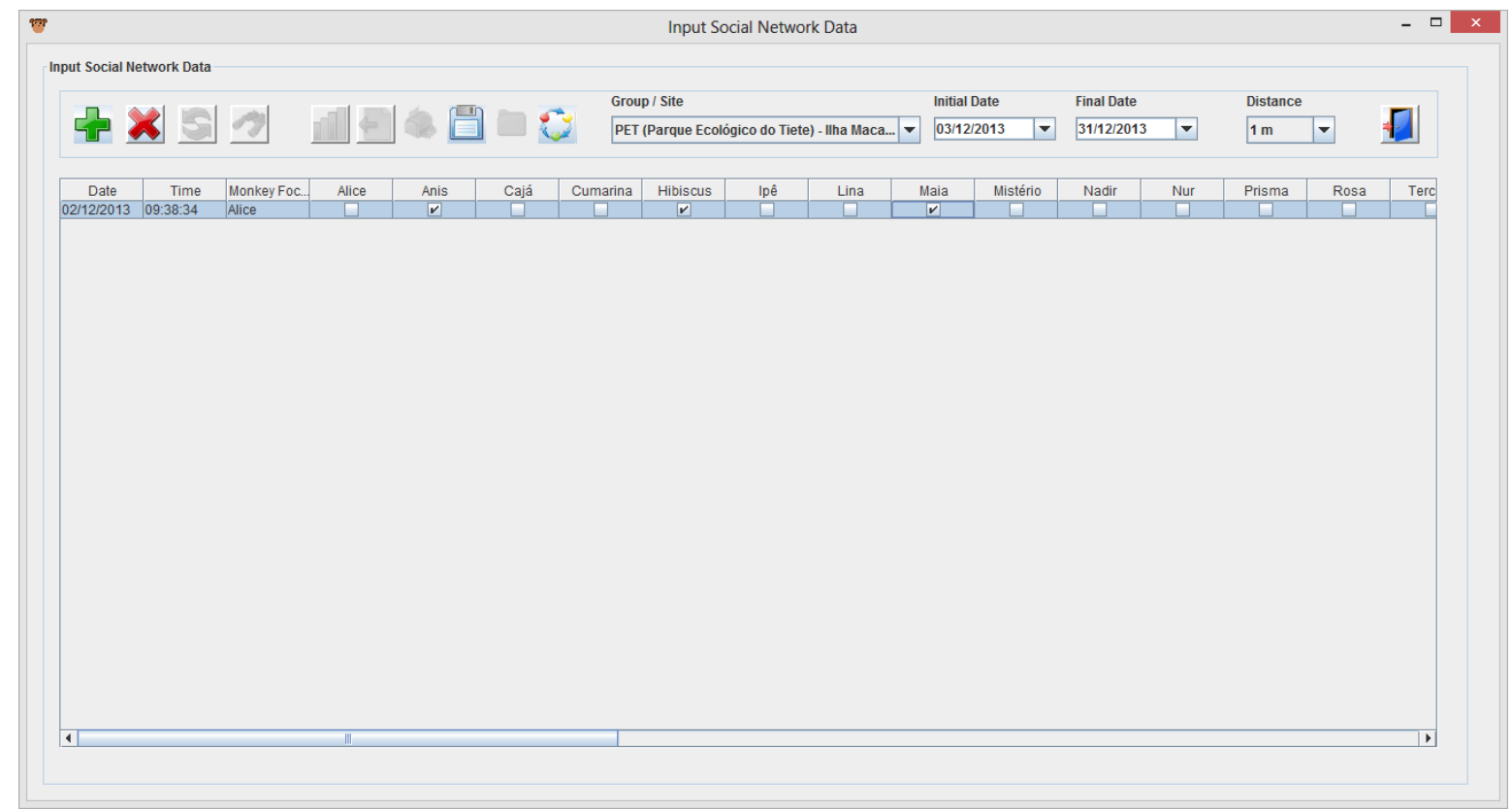

Figura 3.5 -Tela de inserção de dados manuais dos momentos de observação em campo (substitui a planilha eletrônica) e os dados já são gravados na base de dados.

Com os dados disponíveis, ou seja, gravados no banco de dados da ferramenta, pode-se gerar a FGM, agora também com subgrupos (caso exista) que representam as redes sociais. 
É possível escolher o intervalo de observação exato a partir do qual se desejam extrair um grafo, a distância a se considerar, o animal focal e o lugar no qual os macacos foram observados. Na FGM gerada no Gráfico 3.1, os macacos aparecem distribuídos em um círculo. Os pesos das arestas da FGM podem ser exibidos de formas diferentes. Eles foram calculados utilizando o índice de Jaccard. A largura de cada aresta pode ser calculada com base em seu peso (que pode ainda aparecer na forma numérica como rótulo ao lado da aresta). O Gráfico 3.1 e o Gráfico 3.2 exibem alguns exemplos. Em alguns casos, usar a largura de uma aresta para representar seu peso pode ser esteticamente interessante, mas isto pode fazer com que a figura se torne difícil de ser analisada. Neste caso, pode-se optar por representar os pesos das arestas com números.

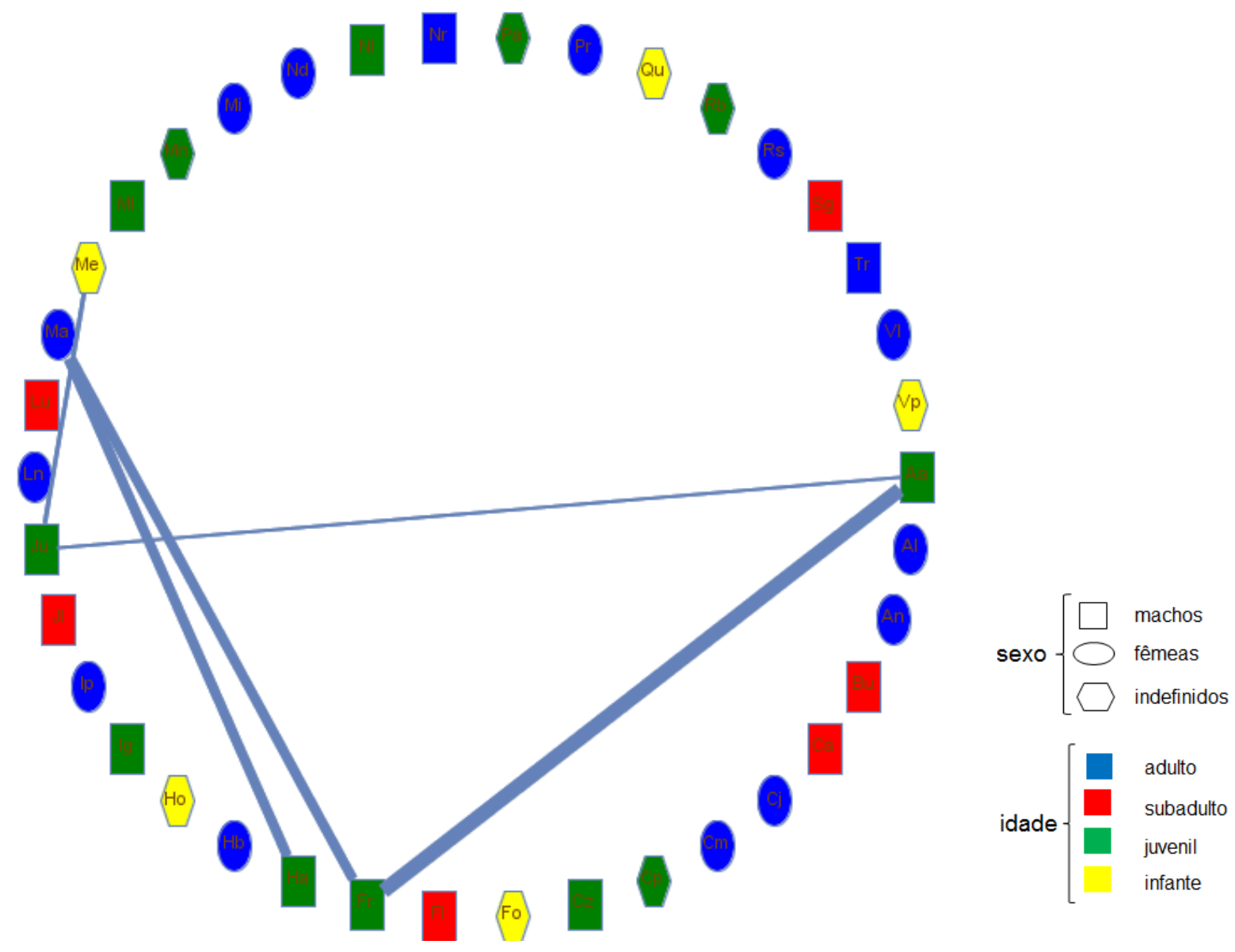

Gráfico 3.1- Uma Floresta Geradora Mínima na qual os pesos das arestas são representados por sua largura. 


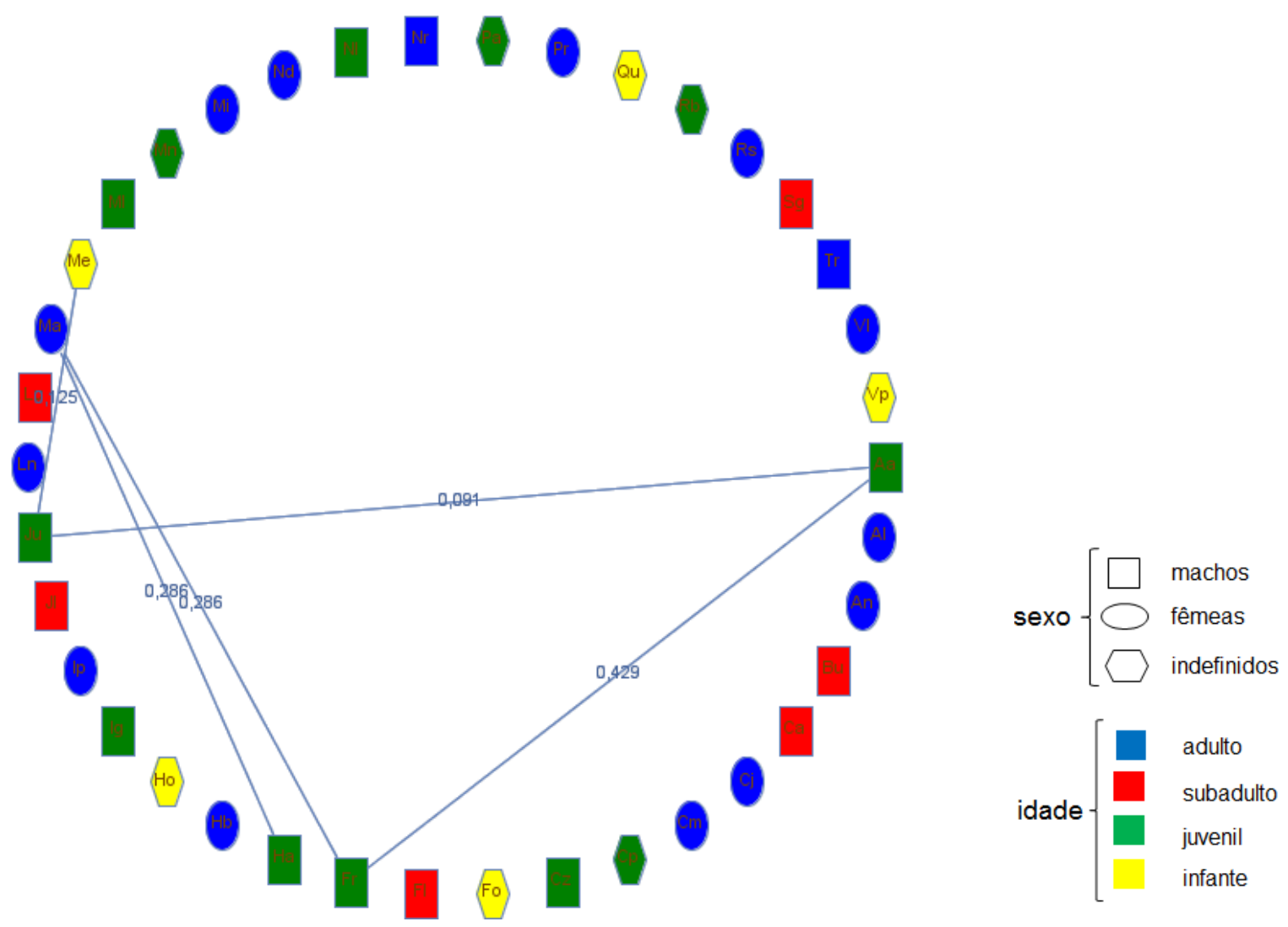

Gráfico 3.2 - Uma FGM na qual os pesos das arestas são representados por um número associado a elas como um rótulo.

Além disso, há que se tratar da representação dos macacos e de seus vários atributos, como mostra a Figura 3.6. No grafo gerado pela ferramenta, o gênero é modelado pelo formato dos vértices (quadrados: machos, elipses: fêmeas, hexágonos: indefinido). Este último pode ser o caso de macacos muito jovens cujo gênero ainda não pode ser determinado. A cor dos vértices modela a faixa etária dos macacos (azul: adulto, vermelho: subadulto, verde: juvenil e amarelo: infante).

A ferramenta armazena os dados em uma base de dados relacional. $\mathrm{Na}$ relação social_network_moment há dois atributos (id_monkey_focus e id_monkey_close) sob uma restrição de chave estrangeira e ambos referenciam o atributo id_monkey na relação monkey. 


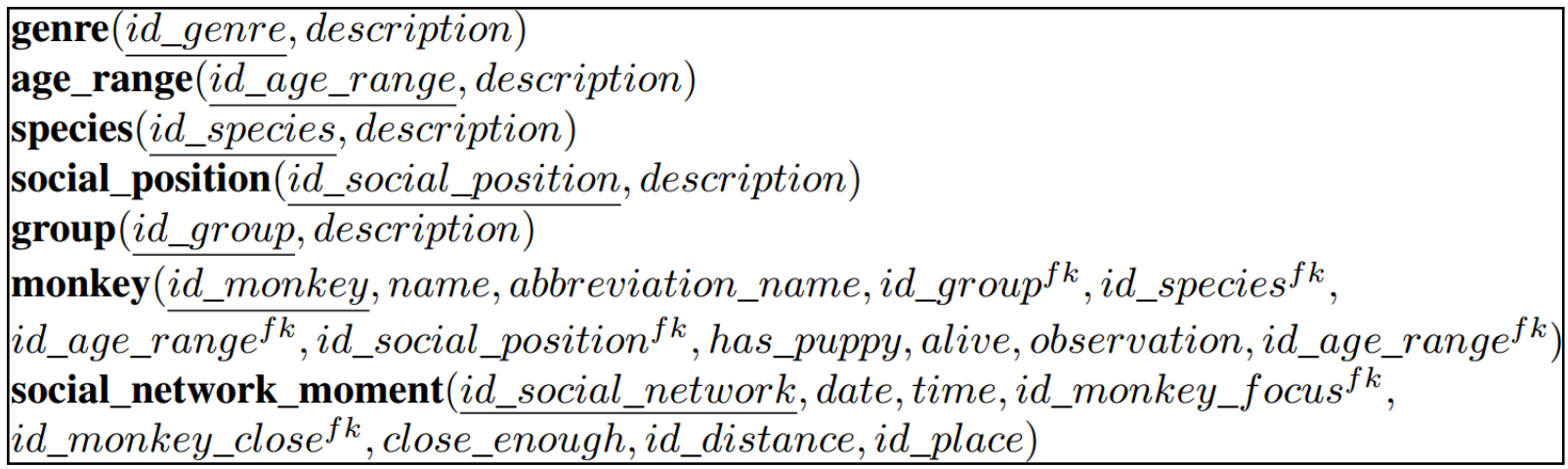

Figura 3.6. - O modelo relacional que a ferramenta proposta usa para armazenar os dados observados.

Eles indicam para um momento específico qual era o sujeito considerado como animal focal e qual era o sujeito que estava ou não próximo dele naquele momento. Note que cada tupla na relação social_network_moment contém informações sobre um único sujeito, indicando se ele estava ou não próximo o bastante do animal focal para a data, horário, distância e lugar, todos especificados naquele momento.

Assim, se em um momento de observação $N_{S}$ sujeitos estavam sob consideração, o sistema armazenará $N_{S}$ tuplas na relação social_network_moment, um para cada sujeito. Desta forma, para um dado intervalo de observação com $m$ momentos de observação, ter-se-ia $m \times N_{S}$ tuplas armazenadas na base de dados. Para maior clareza, os nomes de relações são exibidos em negrito na Figura 3.6.

\subsubsection{Pesos de AGMs}

A seguir serão apresentados os pesos das FGMs com variação de peso para dias e subgrupos diferentes. Pode-se calcular a FGM para o grupo inteiro bem como para subgrupos, por exemplo, composto somente por machos e fêmeas.

Os Gráficos 3.3 e 3.4 resumem os resultados obtidos, os quais podem dar uma ideia da dinâmica dos subgrupos para uma data de observação escolhida (16/06/2012). A distância escolhida para gerar estas estruturas foi de 10 metros. Estes são, naturalmente, apenas alguns exemplos simples do que o sistema proposto pode fazer. 


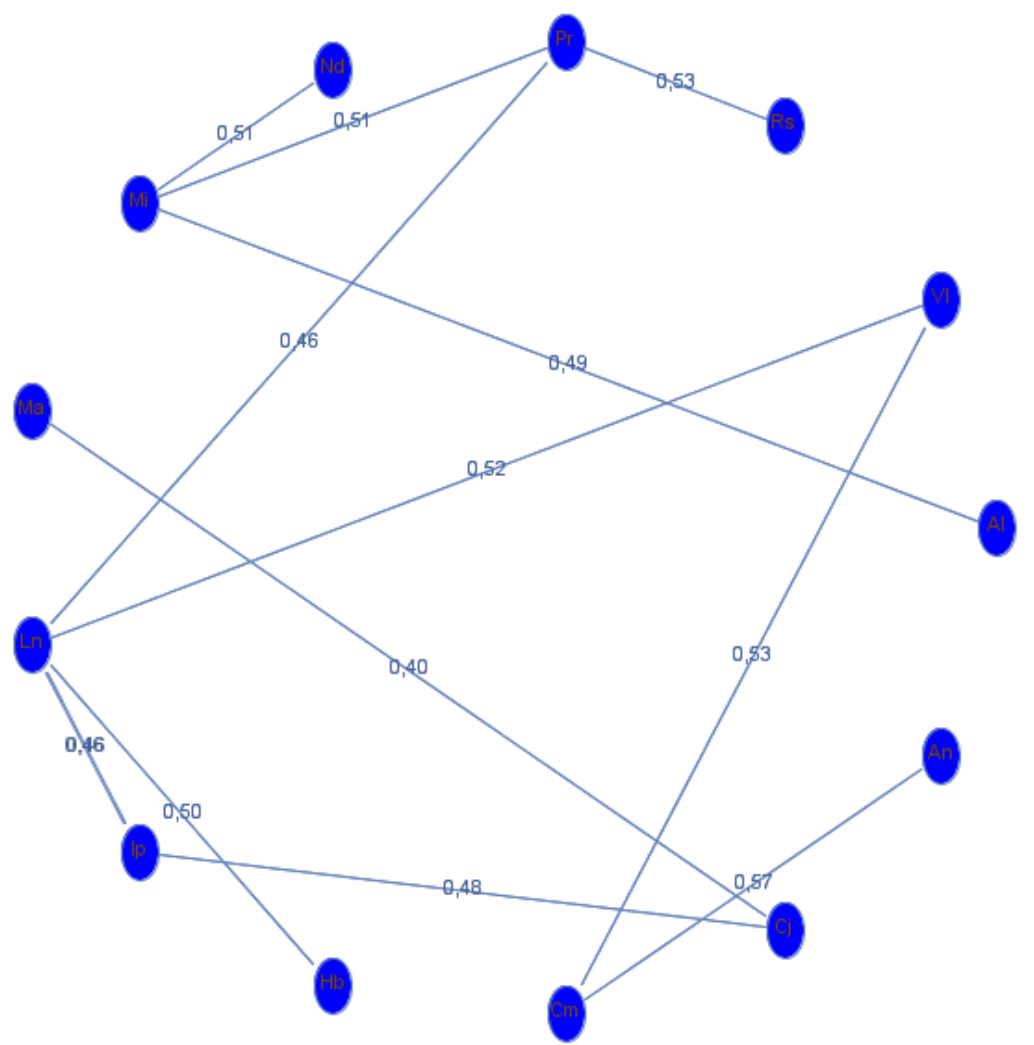

Gráfico 3.3 - Floresta Geradora Mínima calculada para o subgrupo de fêmeas em 16 de junho 2012.

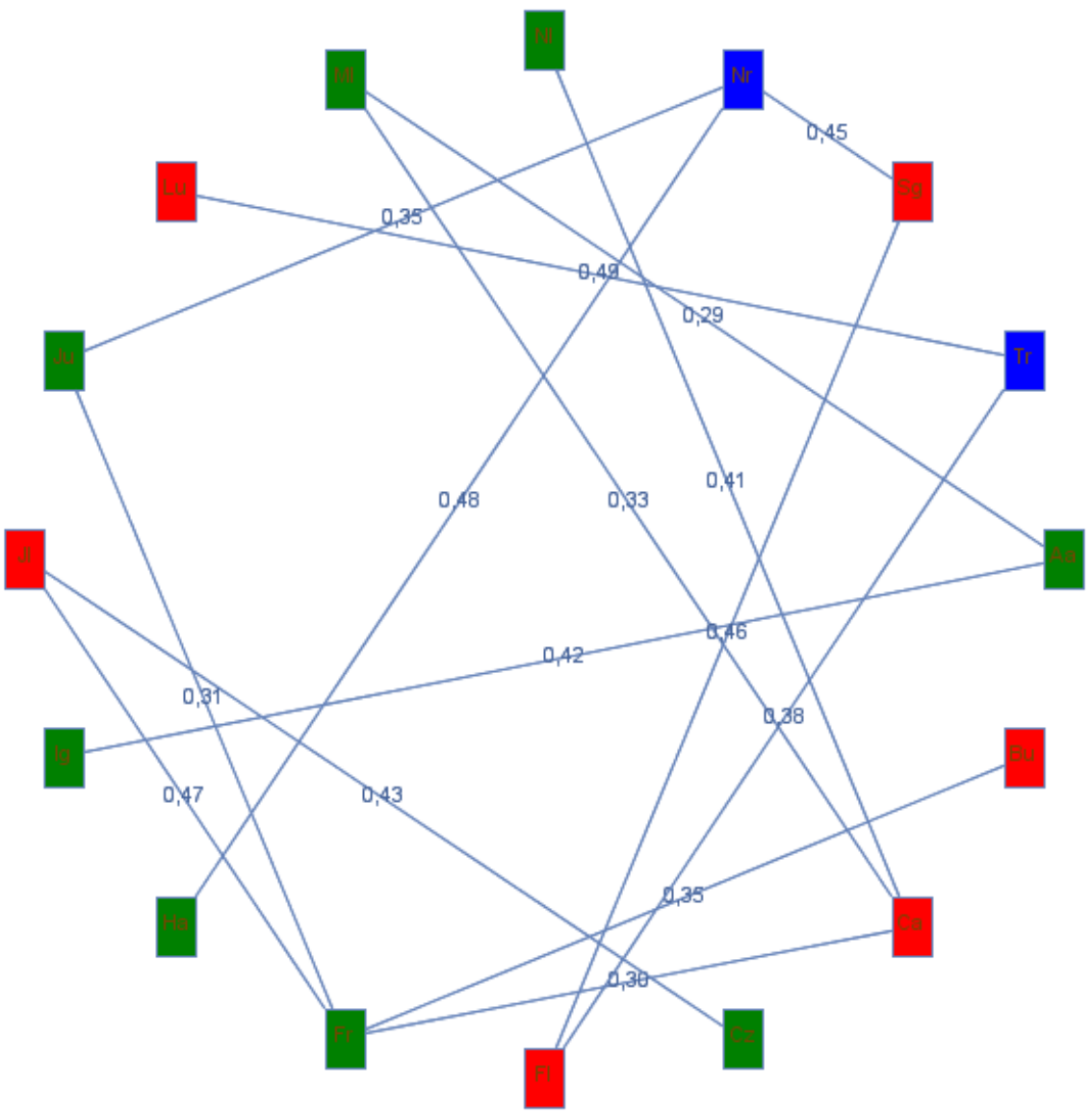

Gráfico 3.4 - Floresta Geradora Mínima calculada para o subgrupo de machos em 16 de junho 2012. 
A seguir será apresentada a proximidade baseada no corte analisando interações entre subgrupos diferentes. Por exemplo, o que aconteceria se, para um dado intervalo de observação, antes de calcular a rede social, fosse separado o grupo em dois conjuntos disjuntos, tais como, por exemplo, o grupo de machos e o grupo de fêmeas? Qual seria a probabilidade de transmissão de conhecimento entre dois subgrupos diferentes? A ferramenta proposta permite separar o grupo com diferentes critérios. Será apresentado um exemplo, separando o grupo em dois subgrupos: o grupo de machos e o grupo de fêmeas. No Gráfico 3.5, é apresentado um grafo no qual as arestas que ligam machos e fêmeas estão destacadas (exibidas em amarelo).

$\mathrm{Na}$ esquerda são apresentados os vértices cuja forma é quadrada, representando os machos. Na direita mostra-se os vértices cuja forma é uma elipse, representando as fêmeas. As arestas amarelas modelam interações entre machos e fêmeas. Estas arestas estão no corte do conjunto de vértices que representa os machos (ou equivalentemente, as fêmeas).

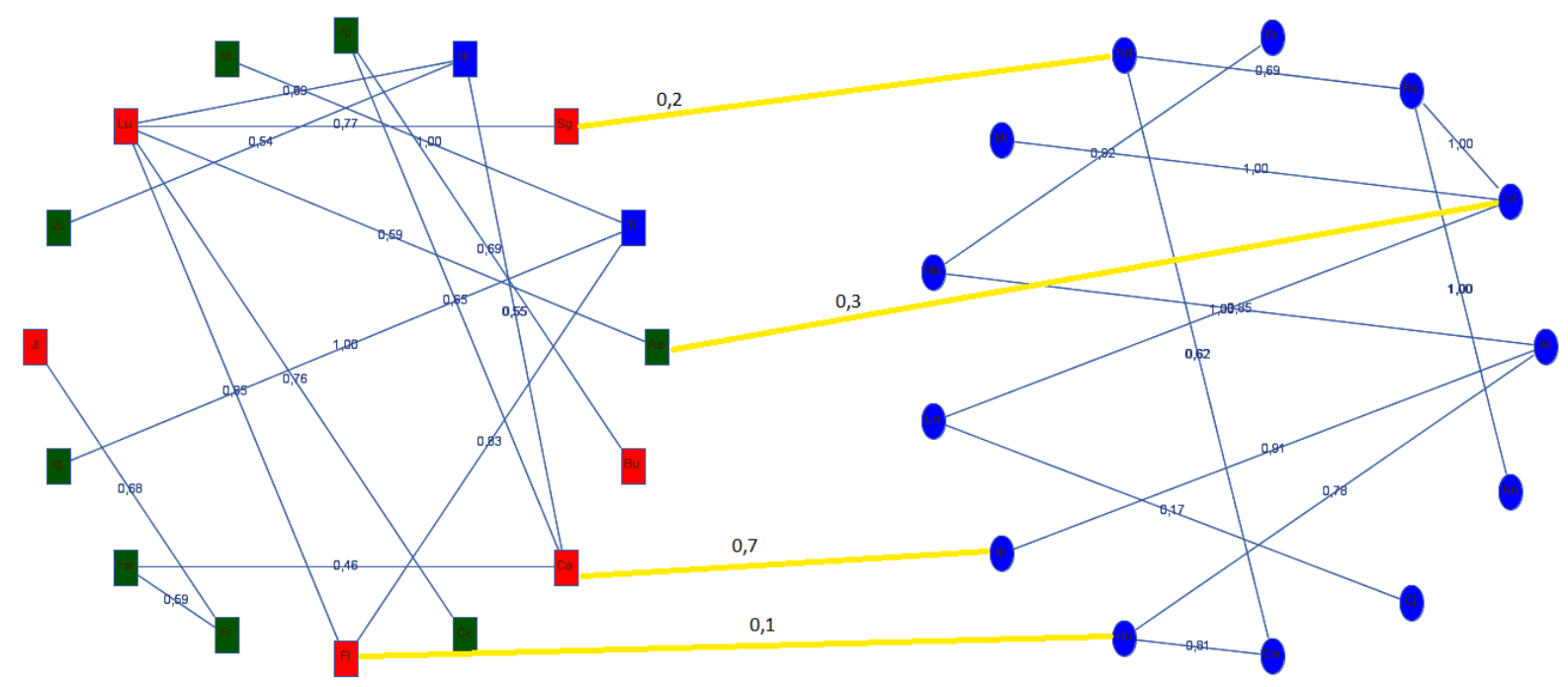

Gráfico 3.5 - Grafo separado pela ferramenta proposta. 


\section{CONCEPÇÃO E DESENVOLVIMENTO DO MODELO E DO AMBIENTE DE SIMULAÇÃO (SOFTWARE HORÁCIO)}

Ao longo deste capítulo será apresentado o modelo de transmissão social de conhecimento adotado pelo projeto, objetivo desta tese, bem como a natureza dos dados observados em campo pelos pesquisadores do LEC do IPUSP que são utilizados para regrar o comportamento do ambiente simulado (plataforma), chamado de HORÁCIO ${ }^{5}$. Esses dados são utilizados para testar a coerência entre o ambiente simulado e o ambiente real observado. Também será mostrado o funcionamento dos mecanismos do simulador utilizado para testar e validar a plataforma desenvolvida.

\subsection{O Modelo de Transmissão de Conhecimento}

Segundo Coussi-Korbel e Fragaszy (1995) citado em Resende (2004), o ambiente em que os macacos habitam, a posição social, os laços afiliativos, entre outros fatores, podem influenciar a transmissão de informação de comportamentos entre os macacos de um grupo. Além disso, a interação entre os sujeitos, a observação de seus comportamentos, a proximidade física e o tempo que permanecem juntos, pode aumentar as chances de transmissão de informação de comportamentos.

Em Resende (2004) também é utilizado o termo transmissão de informação (jargão da área). Nesta tese, ao invés de transmissão de informação, foi utilizado o termo transmissão de conhecimento (citado também na seção 2.4.4). Este é um termo polêmico e por isso é importante frisar como foi utilizado aqui. Neste trabalho, assumiu-se que quando dois macacos estão próximos o bastante um do outro (em um raio de $1 \mathrm{~m}$ ou $10 \mathrm{~m})$, pode existir à transferência ou transmissão de conhecimento (no sentido de competência ou aquisição de conhecimento pragmático) de um macaco para o outro conforme as atividades que cada um está realizando. Cabe ressaltar que não se está utilizando as características citadas anteriormente por Coussi-Korbel e Fragaszy.

\footnotetext{
${ }^{5}$ O nome da ferramenta também vem de um dos macacos da ilha do PET
} 
As seguintes premissas foram adotadas para guiar a concepção do modelo computacional de transmissão de conhecimento adotado:

- um conhecimento (competência) é transmitido de um sujeito para outro apenas quando eles estão próximos (relacionados) e varia conforme as atividades que cada um está realizando;

- o conhecimento é transmitido de forma direcionada, ou seja, do sujeito com maior conhecimento (transmissor) para o sujeito com menor conhecimento (receptor), sendo assim, o conhecimento dos dois sujeitos envolvidos nunca é diminuído.

- o conhecimento do sujeito receptor nunca ultrapassa o conhecimento do sujeito emissor.

Depois de estabelecido que dois sujeitos estão suficientemente próximos (em um raio de $1 \mathrm{~m}$ ou $10 \mathrm{~m}$ ) é utilizada uma equação para a transmissão do conhecimento que depende das atividades que cada um está realizando.

A seguir é apresentada a eq.(1) que é utilizada para a transmissão de conhecimento. Para isso, é necessário definir alguns conjuntos básicos que estão relacionados diretamente com o modelo.

$S=\left\{s_{1, . .,} s_{N_{S}}\right\}$ é o conjunto dos $N_{S}$ sujeitos utilizados no modelo;

$A=\left\{a_{1, . .} a_{N_{A}}\right\}$ é o conjunto das $N_{A}$ atividades que podem ser realizadas pelos sujeitos;

$L=\left\{l_{1, \ldots}, l_{N_{L}}\right\}$ é o conjunto dos $N_{L}$ locais onde os sujeitos podem realizar as atividades.

Sendo $A$ o conjunto das atividades e os sujeitos $S_{i}, S_{j} \in S$, a variação do conhecimento de $S_{i}$ é dada por:

$$
\Delta c_{i}=\left\{\begin{array}{c}
\left(c_{j}-c_{i}\right) M_{a_{i}, a_{j}}, \text { se } c_{j}>c_{i} \\
0 \quad, \text { caso contrário }
\end{array}\right.
$$

Onde:

$\Delta c_{i} \in[0,1]$ : é a variação do aumento do conhecimento do sujeito $S_{i}$;

$c_{i} \in[0,1]$ : é o conhecimento do sujeito $S_{i}$;

$c_{j} \in[0,1]$ : é o conhecimento do sujeito $S_{j}$;

$a_{i} \in A$ : representa a atividade que esta sendo realizada pelo sujeito $S_{i}$;

$a_{j} \in A$ : representa a atividade que esta sendo realizada pelo sujeito $S_{j}$; 
$M \in[0,1]:$ é a matriz dos coeficientes de transmissão de conhecimento composta pelo número total das $N_{A}$ atividades.

Note que $M$ (Figura 4.2) é a matriz que armazena os parâmetros dos coeficientes de transmissão de conhecimento utilizada na transmissão de conhecimento na eq.(1), e que, no modelo utilizado na Figura 4.1, a transmissão do conhecimento ocorre considerando-se exclusivamente as atividades realizadas pelos sujeitos.

O agente $e_{1}$ está realizando a atividade $a_{1}=L=$ locomoção e o sujeito $e_{2}$ está realizando a atividade $a_{2}=B S=$ brincadeira social quando estão próximos um do outro (em um raio de $1 \mathrm{~m}$ ou $10 \mathrm{~m}$ ) no local $l=S Q=$ sítio de quebra de cocos. É importante frisar que os coeficientes de transmissão de conhecimento de $M$ são encontrados pelo algoritmo genético (que será explicado na seção 4.5.1).

Verifica-se qual dos dois sujeitos, $e_{1}$ ou $e_{2}$ possui o maior valor de conhecimento, representados por $c_{1}$ ou $c_{2}$, para estabelecer quem será o sujeito transmissor ou receptor. Neste exemplo o transmissor é o $e_{1}$. Em seguida, verificase a atividade que os dois sujeitos $e_{1}$ e $e_{2}$ estão executando. A atividade $a_{1}$ que é a de maior importância será a do sujeito transmissor $e_{1}$. Por exemplo, se $M_{i j}>M_{i k}$, significa que quando o sujeito transmissor $e_{1}$ (coluna) esta realizando a atividade $a_{1}$, o coeficiente de conhecimento encontrado na matriz de transmissão $M$ (que é o 0,88 ) é transmitido de forma mais efetiva (direcionada) do que a do sujeito $e_{2}$ (linha) que esta realizando a atividade $a_{2}$. Encontrado o coeficiente de transmissão, aplicase a eq.(1) e o conhecimento de $c_{2}$ do sujeito $e_{2}$ é modificado, ou seja, aumentado para 0,88 . 

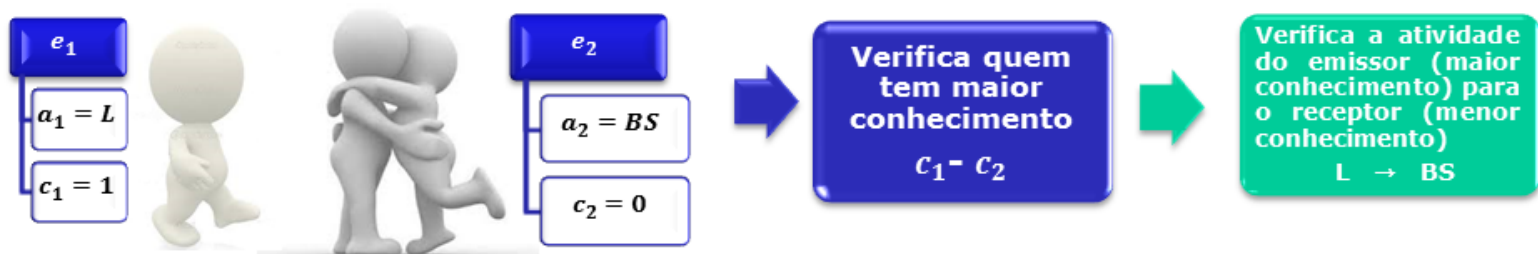

Situação Inicial

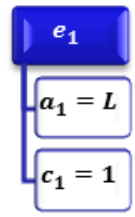

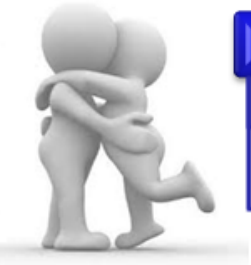

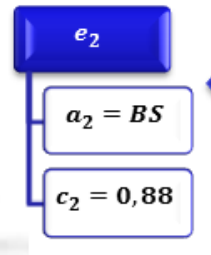

Situação Final
Aplicar a eq.(1)

$M_{\text {aiaj }}\left(c_{1}-c_{2}\right)$

$0.88 \times(1-0)=0.88$

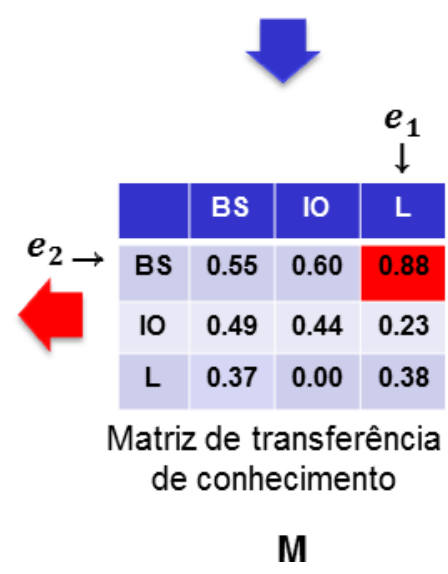

Figura 4.1- Exemplo do Modelo de Transmissão de Conhecimento

Resumindo, a matriz $M$ que esta sendo buscada possui os coeficientes de transmissão de conhecimento utilizados no modelo de transmissão de conhecimento citado anteriormente, particularmente aquele que representa a fração do conhecimento que o sujeito transmissor ao realizar a atividade $a_{j}$ passa para 0 sujeito receptor quando este realiza a atividade $a_{i}$. A equação $C_{R}=C_{R}+$ $M_{i j}\left(C_{T}-C_{R}\right)$ resume esta idéia, onde $C_{R}$ é o Conhecimento do Receptor, o $M_{i j}$ é o elemento da matriz de transmissão (representada na Figura 4.2 como exemplo por 0.88) e $C_{T}$ é o Conhecimento do Transmissor. Os coeficientes da matriz são encontrados pelo algoritmo genético.

\begin{tabular}{|c|c|c|c|}
\hline & $\begin{array}{c}a_{1}=\mathrm{BS} \\
\text { Brincadeira } \\
\text { Social }\end{array}$ & $\begin{array}{c}a_{2}=10 \\
\text { Interaçäo } \\
\text { Observador }\end{array}$ & $\begin{array}{c}a_{3}=\mathrm{L} \\
\text { Locomoçǟo }\end{array}$ \\
\hline $\begin{array}{c}a_{1}=\mathrm{BS} \\
\text { Brincadeira } \\
\text { Social }\end{array}$ & $M_{11}=0.55$ & $M_{12}=0.60$ & $M_{13}=0.88$ \\
$\begin{array}{c}a_{2}=10 \\
\text { Interação } \\
\text { Observador }\end{array}$ & $M_{21}=0.49$ & $M_{22}=0.44$ & $M_{23}=0.23$ \\
$\begin{array}{c}a_{3}=\mathrm{L} \\
\text { Locomoção }\end{array}$ & $M_{31}=0.37$ & $M_{32}=0.00$ & $M_{33}=0.38$ \\
\hline
\end{tabular}

Figura 4.2 - Exemplo da Matriz de Transmissão de Conhecimento 


\subsection{Dados Observados}

A seguir será apresentada a forma usada para o armazenamento dos dados observados e as notações utilizadas.

\subsubsection{Proximidades $\left(P^{O}\right)$;}

A matriz de proximidade $P^{O} \in[0,1]$ armazena as informações referentes às frequências dos encontros observados entre os $N_{S}$ sujeitos, onde $P_{i j}^{O}$ indica a probabilidade do sujeito $S_{i}$ se aproximar do sujeito $S_{j}$. Note que $P^{O}$ é uma matriz simétrica. Neste contexto, a matriz de proximidade pode ser vista como um grafo que representa as relações de encontros entre os sujeitos (o conceito para a construção da matriz de proximidade está na seção 2.4).

\subsubsection{Perfis ( $\left.B^{o}\right)$;}

Para cada sujeito foram observadas quais atividades estavam sendo realizadas e em qual local elas se deram. No sistema, estes dados foram utilizados para encontrar o perfil comportamental de cada sujeito $S_{i}$ denotado por $B^{O}$, dado pela eq.(2):

$$
B_{i}^{O}=\left\{U_{i}^{O}, V_{i}^{O}\right\} \text {, para } i=1, \ldots, N_{S}
$$

Onde:

$U_{i}^{O} \in[0,1]^{N_{A}}$ : é o perfil de atividades, sendo que $U_{i j}^{O}$ indica a proporção de tempo que o sujeito $S_{i}$ gastou realizando a atividade $a_{j}$;

$V_{i}^{O} \in[0,1]^{N_{L}}$ : é o perfil de locais, sendo que $V_{i}^{O}$ indica a proporção de tempo que o sujeito $S_{i}$ gastou no local $l_{i}$.

Note que, por representarem proporções, tem-se que $\sum_{j=1}^{N_{A}} U_{i j}=1$ e $\sum_{j=1}^{N_{L}} V_{i j}=$ 1.

Também se definiu o conjunto de todos os perfis dos sujeitos como mostra a eq.(3) dada:

$$
B^{O}=\left\{B_{i}^{O}\right\}, \text { para } i=1, \ldots, N_{S}
$$




\subsubsection{Proficiências Iniciais (CI ) e Proficiências Finais (CF)}

Além dos dados observados relativos às proximidades entre os sujeitos e aos seus perfis, o sistema também utiliza observações relativas às proficiências de cada sujeito na realização da atividade que expressa diretamente o conhecimento tratado (ex. a quebra de cocos), chamada aqui de atividade específica. Estas atividades são observadas no início e no final do período de observação, e são denominadas de proficiências iniciais $C I^{O}$, e proficiências finais, $C F^{O}$, respectivamente.

As proficiências iniciais observadas, $C I^{O} \in[0,1]^{N_{S}}$, são calculadas segundo a eq.(4):

$$
C I_{j}^{O}=\frac{Q I_{j}^{O}}{T I_{j}^{O}} \text { para } j=1, \ldots, N_{S}
$$

Onde:

$Q I_{j}^{O}$ : é o número de observações, no inicio do período de observação, nas quais o sujeito $S_{j}$ obteve sucesso na realização da atividade específica;

$T I_{j}^{O}$ : é o número total de observações, no inicio do período de observação, nas quais o sujeito $S_{j}$ realiza a atividade específica.

As proficiências finais observadas, $C F^{O} \in[0,1]^{N_{S}}$ são calculadas segundo a eq.(5):

$$
C F_{j}^{O}=\frac{Q F_{j}^{O}}{T F_{j}^{O}} \text { para } j=1, \ldots, N_{S}
$$

Onde:

$Q F_{j}^{O}$ : é o número de observações, no final do período de observação, nas quais o sujeito $S_{j}$ obteve sucesso na realização da atividade específica;

$T F_{j}^{O}$ : é o número total de observações, no final do período de observação, nas quais o sujeito $S_{j}$ realiza a atividade específica.

Os períodos de observação para a obtenção de $C I^{O}$ e $C F^{O}$ devem ser de curta duração (por exemplo, uma semana ou um mês) em comparação com o período utilizado para observar os perfis dos sujeitos (por exemplo, um ou dois anos), pois se precisa de uma medida inicial de o quanto o sujeito sabia (ou conhecia) da atividade específica que está sendo analisada. O mesmo acontece com o período final. Também o período associado a $\mathrm{CI}^{\mathrm{O}}$ deve estar localizado no início do período 
de observação dos perfis ou um pouco antes. Da mesma forma, $C F^{O}$ deve estar localizado no final ou um pouco depois da obtenção dos perfis.

Note que o sistema está lidando exclusivamente com um único conhecimento e que este está associado à atividade específica. Assim, enquanto $C I^{O}$ é utilizado para representar o conhecimento de cada sujeito no início do período considerado pelo sistema, $C F^{O}$ representa o conhecimento de cada sujeito no final do período. Portanto, a diferença $C F^{O}-C^{O}$ representa o quanto cada sujeito aprendeu durante o período de interesse.

\subsection{O Ambiente Simulado}

O ambiente simulado (pode ser visto como uma plataforma ou o modelo proposto) é composto por agentes (Figura 4.3) denominados $e_{1}, e_{2}, e_{3}$ e $e_{4}$, que representam os sujeitos observados, ou seja, os macacos prego. Os dados observados de proximidade $P^{O}$, são as atividades $a_{1}, a_{2}, a_{3}$ e $a_{4}$, que são realizadas no local $l_{1}$ (sítio de quebra de cocos). Os agentes possuem os conhecimentos que são representados por $c_{1}, c_{2}, c_{3}$ e $c_{4}$. O ambiente simulado utiliza os dados reais do modelo social para regrar o comportamento dos agentes no simulador de forma que sejam coerentes com o ambiente real observado. Note que $e_{1}$ está próximo a $e_{2}$, e devido à proximidade que representa a rede social ou um relacionamento entre os dois que foi obtido do perfil dos dados reais, eles podem se encontrar até 10 vezes durante a simulação e sendo assim, pode haver uma transmissão de conhecimento de $e_{1}$ para $e_{2}$.

A fim de propiciar maior coerência na simulação (procurando evitar a ocorrência de situações estranhas), foi proposta a implantação de regras de coerência ${ }^{6}$ que são verificadas a cada iteração do simulador para garantir que ocorrências muito pouco prováveis possam ser evitadas. Desta forma, tem-se um mecanismo que permite ao simulador gerir um comportamento mais próximo do esperado. A atual implementação deste conceito é parcial aplicando-se a situações em que a atividade exige um parceiro para ser devidamente executada.

\footnotetext{
${ }^{6}$ Regras de coerência: o simulador é alimentado por dados brutos coletados em campo do ambiente real gerados automaticamente de forma pseudoaleatórios com distribuição gaussiana, ou seja, são gerados com base nas probabilidades extraídas do ambiente real, incluindo informações estatísticas sobre proximidade e perfil de comportamento (competência) dos agentes.
} 


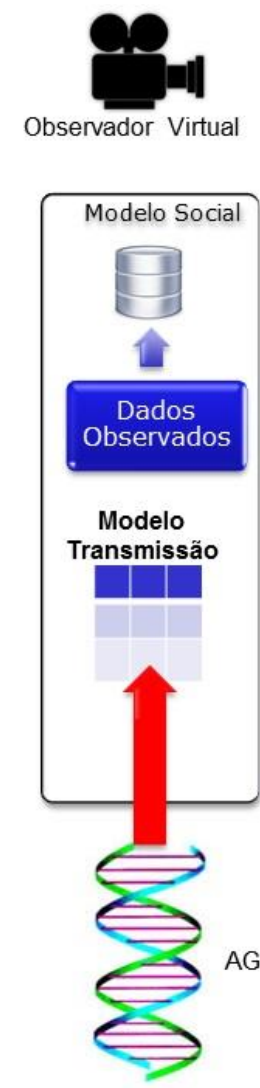

\section{Experimento hipotético}

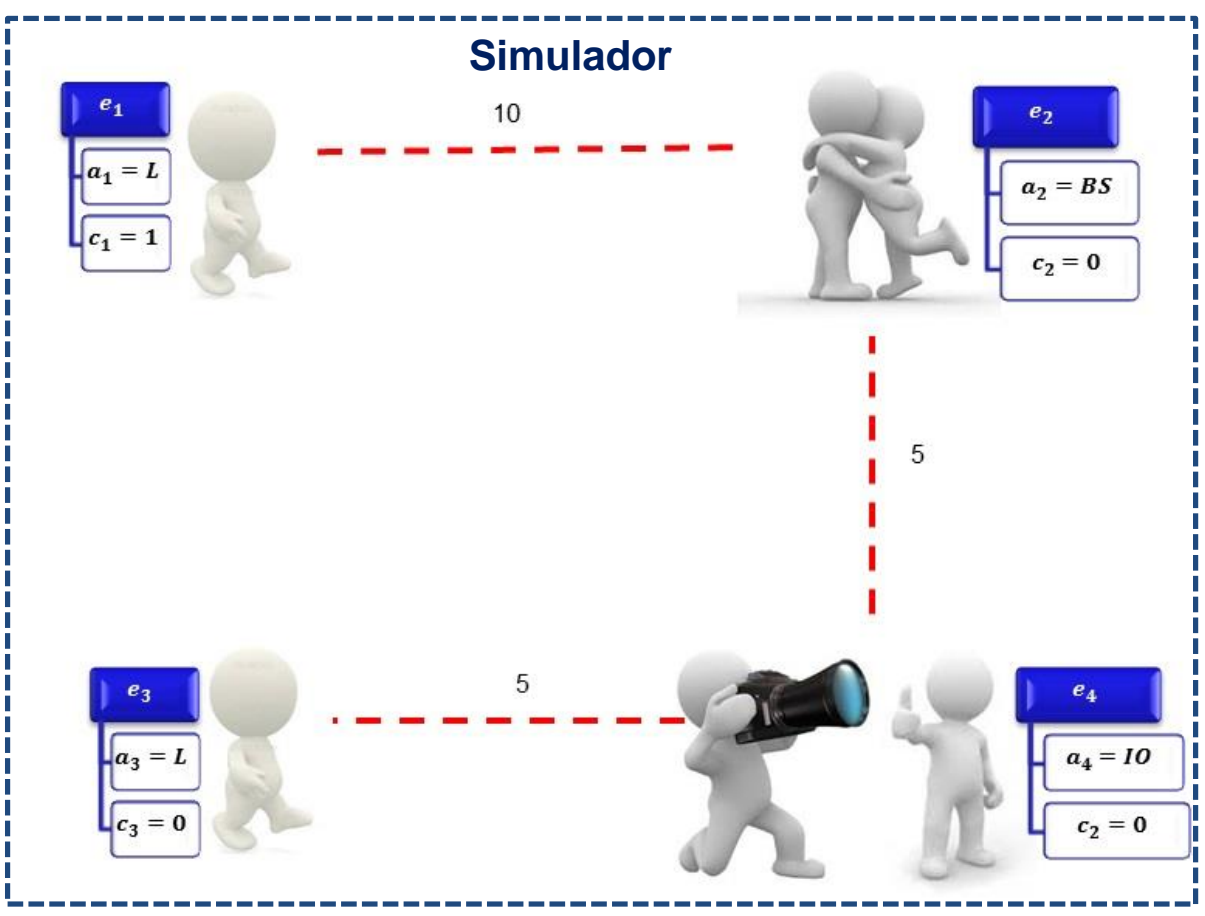

Figura 4.3 - Ambiente Simulado (Plataforma proposta)

A seguir será detalhado o modelo social, os agentes utilizados e como é realizada a simulação. Também são explicados quais e como os dados simulados são extraídos do ambiente simulado que são anotados por um tipo de observador virtual para validar o simulador com o ambiente real.

\subsubsection{O Modelo Social}

Os dados observados relativos às proficiências iniciais observadas $C I^{O}$ são utilizados para definir a quantidade do conhecimento específico que cada agente possui no início da simulação. Após a execução da simulação, o desempenho do modelo social utilizado pelo ambiente simulado é avaliado pela comparação entre as proficiências finais observadas $C F^{O}$ e as proficiências finais simuladas $C F^{S}$ que são lidas dos agentes no final da execução do ambiente.

O modelo social W (Figura 4.4) armazena os dados necessários à criação e execução do ambiente virtual dado pela eq.(6):

$$
W=\left\{C I^{O}, P^{O}, B^{O}, C F^{O}\right\}
$$


onde:

$\mathrm{CI}^{O}$ : é o vetor com as proficiências iniciais observadas;

$P^{O}$ : é a matriz com as proximidades observadas;

$B^{O}$ : é o conjunto de todos os perfis obtidos a partir das observações;

$C F^{O}$ : é o vetor com as proficiências finais observadas;

$\mathrm{CI}^{O}$ : é o vetor com as proficiências iniciais observadas.

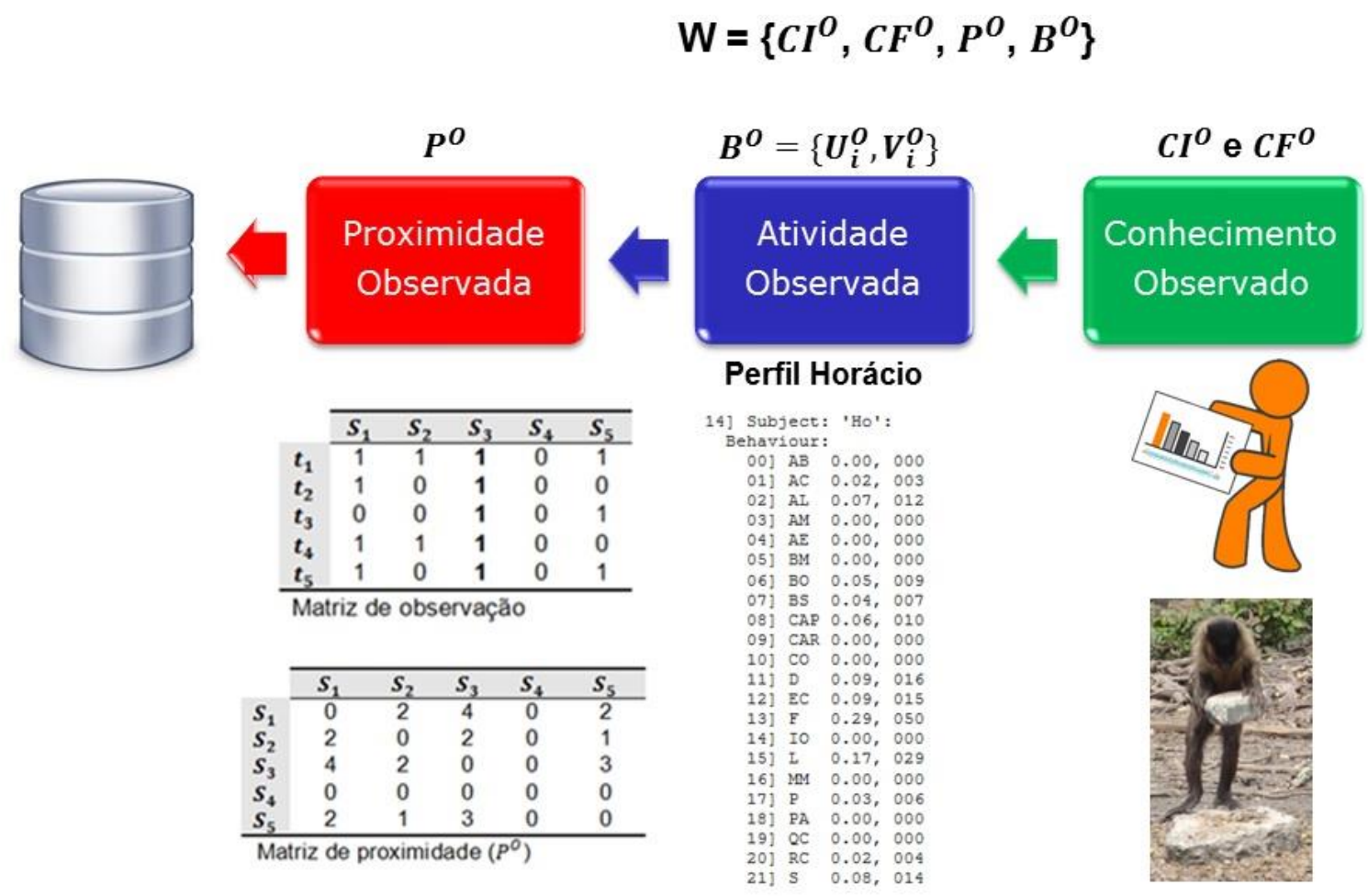

Figura 4.4 - Modelo Social

\subsubsection{O Agente}

No ambiente simulado cada sujeito $S_{i}$ é representado por um agente $e_{i}$ (Figura 4.5). $O$ estado de cada agente no instante de tempo simulado $t$ é dado pela eq.(7):

$$
e_{i}(t)=\left\{B_{i}^{o}, c_{i}(t), a_{i}(t), l_{i}(t)\right\}, \text { para } i=1, \ldots, N_{S}
$$

onde:

$B_{i}^{O}$ : é o perfil observado do sujeito $S_{i}$;

$c_{i}(t) \in[0,1]$ : é o conhecimento do agente no instante $t$;

$a_{i}(t) \in A$ : é a atividade realizada pelo agente no instante $t$;

$l_{i}(t) \in L$ : é o local onde o agente se encontra no instante $t$. 


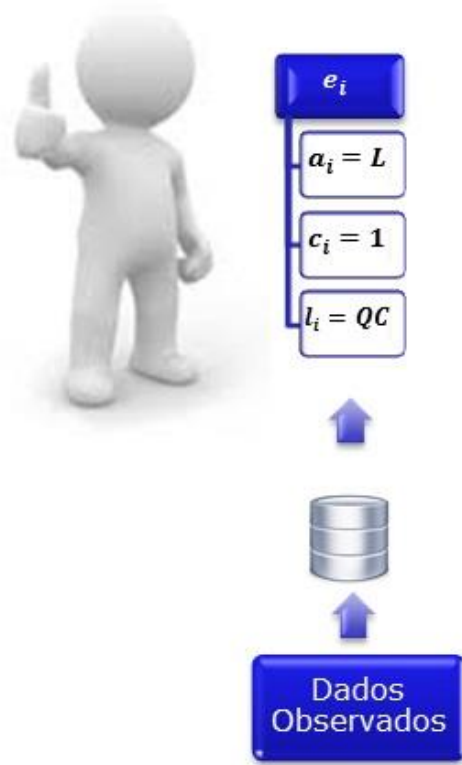

Figura 4.5 - Agente Simulado que representa o macaco

Note que o perfil do agente é obtido dos dados observados e se mantém constante durante toda a simulação.

Além de armazenar o estado atual, o agente é responsável por sugerir a atividade que deseja realizar e o local no qual deseja estar no instante de tempo seguinte ao atual. Ambos os desejos são escolhidos seguindo as estatísticas das proximidades observadas do perfil do agente. Foi construído dessa forma para manter a coerência entre a simulação e o ambiente real.

Dado o sujeito $S_{i}$ e sendo seu perfil de atividades dado por $B_{i}^{O}$, a probabilidade Prob de $S_{i}$ escolher a atividade $a_{j} \in A$ para $o$ instante $t+1$ é dado pela eq.(8):

$$
\text { Prob } a_{j}=U_{i j}^{O} \text {, para } j=1, \ldots, N_{A}
$$

Da mesma forma que a escolha da sugestão de atividade de um agente é realizada com base no perfil de atividades, a escolha da sugestão de localidade tem como base o perfil de localidades. Assim, dado o sujeito $S_{i}$ e sendo seu perfil de localidades dado por $V_{i}^{O}$, a probabilidade $\operatorname{Prob}$ de $S_{i}$ escolher a localidade $l_{j} \in L$ para $\mathrm{o}$ instante $t+1$ é dado pela eq.(9):

$$
\operatorname{Prob}_{j}=V_{i j}^{O} \text {, para } j=1, \ldots, N_{L}
$$


Note que tanto a escolha da atividade desejada pelo agente para a próxima iteração simulada $t+1$, quanto da localidade, são realizadas de forma ponderada conforme a ocorrência das atividades e localidades observadas e que elas não dependem da atividade nem da localização atual do agente.

Finalmente, o simulador é quem aplica o modelo de transmissão de conhecimento quando os agentes se encontram.

\subsubsection{A Simulação}

A simulação do ambiente (Figura 4.3) segue os dados observados contidos no modelo social definido na eq.(6). Para isso, são gerados $N_{S}$ agentes conforme descrito na seção 4.3.2. É importante ressaltar que os agentes são iniciados com as proficiências iniciais observadas (obtidas do ambiente real), definidas na eq.(4).

A execução da simulação é realizada em passos discretos de tempo, $t$, e transcorre conforme o algoritmo apresentado na Figura 4.6 a seguir:

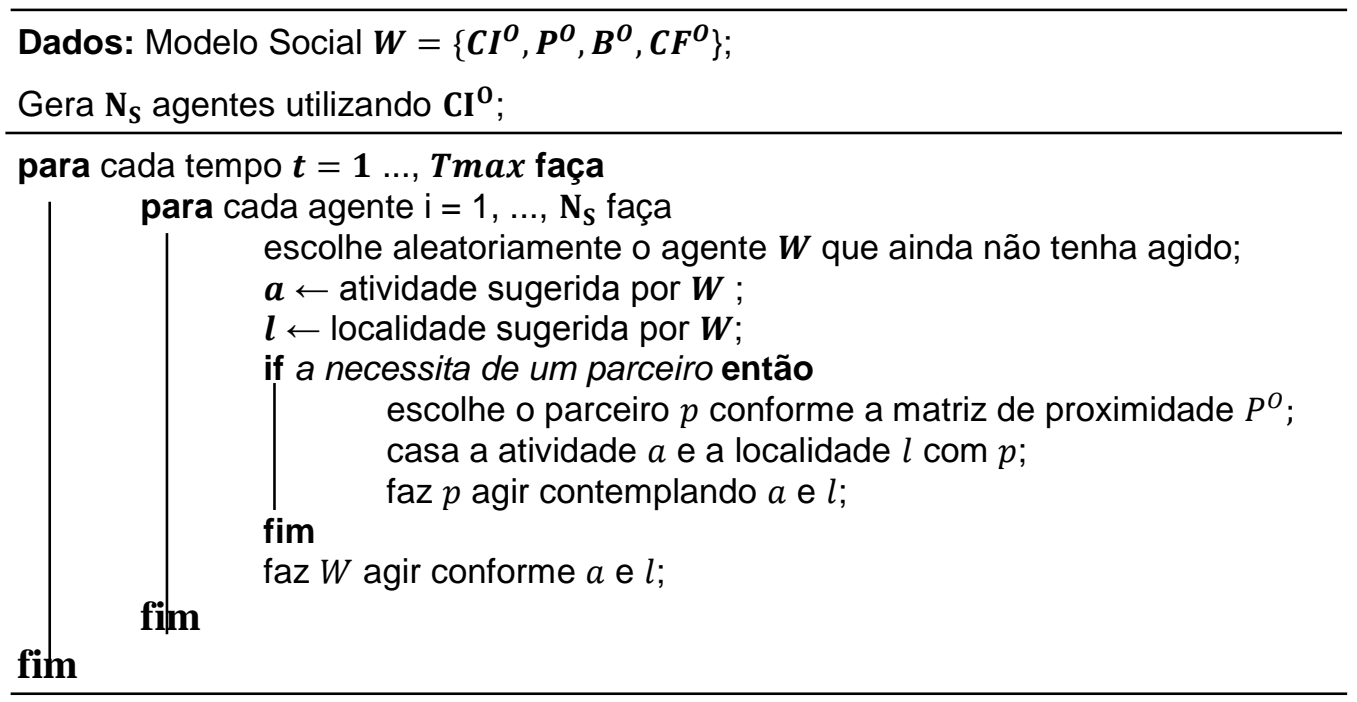

Figura 4.6 - Algoritmo da Simulação

Este algoritmo possui três pontos importantes:

- A escolha do agente: Para cada iteração de tempo do simulador, a sequência na qual os agentes são selecionados para agir é diferente, evitando assim que a sequência de ações criem dinâmicas viciantes 
em conformidade com a posição que os agentes têm no vetor que os armazena.

- A escolha da sugestão de estado pelo agente: Após ter sido escolhido um agente, o ambiente pede que ele apresente uma sugestão de estado para a próxima iteração. Este estado é composto por uma atividade e um local. Porém, algumas atividades só podem ser realizadas com a participação de um segundo agente. Para tais atividades o ambiente é responsável por escolher qual agente desempenhará o papel de parceiro. Cabe ressaltar aqui que a efetivação da ação no contexto desta simulação não requer que ela seja efetivamente implantada (como dito antes, são abstrações do ambiente real).

- A escolha do parceiro: Para a escolha do parceiro de um agente, a matriz de proximidade observada $P^{O}$ é vista como uma matriz de probabilidade de encontros. Assim, a probabilidade Prob do agente $e_{j}$ ser escolhido como parceiro do agente $e_{i}$ é dado pela eq.(10) ${ }^{7}$ :

$$
\operatorname{Prob}\left(e_{j}=\text { parceiro } \mid e_{i}\right)=P_{i j}^{O}=P_{j i}^{O}
$$

Após o parceiro $e_{j}$ ser escolhido é verificado se ele já está realizando alguma atividade em algum lugar. Se não estiver, o ambiente o coloca no mesmo local de $e_{i}$ e pede para que ele escolha uma atividade coerente com a de $e_{i}$. Se $e_{j}$ já estiver alocado, mas sua situação for coerente com a situação de $e_{i}$, então o ambiente pede a $e_{j}$ para que se ajuste à situação de $e_{i}$. Porém, se $e_{j}$ já estiver alocado em alguma situação contraditória à que $e_{i}$ está propondo, um novo parceiro é escolhido. $\mathrm{O}$ processo continua até que algum parceiro se disponha a estar com $e_{i}$ seguindo sua proposta de atividade e local. Caso não seja encontrado nenhum parceiro, o ambiente pede a $e_{i}$ que escolha uma nova sugestão de atividade e local.

- Implicações: Note que as escolhas dos estados futuros realizadas pelos agentes seguem as probabilidades dadas pelos perfis observados e que os encontros entre os agentes seguem as probabilidades fornecidas pela matriz de proximidade observada. Desta

\footnotetext{
${ }^{7}$ Note que $P^{O}$ é uma matriz simétrica
} 
forma, estes comportamentos no ambiente simulado refletem os comportamentos observados no ambiente real.

- Regras de coerência: Um ponto importante para a validação dos estados sugeridos pelos agentes diz respeito à coerência do estado sugerido, seja ela relativa ao próprio estado ou às relações sociais do ambiente simulado. Como exemplo da falta de coerência do próprio estado, pode-se imaginar uma situação onde o agente está realizado a atividade de comer em um local que sabidamente não há comida. Como exemplo da falta de coerência de estados relativos às relações sociais, pode-se pensar em uma situação na qual um agente está realizando a atividade de catação alheia, enquanto seu parceiro está realizando outra atividade incompatível como brigando. Tais regras de coerência são estabelecidas pelo ambiente que não permite este tipo de situação.

- A transmissão do conhecimento: No ambiente simulado toda vez que o agente $e_{i}$ se encontra com outro agente $e_{j}$ há a transmissão do conhecimento do agente que tem o maior conhecimento numa competência específica para o outro. O conhecimento é transmitido considerando-se as atividades que os agentes estão realizando no momento do encontro e é dado pela eq.(1) tendo os agentes $e_{i}$ e $e_{j}$ como os sujeitos $S_{i}$ e $S_{j}$, respectivamente. Note que a matriz $M$, que armazena os coeficientes utilizados pela equação de transmissão do conhecimento é expressada pela eq.(1), apesar de ser utilizada pelo simulador apenas neste momento. Esta matriz é de fundamental importância na determinação do fluxo que o conhecimento terá através dos agentes.

Para esclarecer melhor a simulação apresentada na Figura 4.3, a Figura 4.7 detalha alguns dos passos do simulador. Inicialmente são apresentados exemplos dos conhecimentos iniciais e finais, o perfil e os dados de proximidade que são obtidos através dos dados observados para cada um dos agentes envolvidos na simulação. Estes dados são as regras de coerência que estabelecem as restrições que serão usadas pelo simulador para então selecionar probabilisticamente o local, a atividade e o parceiro a cada instante de tempo da simulação. Note que, conforme 
ocorre o encontro entre os dois agentes, é aplicada a equação do modelo de transmissão de conhecimento que busca o coeficiente de transmissão de conhecimento na matriz hipotética de acordo com as atividades que estão sendo realizadas pelos agentes transmissor e receptor, modificando assim, o conhecimento do agente receptor.

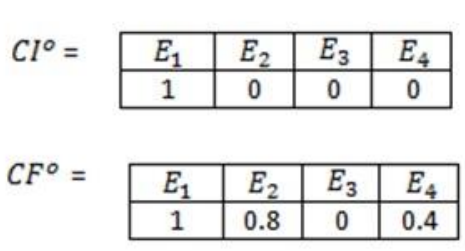

Perfil $V^{O}$
\begin{tabular}{|l|c|c|c|c|}
\hline & $E_{1}$ & $E_{2}$ & $E_{3}$ & $E_{4}$ \\
\hline BS & 0 & 2 & 0 & 0 \\
\hline IO & 0 & 0 & 0 & 2 \\
\hline L & 2 & 0 & 2 & 0 \\
\hline Soma & 2 & 2 & 2 & 2 \\
\hline
\end{tabular}

passos do simulador

Proximidade $P^{O}$
\begin{tabular}{|c|c|c|c|c|}
\hline & $E_{1}$ & $E_{2}$ & $E_{3}$ & $E_{4}$ \\
\hline$E_{1}$ & 0 & 10 & 0 & 0 \\
\hline$E_{2}$ & 10 & 0 & 0 & 5 \\
\hline$E_{3}$ & 0 & 0 & 0 & 5 \\
\hline$E_{4}$ & 0 & 5 & 5 & 0 \\
\hline soma & $10 / 30$ & $15 / 30$ & $5 / 30$ & $10 / 30$ \\
\hline
\end{tabular}

Total de observações no período $=30$

\begin{tabular}{|c|c|c|c|c|c|c|c|c|c|}
\hline \multicolumn{7}{|c|}{$\mathrm{t}=0$} & \multicolumn{5}{|c|}{$\mathrm{t}=1$} \\
\hline & $\mathrm{I}$ & $\mathrm{a}$ & $\mathrm{P}$ & $\mathrm{c}$ & & $\mathrm{I}$ & $\mathrm{a}$ & $\mathrm{P}$ & $\mathrm{c}$ \\
\hline$E_{1}$ & $\mathrm{QC}$ & $\mathrm{L}$ & $E_{2}$ & 1 & $E_{1}$ & $\mathrm{QC}$ & $\mathrm{L}$ & 0 & 1 \\
\hline$E_{2}$ & $\mathrm{QC}$ & $\mathrm{BS}$ & $E_{1}$ & 0 & $E_{2}$ & $\mathrm{QC}$ & $\mathrm{BS}$ & $E_{4}$ & 0.10 \\
\hline$E_{3}$ & $\mathrm{QC}$ & $\mathrm{L}$ & 0 & 0 & $E_{3}$ & $\mathrm{QC}$ & $\mathrm{L}$ & 0 & 0 \\
\hline$E_{4}$ & $\mathrm{QC}$ & $\mathrm{IO}$ & 0 & 0 & $E_{4}$ & $\mathrm{QC}$ & $\mathrm{IO}$ & $E_{2}$ & 0 \\
\hline
\end{tabular}

\begin{tabular}{|c|c|c|c|c|c|c|c|c|c|}
\hline \multicolumn{7}{|c|}{$\mathrm{t}=2$} & \multicolumn{5}{|c|}{$\mathrm{t}=3$} \\
\hline & $\mathrm{I}$ & $\mathrm{a}$ & $\mathrm{P}$ & $\mathrm{c}$ & & $\mathrm{I}$ & $\mathrm{a}$ & $\mathrm{P}$ & $\mathrm{c}$ \\
\hline$E_{1}$ & $\mathrm{QC}$ & $\mathrm{L}$ & 0 & 1 & $E_{1}$ & $\mathrm{QC}$ & $\mathrm{L}$ & 0 & 1 \\
\hline$E_{2}$ & $\mathrm{QC}$ & $\mathrm{BS}$ & $E_{4}$ & 0.10 & $E_{2}$ & $\mathrm{QC}$ & $\mathrm{BS}$ & $E_{4}$ & 0.10 \\
\hline$E_{3}$ & $\mathrm{QC}$ & $\mathrm{L}$ & 0 & 0 & $E_{3}$ & $\mathrm{QC}$ & $\mathrm{L}$ & 0 & 0 \\
\hline$E_{4}$ & $\mathrm{QC}$ & $\mathrm{IO}$ & $E_{2}$ & 0.03 & $E_{4}$ & $\mathrm{QC}$ & $\mathrm{IO}$ & $E_{2}$ & 0.051 \\
\hline
\end{tabular}

\begin{tabular}{|c|c|c|c|c|c|c|c|c|c|}
\hline \multicolumn{9}{|c|}{$\mathrm{t}=4$} & \multicolumn{5}{|c|}{$\mathrm{t}=5$} \\
\hline & $\mathrm{I}$ & $\mathrm{a}$ & $\mathrm{P}$ & $\mathrm{c}$ & & $\mathrm{I}$ & $\mathrm{a}$ & $\mathrm{P}$ & $\mathrm{c}$ \\
\hline$E_{1}$ & $\mathrm{QC}$ & $\mathrm{L}$ & $E_{2}$ & 1 & $E_{1}$ & $\mathrm{QC}$ & $\mathrm{L}$ & 0 & 1 \\
\hline$E_{2}$ & $\mathrm{QC}$ & $\mathrm{BS}$ & $E_{1}$ & 0.10 & $E_{2}$ & $\mathrm{QC}$ & $\mathrm{BS}$ & $E_{4}$ & 0.19 \\
\hline$E_{3}$ & $\mathrm{QC}$ & $\mathrm{L}$ & $E_{4}$ & 0 & $E_{3}$ & $\mathrm{QC}$ & $\mathrm{L}$ & 0 & 0.015 \\
\hline$E_{4}$ & $\mathrm{QC}$ & $\mathrm{IO}$ & $E_{3}$ & 0.051 & $E_{4}$ & $\mathrm{QC}$ & $\mathrm{IO}$ & $E_{2}$ & 0.092 \\
\hline
\end{tabular}

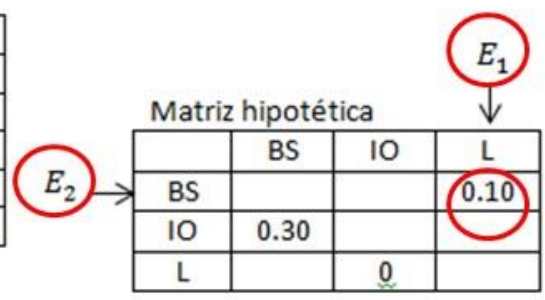

$\mathrm{L}=$ local

$\mathrm{t}=$ tempo

$\mathrm{a}=$ atividade

$P=$ parceiro Próximo

$\mathrm{c}=$ conhecimento

Figura 4.7 - A simulação

O observador virtual tratado na próxima seção (pode ser visto na Figura 4.3) tem a tarefa de ler os dados do ambiente simulado para verificar se estão de acordo com o ambiente real observado.

\subsubsection{Observação do Ambiente Simulado}

Durante a execução da simulação, algumas informações são acumuladas como se houvesse observadores captando dados do ambiente virtual (Figura 4.8). Tais informações seguem a mesma lógica das informações observadas no ambiente real e são utilizadas para regrar o ambiente virtual. Os encontros entre os agentes no ambiente virtual são anotados para compor a matriz conforme a eq.(11) dada: 


$$
P^{S} \in[0,1]
$$

A matriz de proximidade simulada $P^{S}$ armazena a proporção de encontros entre dois agentes durante a simulação, tendo $P^{O}$ como sua similar observacional. Da mesma forma são lidos do ambiente simulado os perfis simulados de cada agente seguindo a eq.(12):

$$
B_{i}^{S}=\left\{U_{i}^{S}, V_{i}^{S}\right\} \text { para } i=1, \ldots, N_{S}
$$

Onde $U_{i}^{S}$ é o perfil de atividades simuladas e $V_{i}^{S}$ é o perfil de locais simulados. Sendo assim, $B_{i}^{O}$ tem $B_{i}^{S}$ como seus similares simulados. Também, o conjunto de todos os perfis simulados é dado pela eq.(13):

$$
B^{S}=\left\{B_{i}^{S}\right\} \text { para } i=1, \ldots, N_{S}
$$

Os dados de proximidade simulada $P^{S}$ e perfis simulados $B^{S}$ são utilizados na averiguação da coerência do simulador com o modelo social que o rege (se está de acordo com o ambiente real). Esta averiguação é importante para saber o quanto as regras de coerência implementadas no simulador o desviam do ambiente real.

No ambiente simulado, as proficiências iniciais observadas $C I^{O}$ são utilizadas para configurar as condições iniciais dos agentes. Já as proficiências finais observadas $C F^{O}$, referem-se aos conhecimentos observados dos sujeitos no final do período observado. O paralelo virtual de $C F^{O}$ é representado pela eq.(14):

$$
C F^{S} \in[0,1]
$$

$C F^{S}$ pode ser obtido a qualquer instante de tempo $t$ da simulação pela eq.(15):

$$
C F_{i}^{S}=c_{i}(t) \text { para } i=1, \ldots, N_{S}
$$

onde:

$c_{i}(t)$ : é o conhecimento acumulado pelo agente $e_{i}$ no instante $t$, como descrito na eq.(7). 


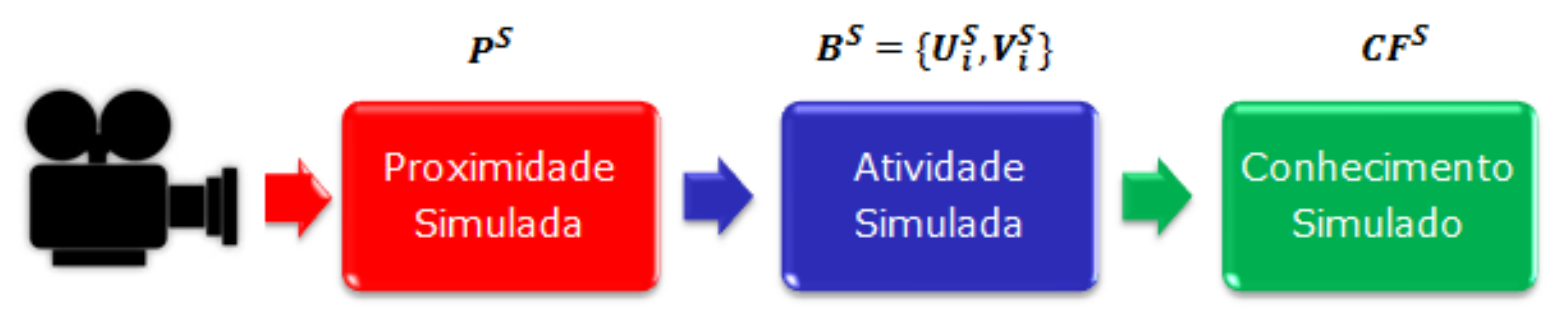

Figura $4.8-O$ observador virtual

\subsection{Exposição do Problema}

Os dados observados são utilizados para construir o modelo social $W$ que juntamente com o modelo de transmissão do conhecimento $M$ constituem a base para o comportamento da simulação no ambiente virtual. Enquanto $W$ é utilizado pelo simulador para manter a coerência da simulação com os dados observados, $M$ é utilizado para implementar o fluxo do conhecimento entre os agentes. Note que $W$ e $M$ se mantêm constantes durante toda a simulação.

As decisões do simulador para iterar o ambiente virtual utilizam probabilidades e não linearidades (regras de coerência) e, portanto, diferentes execuções geram diferentes resultados, mesmo com parâmetros e condições iniciais idênticas. Desta forma, cada execução do simulador é representada separadamente. A eq.(16) apresenta esses parâmetros.

$$
C_{r}^{M}(t)=R_{r}(M, W, t) \text { para } t=1, \ldots, N_{t}, r=1, \ldots, N_{r}
$$

onde:

$N_{t}$ : é o número de iterações para cada execução do simulador;

$N_{r}$ : é o número de vezes que o simulador é executado com os mesmos parâmetros $M$ e $W$;

$C_{r}^{M}(t) \subset[0,1]^{N_{S}}$ : são as proficiências dos agentes no instante de tempo $t$ da execução $r$ do simulador quando o modelo de transmissão $M$ é utilizado.

$O$ modelo $M$ que está sendo buscado deve ser tal que as execuções do simulador $R_{r}$ encontrem as proficiências simuladas $C_{r}^{M}(t)$ próximas às proficiências finais observadas $C F^{O}$ de forma consistente em relação às $r$ execuções do simulador. Para isso, foi utilizado o conjunto $H^{M}=\left\{H_{r}^{M}\right\}_{N_{r}}, H_{r}^{M} \in[0,1]^{N_{S}}$ contendo 
as proficiências que mais se aproximam das esperadas em cada execução, sendo a eq.(17):

$$
H_{r}^{M}=\min _{C_{r}^{M}(t)}\left\|C_{r}^{M}(t)-C F^{O}\right\|, \text { para } r=1, \ldots, N_{r}
$$

Neste ponto, tem-se o conjunto de resultados $H^{M}$ que representa os melhores resultados encontrados pelo simulador utilizando o modelo $M$. A comparação entre os elementos de $H^{M}$ e o resultado esperado $C F^{O}$ é feita por dois critérios:

O primeiro critério é a distância $\delta^{M}$ entre $C F^{O}$ e o ponto médio de $H^{M}$ :

$$
\begin{gathered}
\mu^{M}=\frac{1}{N_{r}} \sum_{r}^{N_{r}} H_{r}^{M} \\
\delta^{M}=\left\|\mu^{M}-C F^{O}\right\|
\end{gathered}
$$

Onde:

$\mu^{M} \in[0,1]^{N_{S}}$ : é o ponto médio de $H^{M}$.

O segundo critério é o desvio padrão $\sigma^{M}$ dos pontos de $H^{M}$ dada pela eq.(19):

$$
\sigma^{M}=\sqrt{\frac{1}{N_{r}}\left[\sum_{r}^{N_{r}}\left\|H_{r}^{M}-\mu^{M}\right\|^{2}\right]}
$$

A Figura 4.9 a seguir apresenta graficamente um exemplo hipotético para ilustrar estes critérios de avaliação da matriz de transmissão através das simulações. 


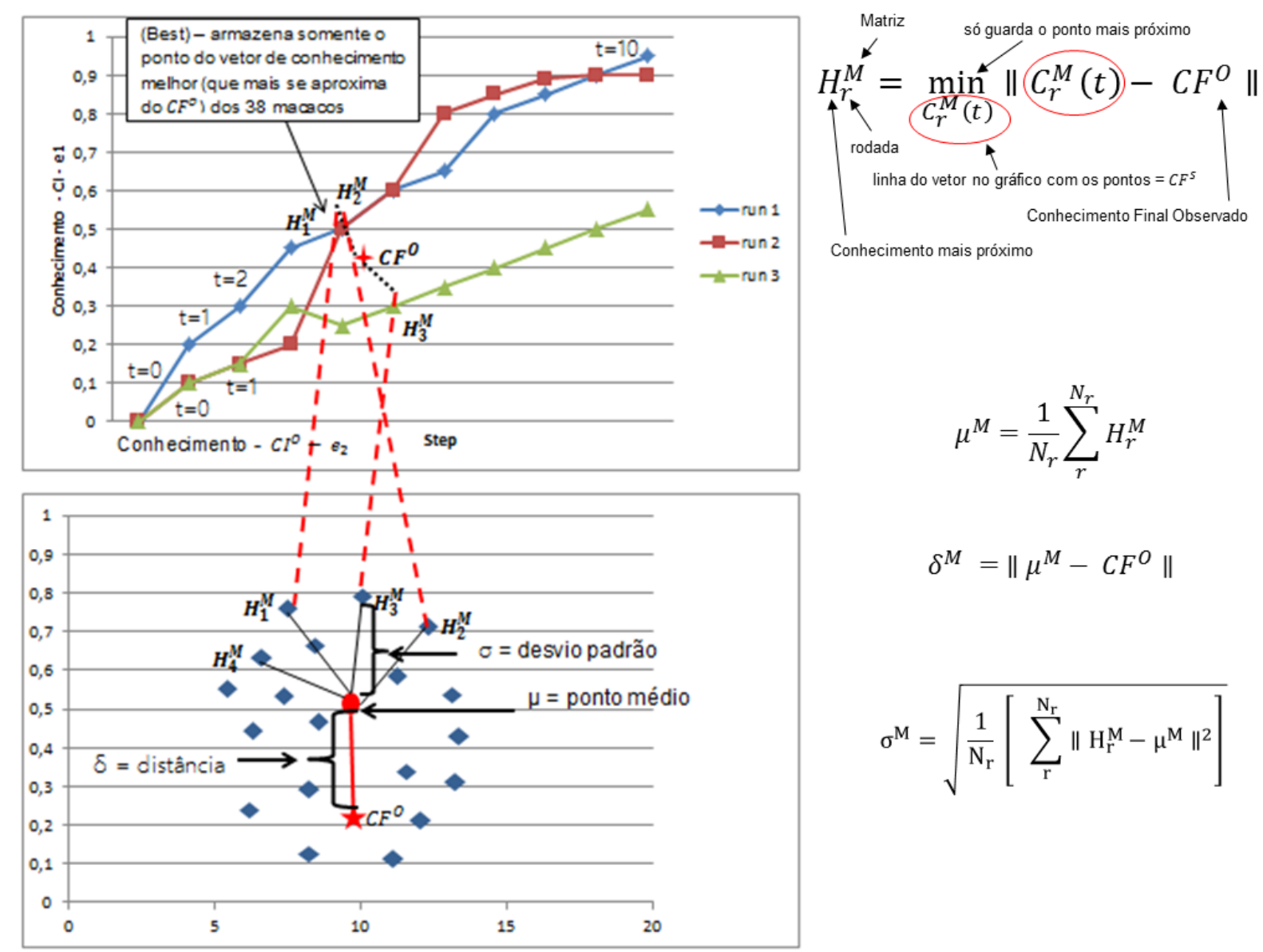

Figura 4.9 - Critérios para avaliação dos melhores resultados encontrados das simulações da matriz

Tendo estabelecido os dois critérios para a avaliação do modelo de transmissão do conhecimento, o problema que estabelece as condições para encontrar o modelo solução, Erro, é definido pela eq.(20):

$$
\operatorname{Erro}(p, M)=\min _{M}\left\{p \sigma^{M}+(1-p) \delta^{M}\right\}
$$

Onde:

$p \in[0,1]$ : é a influência do desvio padrão.

Note que a eq.(20) permite utilizar os critérios de distância e desvio padrão de forma ponderada na determinação da solução $\operatorname{Erro}(p, M)$. Quanto maior o valor de $p$ maior a exigência da convergência das diferentes execuções do simulador entre si em comparação à importância da convergência ao resultado observado.

\subsection{Resolução do Problema}

O problema de encontrar a matriz com os coeficientes para a transmissão de um conhecimento específico definido pela eq.(20) faz uso de um simulador 
computacional não determinístico no nível macroscópico o que torna difícil, se não inviável, o uso de uma abordagem analítica para sua resolução. Assim sendo, optouse pela utilização da técnica computacional de algoritmos genéticos.

Por ser uma técnica conhecida e já amplamente utilizada, não serão descritos os detalhes teóricos dos algoritmos genéticos (o capítulo 2 apresenta um resumo conceitual). Na próxima seção apresenta-se como o algoritmo foi utilizado no trabalho e também as principais decisões tomadas para a sua adaptação ao problema em questão.

\subsubsection{Algoritmo Genético}

O algoritmo genético utilizado é descrito pela Figura 4.10.

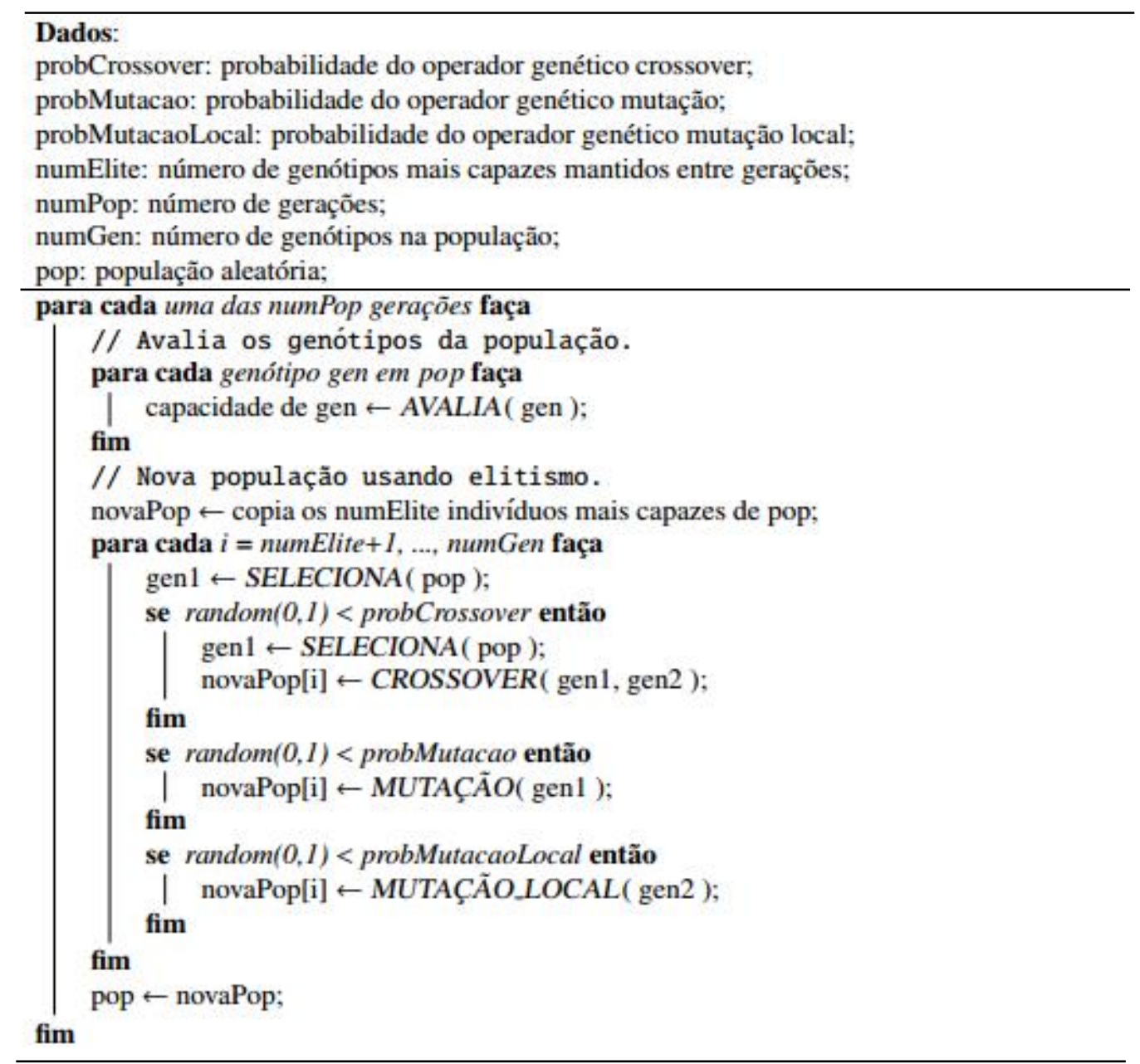

Figura 4.10 - Algoritmo Genético

A adaptação do problema ao algoritmo genético é realizada pelo procedimento avalia, descrito mais adiante. Também, os procedimentos seleciona, 
crossover, mutação e mutação local, apesar de serem comuns aos algoritmos genéticos, serão detalhados para que se perceba as decisões conceituais adotadas.

\subsubsection{Adaptação do Problema ao Algoritmo Genético}

A adaptação do problema ao AG implica em saber como a matriz $M$ é gerada a partir de um genótipo e também em como o simulador é utilizado para encontrar um valor escalar que avalie $M$ e que é utilizado pelo AG para representar a capacidade do genótipo que gerou $M$.

O genótipo é representado pelo vetor $g \in[0,1]^{N_{G}}$ com o número de genótipos $N_{G}=N_{A}^{2}$. A transposição de $g$ para o modelo de transmissão do conhecimento $M$ é realizada de forma direta na eq.(21):

$$
M_{i j}(g)=g_{K} \text {, onde } k=(i-1) N_{A}+j, \quad \forall i, j \in\left[1, N_{A}\right]
$$

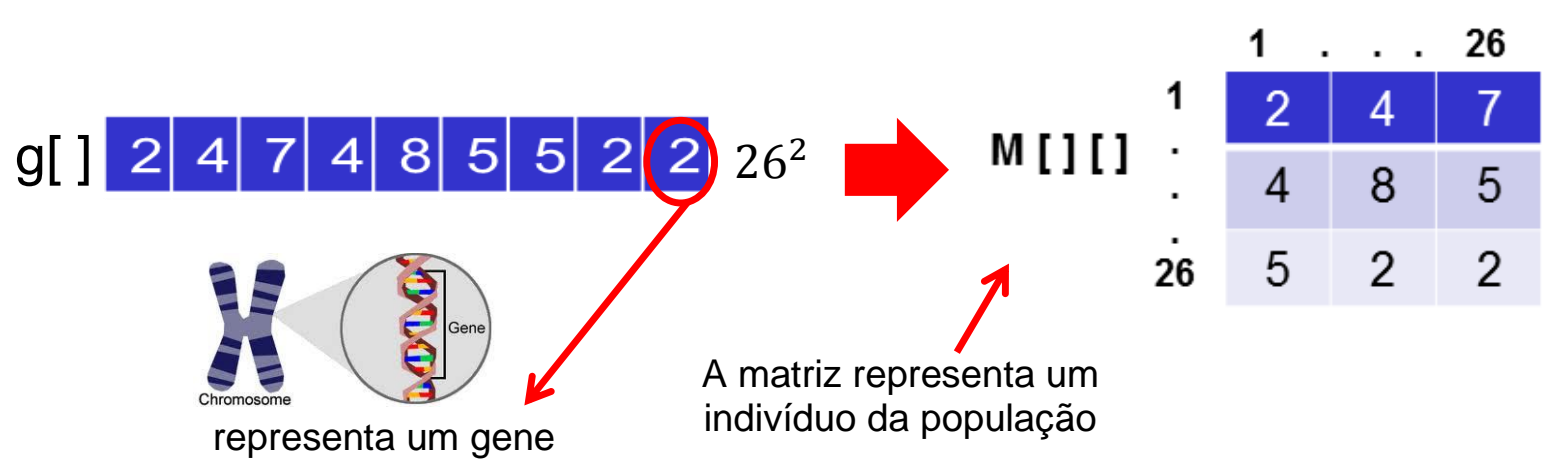

Figura 4.11 - Transposição do vetor g[ ] (genótipo) contendo as $\boldsymbol{N}_{A}$ atividades (por exemplo, 26) para a matriz M[ ] [ ] de transmissão de conhecimento

A avaliação ou fitness do desempenho do genótipo $g$ é realizada pela função de capacitação: $\operatorname{Cap}:[0,1]^{N_{G}+1} \mapsto[0,1]$. Esta função utiliza a eq.(17) para obter o erro de conformidade de $M(g)$ com os dados observados, dado pela eq.(22):

$$
\operatorname{Cap}(g, p)=2-\operatorname{Erro}(p, M(g))-\frac{1}{N_{A}^{2}} \sum M_{i j}(g)
$$

Concluindo, o algoritmo para implementação do procedimento de avaliação de um genótipo pode ser visto na Figura 4.10, avalia, que é implementado pela eq.(22) fixando-se um valor para o peso do desvio padrão $p$. A Figura 4.12 resume 
os critérios de ponderação utilizados para a avaliação (fitness) da matriz de transmissão de conhecimento para verificar o menor erro encontrado.

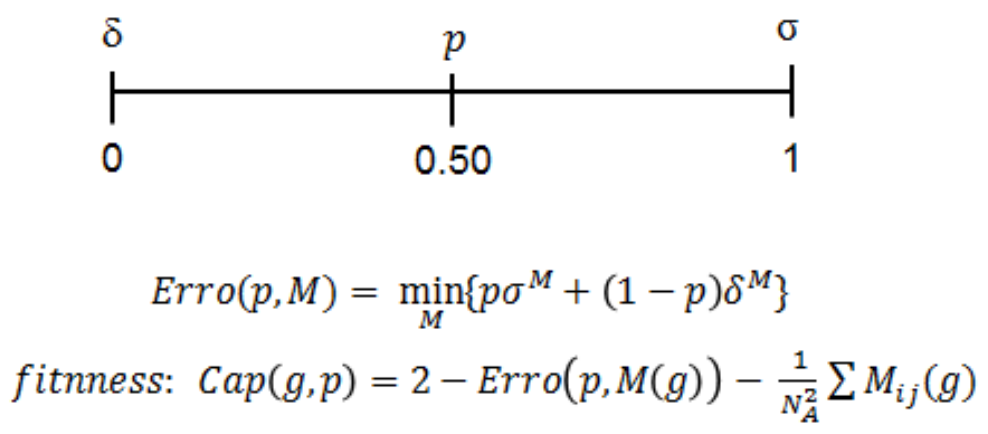

Figura 4.12 - Ponderação dos critérios de avaliação para encontrar o menor erro

\subsubsection{Operadores Genéticos}

Antes da descrição dos operadores genéticos é importante ressaltar que eles utilizam a função $r: \mathbb{R}^{2} \mapsto \mathbb{R}$ para representar a geração de números aleatórios com distribuição uniforme. Garante-se que $x \in[a, b)$ para qualquer $x=r(a, b)$. Note que $r(a, b)$ resulta em um valor diferente a cada vez que é referenciada.

- Seleciona: este procedimento é responsável por selecionar um genótipo dentre um conjunto de genótipos (população) com probabilidades proporcionais às suas capacidades (Figura 4.13). Sejam $P=\left\{g_{i}\right\}_{N_{P}}$, o conjunto de genótipos $g_{i} \in \mathbb{R}^{N_{G}}$ da população de tamanho $N_{P}$ e $f: \mathbb{R}^{N_{G}} \mapsto \mathbb{R}$ a função que indica a capacitação dos genótipos. Primeiro calcula-se o vetor $q \in \mathbb{R}^{N_{G}}$ com os intervalos de pertinência, utilizando:

$$
q_{i}=0, q_{i+1}=q_{i}+f\left(g_{i}\right), \text { para } i=1, \ldots, N_{P}
$$

então escolhe-se o valor aleatório $r_{x}=r\left(0, q_{N_{P}+1}\right)$ que é utilizado para selecionar o genótipo $s \in g$ conforme eq.(23):

$$
s=g_{i} \text {, onde } i \text { é tal que } q_{i}<r_{x}<q_{i+1}
$$




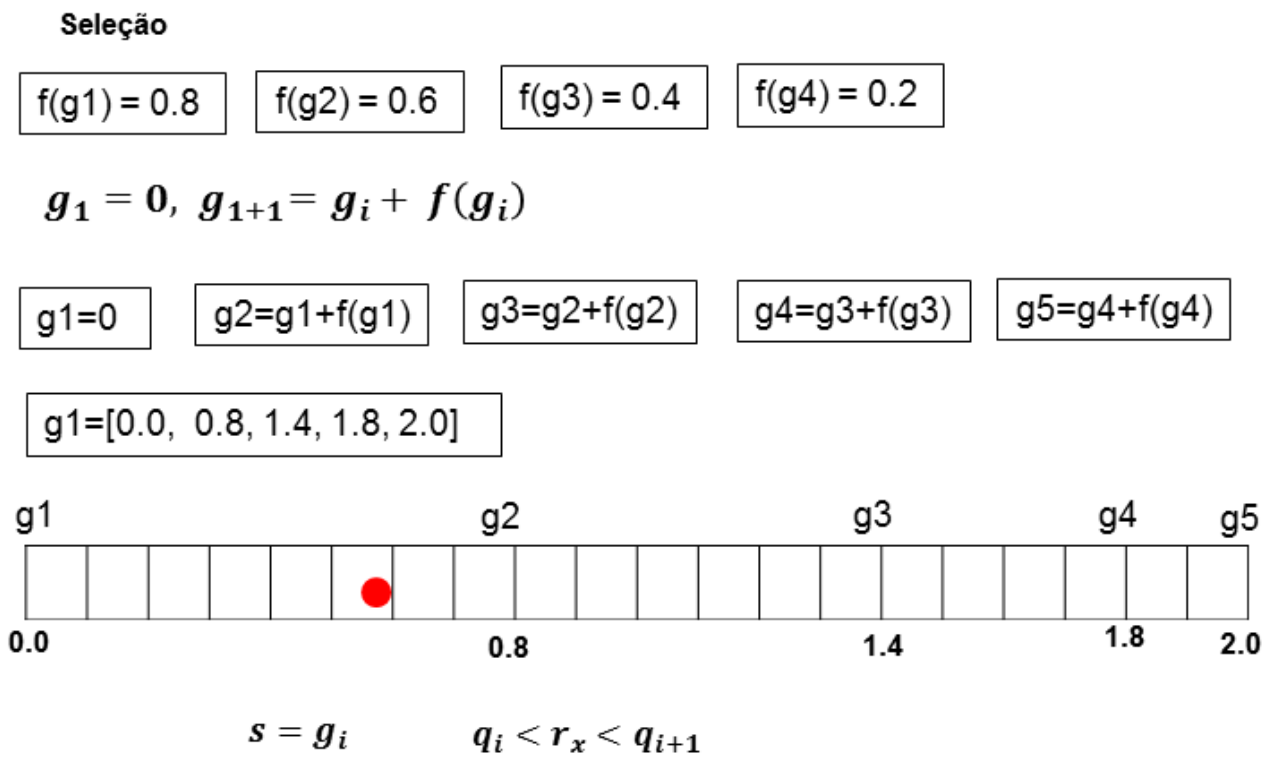

Função de Fitness

Probabilidade em cima da capacitação do genótipo a ser escolhido

Figura 4.13 - Exemplo do procedimento de seleção

- crossover: este operador genético é responsável por gerar um genótipo resultante da mistura de dois outros (Figura 4.14). No procedimento crossover adotado foi utilizado o crossover uniforme. Sejam os genótipos $u, w \in \mathbb{R}^{m}$, o genótipo $g \in \mathbb{R}^{N_{G}}$ resultante da aplicação do operador crossover é dado pela eq.(24):

$$
g_{i}=\left\{\begin{array}{l}
u_{i}, \text { se } r(-1,+1)<0 \\
w_{i}, \text { caso contrário }
\end{array} \text {, para } i=1, \ldots, N_{G}\right.
$$

A Figura 4.14 ilustra o funcionamento deste procedimento. O vetor $\mathrm{r}[\mathrm{]}$ foi gerado aleatoriamente com o propósito de servir para a escolha dos elementos que irão compor o vetor final. Caso o elemento de $r[$ ] seja negativo, então o elemento correspondente de u[ ] é copiado para g[ ], caso seja positivo, então o elemento correspondente de w[ ] é aquele copiado para g[ ]. 


\section{Crossover}

$\mathbf{u}$

$\begin{array}{llllllllllll}0.8 & 0.6 & 0.4 & 0.2 & 0.1 & 0.7 & 0.2 & 0.3\end{array}$

w

$\begin{array}{llllllllllll}0.3 & 0.5 & 0.7 & 0.3 & 0.9 & 0.1 & 0.1 & 0.8\end{array}$

$(-0.2) 0.40 .30 .(-0.5)(-0.8) 0.4(-0.2)$

$\begin{array}{llllllllll}0 & 0.8 & 0.5 & 0.7 & 0.3 & 0.1 & 0.7 & 0.1 & 0.3\end{array}$

Figura 4.14 - Exemplo do procedimento de crossover

- mutação: este operador genético é responsável por gerar o genótipo resultante da mutação de um ou mais genes do genótipo original (Figura 4.15). Sejam o genótipo $u \in \mathbb{R}^{N_{G}}$ e a probabilidade de mutação de um gene em específico, $p_{g} \in[0,1]$, então 0 genótipo $g \in \mathbb{R}^{N_{G}}$ resultante da aplicação da mutação dada pela eq.(25):

$$
g_{i}=\left\{\begin{array}{l}
g_{i}, \text { se } r(0,1)<p_{g} \\
r(0,1), \text { caso contrário }
\end{array}, \text { para } i=1, \ldots, N_{G}\right.
$$

- mutação local: este operador genético é responsável por gerar o genótipo resultante da mutação local de um ou mais genes do genótipo original (Figura 4.15). Enquanto a mutação simples produz novos genes utilizando todo o domínio do gene, no caso o intervalo [0,1], a mutação local produz mutações restritas a um intervalo em torno do valor atual do gene modificado. Sejam o genótipo $u \in \mathbb{R}^{N_{G}}$, a probabilidade de mutação de um gene em específico $p_{g} \in[0,1]$, e 0 tamanho do intervalo $s \in[0,1]$. Então o genótipo resultante da aplicação da mutação local, $g \in \mathbb{R}^{N_{G}}$ é dada pela eq.(26):

$$
g_{i}=\left\{\begin{array}{ll}
g_{i} & , \text { se } r(0,1)<p_{g} \\
r\left(\max \left\{0, g_{i}-s\right\}, \min \left\{1, g_{i}+s\right\}\right), \text { caso contrário }
\end{array}, \text { para } i=1, \ldots, N_{G}\right.
$$


Mutação

$\begin{array}{lllllllll}u & 0.1 & 0.7 & 0.2 & 0.4 & 0.5 & 0.2 & 0.3 & 0.9\end{array}$

$\begin{array}{lllllllll}\text { r } & 0.01 & 0.2 & 0.5 & 0.02 & 0.9 & 0.8 & 0.5 & 0.02\end{array}$

g $\quad$\begin{tabular}{llllllll}
\hline & 0.7 & 0.2 & $\mathrm{x}$ & 0.5 & 0.2 & 0.3 & $\mathrm{x}$
\end{tabular}

Mutação Normal

g $\begin{array}{llllllllll}0.1 & 0.7 & 0.2 & 0.6 & 0.5 & 0.2 & 0.3 & 0.34\end{array}$

Mutação Local

g $\begin{array}{llllllllll}0.15 & 0.7 & 0.2 & 0.35 & 0.5 & 0.2 & 0.3 & 0.87\end{array}$ $\mathrm{pg}=1 / 8=0,125$

$$
g_{j}=\left\{\begin{array}{l}
g_{i}, \text { se } r(0,1)<p_{g} \\
r(0,1), \text { caso contrário }
\end{array}\right.
$$

Gera um número aleatório e verifica se é menor que pg, se for gera um novo valor para g[ ] aleatório, caso contrário, copia do u[ ].

Gera um número aleatório entre 0 e 1.

Gera um número aleatório entre um intervalo de número, por exemplo, $g \in[0.3,0.5]$

$g_{j}= \begin{cases}g_{j} & \text {, se } r(0,1)<p_{g} \\ r\left(\max \left\{0, g_{j}-s\right\}, \min \left\{1, g_{j}+s\right\}\right), \text { caso contrário }\end{cases}$

Figura 4.15 - Exemplo do procedimento de mutação 


\section{IMPLEMENTAÇÃO DA PLATAFORMA COMPUTACIONAL (SOFTWARE HORÁCIO)}

Este capítulo mostra uma visão geral do modelo computacional utilizado para implementar os conceitos expostos no capítulo 4.

\subsection{Módulos}

O diagrama da Figura 5.1 apresenta os módulos que compõe a plataforma construída a partir do modelo e ambiente desenvolvido no capítulo anterior. As setas indicam as relações de dependência entre os módulos implicando que o módulo origem conhece o módulo destino e, portanto, depende dele.

Cada um dos 5 módulos utilizados possui uma responsabilidade específica no sistema descritas a seguir:

- model: este módulo armazena todos os dados necessários para realizar as simulações do sistema. Estes dados compreendem tanto os dados observados $\left(P^{O}, B^{O}, C I^{O}\right.$ e $\left.C F^{O}\right)$, quanto o modelo de transmissão de conhecimento a ser testado $(M)$;

- observation: é responsável por ler os dados observados da base externa que os contém. No caso desta implementação, os dados são lidos de arquivos do tipo .CSV ${ }^{8}$ gerados a partir de planilhas eletrônicas. Este módulo traduz os dados lidos da base de dados, construindo objetos instânciados de classes definidas no módulo model;

- simulator: módulo responsável por criar o ambiente e os agentes virtuais. Também gerencia as execuções das simulações no ambiente mantendo a coerência com os dados observados e utilizando o modelo de transmissão do conhecimento $M$ para estabelecer o fluxo do conhecimento entre os agentes. O módulo também é responsável por avaliar os resultados associados ao desempenho de $M$ e por permitir o uso de $M$ como um indivíduo pelo algoritmo genético.

- ga: este módulo implementa o algoritmo genético utilizado para encontrar o modelo de transmissão do conhecimento $M$ que mais se adeque às condições estabelecidas pelos dados observados.

\footnotetext{
${ }^{8}$ Formato de extensão de arquivo Comma Separated Values.
} 
- gui: implementa a interface gráfica do sistema (Graphic User Interface). Note que o sistema não possui natureza interativa e, portanto, este módulo é utilizado apenas para visualizar alguns resultados e desempenhos intermediários.

Nos próximos itens os componentes (classes) de cada módulo apresentado anteriormente serão apresentados com mais detalhes, ressaltando algumas decisões de implementação que foram tomadas.

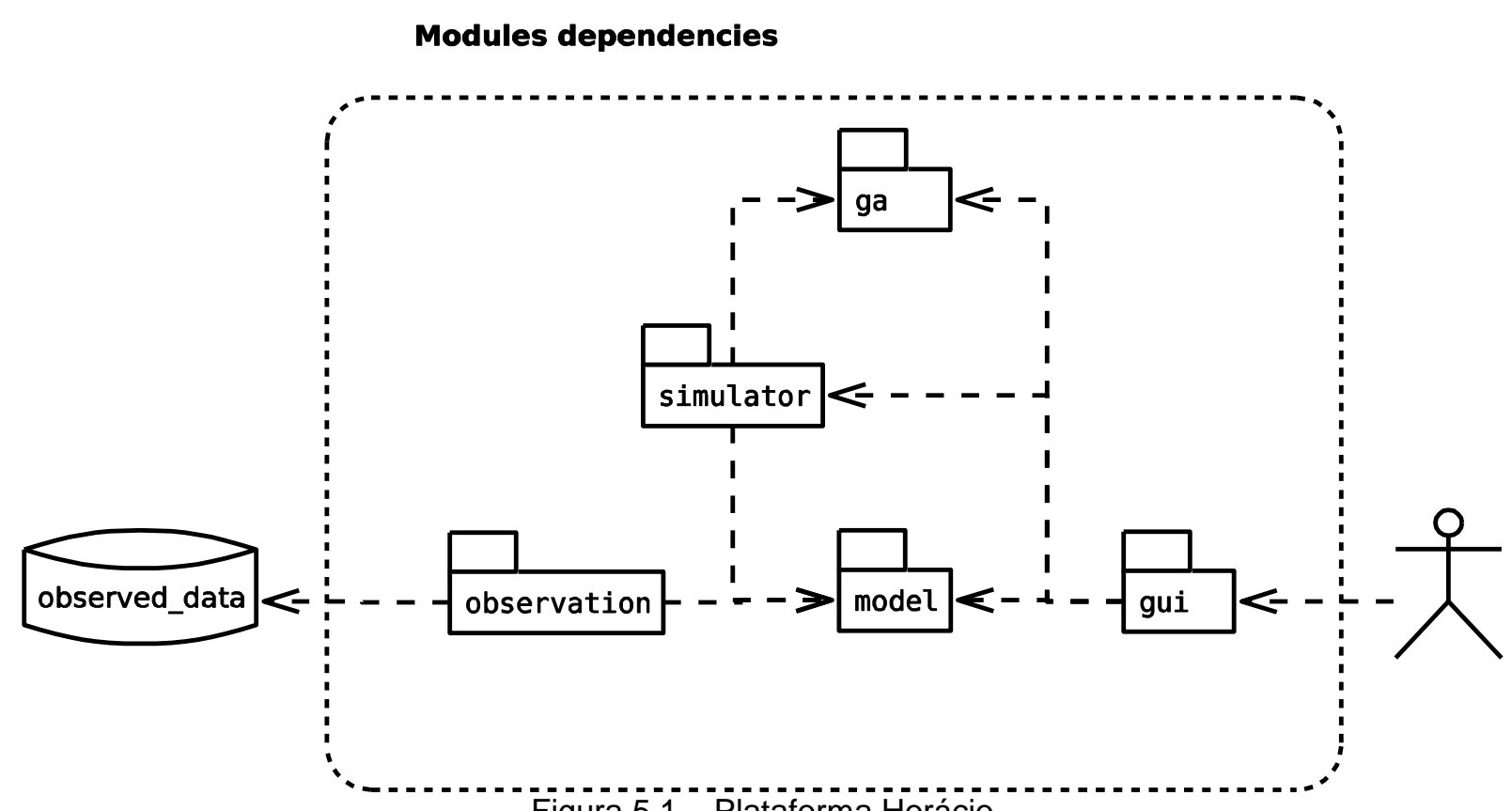

Figura 5.1- Plataforma Horácio

\subsection{Módulo model}

Este módulo contém as classes necessárias para armazenar de forma estruturada os dados observados $\left(P^{O}, B^{O}, C I^{O}\right.$ e $\left.C F^{O}\right)$ e o modelo de transmissão do conhecimento $(M)$ que são agrupados pela classe SocialModel, como mostra a Figura 5.2. Note que a classe ProximityMatrix representa $P^{O}$, SkillSet representa $B^{O}$, ObservedKnowledge representa $C I^{O}$ e $C F^{O}$, e que KnowledgeFlow representa $M$.

Para que o módulo possa desempenhar seu papel, as seguintes responsabilidades internas foram estabelecidas:

- Armazenar o cadastro dos sujeitos $(S)$, atividades $(A)$ e locais $(L)$ que podem ser utilizados pelo sistema, representados pelas classes SubjectSet, BehaviourSet e SubstrateSet respectivamente. Estas classes também permitem as traduções entre os identificadores e os 
nomes dos elementos, funcionalidade necessária para a leitura dos dados observados provenientes da base de dados externa.

- Definir quais atividades serão realmente utilizadas pelo sistema. Esta funcionalidade é necessária para que o sistema possa ignorar atividades observadas que estão na base de dados externa, mas que não interessam ao sistema. A classe AbilityModel desempenha este papel.

- Averiguar a integridade dos dados observados com relação aos sujeitos, atividades e locais. Como a base de dados externa é composta por diferentes arquivos, há a possibilidade de certos elementos não estarem presentes em um ou mais arquivos. Por exemplo, os dados de proximidade podem fazer referência a um sujeito que não esteja presente nos dados relativos às atividades. Esta funcionalidade é implementada pela classe SocialModel fazendo uso da interface Sociallnformation que é implementada pelas classes ObservedKnowledge, ProximityMatrix e SkillSet.

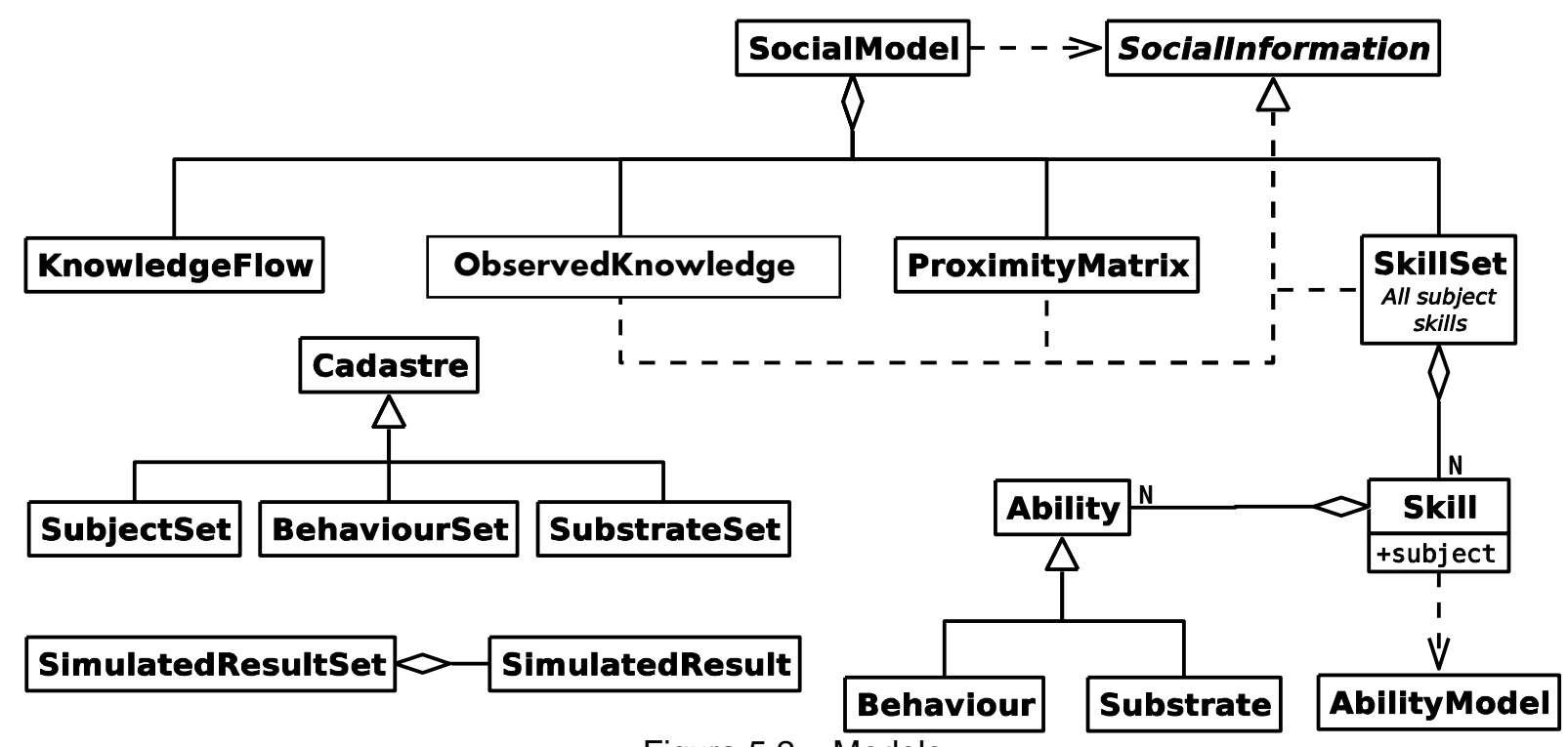

Figura 5.2 - Modelo

\subsection{Módulo de Observação}

Este módulo é responsável pela criação dos objetos computacionais utilizados pelo sistema para representar os dados observados cujas informações estão armazenadas em uma base externa, como mostra o diagrama da Figura 5.3. 
O módulo trata da criação dos objetos computacionais associados às seguintes classes do módulo model:

- ProximityMatrix $\left(P^{0}\right)$ : para gerar os dados da matriz de proximidade é lido um arquivo contendo observações em momentos pontuais que indicam se dois sujeitos foram vistos próximos. Para cada sujeito são somados todos os instantes onde foi observada a proximidade independentemente do momento da observação, ou seja, a informação sobre o tempo é descartada a favor do estabelecimento da frequência de encontros ocorridos durante o período de observação.

- SkillSet $\left(\boldsymbol{B}^{\boldsymbol{O}}\right)$ : Assim como para a matriz de proximidade, o object SkillSet que armazena o perfil individual de cada sujeito é gerado a partir da soma das atividades e localidades observadas sem considerar os instantes temporais. O objetivo é encontrar a frequência com que os sujeitos realizam cada atividade e a frequência com que frequentam os locais considerados.

- ObervedResult $\left(\boldsymbol{C I}^{\boldsymbol{O}}, \boldsymbol{C F}^{\boldsymbol{O}}\right)$ : A geração dos objetos que representam as proficiências iniciais e proficiências finais sobre $o$ conhecimento específico considerado (quebra de coco) por serem menos volumosos e também mais abstratos, não são lidos da base de dados externa, mas sim embutidos no próprio código. A classe ObservedResultFactory foi concebida para que estes dados possam, futuramente, também ser lidos da base de dados ou estipulados pelo usuário através da interface do sistema. 


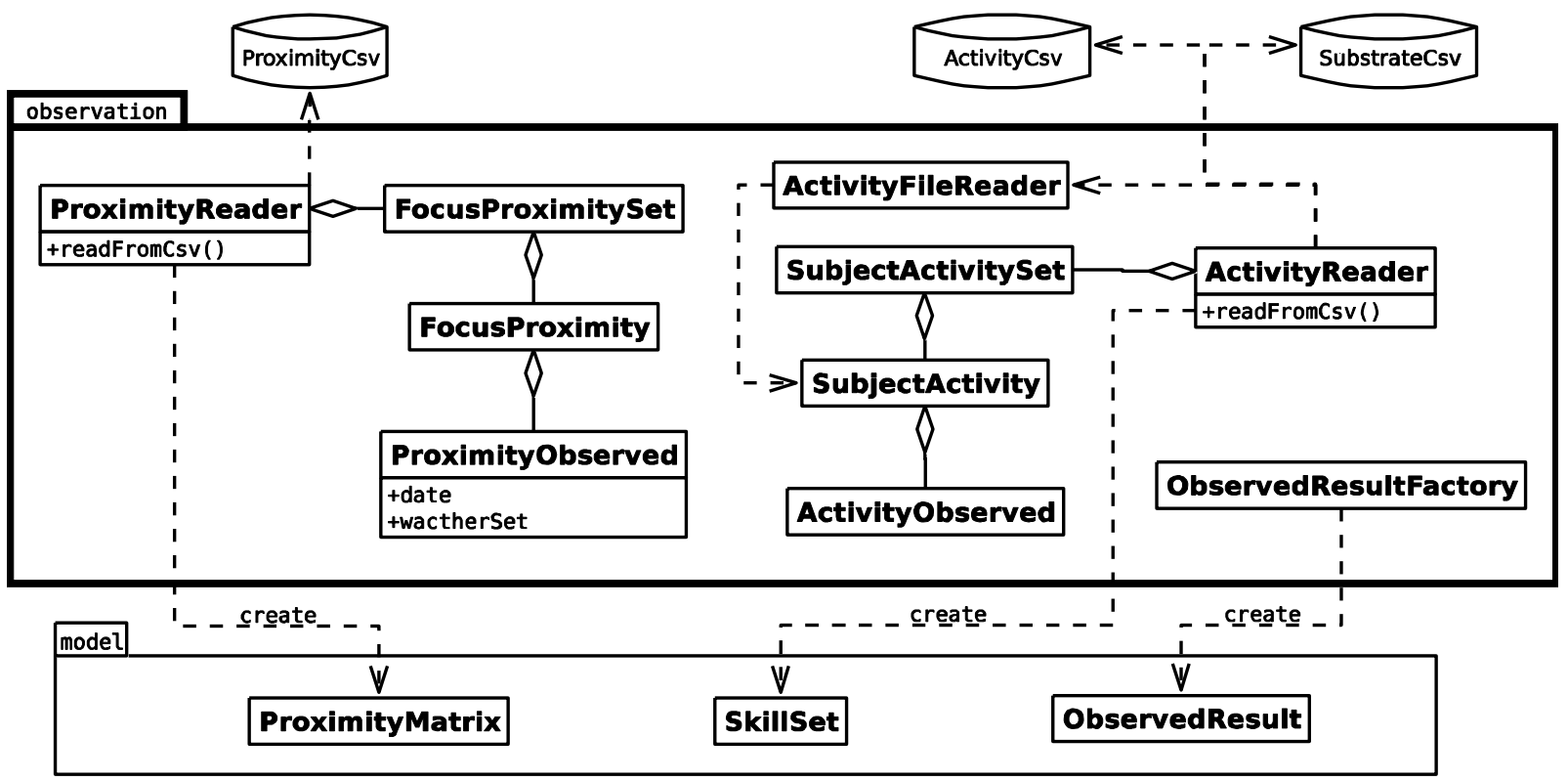

Figura 5.3 - Observação

\subsection{Módulo do Simulador}

O módulo Simulator (Figura 5.4) é responsável pela simulação e tem como base os seguintes conceitos: o simulador (Simulator), 0 ambiente virtual (Environment) e a sociedade de agentes (AgentSet), como mostrado no diagrama da Figura 5.4:

- Simulador: a classe Simulator recebe um objeto que define o modelo social (SocialModel) com as informações suficientes para gerar a simulação. Usando o modelo social, o simulador cria o ambiente virtual. Uma outra responsabilidade desta classe é permitir que os modelos de transmissão do conhecimento que representam os genótipos no algoritmo genético sejam avaliados, motivo pelo qual a classe Simulator implementa a interface GaEnvironment.

- Ambiente: é responsável por criar a sociedade de agentes e configurar suas condições iniciais: perfis $\left(B_{i}^{O}\right)$ e o conhecimento inicial $\left(C I_{i}^{O}\right)$. Também implementa a iteração do ambiente considerando os encontros dos agentes, regrados pela matriz de proximidade $P^{O}$, e os fluxos do conhecimento, regrados pelo modelo de transmissão $M$. $O$ ambiente também é responsável por implementar as regras de coerência que impedem situações proibitivas de combinações de proximidade, atividades e locais que o sistema possa gerar. 
- Sociedade de agentes: representa o conjunto de agentes situados no ambiente virtual. Determina a sequência na qual os agentes agem, implementada de forma aleatória.

- Agente: Para encontrar o estado dos agentes no próximo instante de tempo, o ambiente pede a cada agente uma sugestão do estado no qual ele deseja estar. A coerência da atividade e o local sugerido pelo agente é verificada pelo ambiente para que ele possa encontrar um parceiro que esteja disponível para realizar a atividade sugerida. No caso da atividade necessitar de um parceiro, o ambiente pode pedir que o agente faça outra sugestão, nos casos em que a sugestão avaliada não possa ser realizada.

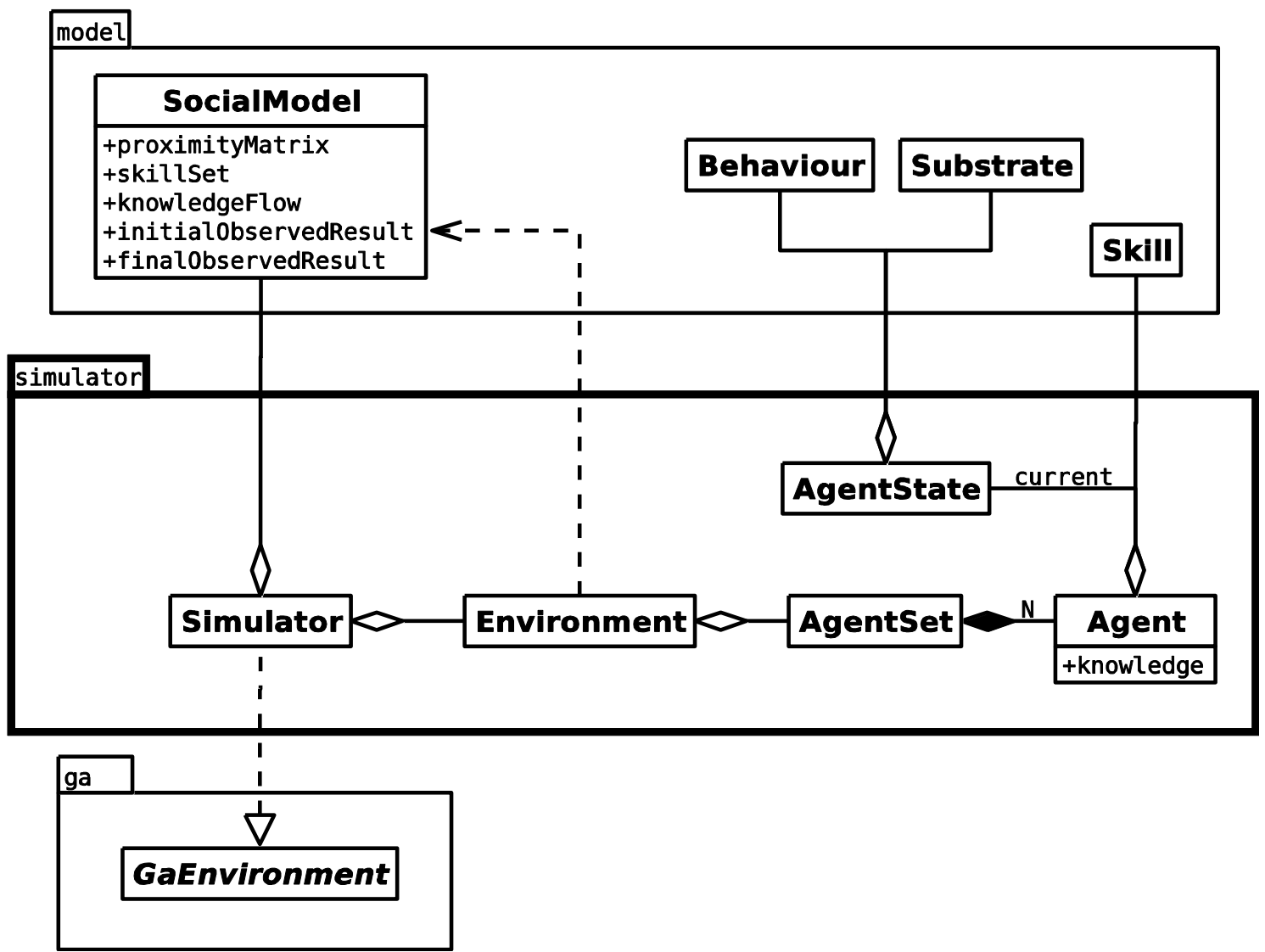

Figura 5.4 - Simulador

\subsection{Módulo do Algoritmo Genético}

Este módulo implementa uma versão básica de algoritmo genético utilizada pelo sistema para estimar um modelo de transmissão do conhecimento, tendo como 
referência sua coerência com os dados observados, segundo o simulador implementado (Figura 5.5).

Note que este módulo não depende dos outros módulos do sistema e que tanto a transposição dos genótipos para os fenótipos (matriz de transmissão $M$ ) quanto a avaliação (GaEnvironment.express()) são criados de forma a não necessitarem que este módulo conheça quem as implementa. Assim sendo, o entendimento da funcionalidade interna deste módulo segue o conteúdo descrito na seção 4.5. Resolução do problema.

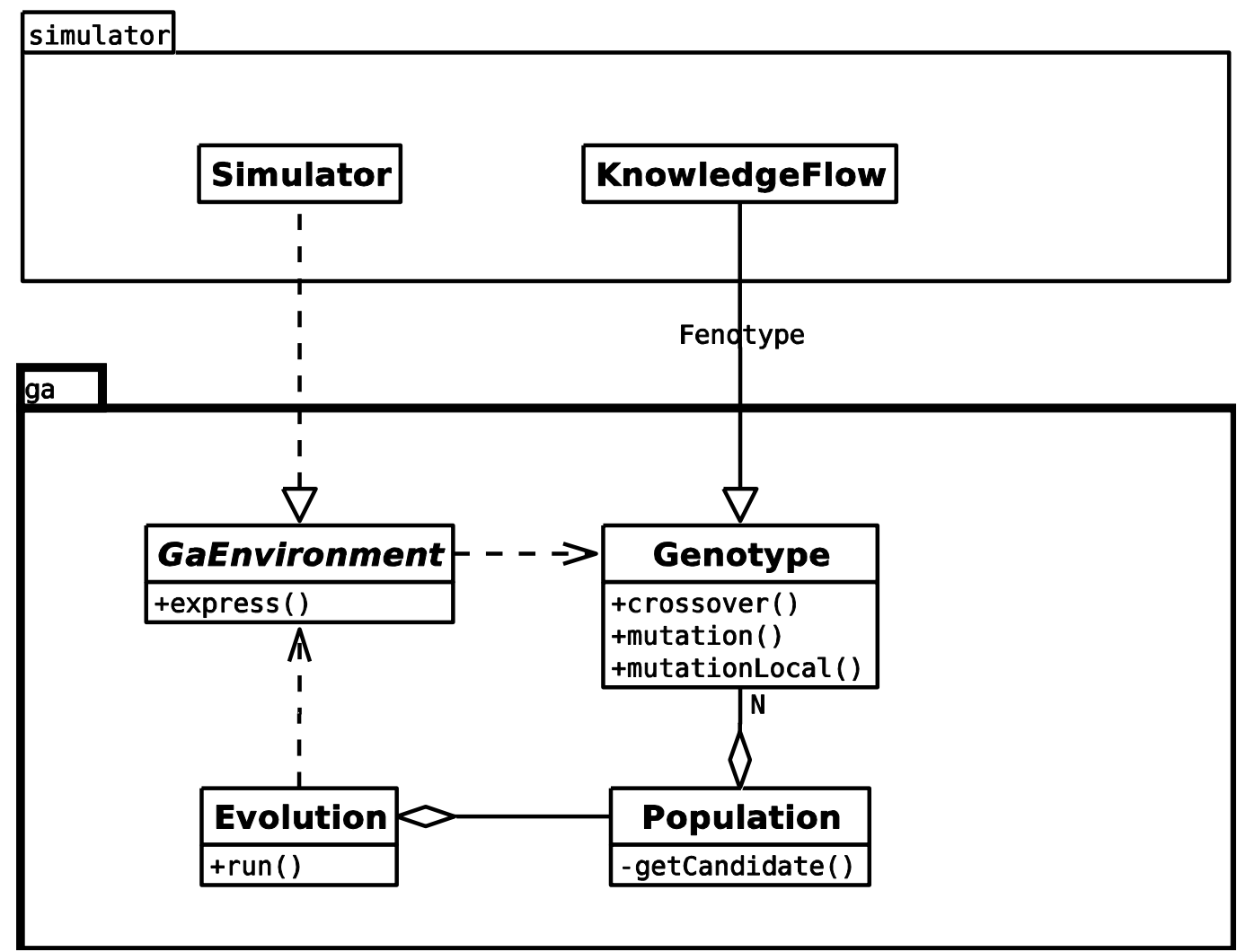

Figura 5.5 - Algoritmo Genético 


\section{ANÁLISE DOS RESULTADOS}

Foram utilizados, como referência para a simulação, dados observados provenientes de um projeto de pesquisa do Laboratório de Etologia Cognitiva do IPUSP. Esses dados estão relacionados às atividades realizadas diariamente pelos macacos prego do PET (arquivos: "agm_1m_quebra1.xls" e "agm_10m_quebra1.xIs"). Também foram utilizados os dados de proximidade relacionados à planilha (arquivo: "focais_periodo_quebra1m.xls" e "focais_periodo_quebra10m.xls"). O período dos dados utilizados é de 2 de dezembro de 2011 a 5 de abril de 2012.

Os macacos prego que fazem parte do experimento estão listados na Tabela A.1 do Anexo A, as atividades na Tabela A.2 do Anexo A e os locais na Tabela A.3 do Anexo A.

Uma descrição mais detalhada de algumas atividades relacionadas à quebra de cocos, chamadas de atividades específicas, podem ser vistas na Tabela A.6. A Tabela A.4 apresenta uma descrição mais detalhada das atividades chamadas de periféricas.

Inicialmente será apresentada uma situação hipotética com os dados observados gerados pelo simulado para um melhor entendimento dos dados e do procedimento de simulação. Em seguida, será mostrada uma situação utilizando os dados reais observados, mas intermediária, com poucas atividades e poucos sujeitos, sendo assim, também passa a ser hipotética. E finalmente será apresentada a situação gerada pelo simulador com todos os dados observados. O computador utilizado para os testes foi um notebook da Asus com processador Intel i3 -236m, CPU $1.40 \mathrm{GHz}, 2.00$ de memória e sistema operacional Windows 8.1 Pro de 64 bits. A linguagem de programação utilizada para desenvolvimento da plataforma Horácio e Cuzco foi Java e o ambiente de programação foi o NetBeans. O software Cuzco utilizou o banco de dados MySql e ambiente de desenvolvimento Workbench. Todos os softwares utilizados para o desenvolvimento são gratuitos. 


\subsection{Primeiro Experimento: hipotético}

O primeiro experimento hipotético procurou ser o mais simples possível para testar a plataforma Horácio e explicar o funcionamento do modelo proposto para validar a ferramenta. Foram utilizados 4 agentes e 3 atividades.

Os parâmetros utilizados para o experimento foram: 200 passos (intervalo de simulação), número de rodadas: 20 (número de vezes que o simulador vai rodar o experimento), número de genótipos: 40 (indivíduos de cada população), número de gerações: 1.000 (populações), peso do desvio padrão: 0.600000, escala: 0.10, menor erro encontrado para cada rodada: 0,001677, fitness: 1,960530 (melhor indivíduo de cada população), o desvio padrão ficou em: 0,009072, a média em: 0,034226, e o tempo de execução do experimento durou: 0:5:24.716. Todos esses dados podem ser vistos na listagem do experimento gerado pelo simulador no Apêndice B com mais detalhes, na Listagem B.1.1.

A simulação utiliza os agentes $\left(e_{1}, e_{2}, e_{3}, e_{4}\right)$ (Figura 6.1) com os

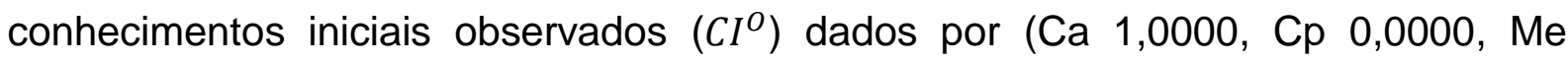
0,0000, Ml 0,0000), respectivamente e conhecimentos finais observados $\left(C F^{O}\right)$ dados por (Ca 1,0000, Cp 0,8000, Me 0,0000, Ml 0,4000). A matriz de atividades (U) é dada por (BS, IO, L) e os perfis $(\mathrm{V})$ de cada agente dados por $V_{1}(0.0,0.0,1.0), V_{2}$ $(1.0,0.0,0.0), V_{3}(0.0,0.0,1.0)$ e finalmente $V_{4}(0.0,1.0,0.0)$.

Na Figura 6.1 é apresentada a situação simulada. Note que pela matriz de proximidade, $e_{1}$ só se encontra com $e_{2} ; e_{2}$ se encontra com $e_{1}$ e $e_{4} ; e_{4}$ se encontra com $e_{2}$ e $e_{3}$; e $e_{3}$ só se encontra com $e_{4}$. Note também que $e_{1}$ só realiza a atividade $\mathrm{L}, e_{2}$ só realiza a atividade $\mathrm{BS}, e_{3}$ só realiza $\mathrm{L}$, e $e_{4}$ só realiza IO. Como no início da simulação apenas $e_{1}$ possui o conhecimento e ele só se encontra com $e_{2}$, neste possível encontro, $e_{1}$ só pode estar realizando $\mathrm{L}$ e $e_{2}$ só pode estar realizando $\mathrm{BS}$. Sendo assim, o coeficiente de transmissão de conhecimento de BS para $L$ deve ser significativo (deve permitir que $e_{2}$ obtenha 0.123 do coeficiente de conhecimento de $\left.e_{1}\right)$. Seguindo o mesmo raciocínio, entre a relação de $e_{2}$ e $e_{4}$, tem-se que o coeficiente de $e_{1}$ passado para $e_{2}$, também é transmitido para o $e_{4}$ obtendo 0.185 de conhecimento do $e_{2}$. Finalmente, a relação entre $e_{4}$ e $e_{3}$ mostra que o coeficiente de transmissão de 10 para $L$ não transmite nada para $e_{3}$ de conhecimento (conhecimento final: 0.000 ) e, portanto deve ser nulo. A Tabela 6.1 mostra o local 
onde estão os coeficientes que influenciam na transmissão do conhecimento para este experimento hipotético e a Tabela 6.2 mostra os coeficientes de transmissão encontrados pelo algoritmo genético.

O experimento testado na plataforma Horácio através de várias simulações mostra que o algoritmo genético convergiu para encontrar a matriz de transmissão de conhecimento e a simulação encontrou a melhor matriz (o melhor individuo de uma população) quando atingiu o conhecimento $C F^{S}$ próximo ao $C F^{O}$. Isso já era esperado, pois o simulador foi construído para isso, ou seja, para dados coerentes de entrada e saída o simulador deve encontrar uma matriz que leve de um ao outro. A validação é feita pela convergência dos dados simulados para os reais. O tempo de execução foi o necessário para que se observasse tal convergência. Este dado (conhecimento final observado) foi fornecido pelos pesquisadores do LEC do IPUSP.

A proposta da tese é verificar se o modelo proposto permite tal convergência, ou seja, se a simulação leva ao encontro do conhecimento final observado. E neste caso, apresentar quais são os coeficientes (encontrados pelo algoritmo genético) da matriz de transmissão de conhecimento que ressaltam as atividades periféricas que podem influenciar na troca de conhecimento de uma atividade específica (quebra de cocos, neste caso).

Depois de encontrados esses coeficientes da matriz de transmissão da Tabela 6.2, é aplicada a equação do modelo de transmissão de conhecimento para quantificar o conhecimento dos agentes. Sendo assim, foi encontrada a melhor matriz de transmissão de conhecimento (pelo algoritmo genético) através dos testes efetuados pelas simulações, para ser utilizado na equação do modelo de transmissão de conhecimento proposto para validar a plataforma Horácio.

A primeira situação hipotética apresentada pode validar a plataforma proposta, o que foi confirmado pelo experimento. A ferramenta consegue propor um cenário condizente com os dados observados e apresenta uma forma de como um certo conhecimento pode ter sua transmissão auxiliada por atividades (periféricas) que aparentemente não tem relação alguma com o conhecimento específico (quebra de cocos). 


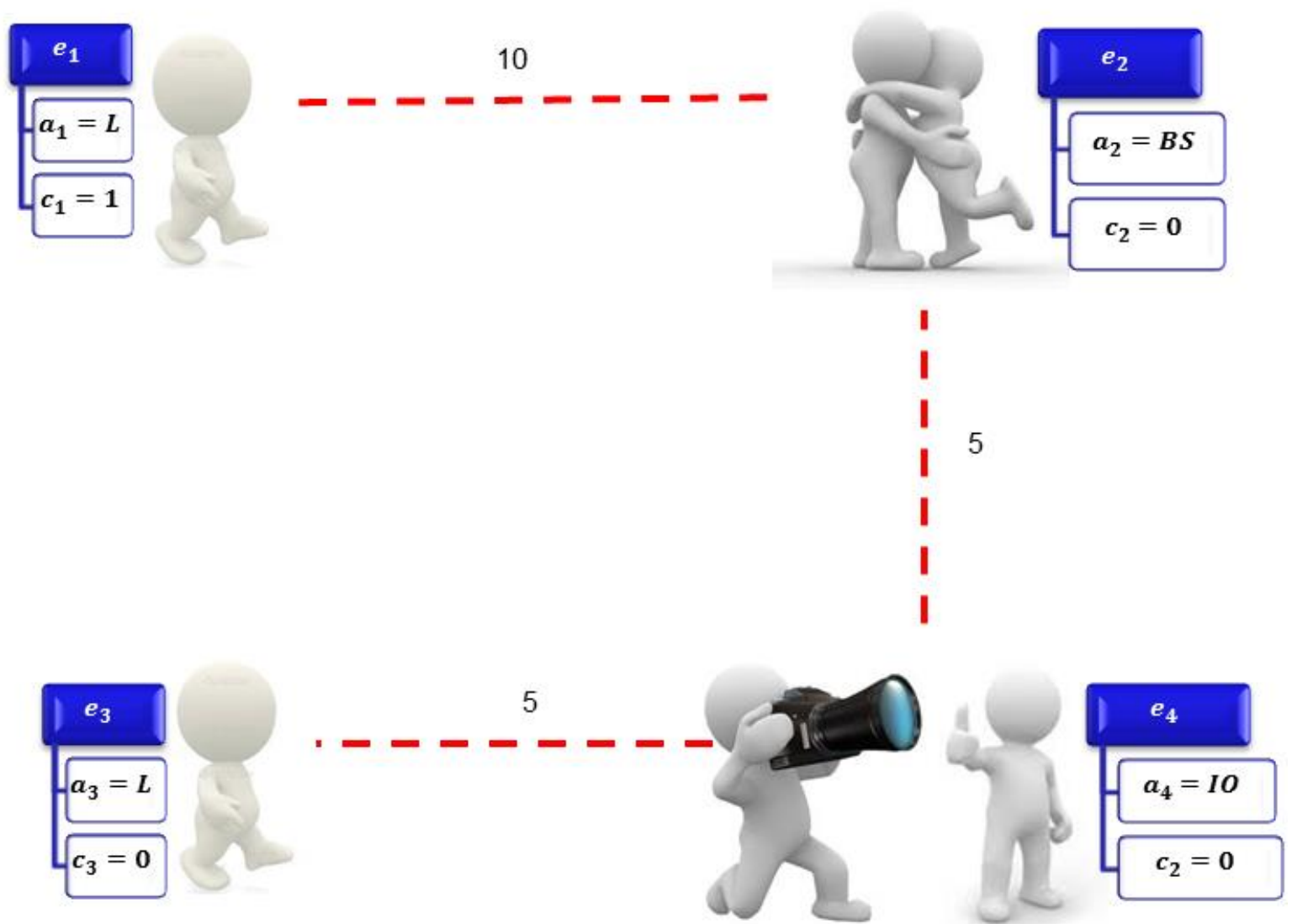

Figura 6.1 - Agentes executando as atividades simuladas

Tabela 6.1 - Matriz de Transmissão de Conhecimento

\begin{tabular}{c|c|c|c}
\hline M & BS & IO & L \\
\hline BS & & & + \\
\hline IO & + & & \\
\hline L & & 0 & \\
\hline
\end{tabular}

Tabela 6.2 - Matriz dos coeficientes de transmissão de conhecimento encontrada pelo algoritmo genético

BS

10

L
BS : $0,000 \quad 0,000 \quad 0,123$
IO : $0,185 \quad 0,000 \quad 0,000$
$\mathbf{L}: \quad 0,000 \quad 0,000 \quad 0,000$ 


\subsection{Segundo Experimento (hipotético intermediário): utiliza os dados observados (6 agentes e 4 atividades)}

O segundo experimento intermediário utilizou os dados reais observados da ilha do PET para testar a plataforma Horácio. Foram utilizados 6 agentes e 4 atividades, sendo assim, se torna também um experimento hipotético (conjunto parcial).

Os parâmetros utilizados para o experimento foram: 1500 passos (intervalo de simulação), número de rodadas: 10 (número de vezes que o simulador vai rodar o experimento), número de genótipos: 40 (indivíduos de cada população), número de gerações: 5.000 (populações), peso do desvio padrão: 0.600000, escala: 0.10 , menor erro encontrado para cada rodada: 0,112615, fitness: 1,927509 (melhor indivíduo de cada população), o desvio padrão ficou em: 0,020858, a média em: 0,020418, e o tempo de execução do experimento durou: 2:56:36.363. Todos esses dados podem ser vistos na listagem do experimento gerado pelo simulador no Apêndice B com mais detalhes, na Listagem B.1.2.

A simulação utiliza os agentes $(\mathrm{Cz}, \mathrm{Nd}, \mathrm{Nl}, \mathrm{Nr}$ e $\mathrm{Sg})$ com os conhecimentos iniciais observados $\left(\mathrm{CI}^{\mathrm{O}}\right)$ dados por $(\mathrm{Cp} 1,0000 \mathrm{Cz} 0,0000 \mathrm{Nd} \mathrm{0,0000} \mathrm{NI} \mathrm{0,0000} \mathrm{Nr}$ $0,0000 \mathrm{Sg} 0,0000)$, respectivamente e conhecimentos finais observados $\left(\mathrm{CF}^{\circ}\right)$ dados por (Cp 1,0000 Cz 0,5000 Nd 0,0000 Nl 0,7000 Nr 1,0000 Sg 1,0000). Os conhecimentos finais simulados encontrados foram (Cp 1,0000 Cz 0,4985 Nd 0,1720 $\mathrm{Nl} 0,4406 \mathrm{Nr}$ 0,9585 Sg 0,9883). A matriz de transmissão de conhecimento encontrada é apresentada a seguir. As atividades (U) e os perfis (V) de cada agente também podem ser observados na Listagem A.2.2 geradas pelo simulador.

Activity coeficients:

$A B$ AL BS CAP

$A B: \quad 0,0000,000 \quad 0,000 \quad 0,013$

AL: $\quad 0,0000,000 \quad 0,2950,000$

BS: $\quad 0,0000,000 \quad 0,0000,000$

CAP: $0,0000,000 \quad 0,0190,000$

O valor encontrado para o elemento da matriz de transmissão de conhecimento, referente ao agente que realizava a atividade de "Comer Alimento Provido" (transmissor) enquanto se encontrou com outro que realizava a atividade de "Abraço" (receptor), fazendo os dois parte da mesma rede social (tendo um elo de ligação através da matriz de proximidade), foi de 0,013 . Isso significa que foi este 
o valor usado na simulação pela equação do modelo de transmissão de conhecimento proposto, a cada ocorrência desta situação. O mesmo pode ser aplicado para os agentes que realizaram a atividade de "Brincadeira Social" (transmissor) quando encontraram com outros agentes que estivessem realizando a atividade de "Alerta" (receptor) utilizando o coeficiente de 0,295 a cada encontro. O coeficiente de 0,019 também foi utilizado para a transmissão de conhecimento dos agentes que realizaram a atividade de "Brincadeira Social" (transmissor) para os agentes que realizaram a atividade de "Comendo Alimento Provido" (receptor).

O segundo experimento testado na plataforma Horácio através de várias simulações mostrou que o algoritmo genético convergiu para encontrar a melhor matriz de transmissão de conhecimento quando atingiu o conhecimento $C F^{S}$ próximo ao $C F^{O}$. Esta segunda situação hipotética utilizando dados reais com poucos sujeitos e poucas atividades também pode validar a plataforma proposta como 0 apresentado no primeiro experimento hipotético.

\subsection{Terceiro Experimento (Dados reais observados na sua completude): utiliza os dados observados (38 agentes e 26 atividades)}

Nesse terceiro experimento foram considerados os dados provenientes do PET, o qual consiste em 38 macacos prego observados em suas atividades diárias com um repertório contemplando 26 atividades. Os parâmetros utilizados para o experimento foram: 800 passos (intervalo de simulação), número de rodadas: 10 (número de vezes que o simulador vai rodar o experimento), número de genótipos: 20 (indivíduos de cada população), número de gerações: 3000 (populações), peso do desvio padrão: 0,600000, escala: 0.10, menor erro encontrado para cada rodada: 0,271753, fitness: 1,879682 (melhor indivíduo de cada população), o desvio padrão ficou em: 0,001145, a média em: 0,010941, e o tempo de execução do experimento durou: 7:38:6.819. Todos esses dados podem ser vistos na listagem do experimento gerado pelo simulador no Apêndice $B$, com mais detalhes, na Listagem B.1.3.

Naturalmente, a convergência depende fortemente dos dados de entrada. Neste caso fica claro que a dimensão do problema aumentou bastante, impactando no tempo dispendido pelo simulador na busca pela convergência. Outros fatores como a diversidade de relações estabelecidas na rede social, e a diversidade de atividades, caracteriza o cenário como sendo complexo. Neste caso, o espaço de 
busca pela solução atinge tal magnitude que se torna difícil, se não altamente improvável, encontrar uma solução. Além disso, vale ressaltar que existem muitas variáveis que não foram consideradas no modelo, o que também pode contribuir para sua imprecisão e consequentemente para que seja capaz de encontrar uma matriz apropriada. Ou seja, o fenômeno de transmissão social de conhecimento do ambiente real é muito mais complexo.

O experimento intermediário pode apresentar resultados melhores por trabalhar com um menor número de sujeitos e menor número de atividades.

Devido ao fato do simulador utilizar probabilidades, as execuções geram diferentes resultados, mesmo com parâmetros e condições iniciais idênticas. Nestes casos o ideal é repetir o experimento várias vezes e analisar a coerência (proximidade) dos valores finais encontrados. Se o desvio padrão for pequeno, então a média serve como um bom resultado.

Sendo assim, pelos resultados, concluímos que se precisa de mais dados de entrada relacionados ao perfil dos macacos (como sexo, atividade de observação de quebra de cocos, idade, afiliação, entre outros) para que se tenha um melhor resultado quando o número de sujeitos analisados for maior. 


\section{CONCLUSÕES E TRABALHOS FUTUROS}

Para se estudar cientificamente um sistema, devem-se fazer algumas suposições sobre seu funcionamento, com base no que é constituído um modelo específico que descreve seu comportamento para análises posteriores. A inteligência artificial e a psicologia comparada deram subsídios e fundamentos para a criação do modelo proposto nesta tese. As simulações resultantes envolvem naturalmente várias abstrações e uma série de simplificações, com o que se podem analisar comportamentos e características de animais. Quando se realiza simulações do comportamento de uma sociedade complexa, é importante frisar que isso ocorre sobre um sistema matemático que não é capaz de representar as propriedades mentais dos primatas, nem a forma fiel do comportamento de uma sociedade. Assim sendo, o comportamento das simulações são limitados às características retratadas em modelos computacionais de modo que os agentes e seus respectivos comportamentos sociais são naturalmente simplificações da realidade.

A tese desenvolvida simula um ambiente virtual composto por agentes virtuais que representam os sujeitos observados de uma sociedade real que se deseja analisar. O simulador funciona como um laboratório de experimentos virtuais onde situações que ainda não aconteceram ou difíceis de serem observadas, poderiam ser testadas.

O objetivo da tese foi à proposição e análise de um modelo social de transmissão de conhecimento que utiliza como base as atividades que os sujeitos estão realizando em seu dia a dia. O modelo social auxilia na transmissão do conhecimento de um sujeito para o outro apenas quando eles estão próximos, estabelecendo assim um tipo de relacionamento (elo de ligação) entre os sujeitos. Para que a simulação tenha coerência com o ambiente real, o comportamento dos agentes simulados é baseado em regras estatísticas utilizando os dados observados do ambiente real.

Foi apresentada uma primeira situação hipotética com poucos sujeitos e poucas atividades para depurar (debugar) e validar a plataforma proposta, o que foi confirmado pelos experimentos 1 e 2. A ferramenta consegue propor um cenário 
condizente com os dados observados e apresenta uma forma de como um certo conhecimento pode ter sua transmissão auxiliada por atividades (periféricas) que aparentemente não tem relação alguma com o conhecimento específico (quebra de cocos).

Apesar de o perfil utilizado considerar somente as atividades dos sujeitos, os resultados mostraram a validade do conceito proposto. Isso ocorreu, mesmo sabendo que outras informações sobre o perfil, tais como idade e gênero, influenciam na transmissão do conhecimento em questão.

Vale ressaltar que os dados de entrada (observados) utilizados na simulação, determinam os resultados finais, de modo que eventuais incoerências nos dados de entrada comprometem o processo como um todo. Da mesma forma, um número pequeno de observações também parece ser crítico para o sucesso do procedimento de simulação. E uma maior quantidade de dados também impõe problemas, na medida em que se torna mais difícil à conversão do simulador para um resultado adequado (pois o espaço de busca pela solução atinge tal magnitude que se torna difícil, se não altamente improvável encontrar uma solução) e a tomada de decisão da plataforma Horácio necessita de mais dados de perfil para um melhor resultado (variáveis que não foram consideradas no modelo, por exemplo, sexo, idade, etc.) como mostrou o terceiro experimento com todos os sujeitos e todas as atividades.

É importante frisar que estamos considerando somente a transferência do conhecimento de um sujeito para outro através da proximidade entre os dois. No sistema não existe aumento (quantificação) do conhecimento (capacidade específica) quando o sujeito realiza uma atividade isoladamente.

Para a plataforma Horácio, a transferência de conhecimento só ocorre quando as atividades realizadas são dependentes de situações sociais relacionadas aos encontros. Mais explicitamente, quando o relacionamento social é considerado como importante para a transmissão de um conhecimento (que está relacionado ao perfil dos agentes baseado nas observações do ambiente real), porém, não é qualquer conhecimento que faz sentido ser transmitido; depende da situação em que se está simulando. 
Na prática, a visão de que o "contágio" do conhecimento está atrelado aos encontros possibilitados pelas dinâmicas sociais nos permite pensar melhor sobre as relações entre as estruturas sociais que caracterizamos e como (e o que) é transmitido; que de outra forma seriam apenas percebidas pelos outros sujeitos através de algum tipo de instrumento de observação, por exemplo, as redes sociais de amigos utilizadas na internet ou a própria televisão (no caso de sociedades humanas).

O entendimento de como o conhecimento é transmitido está diretamente relacionado ao entendimento das relações sociais e ambientais. Dito de outra forma, as relações sociais e as situações ambientais facilitam ou não a transmissão de conhecimento, embora não sejam quaisquer relações e situações que tenham influência nisso.

Pensando-se na influência das atividades sobre a transferência do conhecimento e com o levantamento bibliográfico na área de primatologia, notou-se que outros dados deveriam ser considerados pela plataforma, e que está relacionada ao perfil do sujeito como o sexo, a faixa etária, a afinidade com outros sujeitos, etc.. O perfil atual do agente deste trabalho só possui dados observados sobre as atividades realizadas diariamente pelos sujeitos que são utilizadas para regrar o sistema de acordo com o ambiente real, mas desconsideram nesta implementação os outros fatores mencionados. Portanto, isso é algo que deverá ser incorporado em uma próxima revisão desta plataforma.

A Tabela A.7 que se encontra no Anexo A pode ser vista como um exemplo (não temos os mesmos dados do período estudado no capítulo de resultados) que apresenta a afinidade, a proficiência, o sexo, a faixa etária, entre outras características, dos macacos prego da ilha do PET em 2011 (CARVALHO, 2011).

Segundo as pesquisas de Carvalho (2011) na ilha do PET, duas hipóteses podem influenciar na troca de transmissão de conhecimento: (1) a tolerância social que apresenta as relações íntimas entre dois sujeitos utilizando o cálculo do Grau de Vértice (GV) (representa o número de sujeitos a qual cada macaco está conectado). Segundo Carvalho, a AGM encontra somente as relações mais fortes. Esta medida reflete o quanto o sujeito é tolerado, ou também pode ser visto como o sujeito mais popular; e (2) a observação de sujeitos proficientes na quebra de cocos, que segundo Coelho (2009), a escolha do alvo de observação do sujeito proficiente na 
atividade de quebra de cocos está associada a uma série de ligações mantidas entre o grupo social (por exemplo, afiliação e afinidade), mas as pesquisas também mostram a forte relação entre a observação de sujeitos proficientes e a consequente capacidade de adquirir também tal proficiência (OTTONI et. al., 2005).

Nos resultados deste trabalho não se tinha a atividade de observação de quebra de cocos nos dados observados em campo, que segundo o levantamento bibliográfico, é um dos fatores que influenciam e muito, na transmissão de conhecimento.

Finalmente, a ferramenta Cuzco desenvolvida para o LEC do IPUSP permite que os pesquisadores substituam os processos atualmente manuais (armazenados em planilhas eletrônicas) e em papéis (relatórios de IC), por fluxos eletrônicos de informação. Considerando o processo atual como um todo, isso resulta em redundância de dados, inflexibilidade, baixo nível de segurança, dependência de programas ou dados e dificuldade de compartilhamento entre os softwares (planilha eletrônica e o software que gera a AGM). Ele possui um conjunto de componentes inter-relacionados que coleta (ou recupera), processa, armazena e distribui informações destinadas a apoiar a tomada de decisões, por exemplo, a geração da FGM dinâmica com vários filtros, de várias épocas e independente do foco do trabalho ou da pesquisa, o sistema armazena as informações de forma centralizada mantendo um histórico das informações para as análises posteriores.

Vale a pena ressaltar que os dois softwares podem e devem ser usados conjuntamente, cabendo ao primeiro (Cuzco) a identificação de um subgrupo de estudo e ao segundo (Horácio) o uso deste mesmo subgrupo para análise das influencias estabelecidas entre as diversas competências como apresentado no experimento hipotético 2.

De forma geral, acreditamos que a contribuição da proposta desta tese possa ser ajustada para ser aplicada não somente a primatologia como o estudo de caso desta tese, mas também a outros cenários em que as situações sociais possam servir de apoio para que seus elementos tenham condições em desenvolver ou aprimorar certas competências. A matriz de transmissão de conhecimento proposta correlaciona as diversas competências e as influencias que umas tem sobre as outras e a forma como elas se desenvolvem. 


\subsection{Trabalhos Futuros}

$\mathrm{Na}$ tese desenvolvida foi considerado apenas um conhecimento específico (a quebra de cocos), mas, vale ressaltar que nada impede que outros conhecimentos sejam considerados, pois o software pode ser expandido para abranger uma quantidade de conhecimentos qualquer. Isso, porém, pode ser implementado em trabalhos futuros.

Neste trabalho não foi considerado o perfil do macaco (sexo, afiliação, idade, empatia, entre outros) para analisar a transferência de conhecimento; somente as atividades realizadas. Atividade como observação do macaco proficiente também é um fator que deve ser considerado em uma nova versão desta ferramenta. Esses seriam dados interessantes para serem analisados pela plataforma Horácio e verificar se também influenciam na transferência do conhecimento.

Para verificar a funcionalidade da ferramenta pelo LEC do IPUSP, poderia ser gerado um subgrupo de estudo da ilha do PET com a ferramenta Cuzco e a ferramenta Horácio usar este subgrupo para analisar hipóteses geradas das influencias estabelecidas entre as diversas competências das atividades periféricas apontadas pelo modelo de transferência de conhecimento proposto que podem auxiliar na troca de conhecimento sobre a quebra de cocos. 


\section{AGRADECIMENTOS}

Nós gostaríamos de agradecer ao CNPq (Conselho Nacional de Desenvolvimento Científico e Tecnológico) pela bolsa de doutorado concedida no período de dois anos à aluna Luciene Cristina Alves Rinaldi. Nós gostaríamos de agradecer também a empresa Continental A.G., que através da FUSP (Fundação de Apoio á Universidade de São Paulo) também concedeu a bolsa de doutorado no período de dois anos à aluna Luciene Cristina Alves Rinaldi. 


\section{REFERÊNCIAS BIBLIOGRÁFICAS}

ALTMAN, Jeane. Observational Study of Behavior: Sampling Methods. Behavior, v 49, Issue 3. 1974, p. 227-266. ISSN: 0005-7959

BARABASI, A. L. Linked: How Everything Is Connected to Everything Else and What It Means for Businness, Science and Everyday Life. New York: Penguin Group; 2002. p. 238.

BARCELLOS, J. C. H. "Algoritmos Genéticos Adaptativos: Um Estudo Comparativo". Dissertação de Mestrado em Engenharia de Sistemas Digitais, Politécnica, USP, São Paulo, 2000.

BARRAT, A.; BARTHELEMY, M.; PASTOR-SATORRAS, R.; VESPIGNANI, A. The architecture of complex weighted networks. Proceedings of the National Academy of Sciences. 2004; 101:3747-3752

BATAGELJ, V.; MRVAR, A. PAJEK - Analysis and visualization of large networks. In: Jünger, M.; Mutzel, P.(ed). Graph Drawing Software. Berlin: Springer; 2003. p. 77103.

BAVELAS, A. Communication patterns in task oriented groups. Journal of the Acoustical Society of America.1950; 22:725-730.

BIGGS, N.; LLOYD, E.; WILSON, R. Graph Theory. Oxford: Oxford University Press; 1986. p. 1736-1936.

BONDY, J. A.; MURTY, U. S. R. Graduate Texts in Mathematics: Grafh Teory. Springer, 2008. 666 pp.

BORGATTI, S. P. Netdraw Network Visualization. Harvard, MA: Analytic Technologies; 2002.

BORGATTI, S. P.; MEHRA, A.; BRArSS, D. J., LABIANCA, G. Network analysis in the social sciences.Science.2009; 323:892-895. [PubMed: 19213908].

BRENNER, W., ZARNRKOW, R.; WITTIG, H. Intelligent Software Agents Foundations and Applications.Springer Verlag, 1998.ISBN3- 540-63441-8

BRENT, L. J. N.; LEHMANN, J.; RAMOS-FERNÁNDES, G.Social Network Analysis in the Study of NonHuman Primates: A Historical Perspective. Amercian Journal of .Primatology. National Institutes of Health (NIH), 2011, August; 73 (8): 720-730. Doi: 10.1002/ajp.20949.

BRENT, L. J. N; RAMOS-FERNÁNDES. S. S, DUBUCC, HEISTERMANN M, M. A. Social capital and physiological stress levels in free-ranging adult female rhesus macaques. Physiology and Behavior.2011; 102:76-83. [PubMed: 20933532].

CARVALHO, M. P. Influência social sobre a aprendizagem do uso de ferramentas em um grupo de macacos prego que apresenta o uso espontâneo de quebra de 
cocos (Trabalho de Iniciação Científica). Orientadora: Briseida Dogo de Resene. Instituto de Psicologia da USP. São Paulo, 2011.

COELHO, G. C. Observação por co-específicos e influências sociais na aprendizagem do uso de ferramentas para quebrar cocos por macacos prego (cebus $\mathrm{sp}$ ) em semi-liberdade. Dissertação de Mestrado. Instituto de Psicologia da USP, São Paulo, 2009. 147 p.

CHAI, J.; XIAO, J.; HODGINS, J. Vision-based Control of 3D Facial Animation. Proceedings of Eurographics SIGGRAPH Symposium on Computer Animation, pages 193-206. ACM, San Diego, 2003.

CORMEN, T. H.; LESERSON, C; E.; RIVEST, R.L.; STEIN, C. Introduction to Algorithms, Second Edition. MIT Press and McGraw-Hill, 2009. ISBN 0-262-03293-7. Section 23.2: The algorithms of Kruskal and Prim, pp. 567-574.

COUSSI-KORBEL, S.; FRAGASZY, D. M. On the relation between social dynamics and social learning, Animal Behaviour, v. 50, p. 1441-1453, 1995.

DEUS, I. M. I. De. Jornal on-line: personalização do conteúdo através da tecnologia de agentes inteligentes - Dissertação (Mestrado). - Faculdade de Comunicação, Educação e Turismo, Universidade de Marília, Unimar. 2006.

ERDÕS, P.; RÉNYI, A. On random graphs. Public Mathematics Debrecen.1959; 6:290-297.

FALÓTICO, T. Estudo experimental do uso de ferramentas para a quebra de frutos encapsulados por macacos-prego (Cebus apella) em semiliberdade. Dissertação (mestrado) São Paulo, 2006 - Instituto de Psicologia, Universidade de São Paulo, São Paulo.

FORSYTH, E.; KATZ, L. A matrix approach to the analysis of sociometric data: Preliminary report. Sociometry.1946; 9:340-347.

FOWLER, J. H.; CHRISTAKIS, N. A. Dynamic spread of happiness in a large social network: longitudinal analysis over 20 years in the Framingham Heart Study. British Medical Journal.2008; 337:9.

FRAGASZY, D. M.; PERRY S. Towards a biology of traditions. Em D. M. Fragaszy\& S. Perry (Orgs), The Biology of Traditions. Cambridge: Cambridge University Press. 2003.

FRAGASZY, D. M.; VISALBERGHI, E.; FEDIGAN, L. M. The Complete Capuchin The biology of the genus Cebus. Cambrige, United Kingdom, 2004.

FREEMAN, L. C. The Development of Social Network Analysis.Vancouver, C: $\Sigma P$ Empirical Press; 2004.

FUTUYAMA, D. J. Biologia Evolutiva. Tradução: Fábio de Melo Sene, Ribeirão Preto: Sociedade Brasileira de Genética, 1992. 
GILBERT, E. N. Random graphs. Annals of Mathematical Statistics.1959; 30:11411144.

GOLDBERG, D. E. Genetic Algorithms in Search, Optimization, and Machine Learning. Reading, MA: Addison-Wesley, 1989.

GOODALL, J. Tool-using in primates and other vertebrates. In: Lehrman, D. S.; Hinde R. A.; Shaw E. (eds) Advances in the study of behavior. Academic, New York, 1970.

GUTIÉRREZ, A.; FRÉDÉRIC, V.; THALMANN, D. Stepping into Virtual Reality, Springer-Verlag, London, 2008. ISBN: 978-1-84800-116-9.

HANNEMAN, R. A.; RIDDLE, M. Social network analysis: Theory and applications. Wiki Book available to download. University of California, Riverside.2011. Disponível em: <http://train.ed.psu.edu/WFED-543/SocNet_TheoryApp.pdf>. Acesso em: 10 de maio 2013.

HEYES, C. Imitation, culture and cognition. Animal Behaviour, 46, 1993.Pag. 9991010.

HILL A. L.; RAND, D. G.; NOWAK, M. A.; CHRISTAKIS, N. A. Emotions as infectious diseases in a large social network: the SIS a model. Proceedings of the Royal Society B-Biological Sciences. 2010.1098/rspb.2010.1217.

HINDE, R. A. Primate Social Relationships. Blackwell, London, 1993.

IZAR, P. Análise da estrutura social de um grupo de macacos-prego (Cebus paella) em condições de semi-cativeiro. Dissertação de Mestrado defendida pelo Instituto de Psicologia da Universidade de São Paulo. 1994.

IZAR, P. Female social relationships of Cebus apella nigritus in a southeast atlantic forest: an analysis through ecological models of primate social evolution. Behaviour, vol. 141, p. 71-99, 2004.

JACCARD, P. Etude comparative de la distribution floraledansune portion dêsAlpeset des Jura. Bull. Soc. VaudoiseSci. Nat., 37, 547-579, 1901.

KASPER, C; VOELKL, B. A. social network analysis of primate groups. Primates. 2009; 50:343-356. [PubMed: 19533270]

KING, S.; PARENT, R. E.; OLSAFSKY, B. L. An anatomically-based 3D parametric model to support facial animation and synchronized speech. In Proceedings of Deform 2000, November 29-30, Geneva, 2000. p. 7-19.

KOZA, J. R. Genetic Programming of Computers by Means of Natural Selection. Cambridge, MA: MIT, 1992. 
KRAUSE, J.; JAMES, R.; LUSSEAU, D. Animal social networks: na introduction. Behavioral Ecologyand Sociobiology. 2009; 63:967-973.

LALAND, K. N.; RICHERSON, P. J.; BOYD, R. Developing a Theory of Animal Social Learning. In: HEYES, C. M.; GALEF, B. G. (ed) Social Learning in Animals: the Roots of Culture Academic Press, San Diego, 1996.

LOULA, A. C. Comunicação simbólica entre criaturas artificiais: um experimento em vida artificial. 2004. Dissertação (Mestrado), Universidade Estadual de Campinas, Engenharia Elétrica, Campinas, São Paulo, 2004.

LUCCHESI, C. L. Introdução à Teoria dos Grafos. Unicamp, Instituto de Matemática Pura e Aplicada, Rio de Janeiro: RJ. 1979.

MITCHELL, M. An Introduction to Genetic Algorithms. MIT Press, 1996.

MORENO, J. L. Who shall survive? A new approach to the problem of human interrelations. Washington, DC: Nervous and Mental Disease Publishing Co; 1934. p. 441.

NEWMAN M. E. J. Modularity and community structure in networks. Proceedings of the National Academy of Sciences.2006; 103:8577-8582.

NEWMAN, M. E. J. A measure of between ness centrality based on random walks. Social Networks.2005; 27:39-54.

NEWMAN, M. E. J.; WATTS, D. J.; STROGATZ, S. H. Random graph models of social networks. Proceedings of the National Academy of Sciences of the United States of America.2002; 99:2566-2572. [PubMed: 11875211]

OPSAHL, T. Structure and Evolution of Weighted Networks. London: University of London; 2009.

OTTE, E.; ROUSSEAU, R. Social network analysis: A powerful strategy, also for the information sciences. JournalofInformationScience.2002; 28:441-453.

OTTONI, E. B.; RESENDE, B. D.; IZAR, P. Watching the Best nutcrackers: wat capuchin monkey (cebus apella) know about others tool-using skills. Journal of Animal Cognition, v. 8, p. 115-219, 2005.

PIAGET, J. O nascimento da inteligência na criança. 4. ed. Rio de Janeiro: Zahar, 1982.

RESENDE, B. D.; IZAR, P.; OTTONI, E. B. Social play and spatial tolerance in tufted capuchin monkeys (Cebus apella). Revista de Etologia, v. 6(1), p. 55-61, 2004.

RESENDE, B. D. Ontogenia de comportamentos manipulativos em um grupo de macacos-prego em situação de semiliberdade (Tese de Doutorado), USP, 2004.

RIBEIRO, R. J. L.; TRELEAVEN, P. C.; ALIPE, C. Genetic-Algorithm Programming 
Environments.Computer, Jun. 1994.

RINALDI, L. C. A. R.; PAIVA, D. C. de; NETTO, M. L. Uso de Realidade Virtual em Vida Artificial. (Capítulo de Livro) Em: Costa, R. M. E. M.; Ribeiro, M.W. S. Livro do pré-simpósio, XI Symposiumon Virtual and Augmented Reality, Porto Alegre, 2009. pag. 31-52. ISBN: 857669235-9.

RINALDI, L. C. A.; MOREIRA, R. B. T.; RESENDE, B. D. de; NETTO, M. L. A System for Social Network Analysis. In: The 8th International Conference for Internet Technology and Secured Transactions (ICITST-2013), 2013, London, UK, 2013. p. 126-131.

RINALDI, L. C. R.; CAVALHIERI, M. A.; ASSIS, G. A.; NETTO, M. L. Capítulo do Livro: Uso de Realidade Virtual em Vida Artificial, In: Fundamentos e Tecnologias de Realidade Virtual e Aumentada, VIII Symposium on Virtual Reality, Belém, Pará, Maio, 2006. pag. 366-387. ISBN: 85-7669-068-3.

SCOTT, J. Social Network Analysis: A Handbook. London: Sage Publications; 2000. p. 208.

SEEMAN, T. E. Social ties and health: The benefits of social integration. Annals of Epidemiology. 1996; 6:442-451. [PubMed: 8915476]

TORI, R.; KIRNER, C.; SISCOUTO, R. Fundamentos e Tecnologia de Realidade Virtual e Aumentada. In: Capítulo 6: Humanos Virtuais e Avatares, Em Modesto, F. A. C.; Brega, J. R. F.; Garcia, M. B.; et al. Livro do Pré-simpósio, VIII Symposiumon Virtual Reality, Belém, PA, Editora SBC, Porto Alegre. 2006.

VIANA, G. V. R. "Meta-heurísticas e Programação Paralela em Otimização Combinatória". Fortaleza: EUFC, 1998.

VYGOTSKY, L. V. O Papel do Brinquedo no Desenvolvimento. Em A Formação Social da Mente. São Paulo: Martins Fontes, 1989.

VOELKL, B, NOÉ, R. The influence of social structure on the propagation of social information in artificial primate groups: A graph-based simulation approach. Journal of Theoretical Biology.2008; 252:77-86. [PubMed: 18342891]

VOELKL, B.; KASPER, C. Social structure of primate interaction networks facilitates the emergence of cooperation. Biology Letters.2009; 5:462-464. [PubMed: 19443505]

VOELKL, B.; NOÉ, R. Simulation of information propagation in real-life primate networks: longevity, fecundity, fidelity. Behavioral Ecology and Sociobiology.2010; 64:1449-1459.

WASSERMAN, S.; FAUST, K. Social Network Analysis: Methods and Applications. Granovetter, M. editor. Cambridge: Cambridge University Press; 1994. p. 825 
WATTS, D. J., STROGATZ, S. H. Collective dynamics of 'small-world' networks.Nature.1998; 393:440-442. [PubMed: 9623998]

WEISS, G. Multi-Agent Systems - A Modern Approach to Distributed Artificial Intelligence. MIT Press, 2001, ISBN 0-262-73131-2.

WEY, T.; BLUMSTEIN, D. T.; SHEN, W.; JORDAN, F. Social network analysis of animal behaviour: a promising tool for the study of sociality. Animal Behaviour.2008; 75:333-344.

WHITEHEAD, H. Socprog 2.3 (for MATLAB 7.4). Halifax, Canada: Dalhousie University; 2007.

WOOLDRIDGE, M. An Introduction to MultiAgent Systems. Chichester: John Wiley \& Sons, 2002. $348 \mathrm{p}$.

ZOTOVICI, A.; RINALDI, L. C. A. Construção de um ambiente virtual tridimensional habitado por personagens virtuais com o Alice 2.0. Alice Brasil: anais 2011. Barros E. A. R. et al (org.). São Paulo: Páginas \& Letras Editora e Gráfica, 2011. ISBN: 97885-86508-82-9. 


\section{ANEXO A - Etologia}

Tabela A.1 - Composição do grupo utilizado na pesquisa (RESENDE, 2004).

\begin{tabular}{lllll}
\hline Nome & Abreviação & Sexo & $\begin{array}{l}\text { Faixa } \\
\text { Etária }\end{array}$ & Proficiente \\
\hline Alan & $\mathrm{Aa}$ & sem dados & sem dados & \\
Al & Alice & Fêmea & Adulta & \\
Anis & $\mathrm{An}$ & Fêmea & Adulta & \\
Buriti & $\mathrm{Bu}$ & Fêmea & Subadulto & \\
Caio & $\mathrm{Ca}$ & sem dados & sem dados & Sim \\
Cajá & $\mathrm{Cj}$ & Fêmea & Adulta & \\
Cumarina & $\mathrm{Cm}$ & Fêmea & Adulta & \\
Cupuaçu & $\mathrm{Cp}$ & sem dados & sem dados & Sim \\
Cuzco & $\mathrm{Cz}$ & Macho & Juvenil & Sim \\
Flora & $\mathrm{Fl}$ & Indefinido & Infante & \\
Floyd & $\mathrm{Fo}$ & Macho & Subadulto & Sim \\
Frapê & $\mathrm{Fr}$ & Macho & Juvenil & Sim \\
Haroldo & $\mathrm{Ha}$ & sem dados & sem dados & \\
Hibiscus & $\mathrm{Hb}$ & Fêmea & Adulta & \\
Horácio & $\mathrm{Ho}$ & Indefinido & Infante & \\
lgor & $\mathrm{lg}$ & sem dados & sem dados & \\
Ipê & $\mathrm{Ip}$ & Fêmea & Adulta & \\
Jiló & $\mathrm{Jl}$ & Macho & Indefinido & \\
Júlio & $\mathrm{Ju}$ & sem dados & sem dados & \\
Lina & $\mathrm{Ln}$ & Fêmea & Adulta & \\
Lui & $\mathrm{Lu}$ & Macho & SubAdulto & \\
Maia & $\mathrm{Ma}$ & Fêmea & Adulta & \\
Mei & $\mathrm{Me}$ & Indefinido & Infante & \\
Milo & $\mathrm{Ml}$ & sem dados & sem dados & \\
Minerva & $\mathrm{Mn}$ & sem dados & sem dados & \\
Mistério & $\mathrm{Mi}$ & Fêmea & Adulta & \\
Nadir & $\mathrm{Nd}$ & Fêmea & Adulta & Sim \\
Nuli & $\mathrm{Nl}$ & Macho & Juvenil & \\
Nur & $\mathrm{Nr}$ & Macho & Adulta & \\
Papaia & $\mathrm{Pa}$ & sem dados & sem dados & \\
Prisma & $\mathrm{Pr}$ & Fêmea & Adulta & \\
Quinua & $\mathrm{Qu}$ & Indefinido & Infante & \\
Rabisco & $\mathrm{Rb}$ & sem dados & sem dados & \\
Rosa & $\mathrm{Rs}$ & Fêmea & Adulta & \\
Sagu & $\mathrm{Sg}$ & Macho & Subadulto & Sim \\
Terceiro & $\mathrm{Tr}$ & Macho & Adulta & \\
Vali & $\mathrm{Vl}$ & Fêmea & Adulta & \\
Vip & $\mathrm{Vp}$ & Indefinido & Infante & \\
\hline & & & & \\
\hline
\end{tabular}


Tabela A.2 - Composição das atividades utilizadas na pesquisa (planilha eletrônica fornecida)

\begin{tabular}{ll}
\hline Sigla & Descrição do comportamento \\
\hline CAP & Comendo alimento provido \\
RC & Recebendo catação \\
EC & Efetuando catação \\
AC & Auto-catação \\
D & Deitado \\
S & Sentado \\
BS & Brincadeira social \\
BM & Brincadeira motora \\
BO & Brincadeira com objeto \\
BR & Briga \\
\hline AE & Ameaça (ameaça externa = Alerta?) \\
L & Locomoção \\
CAR & Carregando infante \\
AM & Amamentação \\
MM & Mamando \\
F & Forragear \\
CO & Cópula \\
PA & Pacing \\
AL & Alerta (mudar no projeto. Observar público + \\
& ameaçar macacos da outra ilha?) \\
\hline IO & Interagir com observador \\
P & Parado \\
\hline PAL & Partilhando alimento \\
MO & Montado \\
AB & Abraço \\
QC & Quebrando coco \\
DS & Display sexual \\
\hline & \\
\hline
\end{tabular}

Tabela A.3 - Composição dos Locais (ou substratos) utilizados (planilha eletrônica fornecida)

\begin{tabular}{ll}
\hline Sigla & \\
Substratos & Significado \\
\hline SL & Solo \\
AR & Árvore \\
AB & Arbusto \\
GC & Galho caído \\
TC & Tronco caído \\
BA & Barco \\
CN & Container \\
SI & Sítio de quebra \\
RE & Rede \\
CR & Corda \\
CO & Cocho \\
CP & Capivara \\
\hline
\end{tabular}


Tabela A.4 - Comportamentos registrados (RESENDE, 2004).

\begin{tabular}{l}
\hline Comportamento \\
\hline Comer alimento provido \\
Efetuar catação \\
Receber catação \\
Auto-catação \\
Deitar \\
Sentar \\
Brincadeira
\end{tabular}

Descrição

Ingestão de alimentos pelos tratadores

Um animal limpa a pelagem de outro utilizando mãos e boca

Ter sua pelagem limpa por outro indivíduo

Um animal realiza catação em seu próprio pelo

Um ou mais animais deitados

Um ou mais animais sentados

Social: dois ou mais indivíduos se envolvem em atividades de corrida e perseguição, mordendo, puxando ou segurando o outro.

Motora: um indivíduo realiza movimentos como pular, puxar ou se balançar em galhos de árvores

Briga

Dois ou mais indivíduos se envolvem em um episódio agonístico envolvendo contato físico

Ameaça

Locomoção

Transporte de infantes

Dois ou mais indivíduos se envolvem em um episódio agonístico através de expressões faciais, posturas e vocalizações, sem envolver contato físico

Deslocar-se pelo chão ou pelas árvores

Materna: a mãe carrega o infante no dorso ou em qualquer parte do corpo.

Alomaterna: um indivíduo que não é a mãe do infante realizando essa tarefa

Amamentação materna

A mãe abre os braços e permite que seu infante tenha acesso aos mamilos

Forragear

Deslocamento

Comportamentos de busca, preparação e ingestão de qualquer recurso alimentar retirado do ambiente, exceto alimento provido.

Colisão geralmente em direção oposta ao indivíduo que chegou

Quando um indivíduo ou mais auxiliam outro indivíduo envolvido em um episódio agonístico

Partilha de alimentos

Direta: um indivíduo que esta comendo ou manejando um alimento permite que outro(s) coma $(\mathrm{m})$ e/ou pegue $(\mathrm{m})$ parte desse alimento direto de sua mão.

Indireta: um animal que esta comendo e deixa cair ou abandona pedaços de seu alimento, permitindo que outro(s) se aproxime $(\mathrm{m})$ para comer o que caiu ou foi deixado

Monta

Um indivíduo (macho ou fêmea) monta na parte traseira de outro, mas não realiza necessariamente movimentos pélvicos

Cópula

Um macho monta na parte traseira de uma fêmea no estro e realiza movimentos pélvicos

Interação com o observador

Qualquer comportamento que mostre interação entre o animal observado e o observador

Tabela A.5 - Tipos de ferramentas (Falótico, 2011)

\begin{tabular}{l}
\hline Ferramentas \\
\hline Pedra para cavar "enxada" \\
Pedra para quebrar, esmagar \\
ou acessar alimento "martelo" \\
Pedra de arremesso em display \\
de cio
\end{tabular}

Pedra para pulverizar seixos

Varetas/galhos para sondar Descrição

Utilizada para bater no solo e depois tirar a terra solta com as mãos para acessar raízes, tubérculos e aranhas

Utilizada para quebrar sementes, esmagar alimentos duros, quebrar troncos ou esmagar pequenos animais

Utilizadas por fêmeas em período de preceptivo para atirar em machos aos quais estavam seguindo

Um indivíduo bate uma pedra em outra produzindo um pó que é lambido, esfregado no corpo e/ou cheirado

Utilizada para desentocar lagartos ou invertebrados e acessar $\mathrm{mel} / \mathrm{cera}$

Varetas/galhos utilizados como Varetas utilizadas para cutucar ou espetar outras espécies e "Lanças" episódios de ameaça 
Tabela A.6 - Comportamentos registrados de quebra de cocos (CARVALHO, 2011)

\begin{tabular}{|c|c|c|}
\hline Categorias & Modificadores & Descrição \\
\hline Chega ao sitio & & Aproxima-se da bigorna. \\
\hline Manipula Coco & & Manipula com as mãos os cocos presentes no sítio. \\
\hline \multirow[t]{2}{*}{ Pega Martelo } & Martelo Adequado & $\begin{array}{l}\text { Pega objeto de natureza dura (pedra), com um peso entre } 0,3 \text { e } 0,8 \mathrm{~kg} \text { e com ao } \\
\text { menos uma superfície plana. } \\
\text { Adequadamente: Segura martelo de forma que a superfície plana atinja o coco. } \\
\text { Inadequadamente: segura o martelo de forma diferente da descrita acima, de forma } \\
\text { que o coco não seja atingido adequadamente. }\end{array}$ \\
\hline & Martelo Inadequado & $\begin{array}{l}\text { Pega objeto mais leve }(0.03 \mathrm{~kg}) \text { feito de poliuretano, de tamanho similar a pedras } \\
\text { naturais, porém inapropriadas para romper o endosperma do coco ou pega pedra } \\
\text { natural que possua peso inferior á } 0,3 \text { e que não possua superfície plana. }\end{array}$ \\
\hline \multicolumn{2}{|l|}{ Observa Quebra } & Observa co-específico na atividade de quebra de cocos. \\
\hline Examina chão & & Observa coco ou outros objetos presentes no chão do sítio. \\
\hline \multicolumn{2}{|l|}{ Vigia } & Observa atentamente o que ocorre no ambiente em sua volta. \\
\hline Pega coco & & Pega o coco localizado no sítio \\
\hline \multirow[t]{2}{*}{ Ajeita } & Adequadamente & $\begin{array}{l}\text { Ajeita o coco sobre a bigorna, de tal forma que o coco não escorregue e onde é } \\
\text { possível atingi-lo com o martelo. }\end{array}$ \\
\hline & Inadequadamente & $\begin{array}{l}\text { Ajeita o coco de tal forma que possibilite o seu rolamento ou impossibilite que o } \\
\text { martelo o atinja corretamente, ou mesmo posiciona outro objeto que não seja o coco. }\end{array}$ \\
\hline \multirow[t]{2}{*}{ Golpeia } & Adequadamente & $\begin{array}{l}\text { Atinge o coco posicionado sobre a bigorna de forma que o coco não role nem voe, } \\
\text { mesmo que não quebre o coco totalmente. } \\
\text { Coco posicionado: Golpeia coco que foi posicionado pelo próprio indivíduo. } \\
\text { Coco pré-existente: Golpeia coco que já estava posicionado sobre a bigorna. }\end{array}$ \\
\hline & Inadequadamente & Golpeia o coco fazendo com que voe ou role. \\
\hline \multirow{3}{*}{ Quebra } & Adequada & $\begin{array}{l}\text { Evento em que o sujeito posicionou o coco adequadamente, utilizou martelo } \\
\text { adequado, porém não conseguiu romper o endocarpo do coco. }\end{array}$ \\
\hline & Inadequada & $\begin{array}{l}\text { Evento em que o sujeito utilizou martelo inadequado para golpear o coco ou } \\
\text { manipulou martelo adequado de forma inapropriada para romper o endocarpo, como } \\
\text { não golpear o coco ou golpear outros objetos. }\end{array}$ \\
\hline & Proficiente & $\begin{array}{l}\text { Evento em que o sujeito posicionou o coco adequadamente e golpeou com martelo } \\
\text { adequado, rompendo o endocarpo do coco. }\end{array}$ \\
\hline Sucesso & & Rompe totalmente o endocarpo do coco. \\
\hline \multicolumn{2}{|l|}{ Sucesso Indefinido } & Não foi possível observar se o endocarpo do coco rompeu totalmente. \\
\hline Sem visão do coco & & Não foi possível determinar se o coco foi posicionado ou já era pré-existente. \\
\hline \multicolumn{2}{|l|}{ Scrounging } & Comer cocos no sítio rompidos por outro indivíduo. \\
\hline Ingere & & Alimenta-se do coco quebrado ou restos de coco. \\
\hline \multicolumn{2}{|l|}{ Golpeia outros objetos } & Utiliza martelo para golpear outros objetos encontrados no sítio, além de cocos. \\
\hline Movimento Inepto & & $\begin{array}{l}\text { Manipulação e pedras e cocos com movimentos não incluídos na seqüência } \\
\text { comportamental típica da quebra, como bater o coco no martelo, bater objetos em } \\
\text { troncos de árvore. }\end{array}$ \\
\hline \multicolumn{2}{|l|}{ Sai do sitio } & Afasta-se da bigorna. \\
\hline Outros & & $\begin{array}{l}\text { Executa comportamentos não incluídos na sequiência de quebra de cocos ou individuo } \\
\text { está fora da visão da câmera. }\end{array}$ \\
\hline
\end{tabular}


Tabela A.7 - Apresenta o índice de proficiência (quebra adequada e inadequada) e afinidade (com proximidade de $1 \mathrm{~m}$ e $10 \mathrm{~m}$ ) dos macacos prego da ilha do PET (CARVALHO, 2011)

\begin{tabular}{|c|c|c|c|c|c|c|c|}
\hline \multirow{2}{*}{ Sujeitos } & \multirow{2}{*}{ IP } & \multicolumn{4}{|c|}{ Frequência de Quebra } & \multicolumn{2}{|c|}{ Proximidade } \\
\hline & & Total & Q.A & Q.I & Q.P & $1 \mathrm{~m}$ & $10 \mathrm{~m}$ \\
\hline Edu & 1,5 & 2 & 0 & 0 & $1(0,5)$ & sem dados & sem dados \\
\hline Janete & 2,1 & 36 & $12(0,3)$ & 0 & $23(0,63)$ & $\begin{array}{l}\text { Suspeito } \\
\text { física } \\
\text { Abelha }\end{array}$ & Jaba, Suspeito \\
\hline Davi & 2,2 & 212 & $15(0,07)$ & 0 & $70(0,33)$ & $\begin{array}{c}\text { Claudia } \\
\text { Frida }\end{array}$ & $\begin{array}{c}\text { Claudia, Gorila } \\
\text { Frapê }\end{array}$ \\
\hline Medeiros & 2,2 & 189 & $43(0,22)$ & 0 & $85(0,44)$ & Frape & Vodka \\
\hline Suspeito & 2,5 & 117 & $27(0,23)$ & 0 & $39(0,33)$ & $\begin{array}{l}\text { Janete } \\
\text { Jaba }\end{array}$ & $\begin{array}{c}\text { Acácio } \\
\text { Janete, Gorila }\end{array}$ \\
\hline Vavá & 2,9 & 190 & $32(0,16)$ & $\mathrm{O}$ & $63(0,33)$ & Vodka & Vodka \\
\hline Angélica & 3,3 & 27 & $3(0,11)$ & 0 & $9(0,33)$ & Gorila & Gorila \\
\hline Vick & 3,5 & 387 & $72(0,18)$ & 0 & $127(0,32)$ & $\begin{array}{c}\text { Vodka } \\
\text { Careca } \\
\text { Val }\end{array}$ & $\begin{array}{l}\text { Vodka, Caju, Flufi } \\
\text { Floid }\end{array}$ \\
\hline Ana & 3,7 & 29 & $2(0,06)$ & 0 & $10(0,34)$ & $\begin{array}{c}\text { Aveia } \\
\text { Acácio }\end{array}$ & $\begin{array}{c}\text { Aveia } \\
\text { Gorila,Amora }\end{array}$ \\
\hline Cisca & 3,7 & 176 & $59(0,33)$ & 0 & $67(0,38)$ & Careca & Careca \\
\hline Filó & 3,8 & 6 & $2(0,33)$ & 0 & $2(0,33)$ & $\begin{array}{l}\text { Careca } \\
\text { Física } \\
\text { Floid }\end{array}$ & Careca \\
\hline Amora & 4,1 & 82 & $48(0,71)$ & 0 & $13(0,19)$ & $\begin{array}{c}\text { Fritz } \\
\text { Gorila } \\
\end{array}$ & Ana,Alice \\
\hline Jabá & 4,9 & 44 & $20(0,45)$ & 0 & $11(0,25)$ & Alice,Suspeito & Janete \\
\hline Flufi & 10,7 & 60 & $29(0,48)$ & $8(0,13)$ & $5(0,08)$ & Careca & Vick, Flor, Abelha \\
\hline Fritz & 13 & 7 & $3(0,42)$ & $3(0,42)$ & 0 & Flor, Amora & Frape, Frida \\
\hline Click & 14,5 & 11 & $5(0,45)$ & $1(0,09)$ & $2(0,18)$ & $\begin{array}{l}\text { Careca } \\
\text { Acácio }\end{array}$ & Careca \\
\hline Claudia & 17 & 16 & $5(0,31)$ & $\mathrm{o}$ & 0 & $\begin{array}{l}\text { Cloro } \\
\text { Davi }\end{array}$ & $\begin{array}{l}\text { Cloro } \\
\text { Davi }\end{array}$ \\
\hline Acácio & 17 & 8 & $4(0,5)$ & $1(0,12)$ & 0 & $\begin{array}{l}\text { Ana } \\
\text { Click }\end{array}$ & Suspeito \\
\hline Caca & 35,1 & 58 & $44(0,75)$ & 0 & $3(0,05)$ & Careca & Caju \\
\hline Alice & 0 & 1 & 0 & 0 & 0 & Jabá & Amora \\
\hline Física & $\mathrm{o}$ & 1 & $\mathrm{O}$ & 1 & o & $\begin{array}{c}\text { Janete } \\
\text { Filó } \\
\text { Frida } \\
\end{array}$ & Abelha \\
\hline Frida & $\mathrm{o}$ & $\mathrm{o}$ & $\mathrm{o}$ & 0 & o & $\begin{array}{l}\text { Frapê } \\
\text { Física } \\
\text { Davi }\end{array}$ & Fritz \\
\hline Caju & 0 & 0 & o & 0 & 0 & Careca & $\begin{array}{c}\text { Caca } \\
\text { Cuca,Vick,Frape }\end{array}$ \\
\hline Cuca & 0 & 0 & 0 & 0 & 0 & Careca & Cajú \\
\hline Val & 0 & 0 & 0 & 0 & 0 & Vick & Frape \\
\hline Flor & 0 & 0 & 0 & 0 & 0 & Fritz & Flufi \\
\hline Floid & 0 & 0 & 0 & 0 & 0 & Filó & Vick \\
\hline Frapê & 0 & $\mathrm{O}$ & $\mathrm{o}$ & 0 & 0 & $\begin{array}{c}\text { Frida } \\
\text { Medeiros }\end{array}$ & $\begin{array}{c}\text { Caju } \\
\text { Fritz } \\
\text { Davi,Val } \\
\end{array}$ \\
\hline Vodka & $\mathrm{o}$ & $\mathrm{O}$ & $\mathrm{O}$ & 0 & 0 & $\begin{array}{l}\text { Vavá } \\
\text { Vick }\end{array}$ & $\begin{array}{c}\text { Vavá } \\
\text { Vick,Medeiros } \\
\end{array}$ \\
\hline Gorila & $\mathrm{o}$ & 0 & o & 0 & 0 & $\begin{array}{l}\text { Angélica } \\
\text { Amora } \\
\text { Aveia }\end{array}$ & $\begin{array}{c}\text { Angélica } \\
\text { Ana,Davi,Suspeito }\end{array}$ \\
\hline Cloro & $\mathrm{O}$ & 0 & $\mathrm{O}$ & 0 & 0 & Claudia & $\begin{array}{l}\text { Careca } \\
\text { Claudia }\end{array}$ \\
\hline Abelha & 0 & 0 & 0 & 0 & 0 & Janete & Flufi, Física \\
\hline Aveia & o & 0 & 0 & 0 & 0 & $\begin{array}{c}\text { Ana } \\
\text { Gorila }\end{array}$ & Ana \\
\hline
\end{tabular}


APÊNDICE A - Comparação de Software de Redes Sociais 
Tabela A.1.1 - Características de softwares de Redes Sociais disponíveis no mercado x software desenvolvido (HANNEMAN; RIDDELE, 2011)

\begin{tabular}{|c|c|c|c|c|c|c|}
\hline \multicolumn{7}{|c|}{ Análise de Softwares de Redes Sociais } \\
\hline Produto & $\begin{array}{c}\text { Principal } \\
\text { Funcionalidade }\end{array}$ & $\begin{array}{l}\text { Formato } \\
\text { de Entrada }\end{array}$ & $\begin{array}{l}\text { Formato } \\
\text { de Saída }\end{array}$ & Plataforma & $\begin{array}{l}\text { Licença e } \\
\text { Custo }\end{array}$ & Observações \\
\hline $\begin{array}{l}\text { CUZCO } \\
\text { (RINALDI et } \\
\text { al., 2013) }\end{array}$ & $\begin{array}{l}\text { Gráfico da AGM } \\
\text { com filtros, } \\
\text { Banco de } \\
\text { Dados, interface } \\
\text { simples }\end{array}$ & $\begin{array}{l}\text {.csv, ou } \\
\text { pela própria } \\
\text { interface } \\
\text { gráfica do } \\
\text { sistema }\end{array}$ & $\begin{array}{l}\text { Interface } \\
\text { gráfica do } \\
\text { sistema }\end{array}$ & $\begin{array}{l}\text { Windows, } \\
\text { Linux, etc. } \\
\text { Java }\end{array}$ & $\begin{array}{l}\text { livre para } \\
\text { pesquisas e } \\
\text { colaboração } \\
\text { em grupo - } \\
\text { uso não } \\
\text { comercial }\end{array}$ & $\begin{array}{l}\text { E um software para análise e visualização de redes } \\
\text { dinâmicas através da AGM gerada de forma gráfica e } \\
\text { dinâmica com os dados provenientes do banco de dados } \\
\text { cadastrado. Podem ser utilizados vários filtros para a } \\
\text { geração da AGM. Ele proporciona fácil acesso } \\
\text { exploratório. Cada nó é uma ligação do grafo e tem } \\
\text { propriedades como nome, sigla, sexo, cor, formato, etc. } \\
\text { que são cadastrados e podem ser modificados no banco } \\
\text { de dados para serem exibidos na AGM gráfica. Além } \\
\text { disso, permite o crescimento ou diminuição (morte de } \\
\text { indivíduos) da rede e mudança estrutural. Permite a } \\
\text { identificacaão de subgrupos, papel elementar na análise da } \\
\text { teoria dos grafos como a popular ferramenta UCINET, } \\
\text { além de subgrafos do grafo. É uma ferramenta gratuita e } \\
\text { de código aberto como a maioria das outras para estudo } \\
\text { de psicologia de primatas não humanos, principalmente } \\
\text { nas universidades. Desenvolvido pelos alunos da USP de } \\
\text { São Paulo. Estará disponível no site para download em } \\
\text { breve. }\end{array}$ \\
\hline AllegroGraph & $\begin{array}{l}\text { gráfico, } \\
\text { Banco de } \\
\text { Dados, RDF } \\
\text { com } \\
\text { visualização } \\
\text { Gruff }\end{array}$ & RDF & RDF & $\begin{array}{l}\text { Linux, Mac, } \\
\text { Windows }\end{array}$ & $\begin{array}{l}\text { Livre para } \\
\text { uso não } \\
\text { comercial }\end{array}$ & $\begin{array}{l}\text { AllegroGraph é um software com BD transacional OLTP. } \\
\text { Inclui uma biblioteca de análise de redes sociais. Gruff é } \\
\text { gratuita e disponível para download. Exibe os grafos de } \\
\text { forma visual e subgrafos com suas relações. Por seleção } \\
\text { natural de recursos e predicados, pode-se construir o } \\
\text { grafo visual para mostrar uma variedade de } \\
\text { relacionamentos. O Guff pode também exibir tabelas de } \\
\text { todas as propriedades selecionadas ou gerar tabelas com } \\
\text { consultas que podem ser adicionados ao gráfico visual. }\end{array}$ \\
\hline CFinder & $\begin{array}{l}\text { Encontrar e } \\
\text { visualizar } \\
\text { comunidades }\end{array}$ & .txt & $\begin{array}{l}. t x t, . p d f, \\
. p s, \text {.svg, } \\
. e m f, . g i f, \\
. r a w, . b m p, \\
. j p g, . p n g,\end{array}$ & $\begin{array}{l}\text { Linux, Mac } \\
\text { OS X, } \\
\text { Windows, } \\
\text { Solaris }\end{array}$ & $\begin{array}{l}\text { Livre para } \\
\text { uso não } \\
\text { comercial }\end{array}$ & $\begin{array}{l}\text { É um software para encontrar e visualizar sobreposições } \\
\text { de RS com base no método percolation. Ele permite } \\
\text { customizar visualizações e permite facilidade para } \\
\text { encontrar comunidades. O pacote contém uma versão do } \\
\text { programa, bem como, os scripts apropriados. }\end{array}$ \\
\hline
\end{tabular}


continuação

\begin{tabular}{|c|c|c|c|c|c|c|}
\hline Produto & & & Formato & Plataforma & Licença e & Observações \\
\hline rivato & Funcionalidade & de Entrada & de Saída & & Custo & \\
\hline AutoMap & $\begin{array}{l}\text { Análise de } \\
\text { textos de redes }\end{array}$ &.$t x t$ &. $\operatorname{csv}$ & Java & $\begin{array}{l}\text { Livre para } \\
\text { uso não } \\
\text { comercial }\end{array}$ & $\begin{array}{l}\text { Ferramenta de mineração de dados que suporta a } \\
\text { extração de textos. Destinado a } 3 \text { tipos de informações: } \\
\text { análise de conteúdo, redes semânticas e redes } \\
\text { ontologicamente codificadas, ou seja, uma variedade de } \\
\text { linguagens naturais de processamento/extração de } \\
\text { informações e rotinas (por exemplo, redução e } \\
\text { normalização, resolução anáfora, e-mail, análise de } \\
\text { dados, computação de entropia, leitura escrita a partir } \\
\text { de padrões especificados pelo usuário para } \\
\text { armazenamento no BD) }\end{array}$ \\
\hline UCINET & $\begin{array}{l}\text { Análise de } \\
\text { ferramentas } \\
\text { para redes } \\
\text { sociais }\end{array}$ & $\begin{array}{l}\text { Excel, DI, } \\
\text { text, Pajek, } \\
\text {.net, } \\
\text { Krackplot, } \\
\text { Negopy, } \\
\text { proprietário } \\
\text { s (\#.d e } \\
\text { \#.h) }\end{array}$ & $\begin{array}{l}\text { Excel, DI, } \\
\text { text, Pajek, } \\
\text {.net, } \\
\text { Krackplot, } \\
\text { Mage, } \\
\text { Metis, } \\
\text { proprietário } \\
\text { s (\#.d e } \\
\text { \#.h) }\end{array}$ & windows & Shareware & $\begin{array}{l}\text { É um pacote abrangente para análise de dados das } \\
\text { questões de redes sociais, bem como os dados do } \\
\text { módulo } 1 \text { e } 2 \text {. Lida com } 32.767 \text { nós (com algumas } \\
\text { exceções), embora praticamente muitos procedimentos } \\
\text { fiquem em cerca de } 5.000-10.000 \text { nós. É um método que } \\
\text { inclui medidas de centralidade, identificação de } \\
\text { subgrupos que é um papel elementar na análise da teoria } \\
\text { dos grafos e faz análise estatística baseado em } \\
\text { permutação. Além disso, o pacote tem análises de } \\
\text { matrizes, tais como álgebra matricial e estatística } \\
\text { multivariada. }\end{array}$ \\
\hline Pajek & $\begin{array}{l}\text { Análise e } \\
\text { visualização de } \\
\text { redes de grande } \\
\text { escala }\end{array}$ & $\begin{array}{l}. \text { net, .paj, } \\
. \text { dat } \\
\text { (UCINET), } \\
. \text { ged, .bs, } \\
. m a c, . m o l\end{array}$ & $\begin{array}{l}. \text { net, .paj, } \\
. \text { dat } \\
\text { (UCINET). } \\
. x m l \\
\text { (graphML), } \\
. \text { bs }\end{array}$ & $\begin{array}{l}\text { Windows, } \\
\text { Linux, Mac } \\
\text { Os X }\end{array}$ & $\begin{array}{l}\text { Livre para } \\
\text { uso não } \\
\text { comercial }\end{array}$ & $\begin{array}{l}\text { É um programa amplamente usado para desenho de } \\
\text { redes, tem capacidade analítica significativa e pode ser } \\
\text { utilizado para calcular medidas de centralidade, identificar } \\
\text { buraco estrutural, bloco-modelo e assim por diante. As } \\
\text { macros podem ser gravadas para executar tarefas } \\
\text { repetitivas. Os dados podem ser enviados diretamente } \\
\text { para } R \text {, para calcular estatísticas adicionais. }\end{array}$ \\
\hline Tnet & $\begin{array}{l}\text { Análise de redes } \\
\text { sociais com peso, } \\
2 \text { módulos e redes } \\
\text { longitudinais no } R\end{array}$ & Edgelist & $\begin{array}{l}\text { pode ser } \\
\text { gravado em } \\
\text { R e quase } \\
\text { todos } \\
\text { formatos }\end{array}$ & $\begin{array}{l}\text { Windows, } \\
\text { Linux, } \\
\text { Mac }\end{array}$ & $\begin{array}{l}\text { Open Source } \\
\text { (GPL) }\end{array}$ & $\begin{array}{l}\text { É um pacotes para análise de redes sociais ponderada de } \\
\text { dois módulos, redes longitudinais e com possíveis } \\
\text { extensões. }\end{array}$ \\
\hline
\end{tabular}


continuação

\begin{tabular}{|c|c|c|c|c|c|c|}
\hline Produto & & & Formato & Plataforma & Licenca e & Observações \\
\hline & Funcionalidade & de Entrada & de Saída & & Custo & \\
\hline $\mathrm{R}$ & $\begin{array}{l}\text { Análise de } \\
\text { redes sociais } \\
\text { sem } \\
\text { versatilidade e } \\
\text { ambiente } \\
\text { popular } R\end{array}$ & $\begin{array}{l}\text { R pode ser } \\
\text { lido em } \\
\text { quase } \\
\text { todos os } \\
\text { formatos de } \\
\text { arquivos }\end{array}$ & $\begin{array}{l}\text { pode ser } \\
\text { gravado em } \\
\text { R e quase } \\
\text { todos os } \\
\text { formatos de } \\
\text { arquivos }\end{array}$ & $\begin{array}{l}\text { Windows, } \\
\text { Linux, } \\
\text { Mac }\end{array}$ & Open Source & $\begin{array}{l}\text { R contém vários pacotes relevantes para análise de rede } \\
\text { social: IGRAPH que é um pacote genérico para análise } \\
\text { de RS, executa análises sociométrica de redes; manipula } \\
\text { e exibe objetos de rede Tnet, realiza análise de redes } \\
\text { ponderadas, redes de dois módulos e redes longitudinal. } \\
\text { Implementa modelos com exponencial aleatório para } \\
\text { grafos, tem funções para rede de posição latente e } \\
\text { modelos de fragmentação, fornece modelagem estatística } \\
\text { com distribuição de grau. A maioria dos pacotes fazem } \\
\text { parte do statnet suíte obtidas através de um meta-pacote. }\end{array}$ \\
\hline $\begin{array}{l}\text { CoSBiLab } \\
\text { Graph }\end{array}$ & $\begin{array}{l}\text { Visualização, } \\
\text { análise e } \\
\text { manipulação de } \\
\text { redes }\end{array}$ & $\begin{array}{l}\text {.dot, .txt, .dl } \\
\text { (UCINet), } \\
\text {.spec(Beta } \\
\text { WB), .txt } \\
\text { (MRMC) }\end{array}$ & $\begin{array}{l}. d o t, . t x t, \\
. p n g, \\
. d l(U C I N e t), \\
. p m(\text { PRISM) }\end{array}$ & $\begin{array}{l}\text { Windows } \\
\text { (requer .net } \\
3.5 \text { ) }\end{array}$ & $\begin{array}{l}\text { Livre para } \\
\text { uso não } \\
\text { comercial }\end{array}$ & $\begin{array}{l}\text { CoSBiLabGraph é uma aplicação de análises visuais e } \\
\text { manipulação de Redes. Ele fornece alta personalização } \\
\text { para representação gráfica baseada em propriedades de } \\
\text { redes locais. Os nós podem ser agregados a dispositivos } \\
\text { no espaço manualmente ou por escolha de uma lista de } \\
\text { layouts pré-definidos. O conjunto de índices é fornecido } \\
\text { para medir a importância da posição dos nós em uma } \\
\text { rede. Eles podem ser combinados para definir uma } \\
\text { expressão matemática e um conjunto de exemplos está } \\
\text { disponível no site. }\end{array}$ \\
\hline Commetrix & $\begin{array}{l}\text { Análises e } \\
\text { visualização de } \\
\text { redes dinâmicas }\end{array}$ & $\begin{array}{l}\text { Arquivos de } \\
\text { importação } \\
\text { diretos da } \\
\text { fonte de } \\
\text { dados, BD } \\
\text { padrão e } \\
\text { especificaç } \\
\text { ões de } \\
\text { arquivo } \\
\text { embrev) }\end{array}$ & $\begin{array}{l}\text { Tabelas } \\
\text {.cvs para } \\
\text { RS, } \\
\text { palavras- } \\
\text { chave, } \\
\text { grafos, etc. } \\
\text { em GUl }\end{array}$ & $\begin{array}{l}\text { Qualquer } \\
\text { sistema } \\
\text { que use } \\
\text { Java } \\
\text { (plataforma } \\
\text { Windows) }\end{array}$ & $\begin{array}{l}\text { Teste } \\
\text { gratuito, } \\
\text { licenças } \\
\text { comerciais, } \\
\text { livre para } \\
\text { pesquisas e } \\
\text { colaboração } \\
\text { em grupo }\end{array}$ & $\begin{array}{l}\text { E um software para análise e visualização de redes } \\
\text { dinâmicas. Ele proporciona fácil acesso exploratório e tem } \\
\text { sido aplicado para estudar grafos em redes, mensagens, } \\
\text { levantamentos de RS, e-mail, newsgroups, etc. Cada nó é } \\
\text { uma ligação do evento podendo ter propriedades, etc. Isto } \\
\text { permite animações do crescimento da rede, mudança } \\
\text { estrutural, e tópicos de difusão. Um vídeo curto esta } \\
\text { disponível no site. }\end{array}$ \\
\hline Plotonic & $\begin{array}{l}\text { Análise de } \\
\text { redes sociais }\end{array}$ & $\begin{array}{l}\text { Frases e } \\
\text { palavras }\end{array}$ & $\begin{array}{l}\text { Gráficos e } \\
\text { textos }\end{array}$ & PHP & Comercial & $\begin{array}{l}\text { Serviço web interativo para monitorar redes sociais. } \\
\text { Compila dados de redes sociais psicográficas, } \\
\text { demográficas, charts geográficos e mapas. }\end{array}$ \\
\hline
\end{tabular}




\section{APENDICE B - Listagem das Análises dos Resultados}

Generation 999

$===========$
Fitness : 1,960530
Distance : 0,001056
StdDeviation: 0,008036
CoefAverage : 0,034226

Used parameters

\#\#\#\#\# \#\# \#\#\#\#\# \#\# \#

numstep $\quad: 200$

numRun : 20

numGenotype : 40

numGeneration: 1000

stdDevWeight : 0,600000

scale : 0,100000

Resulting flow

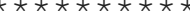

Run: 0, minDistance: 0,042180, Step: 199

Init $\left(\mathrm{CI}^{\wedge} \mathrm{O}\right): \mathrm{Ca} 1,0000 \mathrm{Cp} 0,0000 \mathrm{Me} 0,0000 \mathrm{Ml} 0,0000$

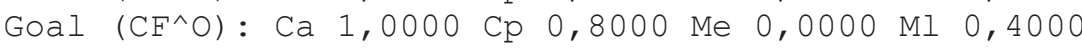

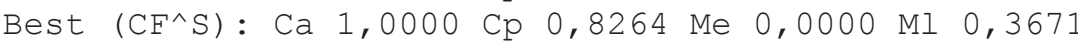

Last (---) : Ca 1,0000 Cp 0,8264 Me 0,0000 Ml 0,3671

Run: 1, minDistance: 0,008589, Step: 188

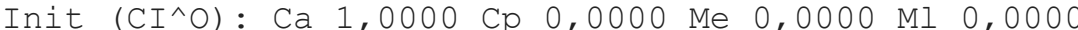

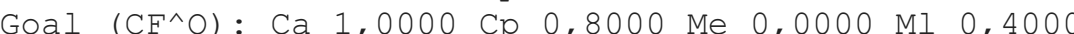

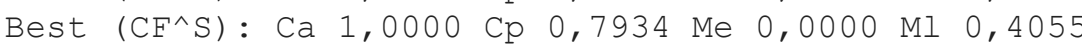

Last (---) : Ca 1,0000 Cp 0,8129 Me 0,0000 Ml 0,4270 
Run: 2, minDistance: 0,007158, Step: 191

Init $\left(\mathrm{CI}^{\wedge} \mathrm{O}\right): \mathrm{Ca} 1,0000 \mathrm{Cp}$ 0,0000 Me 0,0000 Ml 0,0000

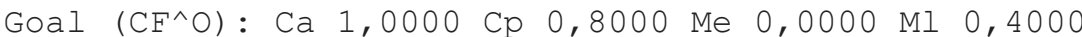

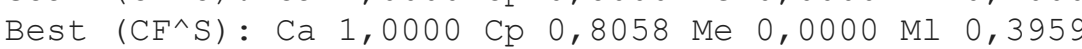

Last (---) : Ca 1,0000 Cp 0,8175 Me 0,0000 Ml 0,4187

Run: 3, minDistance: 0,003633, Step: 193

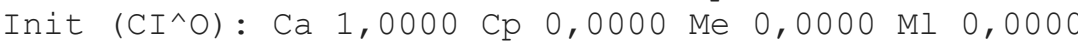

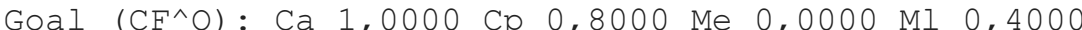

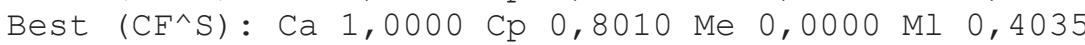

Last (---): Ca 1,0000 Cp 0,8106 Me 0,0000 Ml 0,4182

Run: 4, minDistance: 0,007788, Step: 189

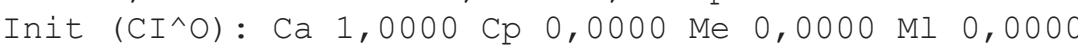

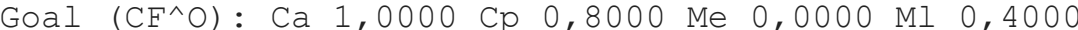

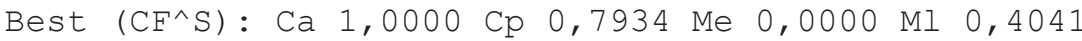

Last $(---)$ : Ca 1,0000 Cp 0,8058 Me 0,0000 Ml 0,4390

Run: 5, minDistance: 0,008395, Step: 199

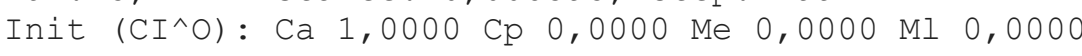

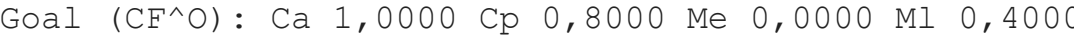

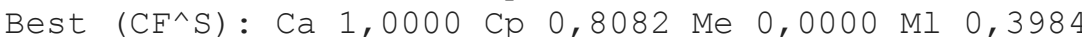
Last $(---)$ : Ca 1,0000 Cp 0,8082 Me 0,0000 Ml 0,3984

Run: 6, minDistance: 0,011844, Step: 188

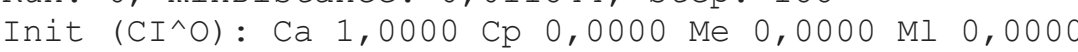

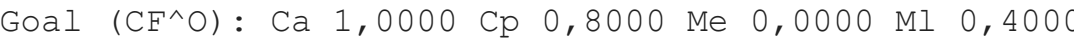

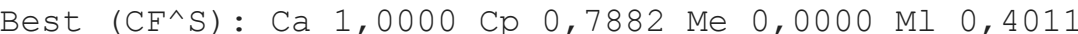
Last (----): Ca 1,0000 Cp 0,8082 Me 0,0000 MI 0,4224

Run: 7, minDistance: 0,006836, Step: 189

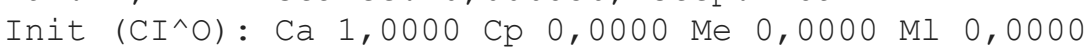

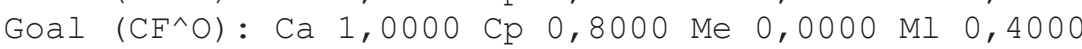

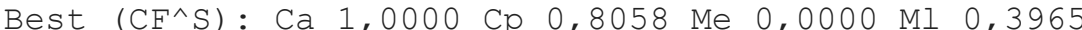
Last (----): Ca 1,0000 Cp 0,8198 Me 0,0000 Ml 0,4264

Run: 8, minDistance: 0,012709, Step: 192

Init $\left(\mathrm{CI}^{\wedge} \mathrm{O}\right)$ : $\mathrm{Ca} 1,0000 \mathrm{Cp} 0,0000 \mathrm{Me} 0,0000 \mathrm{Ml} 0,0000$

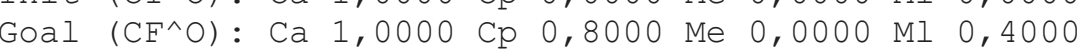


Best $\left(\mathrm{CF}^{\wedge} \mathrm{S}\right): \mathrm{Ca} 1,0000 \mathrm{Cp}$ 0,7934 Me 0,0000 Ml 0,4109 Last (----): Ca 1,0000 Cp 0,8034 Me 0,0000 Ml 0,4318

Run: 9, minDistance: 0,033011, Step: 199

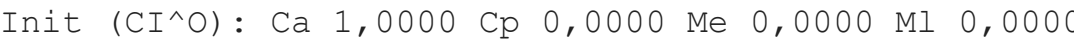

Goal $\left(\mathrm{CF}^{\wedge} \mathrm{O}\right): \mathrm{Ca} 1,0000 \mathrm{Cp}$ 0,8000 Me 0,0000 Ml 0,4000

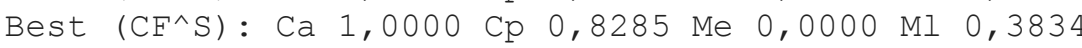

Last (----): Ca 1,0000 Cp 0,8285 Me 0,0000 Ml 0,3834

Run: 10, minDistance: 0,025370, Step: 188

Init $\left(\mathrm{CI}^{\wedge} \mathrm{O}\right)$ : $\mathrm{Ca} 1,0000 \mathrm{Cp}$ 0,0000 Me 0,0000 Ml 0,0000

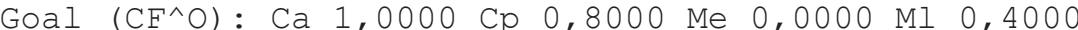

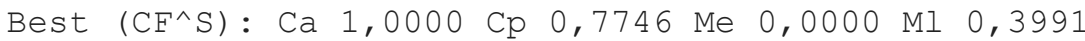

Last (---): Ca 1,0000 Cp 0,7934 Me 0,0000 Ml 0,4263

Run: 11, minDistance: 0,008700, step: 188

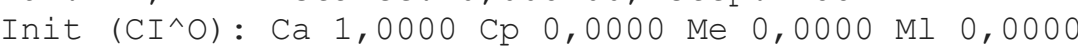

Goal $\left(\mathrm{CF}^{\wedge} \mathrm{O}\right): \mathrm{Ca} 1,0000 \mathrm{Cp}$ 0,8000 Me 0,0000 Ml 0,4000

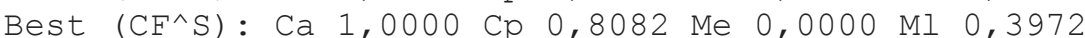

Last $(---)$ : Ca 1,0000 Cp 0,8264 Me 0,0000 Ml 0,4199

Run: 12, minDistance: 0,012963, Step: 189

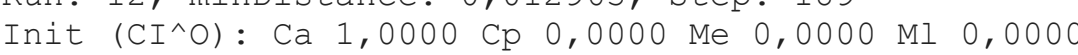

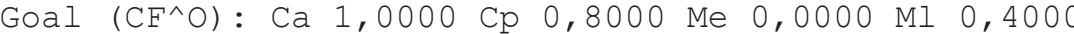

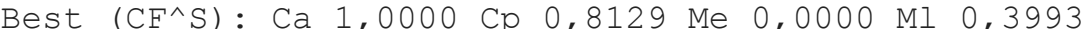
Last $(---)$ : Ca 1,0000 Cp 0,8285 Me 0,0000 Ml 0,4222

Run: 13, minDistance: 0,045469, Step: 198

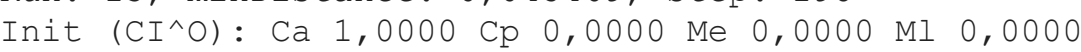

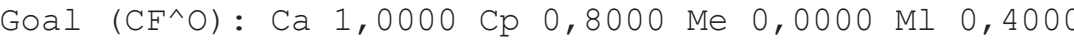

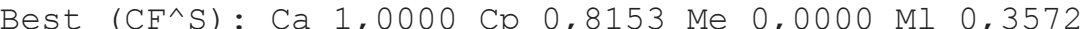
Last (---) : Ca 1,0000 Cp 0,8175 Me 0,0000 Ml 0,3572

Run: 14, minDistance: 0,020760, Step: 188

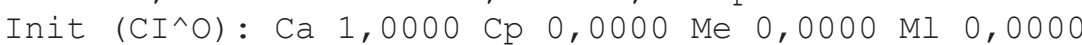

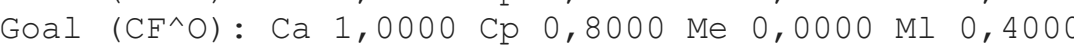

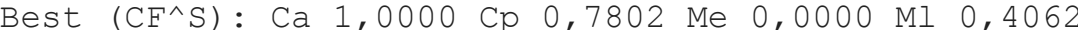
Last (---) : Ca 1,0000 Cp 0,7908 Me 0,0000 Ml 0,4527 
Run: 15, mindistance: 0,019660, Step: 189

Init $\left(\mathrm{CI}^{\wedge} \mathrm{O}\right)$ : $\mathrm{Ca} 1,0000 \mathrm{Cp}$ 0,0000 Me 0,0000 Ml 0,0000

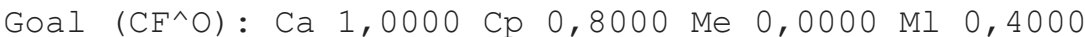

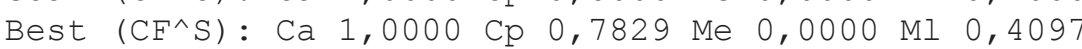

Last (---) : Ca 1,0000 Cp 0,7934 Me 0,0000 Ml 0,4500

Run: 16, minDistance: 0,027658, Step: 195

Init (CI^O): $\mathrm{Ca} 1,0000 \mathrm{Cp} 0,0000 \mathrm{Me} 0,0000 \mathrm{Ml} 0,0000$

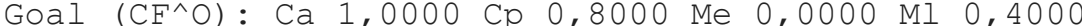

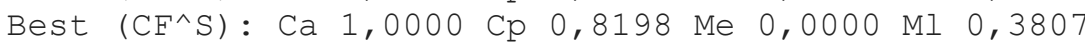

Last (---): Ca 1,0000 Cp 0,8285 Me 0,0000 Ml 0,3807

Run: 17, minDistance: 0,003660, Step: 190

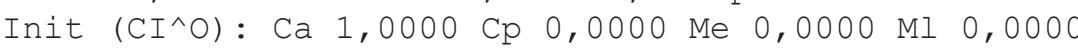

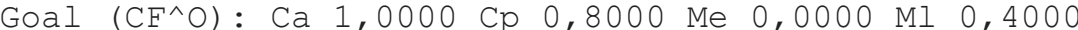

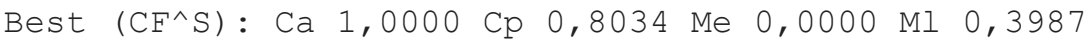

Last (---): Ca 1,0000 Cp 0,8153 Me 0,0000 Ml 0,4279

Run: 18, minDistance: 0,020348, Step: 199

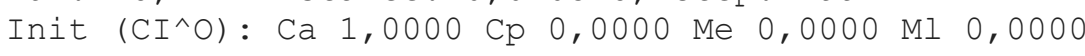
Goal $\left(\mathrm{CF}^{\wedge} \mathrm{O}\right): \mathrm{Ca} 1,0000 \mathrm{Cp}$ 0,8000 Me 0,0000 Ml 0,4000

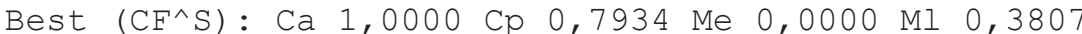
Last (---) : Ca 1,0000 Cp 0,7934 Me 0,0000 MI 0,3807

Run: 19, minDistance: 0,010721, Step: 195

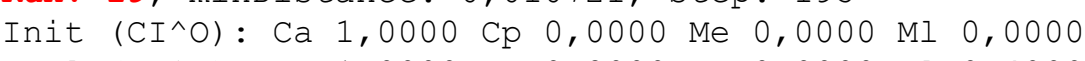

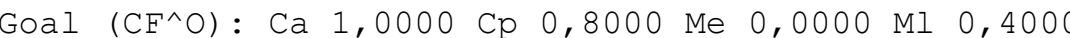
Best $\left(\mathrm{CF}^{\wedge} \mathrm{S}\right): \mathrm{Ca} 1,0000 \mathrm{Cp} 0,8010 \mathrm{Me} 0,0000 \mathrm{Ml} \mathrm{0,4107}$ Last (---) : Ca 1,0000 Cp 0,8082 Me 0,0000 Ml 0,4179

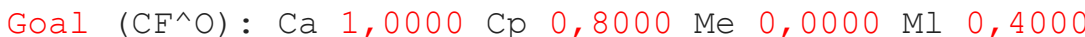
Average : $1,0000 \quad 0,8018 \quad 0,0000 \quad 0,3953$

Fitness : $\quad 1,960530$

Distance : 0,001677

StdDeviation: 0,009072

CoefAverage : 0,034226 
Activity coeficients:

BS IO I

BS : $0,000 \quad 0,000 \quad 0,123$

IO : $0,1850,0000,000$

$\mathrm{L}: 0,0000,0000,000$

\section{SocialModel}

\# \# \# \# \# \# \# \# \# \# \#

Proximity[4] $\left(\mathrm{P}^{\wedge} \mathrm{O}\right)$ :

Ca $\mathrm{Cp}$ Me $\mathrm{Ml}$

upuaçu, $\mathrm{CP}: 10,0$ 0,0 0,0 5,

Mei, Me: 0,0 0,0 0,0 5,0

Milo, $\mathrm{Ml}: 0,0 \quad 5,0 \quad 5,0 \quad 0,0$

Behaviour [4] (U^O) :

00] Subject: 'Ca':

Behaviour:

$00]$ BS $0,00,000$

$01]$ IO $0,00,000$

02 ] $1,00,002$

01] Subject: 'Cp':

Behaviour:

00] BS 1,00, 002

$01]$ IO $0,00,000$

02] L $0,00,000$

02] Subject: 'Me':

Behaviour:

$00]$ BS $0,00,000$

$01]$ IO $0,00,000$

02] L $1,00,002$ 
03] Subject: 'Ml' :

Behaviour:

$00]$ BS $0,00,000$

$01]$ IO $1,00,002$

02] L $0,00,000$

Execution time: $0: 5: 24.716$.

Listagem B.1.1 - Experimento 1 (hipotético): o mais simples possível para testar o software e explicar o funcionamento do modelo proposto (4 agentes e 3 atividades).

Generation 4999

$===========$
Fitness : 1,927509
Distance : 0,102325
StdDeviation: 0,018573
CoefAverage : 0,020418

Activity coeficients:

$$
A B \quad A L \quad B S \quad C A P
$$

$\mathrm{AB}: 0,000 \quad 0,000 \quad 0,000 \quad 0,013$

$\mathrm{AL}: 0,000 \quad 0,000 \quad 0,2950,000$

BS : $0,0000,0000,0000,000$

CAP: $0,000 \quad 0,0000,0190,000$ 


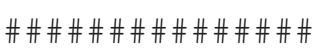

\begin{tabular}{|c|c|}
\hline numstep & $: 1500$ \\
\hline numRun & $: 10$ \\
\hline numGenotype & : 40 \\
\hline numGeneration & $: 5000$ \\
\hline stdDevWeight & $: 0,600000$ \\
\hline cale & $: 0,100000$ \\
\hline
\end{tabular}

Resulting flow

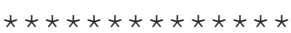

Run: 0, minDistance: 0,271611, Step: 1493

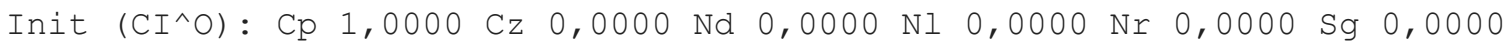

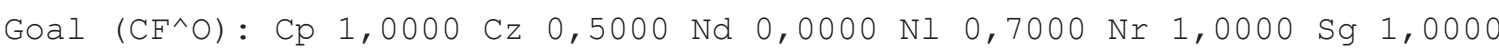

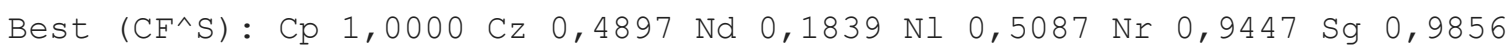

Last (---): Cp 1,0000 Cz 0,4907 Nd 0,1870 Nl 0,5087 Nr 0,9449 Sg 0,9856

Run: 1, minDistance: 0,242507, Step: 1390

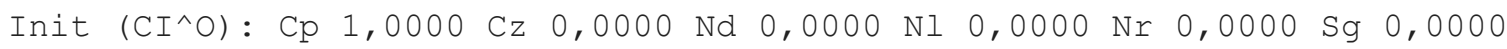

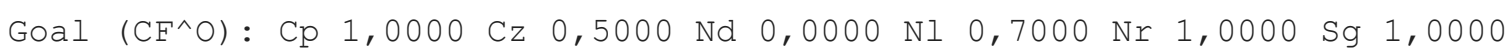

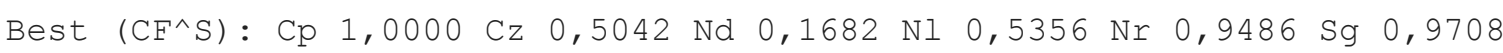
Last (---): Cp 1,0000 Cz 0,5357 Nd 0,1815 Nl 0,5463 Nr 0,9563 Sg 0,9800

Run: 2, minDistance: 0,282333, Step: 1489

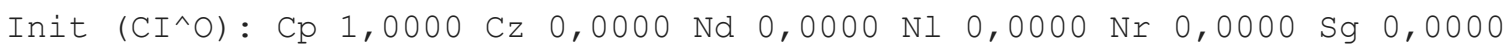




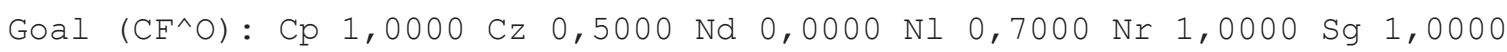

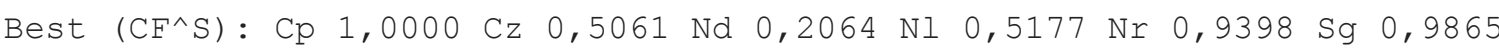
Last (---): Cp 1,0000 Cz 0,5090 Nd 0,2095 Nl 0,5186 Nr 0,9399 Sg 0,9865

Run: 3, minDistance: 0,261807, Step: 1493

Init $\left(\mathrm{CI}^{\wedge} \mathrm{O}\right): \mathrm{Cp} 1,0000 \mathrm{Cz} 0,0000 \mathrm{Nd} 0,0000 \mathrm{Nl} 0,0000 \mathrm{Nr} 0,0000 \mathrm{Sg} \mathrm{0,0000}$

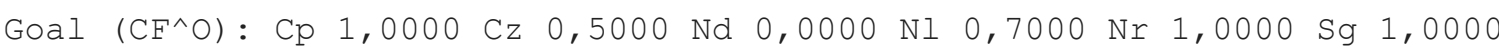

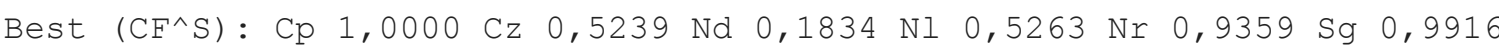
Last (---) : Cp 1,0000 Cz 0,5257 Nd 0,1834 Nl 0,5263 Nr 0,9359 Sg 0,9919

Run: 4, minDistance: 0,345076, step: 1496

Init $\left(\mathrm{CI}^{\wedge} \mathrm{O}\right): \mathrm{Cp} 1,0000 \mathrm{Cz} 0,0000 \mathrm{Nd} 0,0000 \mathrm{Nl} 0,0000 \mathrm{Nr} 0,0000 \mathrm{Sg} \mathrm{0,0000}$

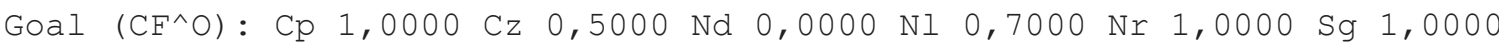

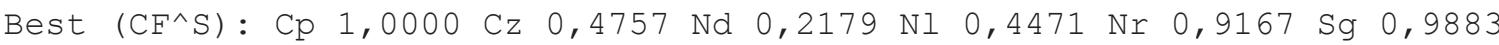
Last (---) : Cp 1,0000 Cz 0,4757 Nd 0,2194 Nl 0,4471 Nr 0,9167 Sg 0,9886

Run: 5, minDistance: 0,242145, Step: 1463

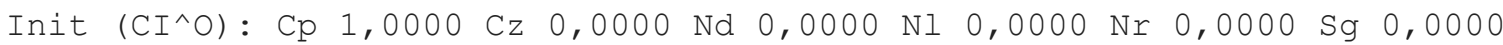

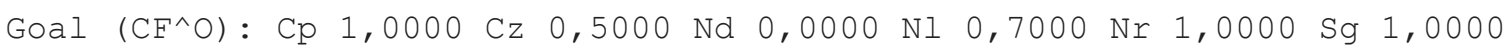

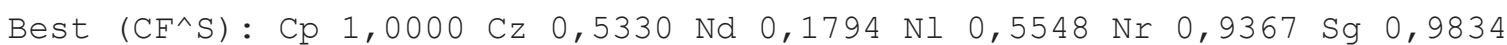
Last (---): Cp 1,0000 Cz 0,5410 Nd 0,1841 Nl 0,5582 Nr 0,9414 Sg 0,9853

Run: 6, minDistance: 0,274338, step: 1493

Init $\left(\mathrm{CI}^{\wedge} \mathrm{O}\right): \mathrm{Cp} 1,0000 \mathrm{Cz} 0,0000 \mathrm{Nd} 0,0000 \mathrm{NI} 0,0000 \mathrm{Nr}$ 0,0000 Sg 0,0000

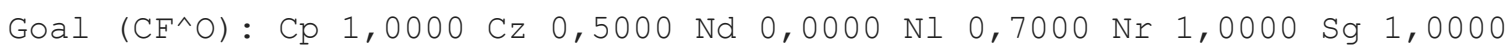

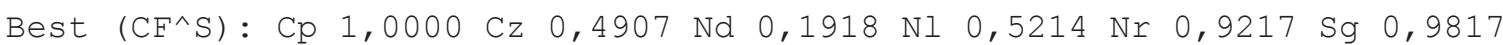


Last (---): Cp 1,0000 Cz 0,4917 Nd 0,1939 Nl 0,5214 Nr 0,9243 Sg 0,9817

Run: 7, minDistance: 0,233175, Step: 1499

Init $\left(\mathrm{CI}^{\wedge} \mathrm{O}\right): \mathrm{Cp} 1,0000 \mathrm{Cz} 0,0000 \mathrm{Nd} 0,0000 \mathrm{Nl} 0,0000 \mathrm{Nr}$ 0,0000 Sg 0,0000

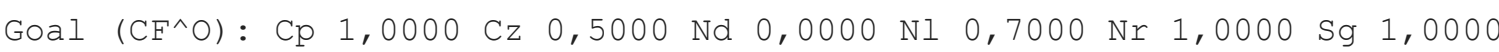

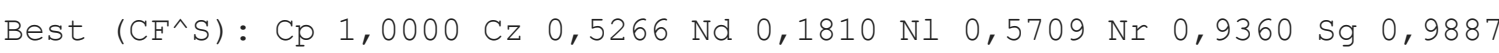

Last (---) : Cp 1,0000 Cz 0,5266 Nd 0,1810 Nl 0,5709 Nr 0,9360 Sg 0,9887

Run: 8, minDistance: 0,313072, step: 1495

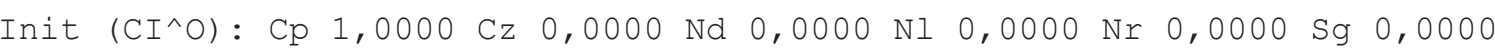

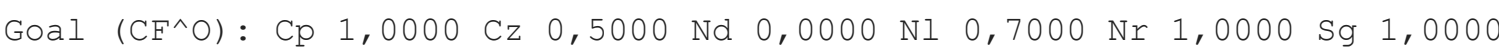

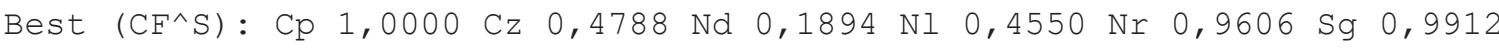
Last (---): Cp 1,0000 Cz 0,4798 Nd 0,1910 Nl 0,4550 Nr 0,9607 Sg 0,9915

Run: 9, minDistance: 0,314244, Step: 1499

Init $\left(\mathrm{CI}^{\wedge} \mathrm{O}\right)$ : $\mathrm{Cp} 1,0000 \mathrm{Cz} 0,0000 \mathrm{Nd} 0,0000 \mathrm{Nl} 0,0000 \mathrm{Nr} 0,0000 \mathrm{Sg} \mathrm{0,0000}$ Goal $\left(\mathrm{CF}^{\wedge} \mathrm{O}\right): \mathrm{Cp} 1,0000 \mathrm{Cz} 0,5000 \mathrm{Nd} 0,0000 \mathrm{Nl} 0,7000 \mathrm{Nr} 1,0000 \mathrm{Sg}$ 1,0000

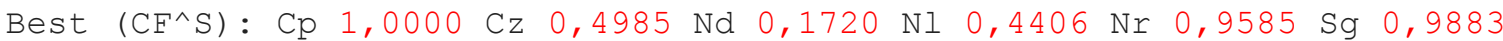
Last (----): Cp 1,0000 Cz 0,4985 Nd 0,1720 Nl 0,4406 Nr 0,9585 Sg 0,9883

Goal (CF^O): $\mathrm{Cp} 1,0000 \mathrm{Cz} 0,5000 \mathrm{Nd} 0,0000 \mathrm{Nl} 0,7000 \mathrm{Nr} 1,0000 \mathrm{Sg} \mathrm{1,0000}$
Average
1,0000
0,5027
0,1873
0,5078
0,9399
0,9856

Fitness : 1,927509

Distance : 0,112615

StdDeviation: 0,020858 
CoefAverage : 0,020418

Activity coeficients:

$$
A B \quad A L \quad B S \quad C A P
$$

$A B: 0,000 \quad 0,000 \quad 0,000 \quad 0,013$

AL : $0,000 \quad 0,000 \quad 0,2950,000$

BS : $0,0000,0000,0000,000$

CAP: $0,000 \quad 0,000 \quad 0,0190,000$

SocialModel

\#\# \#\# \# \# \# \# \# \# \#

Proximity $[6] \quad\left(\mathrm{P}^{\wedge} \mathrm{O}\right)$ :

$\begin{array}{rrrrrrr} & \text { Cp } & \text { Cz } & \text { Nd } & \text { Nl } & \text { Nr } & \text { Sg } \\ \text { Cupuaçu, Cp: } & 0,0 & 109,0 & 29,0 & 63,0 & 115,0 & 68,0 \\ \text { Cuzco, Cz: } 109,0 & 0,0 & 60,0 & 81,0 & 111,0 & 83,0 \\ \text { Nadir, Nd: } 29,0 & 60,0 & 0,0 & 88,0 & 45,0 & 37,0 \\ \text { Nuli, Nl: } & 63,0 & 81,0 & 88,0 & 0,0 & 70,0 & 67,0 \\ \text { Nur, Nr: } 115,0 & 111,0 & 45,0 & 70,0 & 0,0 & 52,0 \\ \text { Sagu, Sg: } & 68,0 & 83,0 & 37,0 & 67,0 & 52,0 & 0,0\end{array}$

Behaviour[6] (U^O) : 
00] Subject: 'Cp': Behaviour:

00] $\mathrm{AB} 0,00,000$

$01] \mathrm{AL} 0,00,000$

02] BS 0,92, 011

03] $\mathrm{CAP} 0,08,001$

01] Subject: 'Cz':

Behaviour:

$00] \mathrm{AB} 0,00,000$

$01] \mathrm{AL} 0,00,000$

02] BS 0,06, 001

03] $\mathrm{CAP} 0,94,016$

02] Subject: 'Nd':

Behaviour:

$00] \mathrm{AB} 0,00,000$

01] AL 0,00, 000

02] BS 0,00, 000

03] $\mathrm{CAP} 1,00,020$

03] Subject: 'Nl':

Behaviour:

$00] \mathrm{AB} 0,00,000$

01] AL 0,04, 001

02] BS 0,00, 000 
03] $\mathrm{CAP} 0,96,022$

04] Subject: 'Nr':

Behaviour:

00] $\mathrm{AB} 0,00,000$

$01] \mathrm{AL} 0,18,003$

02] BS 0,00, 000

03] $\mathrm{CAP} 0,82,014$

05] Subject: 'Sg':

Behaviour:

$00] \mathrm{AB} 0,00,000$

01] AL 0,59, 024

02] BS 0,00, 000

03] $\mathrm{CAP} 0,41,017$

Execution time: 2:56:36.363.

Listagem B.1.2 - Experimento 2 (hipotético intermediário): usando dados reais(6 agentes 4 atividades).

Used parameters

numstep : 800

numRun $\quad: 10$

numGenotype : 20

stdDevWeight : 0,600000

scale : 0,100000

Resulting flow

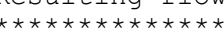


Run: 0, minDistance: 1,653424, Step: 713

Init (CI^O): Aa 0,0000 Al 0,0000 An 0,0000 Bu 0,0000 Ca 0,0000 Cj 0,0000 Cm 0,0000 Cp 1,0000 Cz 0,0000 Fl 0,0000 FO 0,0000 Fr 0,0000 Ha 0,0000 Hb

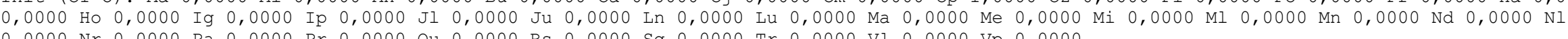
$0,0000 \mathrm{Nr} 0,0000 \mathrm{~Pa} 0,0000 \mathrm{Pr} 0,0000 \mathrm{Qu} 0,0000 \mathrm{Rs} 0,0000 \mathrm{Sg} 0,0000 \mathrm{Tr} 0,0000 \mathrm{Vl}$ 0,0000 Vp 0,0000

Goal ( $\left.\mathrm{CF} \wedge^{\wedge}\right)$ : Aa 0,0000 Al 0,0000 An 0,0000 Bu 0,0000 Ca 0,5000 Cj 0,0000 Cm 0,0000 Cp 1,0000 Cz 1,0000 Fl 0,0000 Fo 0,0000 Fr 0,7000 Ha 0,0000 Hb

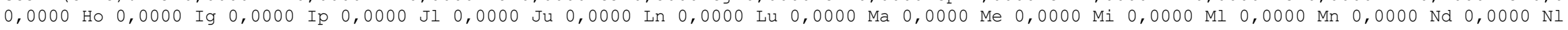

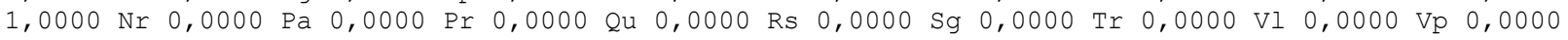

Best ( $\mathrm{CF}^{\wedge} \mathrm{S}$ ): Aa 0,0000 Al 0,0008 An 0,0000 Bu 0,0000 Ca 0,0021 Cj 0,0000 Cm 0,0000 Cp 1,0000 Cz 0,0012 Fl 0,0008 Fo 0,0000 Fr 0,0000 Ha 0,0001 Hb 0,0000 Ho 0,0000 Ig 0,0034 Ip 0,0000 Jl 0,0008 Ju 0,0008 Ln 0,0010 Lu 0,0000 Ma 0,0000 Me 0,0016 Mi 0,0000 Ml 0,0010 Mn 0,0000 Nd 0,0000 N1 $0,0008 \mathrm{Nr} 0,0038 \mathrm{~Pa} 0,0070 \mathrm{Pr} 0,0008$ Qu 0,0008 Rs 0,0000 Sg 0,0000 Tr 0,0000 Vl 0,0008 Vp 0,0000

Last (---): Aa 0,0000 Al 0,0008 An 0,0000 Bu 0,0000 Ca 0,0021 Cj 0,0000 Cm 0,0000 Cp 1,0000 Cz 0,0012 Fl 0,0008 Fo 0,0000 Fr 0,0000 Ha 0,0001 Hb 0,0000 Ho 0,0000 Ig 0,0034 Ip 0,0000 Jl 0,0008 Ju 0,0008 Ln 0,0010 Lu 0,0000 Ma 0,0000 Me 0,0016 Mi 0,0000 Ml 0,0010 Mn 0,0041 Nd 0,0000 N1 $0,0008 \mathrm{Nr} 0,0046 \mathrm{~Pa} 0,0070 \mathrm{Pr} 0,0008$ Qu 0,0008 Rs 0,0000 Sg 0,0000 Tr 0,0000 Vl 0,0008 Vp 0,0000

Run: 1, minDistance: 1,652605, Step: 429

Init $\left(\mathrm{CI}^{\wedge} \mathrm{O}\right)$ : Aa $0,0000 \mathrm{Al} 0,0000 \mathrm{An} 0,0000 \mathrm{Bu} 0,0000 \mathrm{Ca} 0,0000 \mathrm{Cj} 0,0000 \mathrm{Cm} 0,0000 \mathrm{Cp} 1,0000 \mathrm{Cz} 0,0000 \mathrm{Fl} 0,0000 \mathrm{Fo} 0,0000 \mathrm{Fr} 0,0000 \mathrm{Ha} 0,0000 \mathrm{Hb}$ $0,0000 \mathrm{Ho} 0,0000 \mathrm{Ig} 0,0000 \mathrm{Ip} 0,0000 \mathrm{Jl} 0,0000 \mathrm{Ju} 0,0000 \mathrm{Ln} 0,0000 \mathrm{Lu} 0,0000 \mathrm{Ma} 0,0000 \mathrm{Me} 0,0000 \mathrm{Mi} 0,0000 \mathrm{Ml} 0,0000 \mathrm{Mn} 0,0000 \mathrm{Nd} 0,0000 \mathrm{NI}$

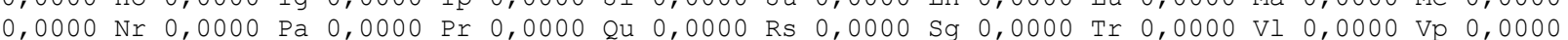

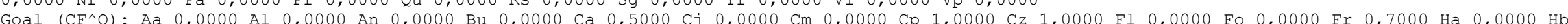

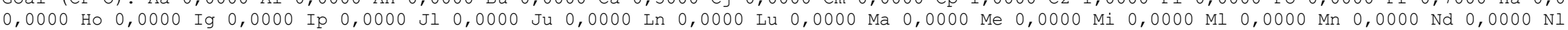
$1,0000 \mathrm{Nr} 0,0000 \mathrm{~Pa} 0,0000 \mathrm{Pr} 0,0000 \mathrm{Qu} 0,0000 \mathrm{Rs} 0,0000 \mathrm{Sg} 0,0000 \mathrm{Tr} 0,0000 \mathrm{Vl} 0,0000 \mathrm{Vp} \mathrm{0,0000}$

Best ( $\left.\mathrm{CF}^{\wedge} \mathrm{S}\right)$ : Aa 0,0000 Al 0,0000 An 0,0000 Bu 0,0000 Ca 0,0057 Cj 0,0000 Cm 0,0000 Cp 1,0000 Cz 0,0008 Fl 0,0000 Fo 0,0000 Fr 0,0000 Ha 0,0000 Hb $0,0000 \mathrm{Ho} 0,0000 \mathrm{Ig} 0,0016 \mathrm{Ip} \mathrm{0,0000} \mathrm{Jl} \mathrm{0,0000} \mathrm{Ju} \mathrm{0,0016} \mathrm{Ln} \mathrm{0,0059} \mathrm{Lu} \mathrm{0,0000} \mathrm{Ma} \mathrm{0,0022} \mathrm{Me} \mathrm{0,0010} \mathrm{Mi} \mathrm{0,0000} \mathrm{Ml} \mathrm{0,0000} \mathrm{Mn} \mathrm{0,0000} \mathrm{Nd} \mathrm{0,0000} \mathrm{N1}$

$0,0008 \mathrm{Nr} 0,0022 \mathrm{~Pa} \mathrm{0,0000} \operatorname{Pr} 0,0000$ Qu 0,0000 Rs 0,0058 Sg 0,0000 Tr 0,0000 Vl 0,0000 Vp 0,0000

Last (---): Aa 0,0001 Al 0,0000 An 0,0000 Bu 0,0000 Ca 0,0057 Cj 0,0000 Cm 0,0001 Cp 1,0000 Cz 0,0008 Fl 0,0000 Fo 0,0000 Fr 0,0001 Ha 0,0000 Hb $0,0000 \mathrm{Ho} 0,0001 \mathrm{Ig} 0,0026 \mathrm{Ip} 0,0000 \mathrm{Jl}$ 0,0001 Ju 0,0040 Ln 0,0059 Lu 0,0000 Ma 0,0022 Me 0,0034 Mi 0,0000 Ml 0,0016 Mn 0,0000 Nd 0,0000 N1 $0,0008 \mathrm{Nr} 0,0022 \mathrm{~Pa} 0,0026 \mathrm{Pr} 0,0000$ Qu 0,0041 Rs 0,0105 Sg 0,0001 Tr 0,0008 Vl 0,0000 Vp 0,0000

Run: 2, minDistance: 1,652655, Step: 556

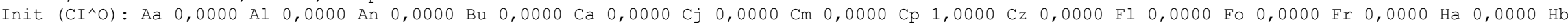
$0,0000 \mathrm{Ho} 0,0000 \mathrm{Ig}$ 0,0000 Ip 0,0000 Jl 0,0000 Ju 0,0000 Ln 0,0000 Lu 0,0000 Ma 0,0000 Me 0,0000 Mi 0,0000 Ml 0,0000 Mn 0,0000 Nd 0,0000 N1 $0,0000 \mathrm{Nr} 0,0000 \mathrm{~Pa} 0,0000 \mathrm{Pr} 0,0000$ Qu 0,0000 Rs 0,0000 Sg 0,0000 Tr 0,0000 V1 0,0000 Vp 0,0000

Goal ( $\left.\mathrm{CF}^{\wedge} \mathrm{O}\right)$ : Aa 0,0000 Al 0,0000 An 0,0000 Bu 0,0000 Ca 0,5000 Cj 0,0000 Cm 0,0000 Cp 1,0000 Cz 1,0000 Fl 0,0000 Fo 0,0000 Fr 0,7000 Ha 0,0000 Hb

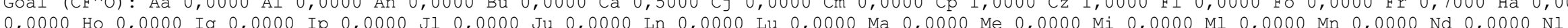

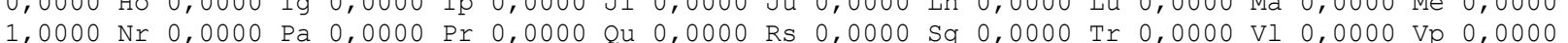

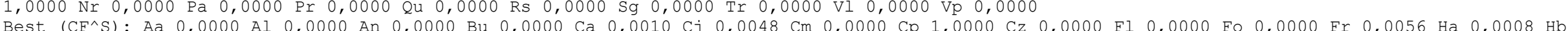

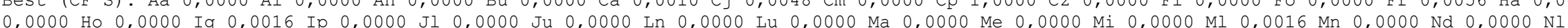

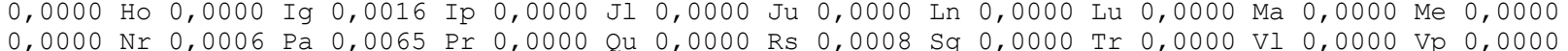

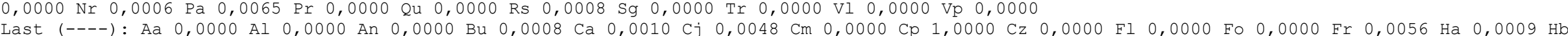

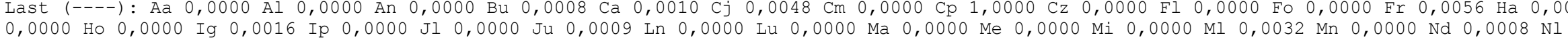

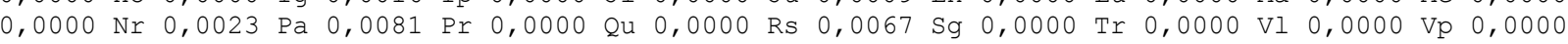

Run: 3, minDistance: 1,653858, Step: 385

Init (CI^O): Aa 0,0000 Al 0,0000 An 0,0000 Bu 0,0000 Ca 0,0000 Cj 0,0000 Cm 0,0000 Cp 1,0000 Cz 0,0000 Fl 0,0000 Fo 0,0000 Fr 0,0000 Ha 0,0000 Hb $0,0000 \mathrm{Ho} 0,0000 \mathrm{Ig}$ 0,0000 Ip 0,0000 Jl 0,0000 Ju 0,0000 Ln 0,0000 Lu 0,0000 Ma 0,0000 Me 0,0000 Mi 0,0000 Ml 0,0000 Mn 0,0000 Nd 0,0000 N1

$0,0000 \mathrm{Nr} 0,0000 \mathrm{~Pa} 0,0000 \operatorname{Pr} 0,0000$ Qu 0,0000 Rs 0,0000 Sg 0,0000 Tr 0,0000 Vl 0,0000 Vp 0,0000 
Goal $\left(\mathrm{CF}^{\wedge} \mathrm{O}\right): \mathrm{Aa} 0,0000 \mathrm{Al} 0,0000 \mathrm{An} 0,0000 \mathrm{Bu} 0,0000 \mathrm{Ca} 0,5000 \mathrm{Cj} 0,0000 \mathrm{Cm} 0,0000 \mathrm{Cp} 1,0000 \mathrm{Cz} 1,0000 \mathrm{Fl} 0,0000 \mathrm{Fo} 0,0000 \mathrm{Fr} 0,7000 \mathrm{Ha} 0,0000 \mathrm{Hb}$

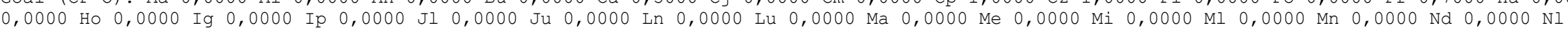
$1,0000 \mathrm{Nr} 0,0000 \mathrm{~Pa} 0,0000 \mathrm{Pr} 0,0000 \mathrm{Qu} 0,0000 \mathrm{Rs} 0,0000 \mathrm{Sg} \mathrm{0,0000} \operatorname{Tr} 0,0000 \mathrm{Vl} 0,0000 \mathrm{Vp} 0,0000$

Best ( $\left.\mathrm{CF}^{\wedge} \mathrm{S}\right)$ : Aa 0,0000 Al 0,0000 An 0,0000 Bu 0,0000 Ca 0,0032 Cj 0,0000 Cm 0,0000 Cp 1,0000 Cz 0,0000 Fl 0,0048 Fo 0,0000 Fr 0,0012 Ha 0,0000 Hb 0,0000 Ho $0,0000 \mathrm{Ig} 0,0000 \mathrm{Ip} \mathrm{0,0000} \mathrm{Jl} \mathrm{0,0000} \mathrm{Ju} \mathrm{0,0000} \mathrm{Ln} \mathrm{0,0000} \mathrm{Lu} \mathrm{0,0000} \mathrm{Ma} \mathrm{0,0000} \mathrm{Me} \mathrm{0,0000} \mathrm{Mi} \mathrm{0,0000} \mathrm{Ml} \mathrm{0,0000} \mathrm{Mn} \mathrm{0,0000} \mathrm{Nd} \mathrm{0,0008} \mathrm{N1}$ $0,0000 \mathrm{Nr} 0,0008 \mathrm{~Pa} 0,0032 \mathrm{Pr} 0,0000$ Qu 0,0000 Rs 0,0008 Sg 0,0008 Tr 0,0000 Vl 0,0000 Vp 0,0010

Last (---): Aa 0,0000 Al 0,0000 An 0,0000 Bu 0,0048 Ca 0,0032 Cj 0,0000 Cm 0,0000 Cp 1,0000 Cz 0,0000 Fl 0,0048 Fo 0,0000 Fr 0,0012 Ha 0,0010 Hb 0,0000 Ho 0,0001 Ig 0,0000 Ip 0,0000 Jl 0,0000 Ju 0,0016 Ln 0,0001 Lu 0,0014 Ma 0,0000 Me 0,0009 Mi 0,0000 Ml 0,0000 Mn 0,0000 Nd 0,0008 N1 $0,0000 \mathrm{Nr} 0,0024 \mathrm{~Pa} 0,0075 \mathrm{Pr} 0,0017$ Qu 0,0000 Rs 0,0008 Sg 0,0008 Tr 0,0000 vl 0,0000 Vp 0,0010

Run: 4, minDistance: 1,652000, Step: 642

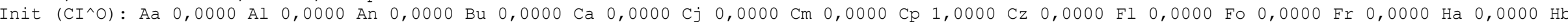
$0,0000 \mathrm{Ho} 0,0000 \mathrm{Ig} 0,0000 \mathrm{Ip} 0,0000 \mathrm{Jl} 0,0000 \mathrm{Ju} 0,0000 \mathrm{Ln}$ 0,0000 Lu 0,0000 Ma 0,0000 Me 0,0000 Mi 0,0000 Ml 0,0000 Mn 0,0000 Nd 0,0000 N1

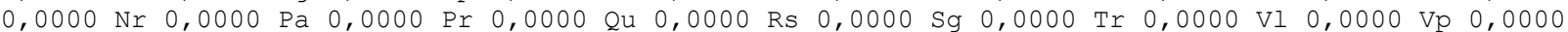

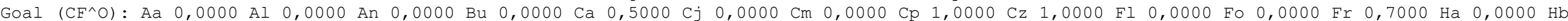

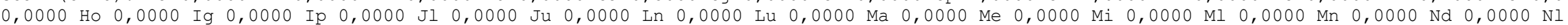
$1,0000 \mathrm{Nr} 0,0000 \mathrm{~Pa} 0,0000 \mathrm{Pr} 0,0000$ Qu 0,0000 Rs 0,0000 Sg 0,0000 Tr 0,0000 V1 0,0000 Vp 0,0000

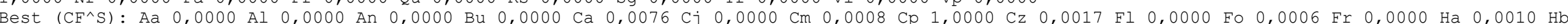

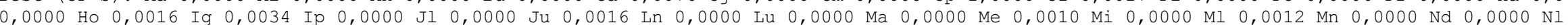

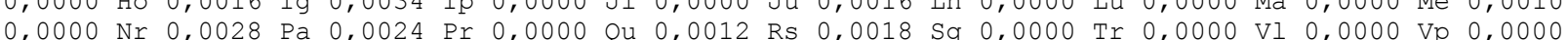

Last (---): Aa $0,0000 \mathrm{Al} 0,0000 \mathrm{An} 0,0000 \mathrm{Bu} 0,0009 \mathrm{Ca} 0,0076 \mathrm{Cj} 0,0000 \mathrm{Cm} 0,0008 \mathrm{Cp} 1,0000 \mathrm{Cz} 0,0017 \mathrm{Fl} 0,0000 \mathrm{FO} 0,0006 \mathrm{Fr} \mathrm{O}, 0000 \mathrm{Ha} 0,0010 \mathrm{Hb}$

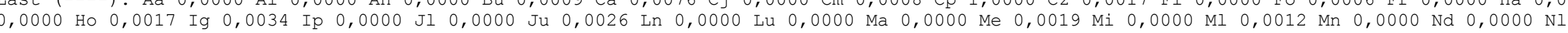
$0,0000 \mathrm{Nr} 0,0028 \mathrm{~Pa} \mathrm{0,0049} \mathrm{Pr} 0,0000$ Qu 0,0012 Rs 0,0018 Sg 0,0000 Tr 0,0000 VI 0,0000 Vp 0,0000

Run: 5, minDistance: 1,652623, Step: 784

Init (CI^O): Aa 0,0000 Al 0,0000 An 0,0000 Bu 0,0000 Ca 0,0000 Cj 0,0000 Cm 0,0000 Cp 1,0000 Cz 0,0000 Fl 0,0000 Fo 0,0000 Fr 0,0000 Ha 0,0000 Hb

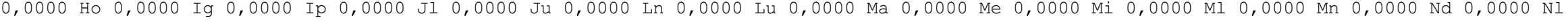
$0,0000 \mathrm{Nr} 0,0000 \mathrm{~Pa} 0,0000 \mathrm{Pr} 0,0000 \mathrm{Qu} 0,0000 \mathrm{Rs} 0,0000 \mathrm{Sg} 0,0000 \mathrm{Tr}$ 0,0000 Vl 0,0000 Vp 0,0000

Goal ( $\left.\mathrm{CF}^{\wedge} \mathrm{O}\right)$ : Aa 0,0000 Al 0,0000 An 0,0000 Bu 0,0000 Ca 0,5000 Cj 0,0000 Cm 0,0000 Cp 1,0000 Cz 1,0000 Fl 0,0000 Fo 0,0000 Fr 0,7000 Ha 0,0000 Hb $0,0000 \mathrm{Ho} 0,0000 \mathrm{Ig} 0,0000 \mathrm{Ip} 0,0000 \mathrm{Jl} 0,0000 \mathrm{Ju}$ 0,0000 Ln 0,0000 Lu 0,0000 Ma 0,0000 Me 0,0000 Mi 0,0000 Ml 0,0000 Mn 0,0000 Nd 0,0000 N1 $1,0000 \mathrm{Nr} 0,0000 \mathrm{~Pa} 0,0000 \mathrm{Pr} 0,0000$ Qu 0,0000 Rs 0,0000 Sg 0,0000 Tr 0,0000 Vl 0,0000 Vp 0,0000

Best ( $\mathrm{CF}^{\wedge} \mathrm{S}$ ): Aa 0,0000 Al 0,0000 An 0,0000 Bu 0,0000 Ca 0,0060 Cj 0,0009 Cm 0,0000 Cp 1,0000 Cz 0,0000 Fl 0,0001 Fo 0,0000 Fr 0,0021 Ha 0,0000 Hb

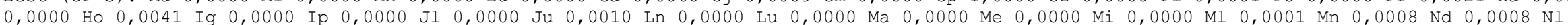
$0,0000 \mathrm{Nr} 0,0000 \mathrm{~Pa} 0,0017 \mathrm{Pr} 0,0068$ Qu 0,0012 Rs 0,0000 Sg 0,0000 Tr 0,0008 V1 0,0008 Vp 0,0000

Last (---): Aa 0,0000 Al 0,0000 An 0,0000 Bu 0,0000 Ca 0,0060 Cj 0,0009 Cm 0,0000 Cp 1,0000 Cz 0,0000 Fl 0,0001 Fo 0,0000 Fr 0,0021 Ha 0,0000 Hb

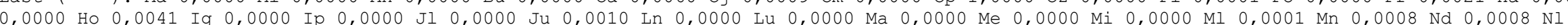

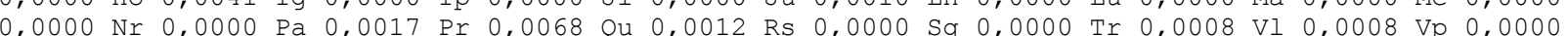

Run: 6, minDistance: 1,653737, Step: 772

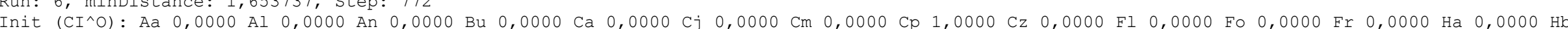

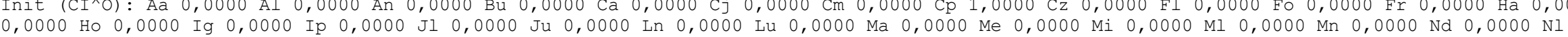
$0,0000 \mathrm{Nr} 0,0000 \mathrm{~Pa} 0,0000 \mathrm{Pr} 0,0000$ Qu 0,0000 Rs 0,0000 Sg 0,0000 Tr 0,0000 Vl 0,0000 Vp 0,0000

Goal $\left(\mathrm{CF}^{\wedge} \mathrm{O}\right)$ : Aa 0,0000 Al 0,0000 An 0,0000 Bu 0,0000 Ca 0,5000 Cj 0,0000 Cm 0,0000 Cp 1,0000 Cz 1,0000 Fl 0,0000 Fo 0,0000 Fr 0,7000 Ha 0,0000 Hb $0,0000 \mathrm{Ho} 0,0000 \mathrm{Ig} 0,0000 \mathrm{Ip} 0,0000 \mathrm{Jl} 0,0000 \mathrm{Ju}$ 0,0000 Ln 0,0000 Lu 0,0000 Ma 0,0000 Me 0,0000 Mi 0,0000 Ml 0,0000 Mn 0,0000 Nd 0,0000 N1 $1,0000 \mathrm{Nr} 0,0000 \mathrm{~Pa} 0,0000 \operatorname{Pr} 0,0000$ Qu 0,0000 Rs 0,0000 Sg 0,0000 Tr 0,0000 Vl 0,0000 Vp 0,0000

Best ( $\left.\mathrm{CF}^{\wedge} \mathrm{S}\right)$ : Aa 0,0000 Al 0,0000 An 0,0000 Bu 0,0008 Ca 0,0018 Cj 0,0000 Cm 0,0016 Cp 1,0000 Cz 0,0012 Fl 0,0008 Fo 0,0000 Fr 0,0008 Ha 0,0026 Hb 0,0008 Ho 0,0000 Ig 0,0026 Ip 0,0000 Jl 0,0048 Ju 0,0008 Ln 0,0000 Lu 0,0000 Ma 0,0000 Me 0,0074 Mi 0,0000 Ml 0,0016 Mn 0,0000 Nd 0,0000 Nl $0,0000 \mathrm{Nr} 0,0000 \mathrm{~Pa} 0,0019 \operatorname{Pr} 0,0048$ Qu 0,0000 Rs 0,0008 Sg 0,0008 Tr 0,0000 Vl 0,0000 Vp 0,0000 
Last (---): Aa 0,0000 Al 0,0000 An 0,0000 Bu 0,0008 Ca 0,0018 Cj 0,0000 Cm 0,0016 Cp 1,0000 Cz 0,0012 Fl 0,0008 Fo $0,0000 \mathrm{Fr} 0,0008 \mathrm{Ha} 0,0026 \mathrm{Hb}$

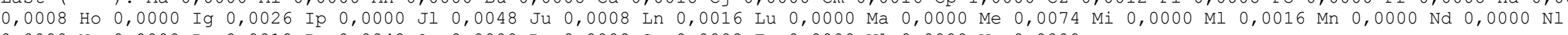

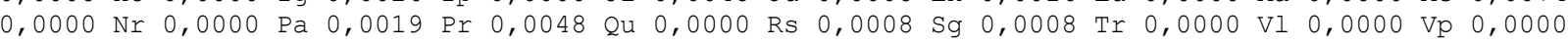

Run: 7, minDistance: 1,652601, Step: 748

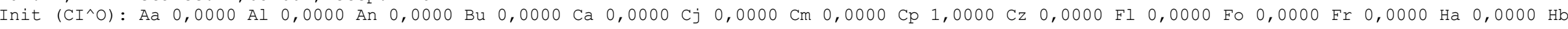

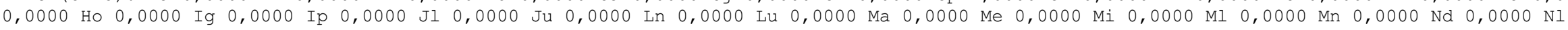

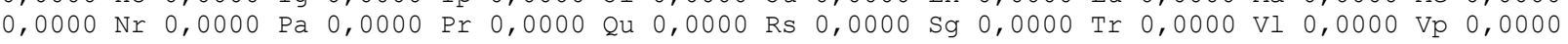

Goal ( $\left.\mathrm{CF}^{\wedge} \mathrm{O}\right)$ : Aa 0,0000 Al 0,0000 An 0,0000 Bu 0,0000 Ca 0,5000 Cj 0,0000 Cm 0,0000 Cp 1,0000 Cz 1,0000 Fl 0,0000 Fo 0,0000 Fr 0,7000 Ha 0,0000 Hb 0,0000 Ho 0,0000 Ig 0,0000 Ip 0,0000 Jl 0,0000 Ju 0,0000 Ln 0,0000 Lu 0,0000 Ma 0,0000 Me 0,0000 Mi 0,0000 Ml 0,0000 Mn 0,0000 Nd 0,0000 N1 $1,0000 \mathrm{Nr} 0,0000 \mathrm{~Pa} 0,0000 \mathrm{Pr} 0,0000 \mathrm{Qu} 0,0000 \mathrm{Rs} 0,0000 \mathrm{Sg} 0,0000 \mathrm{Tr}$ 0,0000 Vl 0,0000 Vp 0,0000

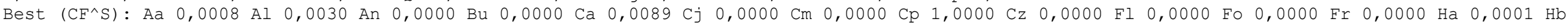
0,0008 Ho 0,0009 Ig 0,0008 Ip 0,0008 Jl 0,0000 Ju 0,0018 Ln 0,0000 Lu 0,0000 Ma 0,0000 Me 0,0025 Mi 0,0000 Ml 0,0009 Mn 0,0012 Nd 0,0000 N1 $0,0000 \mathrm{Nr} 0,0034 \mathrm{~Pa} 0,0027 \mathrm{Pr} 0,0000$ Qu 0,0000 Rs 0,0001 Sg 0,0000 Tr 0,0008 V1 0,0000 Vp 0,0008

Last (---): Aa 0,0008 Al 0,0030 An 0,0000 Bu 0,0000 Ca 0,0089 Cj 0,0000 Cm 0,0000 Cp 1,0000 Cz 0,0000 Fl 0,0000 Fo 0,0000 Fr 0,0000 Ha 0,0001 Hb

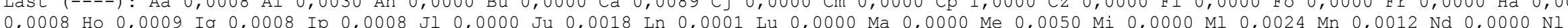
$0,0000 \mathrm{Nr} 0,0034 \mathrm{~Pa} 0,0037 \mathrm{Pr} 0,0000$ Qu 0,0000 Rs 0,0001 Sg 0,0000 Tr 0,0008 V1 0,0000 Vp 0,0008

Run: 8, minDistance: 1,654057 , Step: 657

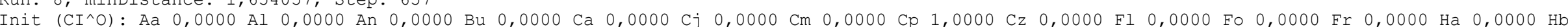

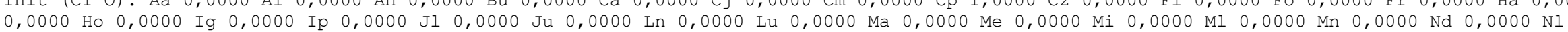
$0,0000 \mathrm{Nr} 0,0000 \mathrm{~Pa} 0,0000 \mathrm{Pr} 0,0000 \mathrm{Qu} 0,0000 \mathrm{Rs} 0,0000 \mathrm{Sg} 0,0000 \mathrm{Tr} 0,0000 \mathrm{VI} 0,0000 \mathrm{Vp} \mathrm{0,0000}$

Goal ( $\left.\mathrm{CF}^{\wedge} \mathrm{O}\right)$ : Aa 0,0000 Al 0,0000 An 0,0000 Bu 0,0000 Ca 0,5000 Cj 0,0000 Cm 0,0000 Cp 1,0000 Cz 1,0000 Fl 0,0000 Fo 0,0000 Fr 0,7000 Ha 0,0000 Hb

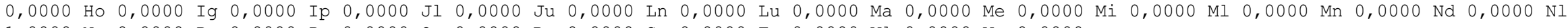
$1,0000 \mathrm{Nr} 0,0000 \mathrm{~Pa} \mathrm{0,0000} \operatorname{Pr} 0,0000$ Qu 0,0000 Rs 0,0000 Sg 0,0000 Tr 0,0000 Vl 0,0000 Vp 0,0000

Best ( $\left.\mathrm{CF}^{\wedge} \mathrm{S}\right)$ : Aa 0,0000 Al 0,0000 An 0,0000 Bu 0,0000 Ca 0,0008 Cj 0,0008 Cm 0,0000 Cp 1,0000 Cz 0,0008 Fl 0,0016 Fo 0,0000 Fr 0,0000 Ha 0,0000 Hb $0,0008 \mathrm{Ho} 0,0010 \mathrm{Ig}$ 0,0000 Ip 0,0000 Jl 0,0000 Ju 0,0008 Ln 0,0000 Lu 0,0000 Ma 0,0000 Me 0,0046 Mi 0,0000 Ml 0,0008 Mn 0,0000 Nd 0,0012 N1 $0,0008 \mathrm{Nr} 0,0000 \mathrm{~Pa} 0,0035 \mathrm{Pr} 0,0016 \mathrm{Qu} 0,0000 \mathrm{Rs} 0,0000 \mathrm{Sg} 0,0000 \operatorname{Tr} 0,0000 \mathrm{Vl}$ 0,0000 Vp 0,0000

Last (---): Aa 0,0000 Al 0,0000 An 0,0000 Bu 0,0000 Ca 0,0008 Cj 0,0008 Cm 0,0000 Cp 1,0000 Cz 0,0008 Fl 0,0016 Fo 0,0000 Fr 0,0000 Ha 0,0000 Hb $0,0008 \mathrm{Ho} 0,0018 \mathrm{Ig} 0,0000 \mathrm{Ip} 0,0000 \mathrm{Jl}$ 0,0000 Ju 0,0032 Ln 0,0000 Lu 0,0000 Ma 0,0000 Me 0,0056 Mi 0,0000 Ml 0,0008 Mn 0,0000 Nd 0,0012 N1 $0,0008 \mathrm{Nr} 0,0000 \mathrm{~Pa} 0,0044 \mathrm{Pr} 0,0016 \mathrm{Qu} \mathrm{0,0000} \mathrm{Rs} 0,0000 \mathrm{Sg} 0,0000 \mathrm{Tr}$ 0,0000 Vl 0,0000 Vp 0,0000

Run: 9, minDistance: 1,653057, Step: 695

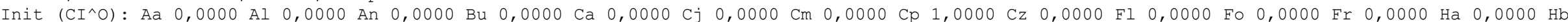
$0,0000 \mathrm{Ho} 0,0000 \mathrm{Ig} 0,0000 \mathrm{Ip} 0,0000 \mathrm{Jl} 0,0000 \mathrm{Ju} 0,0000 \mathrm{Ln} 0,0000 \mathrm{Lu} 0,0000 \mathrm{Ma} 0,0000 \mathrm{Me} 0,0000 \mathrm{Mi} 0,0000 \mathrm{Ml} 0,0000 \mathrm{Mn} 0,0000 \mathrm{Nd} 0,0000 \mathrm{~N} 1$

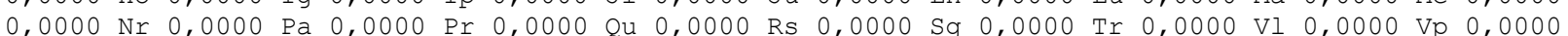

Goal ( $\left.\mathrm{CF}^{\wedge} \mathrm{O}\right):$ : Aa 0,0000 Al $0,0000 \mathrm{An} 0,0000 \mathrm{Bu} 0,0000 \mathrm{Ca} 0,5000 \mathrm{Cj} 0,0000 \mathrm{Cm} \mathrm{0,0000} \mathrm{Cp} 1,0000 \mathrm{Cz} 1,0000 \mathrm{Fl} 0,0000 \mathrm{FO} 0,0000 \mathrm{Fr} 0,7000 \mathrm{Ha} 0,0000 \mathrm{Hb}$

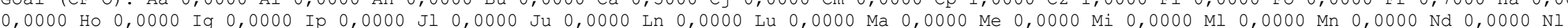

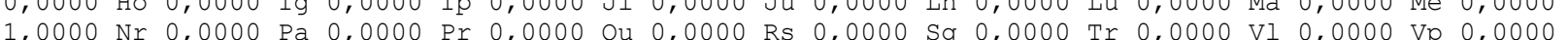

Best ( $\left.\mathrm{CF}^{\wedge} \mathrm{S}\right)$ : Aa 0,0000 Al 0,0000 An 0,0000 Bu 0,0000 Ca 0,0035 Cj 0,0008 Cm 0,0008 Cp 1,0000 Cz 0,0014 Fl $0,0000 \mathrm{Fo} 0,0000 \mathrm{Fr} 0,0008 \mathrm{Ha} 0,0008 \mathrm{Hb}$

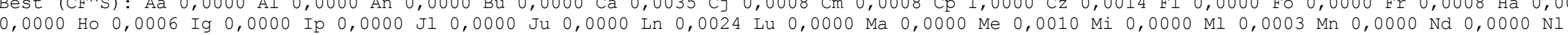

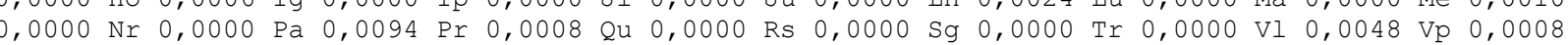

Last (---): Aa 0,0000 Al 0,0000 An 0,0008 Bu 0,0000 Ca 0,0035 Cj 0,0008 Cm 0,0008 Cp 1,0000 Cz 0,0014 Fl 0,0000 Fo 0,0000 Fr 0,0008 Ha 0,0008 Hb $0,0000 \mathrm{Ho} 0,0006 \mathrm{Ig} 0,0000 \mathrm{Ip} 0,0000 \mathrm{Jl} 0,0000 \mathrm{Ju}$ 0,0000 Ln 0,0024 Lu 0,0000 Ma 0,0000 Me 0,0010 Mi 0,0000 Ml 0,0003 Mn 0,0000 Nd 0,0000 N1

$0,0000 \mathrm{Nr} 0,0000 \mathrm{~Pa} 0,0094 \mathrm{Pr} 0,0008$ Qu 0,0000 Rs 0,0000 Sg 0,0000 Tr 0,0000 Vl 0,0048 Vp 0,0008

Goal ( $\left.\mathrm{CF}^{\wedge} \mathrm{O}\right)$ : Aa 0,0000 Al 0,0000 An 0,0000 Bu 0,0000 Ca 0,5000 Cj 0,0000 Cm 0,0000 Cp 1,0000 Cz 1,0000 Fl 0,0000 Fo 0,0000 Fr 0,7000 Ha 0,0000 Hb $0,0000 \mathrm{Ho} 0,0000 \mathrm{Ig} 0,0000 \mathrm{Ip} 0,0000 \mathrm{Jl}$ 0,0000 Ju 0,0000 Ln 0,0000 Lu 0,0000 Ma 0,0000 Me 0,0000 Mi 0,0000 Ml 0,0000 Mn 0,0000 Nd 0,0000 N1

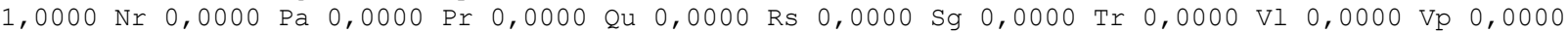


$\begin{array}{cccccccccccccccccccc}\text { Average } & : & 0,0001 & 0,0004 & 0,0000 & 0,0001 & 0,0041 & 0,0007 & 0,0003 & 1,0000 & 0,0007 & 0,0008 & 0,0001 & 0,0011 & 0,0005 \\ 0,0003 & 0,0008 & 0,0013 & 0,0001 & 0,0006 & 0,0009 & 0,0009 & 0,0000 & 0,0002 & 0,0019 & 0,0000 & 0,0007 & 0,0002 & 0,0003 & 0,003\end{array}$

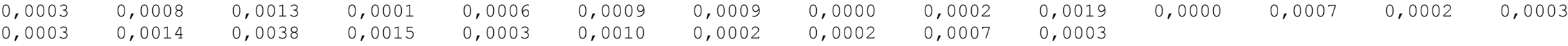

Fitness $\quad: 1,879682$

Distance $\quad: 0,271753$

StdDeviation: 0,001145

CoefAverage : 0,010941

Activity coeficients:

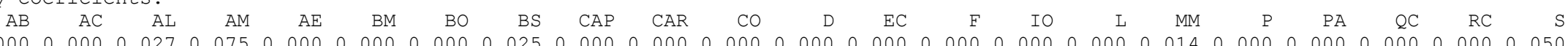

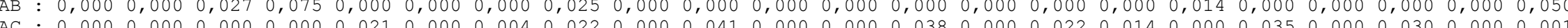

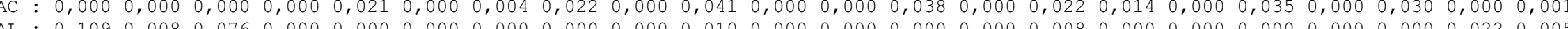

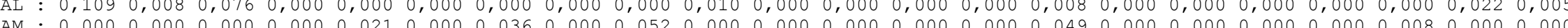

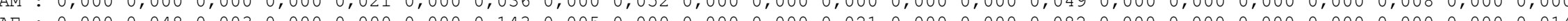
AM : :

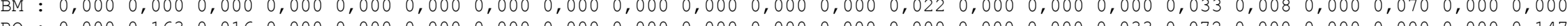

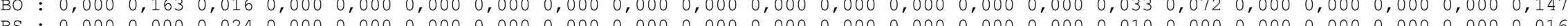

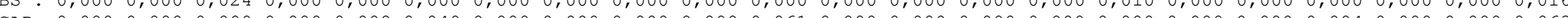
CAP : $0,0000,0000,0000,000,0080,0490,0000,000,0000,0000,0610,0000,0000,0000,0000,0000,0000,0000,0040,0000,0000,063$ CAR: $0,0000,0000,0000,0250,0850,0000,0000,0000,0000,0230,0000,0050,0000,0670,1190,0930,0000,0000,0000,0000,0000,057$

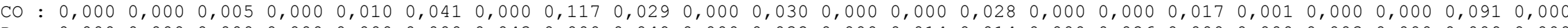
$\mathrm{D}: \mathrm{:}: 0,0000,0000,0000,0000,0000,0000,0430,0000,0490,0000,0320,0000,0140,0140,0000,0260,0000,0000,0030,0000,0090,000$

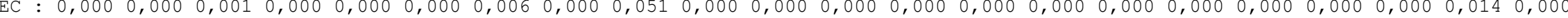

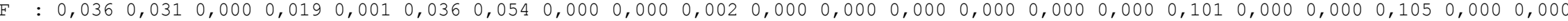

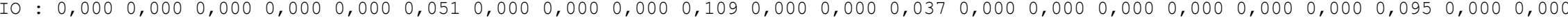

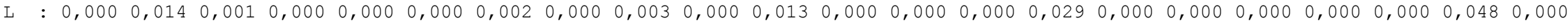

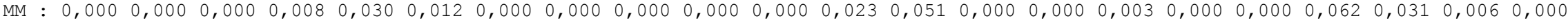

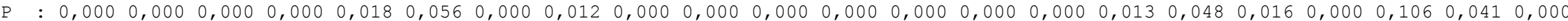

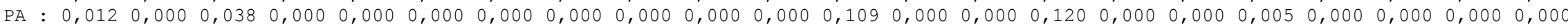

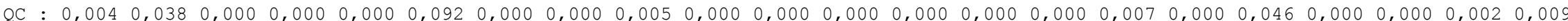

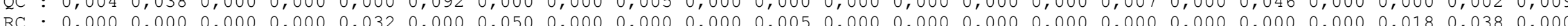

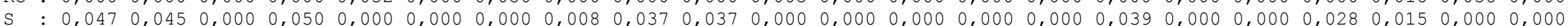

\section{SocialModel}

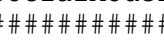

Proximity[37] $\left(\mathrm{P}^{\wedge} \mathrm{O}\right)$ :

$\begin{array}{rrcccccccccccccccccccccc} & & \mathrm{Aa} & \mathrm{Al} & \mathrm{An} & \mathrm{Bu} & \mathrm{Ca} & \mathrm{Cj} & \mathrm{Cm} & \mathrm{Cp} & \mathrm{Cz} & \mathrm{Fl} & \mathrm{F} O & \mathrm{Fr} & \mathrm{Ha} & \mathrm{Hb} & \mathrm{Ho} & \mathrm{Ig} & \mathrm{Ip} & \mathrm{Jl} & \mathrm{Ju} & \mathrm{Ln} & \mathrm{Lu}\end{array}$

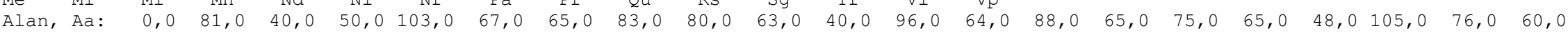
$\begin{array}{llllllllllllllll}59,0 & 100,0 & 23,0 & 116,0 & 71,0 & 20,0 & 50,0 & 82,0 & 66,0 & 74,0 & 72,0 & 73,0 & 50,0 & 37,0 & 102,0 & 59,0\end{array}$ $\begin{array}{llllllllllllllllllllll}\text { Alice, Al: } & 81,0 & 0,0 & 45,0 & 39,0 & 48,0 & 54,0 & 47,0 & 67,0 & 93,0 & 59,0 & 66,0 & 55,0 & 45,0 & 87,0 & 30,0 & 44,0 & 32,0 & 44,0 & 36,0 & 49,0 & 24,0\end{array}$ $\begin{array}{lllllllllllllllllll}38,0 & 41,0 & 50,0 & 50,0 & 27,0 & 26,0 & 45,0 & 67,0 & 28,0 & 18,0 & 85,0 & 43,0 & 101,0 & 66,0 & 89,0 & 78,0\end{array}$ 


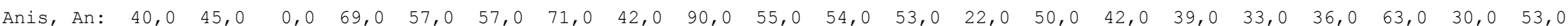
$\begin{array}{llllllllllllllll}25,0 & 54,0 & 58,0 & 14,0 & 17,0 & 78,0 & 74,0 & 57,0 & 35,0 & 30,0 & 84,0 & 41,0 & 86,0 & 88,0 & 66,0 & 28,0\end{array}$

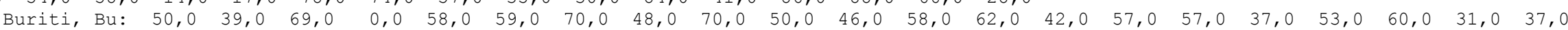
$47,0 \quad 69,0 \quad 54,0 \quad 57,0 \quad 32,0 \quad 61,0 \quad 54,0 \quad 36,0 \quad 41,0 \quad 46,0 \quad 100,0 \quad 65,0 \quad 45,0 \quad 71,0 \quad 67,0 \quad 52,0$

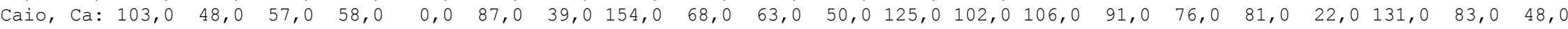

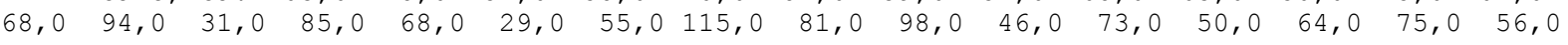

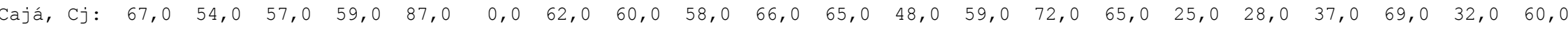
$44,0 \quad 54,0 \quad 44,0 \quad 54,0 \quad 56,0 \quad 51,0 \quad 56,0 \quad 75,0 \quad 48,0 \quad 58,0 \quad 33,0 \quad 69,0 \quad 76,0 \quad 78,0 \quad 64,0 \quad 54,0$

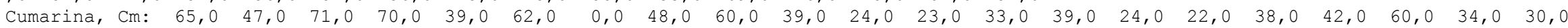

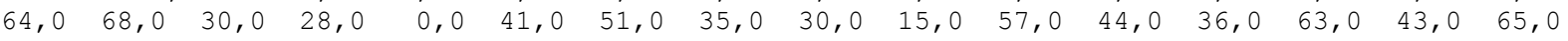

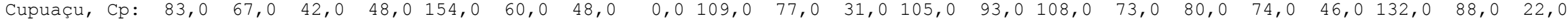

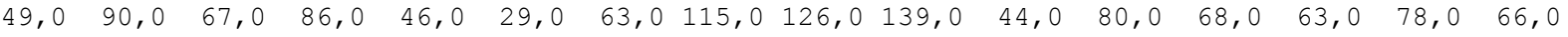

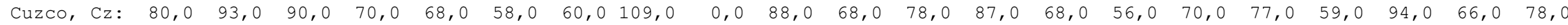
$78,0 \quad 65,0 \quad 99,0 \quad 93,0 \quad 65,0 \quad 60,0 \quad 81,0 \quad 111,0 \quad 75,0 \quad 71,0 \quad 80,0 \quad 52,0 \quad 83,0 \quad 71,0 \quad 84,0 \quad 61,0$

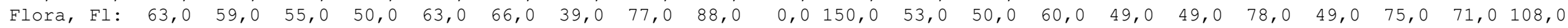

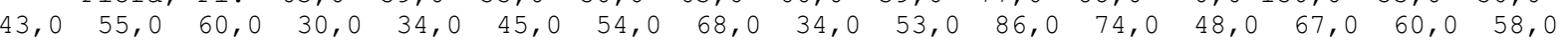

Floyd, Fo: $40,0 \quad 66,0 \quad 54,0 \quad 46,0 \quad 50,0 \quad 65,0 \quad 24,0 \quad 31,0 \quad 68,0 \quad 150,0 \quad 0,0 \quad 27,0 \quad 59,0 \quad 34,0 \quad 23,0 \quad 56,0 \quad 63,0 \quad 81,0 \quad 30,0 \quad 56,0 \quad 80,0$

$\begin{array}{llllllllllllllllll}51,0 & 50,0 & 34,0 & 27,0 & 46,0 & 43,0 & 62,0 & 73,0 & 32,0 & 42,0 & 76,0 & 59,0 & 60,0 & 48,0 & 51,0 & 41,0\end{array}$

Frapê, Fr: $96,0 \quad 55,0 \quad 53,0 \quad 58,0 \quad 125,0 \quad 48,0 \quad 23,0 \quad 105,0 \quad 78,0 \quad 53,0 \quad 27,0 \quad 0,0 \quad 130,0 \quad 98,0 \quad 109,0 \quad 107,0 \quad 88,0 \quad 49,0 \quad 111,0 \quad 102,0 \quad 76,0$ $37,0105,0 \quad 58,0 \quad 90,0 \quad 39,0 \quad 29,0 \quad 80,0 \quad 89,0 \quad 84,0 \quad 107,0 \quad 56,0 \quad 53,0 \quad 41,0 \quad 47,0 \quad 52,0 \quad 42,0$

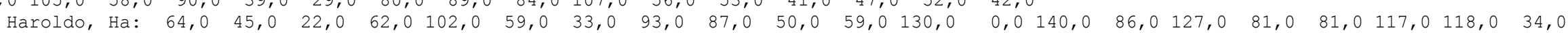

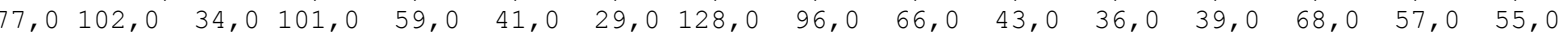

Hibiscus, $\mathrm{Hb}: \quad 88,0 \quad 87,0 \quad 50,0 \quad 42,0 \quad 106,0 \quad 72,0 \quad 39,0 \quad 108,0 \quad 68,0 \quad 60,0 \quad 34,0 \quad 98,0 \quad 140,0 \quad 0,0 \quad 76,0 \quad 86,0 \quad 90,0 \quad 47,0 \quad 76,0 \quad 134,0 \quad 62,0$ $\begin{array}{llllllllllllllll}53,0 & 109,0 & 35,0 & 65,0 & 47,0 & 48,0 & 66,0 & 190,0 & 75,0 & 77,0 & 56,0 & 58,0 & 70,0 & 48,0 & 80,0 & 78,0\end{array}$

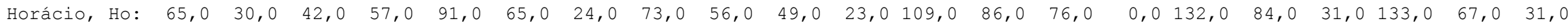

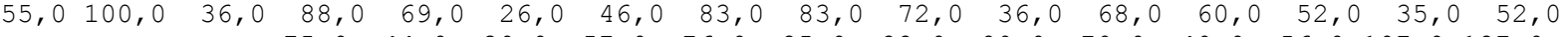

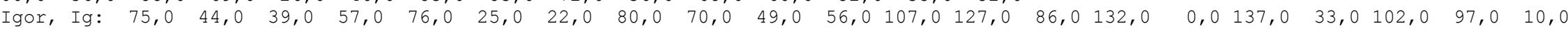
$\begin{array}{lllllllllllllllll}75,0 & 112,0 & 20,0 & 124,0 & 58,0 & 18,0 & 54,0 & 92,0 & 91,0 & 53,0 & 36,0 & 57,0 & 78,0 & 45,0 & 37,0 & 67,0\end{array}$

$\begin{array}{ccccccccccccccccccccc}\text { Ipê, Ip: } \quad 65,0 & 32,0 & 33,0 & 37,0 & 81,0 & 28,0 & 38,0 & 74,0 & 77,0 & 78,0 & 63,0 & 88,0 & 81,0 & 90,0 & 84,0 & 137,0 & 0,0 & 32,0 & 84,0 & 111,0 & 29,0\end{array}$ $\begin{array}{llllllllllllllll}76,0 & 81,0 & 33,0 & 74,0 & 45,0 & 28,0 & 38,0 & 102,0 & 67,0 & 78,0 & 36,0 & 62,0 & 65,0 & 49,0 & 44,0 & 43,0\end{array}$

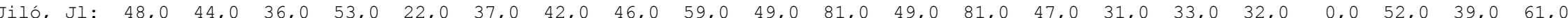
$\begin{array}{lllllllllllllllll}59,0 & 50,0 & 72,0 & 31,0 & 69,0 & 67,0 & 63,0 & 28,0 & 39,0 & 70,0 & 52,0 & 59,0 & 51,0 & 83,0 & 51,0\end{array}$

53,0 5

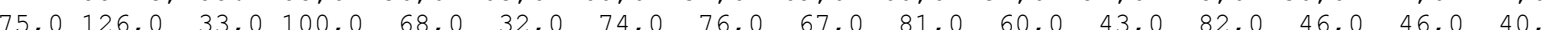

$\begin{array}{llllllllllllllllllll} & & \end{array}$

$\begin{array}{llllllllllllllllll}62,0 & 89,0 & 41,0 & 48,0 & 57,0 & 37,0 & 47,0 & 152,0 & 73,0 & 96,0 & 48,0 & 54,0 & 59,0 & 54,0 & 56,0 & 72,0\end{array}$

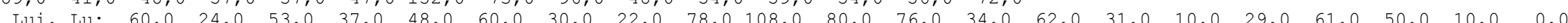

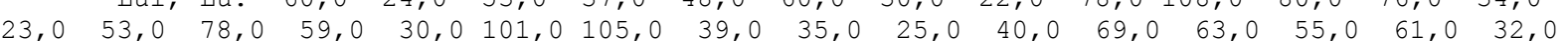

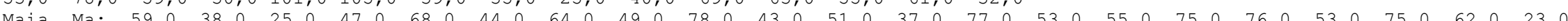
$\begin{array}{lllllllllllllllll}0,0 & 87,0 & 29,0 & 27,0 & 36,0 & 30,0 & 36,0 & 59,0 & 57,0 & 42,0 & 51,0 & 56,0 & 62,0 & 89,0 & 61,0 & 61,0\end{array}$

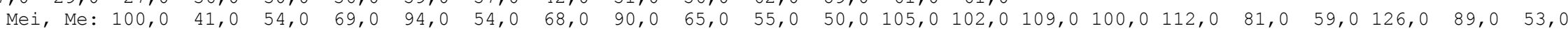

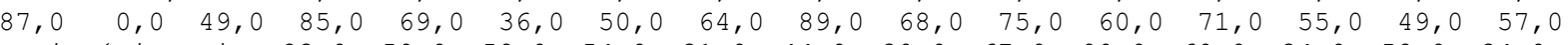

Mistério, Mi: $23,0 \quad 50,0 \quad 58,0 \quad 54,0 \quad 31,0 \quad 44,0 \quad 30,0 \quad 67,0 \quad 99,0 \quad 60,0 \quad 34,0 \quad 58,0 \quad 34,0 \quad 35,0 \quad 36,0 \quad 20,0 \quad 33,0 \quad 50,0 \quad 33,0 \quad 41,0 \quad 78,0$

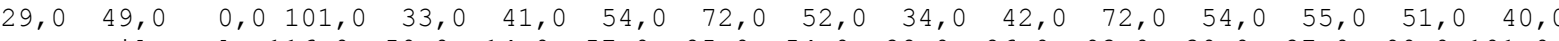

Milo, Ml: $116,0 \quad 50,0 \quad 14,0 \quad 57,0 \quad 85,0 \quad 54,0 \quad 28,0 \quad 86,0 \quad 93,0 \quad 30,0 \quad 27,0 \quad 90,0 \quad 101,0 \quad 65,0 \quad 88,0 \quad 124,0 \quad 74,0 \quad 72,0 \quad 100,0 \quad 48,0 \quad 59,0$

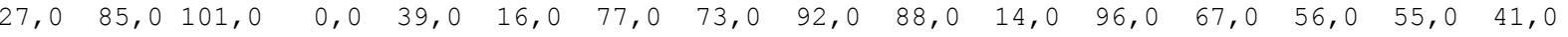

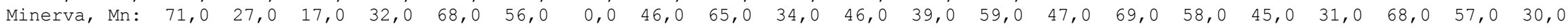

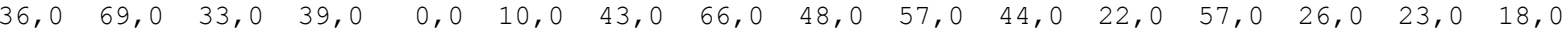




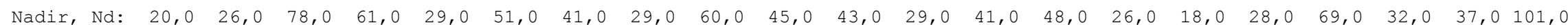
$\begin{array}{lllllllllllllllllll}30,0 & 36,0 & 41,0 & 16,0 & 10,0 & 0,0 & 88,0 & 45,0 & 20,0 & 18,0 & 46,0 & 36,0 & 37,0 & 77,0 & 59,0 & 30,0\end{array}$

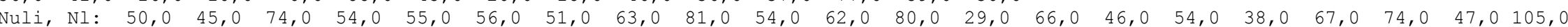
$\begin{array}{llllllllllllllll}36,0 & 50,0 & 54,0 & 77,0 & 43,0 & 88,0 & 0,0 & 70,0 & 27,0 & 56,0 & 45,0 & 60,0 & 67,0 & 49,0 & 65,0 & 63,0\end{array}$

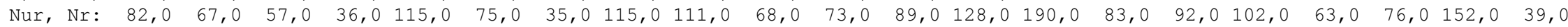
$\begin{array}{llllllllllllllllllllll}59,0 & 64,0 & 72,0 & 73,0 & 66,0 & 45,0 & 70,0 & 0,0 & 89,0 & 103,0 & 56,0 & 142,0 & 52,0 & 54,0 & 109,0 & 74,0\end{array}$

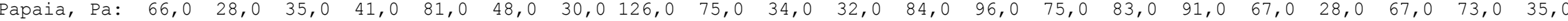

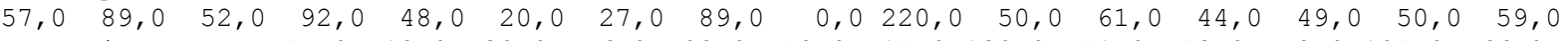

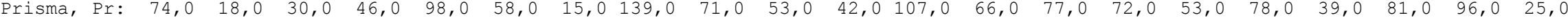
$42,0 \quad 68,0 \quad 34,0 \quad 88,0 \quad 57,0 \quad 18,0 \quad 56,0 \quad 103,0 \quad 220,0 \quad 0,0 \quad 56,0 \quad 36,0 \quad 40,0 \quad 41,0 \quad 50,0 \quad 58,0$

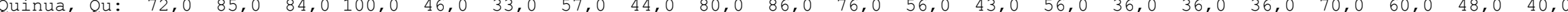

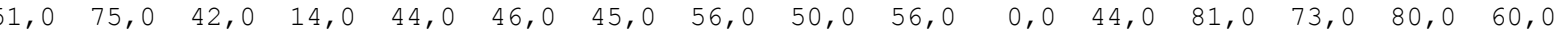

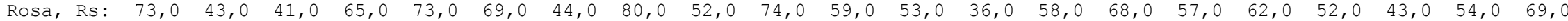

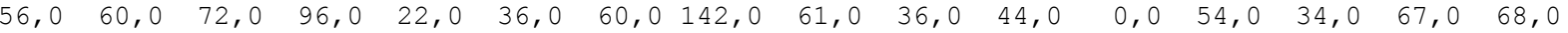

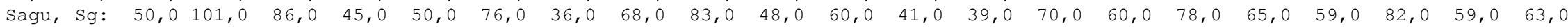
$\begin{array}{llllllllllllllllll}62,0 & 71,0 & 54,0 & 67,0 & 57,0 & 37,0 & 67,0 & 52,0 & 44,0 & 40,0 & 81,0 & 54,0 & 0,0 & 60,0 & 39,0 & 30,0\end{array}$

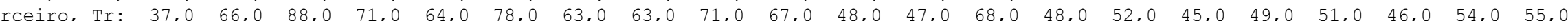
$\begin{array}{lllllllllllllllllll}89,0 & 55,0 & 55,0 & 56,0 & 26,0 & 77,0 & 49,0 & 54,0 & 49,0 & 41,0 & 73,0 & 34,0 & 60,0 & 0,0 & 78,0 & 59,0\end{array}$

Vali, Vl: $102,0 \quad 89,0 \quad 66,0 \quad 67,0 \quad 75,0 \quad 64,0 \quad 43,0 \quad 78,0 \quad 84,0 \quad 60,0 \quad 51,0 \quad 52,0 \quad 57,0 \quad 80,0 \quad 35,0 \quad 37,0 \quad 44,0 \quad 83,0 \quad 46,0 \quad 56,0 \quad 61,0$ $\begin{array}{lllllllllllllllllllllllll}61,0 & 49,0 & 51,0 & 55,0 & 23,0 & 59,0 & 65,0 & 109,0 & 50,0 & 50,0 & 80,0 & 67,0 & 39,0 & 78,0 & 0,0 & 100,0\end{array}$

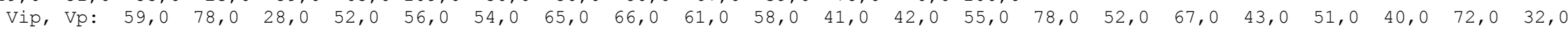
$61,0 \quad 57,0 \quad 40,0 \quad 41,0 \quad 18,0 \quad 30,0 \quad 63,0 \quad 74,0 \quad 59,0 \quad 58,0 \quad 60,0 \quad 68,0 \quad 30,059,0100,0 \quad 0,0$

Behaviour[37] $\left(U^{\wedge} 0\right)$ :

00] Subject: 'Aa':

Behaviour:

$00] A B \quad 0,00,000$

02] AL $0,01,002$

03] $\mathrm{AM} 0,00,000$

$04] \mathrm{AE} \quad 0,00,000$

05] $\mathrm{BM} 0,04,008$

05] BM 0,04, 008

06] BO $0,00,000$

07 87 $0,01,003$

08] CAP 0,05, 011

09] CAR 0,00, 000

10] CO $0,00,000$

11] D $0,08,017$

$\begin{array}{llll}12] & \mathrm{EC} & 0,00, & 001 \\ 13] & \mathrm{F} & 0,53, & 115\end{array}$

13] F $0,53,115$

14] IO $0,00,001$

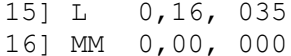

17] $\mathrm{P} \quad 0,01,002$

18] $\mathrm{PA} 0,00,000$

19] QC $0,00,000$

20] RC $0,00,000$

21] S $0,10,022$ 
01] Subject: 'Al':

Behaviour:

$00] \mathrm{AB} 0,01,001$

$01] \mathrm{AC} 0,00,000$

02] $\mathrm{AL} 0,04,006$

03] AM 0,03, 004

$04] \mathrm{AE} 0,00,000$

05] BM $0,00,000$

06] BO $0,00,000$

07] BS 0,00, 000

08] CAP 0,09, 013

09] CAR $0,00,000$

10] CO $0,00,000$

11] D $0,06,009$

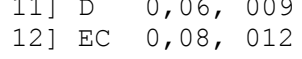

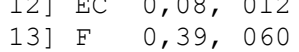

$14]$ IO $0,00,000$

15] L $0,05,007$

16] $\mathrm{MM} 0,00,000$

17] $\mathrm{P} \quad 0,03,004$

18] $\mathrm{PA} 0,00,000$

19] QC $0,00,000$

20] RC $0,01,002$

$21] \mathrm{S} 0,22,034$

02] Subject: 'An':

Behaviour:

$00] \mathrm{AB} 0,00,000$

01] AC $0,00,000$

02] AL 0,00, 000

03] $\mathrm{AM} 0,01,001$

04] $\mathrm{AE} 0,00,000$

05] BM $0,00,000$

06] $\mathrm{BO} 0,00,000$

07] BS 0,01, 001

08] CAP $0,02,003$

$\begin{array}{lll}09] & \text { CAR } 0,00, & 000 \\ 10] & \text { CO } 0,00, & 000\end{array}$

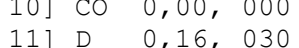

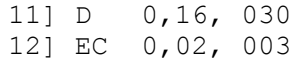

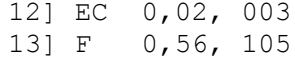

14] IO $0,00,000$

15] L $0,10,018$

16] MM $0,00,000$

17] $P \quad 0,01,002$

18] $\mathrm{PA} 0,00,000$

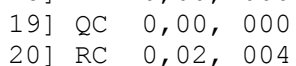


21] $S \quad 0,12,022$

03] Subject: 'Bu':

Behaviour:

$00] \mathrm{AB} 0,00,000$

01] $\mathrm{AC} 0,00,000$

02] AL $0,00,000$

03] $\mathrm{AM} 0,00,000$

$04] \mathrm{AE} 0,00,000$

05] BM 0,00, 000

06] $\mathrm{BO} 0,00,000$

07] BS $0,01,002$

08] CAP $0,07,012$

09] CAR 0,00, 000

10] CO 0,00, 000

$11]$ D $0,06,010$

$\begin{array}{lll}11] & D & 0\end{array}$

$\begin{array}{llll}12] & \text { EC } & 0,00, & 000 \\ 13] & \mathrm{F} & 0,35, & 062\end{array}$

$\begin{array}{lll}13] & \text { F } 0,01, & 001\end{array}$

$\begin{array}{lll}14] & \text { IO } 0,01, & 001 \\ 15] \text { L } 0,18, & 033\end{array}$

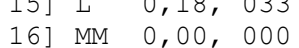

16] MM $0,00,000$

$\begin{array}{llll}17] & \mathrm{P} & 0,06, & 011 \\ 18] & \mathrm{PA} & 0,00, & 000\end{array}$

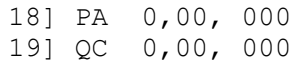

20] RC 0,01, 001

$21] \mathrm{S} \quad 0,26,047$

04] Subject: 'Ca':

Behaviour:

$00] A B \quad 0,01,001$

$01]$ AC $0,00,000$

03] AM $0,00,000$

03] AM $0,00,000$

$04] \mathrm{AE} 0,00,000$

05] $\mathrm{BM}, 0,02,003$

$06]$ BO $0,02,003$

07] BS 0,11, 020

08] CAP 0,04, 007

09] CAR $0,00,000$
10] CO $0,00,000$

10] $\mathrm{CO} \quad 0,00,000$

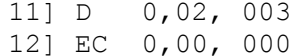

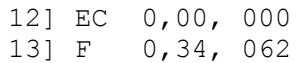

14] IO $0,01,001$

15] L $0,28,050$

16] MM $0,00,000$

17] $\mathrm{P} \quad 0,02,003$

18] $\mathrm{PA} 0,00,000$

19] $\mathrm{QC} 0,00,000$ 
20] RC $0,00,000$ 21] $\mathrm{S} \quad 0,15,028$

05] Subject: 'Cj':

Behaviour:

$00] \mathrm{AB} 0,00,000$

01] AC $0,01,002$

02] $\mathrm{AL} \quad 0,01,001$

03] $\mathrm{AM} 0,01,001$

$04] \mathrm{AE} 0,00,000$

05] BM $0,00,000$

06] BO $0,00,000$

07] BS $0,00,000$

08] CAP $0,05,007$

09] CAR 0,05, 007

09] CAR 0,00, 000

10] $\mathrm{CO} 0,00,000$

$\begin{array}{llll}11] & \mathrm{D} & 0,25, & 036 \\ 12] & \mathrm{EC} & 0,03, & 004\end{array}$

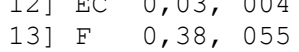

13] F $14,38,055$

15] L $0,13,019$

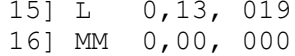

17] $\mathrm{P} 0,03,004$

18] PA $0,00,000$

19] QC $0,00,000$

20] RC $0,01,002$

21] S $0,08,012$

06] Subject: ' $\mathrm{Cm}$ '

Behaviour:

$\begin{array}{llll}00] & A B & 0,01, & 001 \\ 01] & A C & 0,00, & 000\end{array}$

11] AC $0,00,000$

02] AL $0,00,000$

03] AM 0,02, 003

$04] \mathrm{AE} 0,00,000$

05] $\mathrm{BM} 0,00,000$

06] BO $0,00,000$

07] BS $0,00,000$

08] CAP 0,10, 015

09] CAR $0,00,000$

10] $\mathrm{CO} 0,00,000$

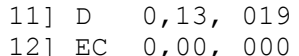

13] F $0,25,037$

14] IO $0,00,000$

15] L $0,17,026$

16] $\mathrm{MM} 0,00,000$

17] P $0,04,006$

18] $\mathrm{PA} 0,00,000$ 
19] $\mathrm{QC} 0,00,000$ $\begin{array}{llll}20] & R C & 0,02, & 003 \\ 21] & S & 0,27, & 041\end{array}$

07] Subject: 'Cp':

Behaviour:

00] $\mathrm{AB} 0,00,000$

01] AC $0,00,000$

02] $\mathrm{AL} 0,00,000$

03] $\mathrm{AM} 0,00,000$

04] $\mathrm{AE} 0,00,000$

05] BM $0,01,002$

06] $\mathrm{BO} 0,01,002$

07] BS $0,08,011$

08] $C A P, 08,011$

09] CAP 0,01, 001

09] CAR $0,00,000$

10] CO $0,00,000$

11] $D$ 0,05, 007

$\begin{array}{llll}12] & \mathrm{EC} & 0,01, & 001 \\ 13] & \mathrm{F} & 0,40, & 055\end{array}$

$14]$ IO $0,01,001$

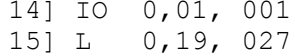

$\begin{array}{llll}15] & \mathrm{L} & 0,19, & 027 \\ 16] & 0,00, & 000\end{array}$

17] P 0, 03, 004

18] $\mathrm{PA} 0,00,000$

19] $\mathrm{QC} \quad 0,03,004$

$\begin{array}{llll}20] & \mathrm{RC} & 0,01, & 001 \\ 21] & \mathrm{S} & 0,17, & 023\end{array}$

08] Subject: 'Cz'.

Behaviour:

$00] \mathrm{AB} 0,00,000$

$01] \mathrm{AC} \quad 0,00,000$

02] AL $0,00,000$

03] AM 0,00, 000

$04] \mathrm{AE} \quad 0,02,002$

05] $\mathrm{BM} 0,00,000$

06] $\mathrm{BO} 0,01,001$

07] BS 0,01, 001

08] CAP $0,13,016$

09] CAR $0,00,000$

10] $\mathrm{CO} \quad 0,00,000$

12] EC $0,01,001$

13] $\mathrm{F} \quad 0,41,053$

14] IO $0,00,000$

15] L $0,20,025$

16] MM $0,00,000$

17] $\mathrm{P} 0,04,005$ 
18] $\mathrm{PA} 0,00,000$

19] $\mathrm{QC} \quad 0,00,000$

$\begin{array}{llll}20] & \mathrm{RC} & 0,00, & 000 \\ 21] \mathrm{S} & 0,16, & 021\end{array}$

09] Subject: 'Fl':

Behaviour:

00] $\mathrm{AB} 0,00,000$

$01] \mathrm{AC} 0,00,000$

02] $\mathrm{AL} 0,00,000$

03] AM $0,00,000$

$04] \mathrm{AE} 0,01,002$

05] BM $0,00,000$

06] BO $0,01,001$

07] BS 0,01, 001

08] CAP 0,08, 011

09] CAR 0,00, 000

11] D $0,07,010$

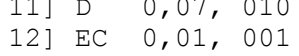

$\begin{array}{llll}12] & \text { EC } & 01, & 001 \\ 13] & F & 0,42, & 061\end{array}$

$\begin{array}{llll}13] & \text { F } & 0,42, & 061 \\ 14] & \text { IO } 0,00, & 000\end{array}$

15] L $0,22,032$

16] MM $0,00,000$

17] P 0,03, 005

18] $\mathrm{PA} 0,00,000$

19] QC $0,00,000$

20] RC $0,00,000$

10] Subject: 'Fo':

Behaviour:

00] $A B \quad 0,00,000$

01] AC 0,00, 000

$01]$ AC $0,00,000$

02] AL 0,01, 002

03 AM $0,00,000$

04] AE $0,01,002$

05] BM $0,00,000$

06] BO $0,01,001$

07] BS 0,01, 001

08] CAP 0,06, 008

09] CAR 0, 00, 000

10] CO $0,00,000$

11] D $0,02,003$

12] EC $0,01,001$

13] $\mathrm{F} \quad 0,36,052$

14] IO $0,00,000$

15] L $0,16,023$

16] MM $0,00,000$ 
17] $P \quad 0,03,005$

18] PA $0,00,000$

19] $\mathrm{QC} \quad 0,00,000$

$\begin{array}{llll}20] & R C & 0,00, & 000 \\ 21] & S & 0,31, & 045\end{array}$

11] Subject: 'Fr':

Behaviour:

$00] A B \quad 0,00,000$

02] $\mathrm{AL} 0,04,005$

03] AM $0,00,000$

$04] \mathrm{AE} \quad 0,01,001$

05] BM $0,00,000$

06] BO $0,00,000$

07] BS 0,02, 002

08] CAP 0,04, 005

09] CAR 0,00, 000

10] CO $0,00,000$

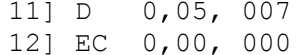

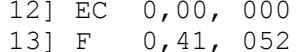

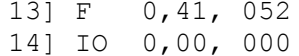

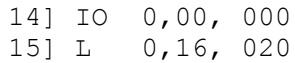

16] MM 0,00, 000

17] $\mathrm{P} \quad 0,11,014$

18] $\mathrm{PA} 0,00,000$

19] $\mathrm{QC} \quad 0,00,000$

20] RC $0,00,000$

21] $\mathrm{S} 0,17,022$

12] Subject: 'Ha':

Behaviour:

00] $\mathrm{AB} 0,00,000$

01] AC 0,00, 001

02] $\mathrm{AL} 0,00,001$

03] $\mathrm{AM} 0,00,000$

04] AE $0,00,001$

05] BM 0,00, 001

$\begin{array}{llll}06] & \text { BO } & 0,00, & 001 \\ 07] & \text { BS } & 0,07, & 016\end{array}$

08] CAP $0,06,014$

09] CAR 0, 00, 000

10] $\mathrm{CO} 0,00,000$

11] $\mathrm{D} \quad 0,02,004$

12] EC $0,02,005$

14] IO $0,00,000$

15] L $0,27,060$ 
16] MM $0,00,001$

17] $\mathrm{P} 0,07,016$

18] $\mathrm{PA} 0,00,000$

$\begin{array}{lll}19] \mathrm{QC} & 0,00,000 \\ 20] \mathrm{RC} & 0,00, & 000\end{array}$

$21] \mathrm{S} \quad 0,09,021$

13] Subject: 'Hb':

Behaviour:

00] $\mathrm{AB} 0,00,000$

01] $\mathrm{AC} 0,00,000$

02] $\mathrm{AL} 0,21,035$

03] AM 0,01, 001

$04] \mathrm{AE} \quad 0,01,001$

05] BM $0,00,000$

06] BO $0,00,000$

07] BS $0,00,000$

08] CAP 0,05, 008

09] CAR $0,00,000$

$\begin{array}{llll}10] & C O & 0,00, & 000 \\ 11] & D & 0,04, & 007\end{array}$

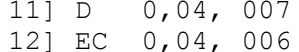

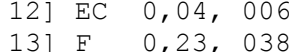

$\begin{array}{llll}13] & \text { F } & 0,23, & 038 \\ 14] & \text { IO } & 0,00, & 000\end{array}$

15] L $0,13,021$

16] MM $0,00,000$

17] $P \quad 0,02,003$

18] $\mathrm{PA} 0,00,000$

19] $\mathrm{QC} 0,00,000$

$\begin{array}{llll}20] & R C & 0,05, & 009 \\ 21] & S & 0,23, & 038\end{array}$

14] Subject: 'Ho':

Behaviour:

$00] \mathrm{AB} 0,00,000$

01] $\mathrm{AC} 0,02,003$

02] AL $0,07,012$

03] AM $0,00,000$

$04] \mathrm{AE} \quad 0,00,000$

05] BM $0,00,000$

06] BO 0,05, 009

07] BS 0,04, 007

08] CAP 0,06, 010

09] CAR $0,00,000$

10] $\mathrm{CO} 0,00,000$

11] $\mathrm{D} 0,09,016$

12] $\mathrm{EC} 0,09,015$

13] $\mathrm{F} \quad 0,29,050$

14] IO $0,00,000$ 
15] L $0,17,029$

16] MM $0,00,000$

17] $\mathrm{P} \quad 0,03,006$

18] PA $0,00,000$

19] $\mathrm{QC} 0,00,000$

$\begin{array}{llll}20] & \mathrm{RC} & 0,02, & 004 \\ 21] & \mathrm{S} & 0,08, & 014\end{array}$

15] Subject: 'Ig':

Behaviour:

00] $A B \quad 0,00,000$

01] $\mathrm{AC} 0,00,000$

02] $\mathrm{AL} 0,00,000$

03] AM $0,00,000$

04] $\mathrm{AE} 0,00,000$

05] BM 0,03, 008

06] BO 0,00, 000

07] BS 0,11, 026

08] CAP 0,02, 006

$\begin{array}{lll}09] & \text { CAR } 0,00, & 000 \\ 10] & \text { CO } 0,00, & 000\end{array}$

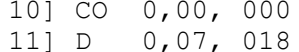

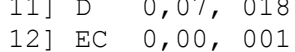

13] F $0,35,085$

14] IO $0,01,002$

15] L $0,27,066$

16] $\mathrm{MM} 0,01,002$

17] $\mathrm{P} \quad 0,01,002$

18] $\mathrm{PA} 0,00,000$

19] $\mathrm{QC} \quad 0,00,000$

20] RC $0,04,010$

21] $\mathrm{S} \quad 0,08,020$

16] Subject: 'Ip':

Behaviour:

00] $\mathrm{AB} 0,00,000$

01] AC $0,00,000$

02] $\mathrm{AL} 0,07,012$

03] AM 0,04, 007

$04] \mathrm{AE} 0,01,001$

05] BM 0,00, 000

06] BO $0,00,000$

07] BS 0,00, 000

08] CAP 0,04, 006

09] CAR 0,00, 000

10] $\mathrm{CO} 0,00,000$

$11] \mathrm{D} \quad 0,12,020$

12] EC $0,01,001$

13] F $0,40,066$ 
14] IO $0,00,000$ 15] L $0,14,024$ 16] MM $0,00,000$ $\begin{array}{llll}17] & \mathrm{P} & 0,01, & 001 \\ 18] & \mathrm{PA} & 0,00, & 000\end{array}$ 19] QC 0, 00,000 20] RC 0,04, 007 21] S $0,13,022$

17] Subject: 'Jl':

Behaviour:

$00] \mathrm{AB} \quad 0,00,000$

01] AC $0,00,000$

02] AL $0,02,002$

03] AM 0,00, 000

04] $\mathrm{AE} 0,01,001$

05] BM 0,00, 000

06] BO $0,00,000$

07] BS $0,00,000$

08] CAP 0,04, 004

$\begin{array}{lll}09] & \text { CAR } 0,00, & 000 \\ 10] & \text { CO } 0,00, & 000\end{array}$

10] CO $0,00,000$

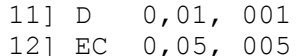

13] F $0,34,037$

14] IO $0,00,000$

15] L $0,30,033$

16] MM $0,00,000$

17] $P \quad 0,01,001$

18] $\mathrm{PA} 0,00,000$

19] QC $0,00,000$

20] RC $0,00,000$

21] $\mathrm{S} \quad 0,23,025$

18] Subject: 'Ju':

Behaviour:

00] $A B 0,00,000$

01] AC $0,00,000$

02] AL $0,07,012$

03] $\mathrm{AM} 0,00,000$

04] $\mathrm{AE} 0,01,001$

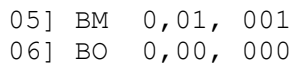

07] BS 0,05, 009

08] CAP 0,11, 018

09] CAR 0,00, 000

10] CO $0,00,000$

11] D $0,01,001$ 
13] $\mathrm{F} \quad 0,23,039$

14] IO $0,00,000$

15] L $0,23,038$

16] MM $0,00,000$

17] $\mathrm{P} \quad 0,02,003$

18] $\mathrm{PA} 0,00,000$

19] $\mathrm{QC} 0,00,000$

20] RC $0,00,000$

21] $\mathrm{S} \quad 0,27,046$

19] Subject: 'Ln':

Behaviour:

$00] \mathrm{AB} \quad 0,00,000$

$01]$ AC $0,01,002$

02] AL $0,07,013$

03] AM $, 00,000$

$04] \mathrm{AE} \quad 0,00,000$

05] BM $0,00,000$

06] BO $0,00,000$

07] BS 0,02, 004

08] CAP 0,02, 003

09] CAR 0,00, 000

10] $\mathrm{CO} 0,00,000$

11] D $0,01,001$

12] $\mathrm{EC} 0,09,017$

13] F $0,42,083$

14] IO $0,00,000$

15] L $0,15,030$

16] MM $0,00,000$

17] $\mathrm{P} \quad 0,02,004$

18] PA $0,00,000$

19] $\mathrm{QC} \quad 0,00,000$

20] RC $0,02,003$

21] S $0,19,037$

20] Subject: 'Lu'

Behaviour:

00] $\mathrm{AB} 0,00,000$

01] AC $0,00,000$

02] $\mathrm{AL} \quad 0,00,000$

03] AM $0,00,000$

$\begin{array}{lll}04] \mathrm{AE} & 0,01, & 001 \\ 05] \mathrm{BM} & 0,00, & 000\end{array}$

06] BO $0,00,000$

07] BS $0,00,000$

08] CAP 0,15, 018

09] CAR 0,00, 000

10] $\mathrm{CO} 0,00,000$

11] $\mathrm{D} 0,19,023$ 
12] EC $0,00,000$

13] F $0,27,033$

14] IO $0,00,000$

15] L $0,19,023$

16] MM $0,00,000$

17] $P \quad 0,02,002$

18] $\mathrm{PA} 0,00,000$

19] $\mathrm{QC} 0,00,000$

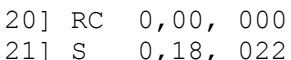

21] Subject: 'Ma':

Behaviour:

00] $A B \quad 0,00,000$

01] AC $0,00,000$

02] $\mathrm{AL} 0,02,003$

03] AM $0,00,000$

04] AE $0,00,000$

05] BM $0,00,000$

06] BO $0,00,000$

07] BS $0,00,000$

08] CAP 0,00, 000

09] CAR 0,00, 000

10] CO $0,00,000$

11] D $0,21,035$

12] EC $0,02,003$

13] $\mathrm{F} \quad 0,32,053$

$\begin{array}{lll}14] & \text { IO } 0,00, & 000 \\ 15] \text { L } & 0,14,024\end{array}$

16] MM $0,00,000$

17] $\mathrm{P} \quad 0,02,003$

18] $\mathrm{PA} 0,00,000$

19] QC $0,00,000$

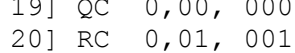

$\begin{array}{llll}20] & \mathrm{RC} & 0,01, & 001 \\ 21] \mathrm{S} & 0,27, & 045\end{array}$

22] Subject: 'Me' :

Behaviour:

00] $A B \quad 0,01,001$

$01] \mathrm{AC} \quad 0,00,000$

02] $\mathrm{AL} 0,03,005$

03] AM 0,00, 000

$04] \mathrm{AE} 0,00,000$

05] BM $0,03,005$

06] BO 0,01, 001

07] BS 0,08, 014

08] CAP 0,06, 010

09] CAR 0,00, 000

10] $\mathrm{CO} 0,00,000$ 
11] D $0,07,012$

12] EC $0,00,000$

13] $\mathrm{F} \quad 0,32,055$

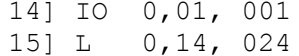

16] MM 0,00, 000

17] P $0,05,008$

18] $\mathrm{PA} 0,00,000$

19] $\mathrm{QC} \quad 0,00,000$

20] RC $0,00,000$

23] Subject: 'Mi':

Behaviour:

00] $\mathrm{AB} 0,00,000$

01] $\mathrm{AC} 0,00,000$

02] $\mathrm{AL} 0,00,000$

03] AM $0,01,002$

04] $\mathrm{AE} 0,01,001$

05] BM $0,00,000$

06] BO $0,00,000$

07] BS $0,00,000$

08] CAP $0,14,020$

09] CAR 0, 00, 000

10] $\mathrm{CO} 0,00,000$

11] $\mathrm{D} 0,11,015$

12] $\mathrm{EC} 0,01,001$

13] $\mathrm{F} \quad 0,44,061$

14] IO $0,00,000$

15] L $0,14,020$

16] MM $0,00,000$

17] P $0,04,005$

18] PA $0,00,000$

19] QC $0,00,000$

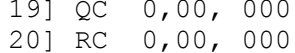

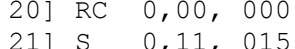

24] Subject: 'Ml' :

Behaviour:

$00] \mathrm{AB} 0,00,001$

01] AC 0,00, 001

02] AL 0,00, 001

03] AM 0, 00, 000

$04] \mathrm{AE} 0,00,000$

05] BM $0,05,013$

06] BO $0,00,001$

07] $\mathrm{BS} 0,05,013$

08] CAP $0,06,016$

09] CAR 0,00, 000 
10] CO $0,00,000$

11] D $0,02,005$

12] $\mathrm{EC} 0,00,000$

13] $\mathrm{F} \quad 0,39,099$

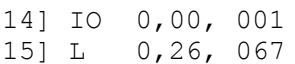

16] MM $0,01,003$

17] $\mathrm{P} 0,04,009$

18] $\mathrm{PA} 0,00,000$

19] $\mathrm{QC} 0,00,000$

20] RC $0,00,000$

21] S $0,10,026$

25] Subject: 'Mn':

Behaviour:

$00] \mathrm{AB} 0,00,000$

01] $\mathrm{AC} 0,00,000$

02] $\mathrm{AL} 0,00,000$

03] $\mathrm{AM} 0,00,000$

$04] \mathrm{AE} 0,00,000$

05] BM 0,00, 000

06] BO 0,00, 000

07] BS $0,00,000$

08] CAP 0,18, 007

09] CAR 0,00, 000

10] CO $0,00,000$

11] $\mathrm{D} \quad 0,25,010$

12] EC $0,00,000$

13] $\mathrm{F} \quad 0,35,014$

14] IO $0,00,000$

15] L 0,13, 005

16] MM $0,00,000$

17] P $0,05,002$

18] PA 0,00, 000

19] QC $0,00,000$

20] RC $0,00,000$

$\begin{array}{llll}20] & R C & 0,00, & 000 \\ 21] & S & 0,05, & 002\end{array}$

26] Subject: 'Nd':

Behaviour:

$00] \mathrm{AB} 0,00,000$

01] $\mathrm{AC} 0,01,001$

02] AL $0,00,000$

03] AM 0, 00, 000

$04] \mathrm{AE} 0,00,000$

05] BM 0,00, 000

06] BO $0,00,000$

07] BS $0,00,000$

08] CAP 0,14, 020 
09] CAR $0,00,000$

10] CO $0,00,000$

11] $\mathrm{D} 0,15,022$

12] EC $0,00,000$

13] $\mathrm{F} \quad 0,29,042$

14] IO $0,00,000$

15] L $0,17,025$

16] MM $0,00,000$

17] $\mathrm{P} \quad 0,03,005$

18] $\mathrm{PA} 0,00,000$

19] QC $0,00,000$

20] RC $0,00,000$

$21] \mathrm{S} \quad 0,22,032$

27] Subject: 'Nl':

Behaviour:

$00] A B \quad 0,00,000$

01] AC $0,01,002$

02] $\mathrm{AL} 0,01,001$

03] AM 0,00, 000

$04] \mathrm{AE} \quad 0,00,000$

05] BM 0,00, 000

06] BO 0,00, 000

07] BS 0, 00,000

08] CAP 0,13, 022

09] CAR 0,00, 000

10] $\mathrm{CO} 0,00,000$

11] D $0,07,012$

13] $\mathrm{F} \quad 0,49,083$

14] IO $0,00,000$

15] L $0,13,022$

16] MM $0,00,000$

17] $\mathrm{P} 0,06,010$

18] PA 0,00, 000

19] $\mathrm{QC} 0,02,003$

20] RC $0,00,000$

21] $\mathrm{S} 0,08,013$

28] Subject: 'Nr':

Behaviour:

$00] \mathrm{AB} 0,00,000$

01] AC $0,06,006$

02] AL $0,03,003$

03] AM $0,00,000$

$04] \mathrm{AE} \quad 0,00,000$

05] BM 0,00, 000

06] BO $0,00,000$

07] BS $0,00,000$ 
08] CAP 0,14, 014

09] CAR $0,00,000$

10] $\mathrm{CO} 0,00,000$

11] $\mathrm{D} \quad 0,17,017$

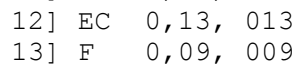

14] IO $0,01,001$

15] L $0,06,006$

16] MM $0,00,000$

17] $\mathrm{P} \quad 0,07,007$

18] $\mathrm{PA} 0,00,000$

19] QC $0,00,000$

20] RC 0,07, 007

21] S $0,19,020$

29] Subject: 'Pa':

Behaviour:

$00] A B \quad 0,01,001$

01] $\mathrm{AC} 0,00,000$

02] AL $0,00,000$

$\begin{array}{lll}03] \mathrm{AM} & 0,00, & 000 \\ 04] \mathrm{AE} & 0,00, & 000\end{array}$

$04] \mathrm{AE} \quad 0,00,000$

$05]$
$06]$ BO $0,05,00,006$

$\begin{array}{lll}06] & \text { BO } 0,00, & 000 \\ 07] & \text { BS } 0,15, & 017\end{array}$

08] CAP 0,00, 000

09] CAR 0,00, 000

10] $\mathrm{CO} 0,00,000$

11] $\mathrm{D} 0,00,000$

12] EC $0,00,000$

13] F $0,33,039$

14] IO $0,00,000$

15] L $0,33,039$

16] $\mathrm{MM} 0,00,000$

17] $\mathrm{P} \quad 0,03,003$

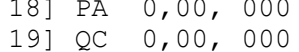

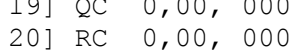

$\begin{array}{llll}20] & \mathrm{RC} & 0,00, & 000 \\ 21] & \mathrm{S} & 0,10, & 012\end{array}$

30] Subject: 'Pr':

Behaviour:

$00] \mathrm{AB} 0,00,000$

01] $\mathrm{AC} 0,00,000$

02] $\mathrm{AL} 0,01,001$

03] $\mathrm{AM} \quad 0,03,004$

04] $\mathrm{AE} \quad 0,00,000$

$\begin{array}{lll}05] & \text { BM } 0,00, & 000 \\ 06] & \text { BO } 0,00, & 000\end{array}$ 
07] BS $0,00,000$

08] CAP 0,02, 003

09] CAR 0,00, 000

10] $\mathrm{CO} 0,00,000$

11] D $0,06,007$

12] EC $0,00,000$

13] F $0,39,049$

14] IO $0,00,000$

15] L $0,19,024$

16] MM $0,00,000$

17] $\mathrm{P} 0,06,008$

18] $\mathrm{PA} 0,00,000$

19] $\mathrm{QC} \quad 0,00,000$

20] RC 0,01, 001

21] S $0,23,029$

31] Subject: 'Qu':

Behaviour:

$00] \mathrm{AB} 0,00,000$

$01] \mathrm{AC} \quad 0,00,000$

02] AL $0,00,000$

03] $\mathrm{AM} 0,00,000$

$\begin{array}{llll}04] & \mathrm{AE} & 0,00, & 000 \\ 05] & \mathrm{BM} & 0,00, & 000\end{array}$

$06]$ BO $0,00,000$

07] BS 0,00, 000

08] CAP $0,08,014$

09] CAR 0,00, 000

10] $\mathrm{CO} 0,00,000$

11] D $0,00,000$

12] EC $0,00,000$

13] $\mathrm{F} \quad 0,58,099$

14] IO $0,00,000$

15] L $0,12,021$

16] $\mathrm{MM} 0,00,000$

18] PA 0,00, 000

18] PA $0,00,000$

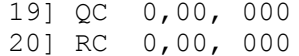

$\begin{array}{llll}20] & \mathrm{RC} & 0,00, & 000 \\ 21] \mathrm{S} & 0,16, & 027\end{array}$

32] Subject: 'Rs':

Behaviour:

$00] \mathrm{AB} 0,00,000$

01] $\mathrm{AC} 0,00,000$

02] $\mathrm{AL} 0,00,000$

03] AM $0,00,000$

$04] \mathrm{AE} 0,00,000$

05] BM 0,00,000 
06] BO $0,00,000$

07] BS $0,00,000$

08] CAP 0,07, 011

09] CAR 0,00, 000

10] CO $0,00,000$

11] $\mathrm{D} 0,06,010$

12] EC $0,08,012$

13] $\mathrm{F} \quad 0,36,058$

14] IO $0,01,001$

15] L $0,15,024$

16] MM $0,00,000$

17] $\mathrm{P} \quad 0,02,003$

18] $\mathrm{PA} 0,00,000$

19] QC $0,00,000$

20] RC $0,03,005$

$\begin{array}{lll}20] \mathrm{RC} & 0,03, & 005 \\ 21] \mathrm{S} & 0,23,036\end{array}$

33] Subject: 'Sg':

Behaviour:

$00] A B \quad 0,00,000$

$01]$ AC $0,00,000$

02] $\mathrm{AL} 0,12,024$

$\begin{array}{llll}03] \mathrm{AM} & 0,00, & 000 \\ 04] \mathrm{AE} & 0,01, & 001\end{array}$

$05] \mathrm{BM} 0,00,000$

06] BO 0,01, 002

07] BS $0,00,000$

08] CAP 0,09, 017

09] CAR 0,00, 000

10] $\mathrm{CO} 0,00,000$

11] D $0,20,040$

12] EC $0,01,001$

13] $\mathrm{F} \quad 0,25,049$

14] IO $0,00,000$

15] L $0,14,027$

16] $\mathrm{MM} 0,00,000$

17] $\mathrm{P} \quad 0,01,002$

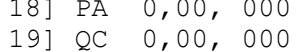

$\begin{array}{lll}19] \mathrm{QC} & 0,00, & 000 \\ 20] \mathrm{RC} & 0,01, & 002\end{array}$

$\begin{array}{llll}20] & R C & 0,01, & 002 \\ 21] & S & 0,17, & 033\end{array}$

34] Subject: 'Tr':

Behaviour:

$00] \mathrm{AB} 0,00,000$

$01] \mathrm{AC} 0,01,002$

02] $\mathrm{AL} 0,16,024$

03] $\mathrm{AM} 0,00,000$

$04] \mathrm{AE} \quad 0,00,000$ 
05] BM 0,00, 000

06] BO 0,00, 000

07] BS 0,00, 000

08] CAP 0, 05, 008

09] CAR 0,00, 000

10] CO $0,00,000$

11] D $0,07,010$

12] EC $0,02,003$

13] $\mathrm{F} \quad 0,21,032$

14] IO $0,00,000$

15] L $0,13,020$

16] MM $0,00,000$

17] $P \quad 0,03,004$

18] PA $0,00,000$

19] QC $0,00,000$

$\begin{array}{llll}19] & \text { QC } & 0,00, & 000 \\ 20] & \text { RC } & 0,01, & 002\end{array}$

$\begin{array}{llll}20] & \mathrm{RC} & 0,01, & 002 \\ 21] & \mathrm{S} & 0,31, & 047\end{array}$

35] Subject: 'Vl':

Behaviour:

$00] A B \quad 0,00,000$

01] $\mathrm{AC} 0,01,001$

02] $\mathrm{AL} 0,00,000$

$\begin{array}{llll}03] \mathrm{AM} & 0,01, & 001 \\ 04] \mathrm{AE} & 0,00, & 000\end{array}$

05] $\mathrm{BM} 0,00,000$

06] BO $0,00,000$

$07]$ BS $0,00,000$

08] CAP 0,14, 027

09] CAR $0,00,000$

10] CO $0,00,000$

11] $\mathrm{D} \quad 0,12,024$

12] EC $0,06,012$

13] F $0,15,030$

14] IO $0,00,000$

$\begin{array}{llll}15] & \mathrm{L} & 0,16, & 031 \\ 16] & \mathrm{MM} & 0,00, & 000\end{array}$

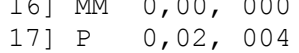

$\begin{array}{llll}17] & \mathrm{P} & 0,02, & 004 \\ 18] & \mathrm{PA} & 0,00, & 000\end{array}$

$\begin{array}{lll}18] \mathrm{PA} & 0,00, & 000 \\ 19] \mathrm{OC} & 0,00, & 000\end{array}$

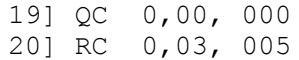

$\begin{array}{llll}20] & R C & 0,03, & 005 \\ 21] & S & 0,31, & 062\end{array}$

36] Subject: 'Vp':

Behaviour:

00] $\mathrm{AB} 0,00,000$

01] $\mathrm{AC} 0,00,000$

02] $\mathrm{AL} 0,00,000$

03] AM $0,00,000$ 
04] $\mathrm{AE} 0,00,000$

05] BM $0,00,000$

06] BO $0,00,000$

07] BS 0,01, 002

08] CAP 0,01, 002

09] CAR 0,00, 000

10] $\mathrm{CO} 0,00,000$

11] $\mathrm{D} \quad 0,03,006$

12] $\mathrm{EC} 0,03,005$

13] $\mathrm{F} \quad 0,52,095$

14] IO $0,01,001$

15] L $0,22,041$

16] $\mathrm{MM} 0,00,000$

17] $\mathrm{P} \quad 0,02,003$

18] PA $0,00,000$

18] PA $0,00,000$

19] $\mathrm{QC} 0,00,000$

$\begin{array}{llll}20] & \mathrm{RC} & 0,01, & 001 \\ 21] & \mathrm{S} & 0,15, & 028\end{array}$

Execution time: $7: 38: 6.819$.

Listagem B.1.3 - Experimento 3: usando dados reais com todos os dados reais(38 agentes e 29 atividades). 
